\title{
Using Wenger's social theory of learning to examine university teachers' understanding of how instructional technology affects their experience in practice
}

\author{
Laura L. Adams \\ West Virginia University
}

Follow this and additional works at: https://researchrepository.wvu.edu/etd

\footnotetext{
Recommended Citation

Adams, Laura L., "Using Wenger's social theory of learning to examine university teachers' understanding of how instructional technology affects their experience in practice" (2010). Graduate Theses,

Dissertations, and Problem Reports. 2939.

https://researchrepository.wvu.edu/etd/2939

This Dissertation is protected by copyright and/or related rights. It has been brought to you by the The Research Repository @ WVU with permission from the rights-holder(s). You are free to use this Dissertation in any way that is permitted by the copyright and related rights legislation that applies to your use. For other uses you must obtain permission from the rights-holder(s) directly, unless additional rights are indicated by a Creative Commons license in the record and/ or on the work itself. This Dissertation has been accepted for inclusion in WVU Graduate Theses, Dissertations, and Problem Reports collection by an authorized administrator of The Research Repository @ WVU.

For more information, please contact researchrepository@mail.wvu.edu.
} 
Using Wenger's Social Theory of Learning to Examine University Teachers' Understanding of How Instructional Technology Affects Their Experience in Practice

\author{
Laura L. Adams
}

Dissertation submitted to the College of Human Resources and Education at West Virginia University in partial fulfillment of the requirements

for the degree of

Doctor of Education

In

Technology Education

\author{
Neal Shambaugh, Ph.D., Chair \\ Pamela Whitehouse, Ph.D. \\ Ugur Kale, Ph.D \\ Patricia Obenauf, Ph.D. \\ Jaci Webb-Dempsey, Ph.D.
}

Department of Technology, Learning, and Culture

Morgantown, West Virginia

2010 


\begin{abstract}
Using Wenger's Social Theory of Learning to Examine University Teachers' Understanding of How Instructional Technology Affects Their Experience in Practice
\end{abstract}

\title{
Laura L. Adams
}

The purpose of this study was to take an exploratory look at how university teachers come to understand their experience in educational practice and their professional role as teachers who integrate instructional technology into their coursework using the framework provided by Wenger's Social Theory of Learning. University faculty who teach in a college of education that integrate instructional technology into their courses were important to inform this study.

Qualitative research methods were used to gather data that was collected from 1) university teachers' engagement in an annual instructional technology professional development activity and 2) eight participants who teach in a college of education. Data collected from the teachers' engagement in a professional development activity included a week long observation, binders that chronologically described the history of the professional development activity, the college's current technology support structures, and shared resources that help teachers within the college integrate instructional technology. Data collected from the eight teacher participants to inform case studies included interviews, observations, and the review of the participants' courses from one academic semester that displayed instructional technology integration. The data from the teachers' engagement in the professional development activity and the eight teacher participants was analyzed and coded by the framework provided by Wenger's Social Theory of Learning to identify emergent themes and patterns that informed the teachers' understanding and experience of their role responsible to integrate instructional technology.

Findings of this research revealed the importance for teachers to collectively discuss their experiences teaching with instructional technology, the importance for teachers to engage in professional development opportunities that focus on pedagogical practices using instructional technology, the importance for teachers to observe and view other colleagues' instructional choices with the use of instructional technology, and the opportunity for teachers to become more familiar with synchronous audio-video communication technology to enable for more authentic teaching experiences with their students.

Keywords: Social Theory of Learning, identity, practice, meaning, community, instructional technology, teacher professional development 


\section{Acknowledgements}

The challenging process to complete a dissertation and doctorate degree can be an opportunity for growth and transformation as it is a continual path of examination not only of the research, but also of the self as one tries to balance life along with the work. When I reflect upon the experiences of this process, I am humbled and amazed by the support and guidance from teachers, family, and friends. This was a path I never walked alone and it is necessary to acknowledge and express my sincere appreciation of the contributions and efforts made from those who helped me during this process.

Let me start by saying that for the years that I have been a part of the Technology Education department, I have been fortunate to be provided with the valuable opportunities to learn and expand my awareness through the teachings of the former professors of the department. I sincerely thank the teachers Dr. Maughan, Dr. Wells, and Dr. McCrory for accepting me into the program and their time working with me. I am especially grateful to Dr. Maughan for his extra effort and attention seeing me through the program of study process as he was leaving for another university. His efforts enabled me to advance to the comprehensive exam and dissertation phase of the doctorate degree.

Next I would like to express my gratitude to the participants of this study for selflessly giving their valuable time, sharing their perspectives, and allowing me into their classrooms. University teachers' jobs are complex and filled with many different responsibilities and I was privileged to learn from their individual experiences. I am grateful that they allowed me into their teaching lives as their contributions were invaluable to my research.

I wish to express my appreciation to my committee as I am so thankful for their time, efforts, and continued support and encouragement through the times of struggle when it would have been so easy to walk away from the work.

There is not enough I can say about my advisor Dr. Neal Shambaugh who has always been concerned that I chose my own path through the doctorate process. Recognizing that I needed to carve out a path for myself, he continually shared his resources, advice, and wisdom in order for me to keep going and moving forward. I am 
so grateful that he always had confidence and belief in me. Thank you Dr. Shambaugh for your trust and faith in me and for always paying attention!

I cannot thank Dr. Jaci Webb-Dempsey enough who opened my eyes to the incredible process of qualitative research. I am so thankful that she stayed on my committee through a change in university and for always being so positive and encouraging about my research. Thank you Jaci for seeing me through this process!

I am grateful to Dr. Pat Obenauf who I was fortunate to be introduced to early in my doctorate experience by a very dear person, Dr. Tina Sayers-Walker. Dr. Pat showed me kindness and compassion by always providing an open door to help me as I struggled through this process. Thank you Dr. Pat for sharing your wisdom and giving me the confidence to continue working!

I feel very fortunate to have had Dr. Pamela Whitehouse on my committee as she was generous to give her time and share critical resources which helped my understanding and provided clarity to the many layers of Wenger's theory. Thank you Dr. Whitehouse for sharing your knowledge on a difficult theory!

I am so appreciative of Dr. Ugar Kale, for being on my committee and contributing his point of view which extended the boundaries of my research. Thank you Dr. Kale for your enthusiasm and rigor which improved the quality of my work!

It is important for me to thank Tim Mitchem for his contributions and help toward my research. His experience and insightful perspective of the inter-working nature of teachers learning and integrating instructional technology was very valuable toward the understandings gained during the data analysis process. Thank you Tim for giving your time and adding your good sense of humor which always made the path more enjoyable!

Ann Crabtree provides an invaluable service to the students of the Technology, Learning and Culture Department. Thank you so very much Ann for always helping put my academic affairs in order as your efforts were some of the most critical toward my success. Thank you for your attention to the graduate students in the department.

I wish to thank Dr. Bill Reger-Nash and Dr. Richard Hartnett who I would see frequently biking and running. I am so grateful for their encouragement and advice when I was trying to find understanding in my research as I was running on the trail. Their words of support came a critical times when I really needed them. 
There is not enough I can say about the care and support given to me from David Dineen. His continued kindness and encouragement gave me the ability to work past my own limitations and gave me the strength to continue to function through the most challenging of times. I am especially grateful for his ability to make me laugh, knowing when I needed a break, and always being interested in my success. Thank you Dave for always supporting me and seeing me through this process!

It is impossible to express and fully articulate how truly appreciative I am of the incredibly important efforts made from my family to help me through this doctorate and the dissertation process. I would not be where I am today without the love, support, and belief my parents have had in me. I am so grateful to my mother who had the courage 20 years ago to make sure that I went to college and get an education. As I have been her "girl with the curl” at times, she have never given up on me, always stuck with me, and supported me through the struggle. Her great energy, positive attitude, and infectious enthusiasm always served as motivation to keep me marching forward. I am so grateful for the support and consistent encouragement from my father. His wisdom, good sense of humor, and insightful perspective kept me on track working toward the goal of completing the degree. As we were both going through the process of working on our dissertations, it was great to be able to share and discuss the progress of our work. I am so very thankful of my brothers Sean and Zane for their well timed pep talks and humor helping get me through the challenging times. Thank you guys for always having confidence and faith in me when I didn't have it for myself. I love you all dearly and I'm so grateful for your unwavering support toward my academic efforts.

Through all of these acknowledgements, there is one very important person I wish to thank. It is important to acknowledge Ken McPherson who saw possibility in me to get my doctorate that I never would have seen for myself. Ken was the person who opened the door and provided me with this opportunity. I am forever grateful for his invitation to work in higher education and his introduction to the prospect of obtaining my doctorate. I will never forget what you've done for me. 


\section{List of Tables}

Table 1 Components and definitions of a Social Theory of Learning....................... 9

Table 2 Data sources to inform research questions........................... 65

Table 3 Interview questions created to inform research question one, identity.... 65

Table 4 Interview questions created to inform research question two, practice... $\quad 66$

Table 5 Interview questions created to inform research question three, meaning.. $\quad 67$

Table 6 Interview questions created to inform research question four, $\quad 67$

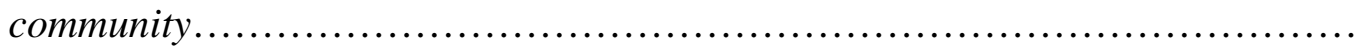

Table 7 Observation guide criteria to capture practice components............... 68

Table 8 Observation guide criteria to capture community components........... 68

Table 9 Document analysis criteria to capture practice components.............. 69

Table 10 Document analysis criteria to capture community components.......... 69

Table 11 Data sources and collection methods to inform research questions... $\quad 70$

Table 12 Timeline of data sources collected............................. 71

Table 13 Data methods and sources to inform the Social Theory of Learning..... 79

Table 14 A priori codes established to inform Social Theory of Learning 83

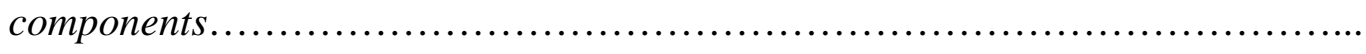

Table 15 Coding process to inform case narratives....................... 86

Table 16 Grouping of participant cases into teaching positions................. 88

Table 17 Summaries from grouping of the components to identify themes........ 90

Table 18 Data from faculty engaging in community activity to inform community 93

subcomponents.........................................................

Table 19 Internet applications taught during Faculty Academy................. 115 
Table 20 Communication technology taught during Faculty Academy............ 116

Table 21 Presentation technology taught during Faculty Academy................ 116

Table 22 HTML editors and course management systems taught during Faculty 117

Academy

Table 23 Audio, video, and digital imaging technology taught during Faculty

Academy

Table 24 Concept map software taught during Faculty Academy

Table 25 University resources available taught during Faculty Academy..........

Table 26 Interactive whiteboard technology taught during Faculty Academy......

Table 27 Microsoft Office technology taught during the Faculty Academy

Table 28 Other technology taught during the Faculty Academy

Table 29 Process of data analysis and synthesis for the participant case studies..

Table 30 Participant information..............................................

Table 31 Instructional technology choices for Nathan's course................... 153

Table 32 Instructional technology choices for Elaine's course.................... 182

Table 33 Instructional technology choices for Richard's course................... 223

Table 34 Instructional technology choices for Ruth’s course..................... 252

Table 35 Instructional technology choices for Wanda's course................... 274

Table 36 Instructional technology choices for Charles' course................... 295

Table 37 Instructional technology choices for Tanya's course................... 326

Table 38 Instructional technology choices for Michael's course................... 351

Table 39 Participants’ use of instructional technology for Fall 2008 semester.... 376

Table 40 Subcomponents relevant for college of education community............ 404 


\section{List of Figures}

Figure 1. Components of a Social Theory of Learning............................ 24

Figure 2. Social Theory of Learning model applied to college of education

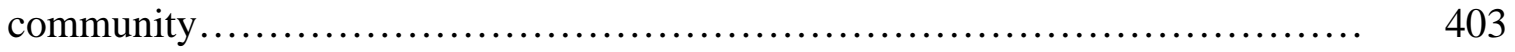




\section{Table of Contents}

Abstract.................................................................... ii

Acknowledgements................................................... iii

List of Tables................................................................ vi

List of Figures.................................................... viii

Table of Contents.................................................... ix

Chapter One: Introduction............................................... 1

Transformative Nature of Technology on Society...................... 1

Transformative Nature of Technology on Being...................... 2

Transformative Nature of Our Relationships with Technology............. 3

Technological Change and Social Transformation..................... 3

Social Transformation and the Computer........................... 4

Transformative Nature of Technology on Education.................... 5

The Problem......................................................... 6

The Need for the Study........................................ 6

Purpose of the Study.............................................. 8

Research Questions ............................................ 10

Significance of the Study...................................... 10

Chapter Two: Literature Review...................................... 11

Context of Learning............................................ 11

Perceptions of the University Culture $. . \ldots \ldots \ldots \ldots \ldots \ldots \ldots \ldots \ldots \ldots \ldots \ldots . . \ldots \ldots \ldots$

University as a Community of Practice............................ 13

University as a Learning Organization............................. 13 
Professional Development......................................... $\quad 14$

Development of University Teachers Identity over Time.................. 15

Tension Between Teachers’ Attention to Discipline Versus Teaching...... 16

Teacher Allegiance to their Discipline over their Institution................ 16

Change in University Culture........................................ 17

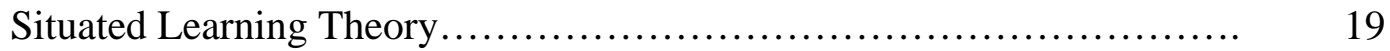

A Social Theory of Learning........................................ $\quad 20$

Social Participation in Communities of Practice.......................... 22

Components of the Social Theory of Learning........................... 24

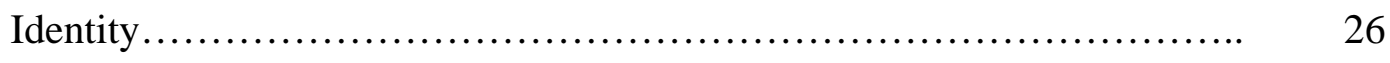

Main Characteristics of Identity .............................. 27

Lived Experience..................................... $\quad 27$

Negotiated Experience.................................. 28

Social-Community Membership......................... 28

Learning Process...................................... $\quad 29$

Nexus of Multimembership.............................. $\quad 29$

Modes of Belonging.......................................... 29

Engagement....................................... 30

Imagination........................................... $\quad 30$

Types of Trajectories.......................................... 31

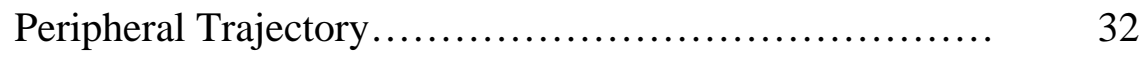

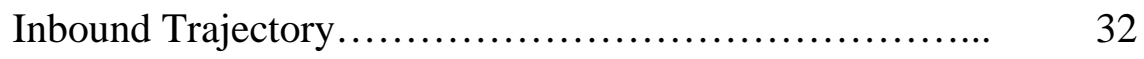

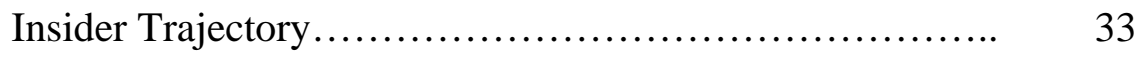




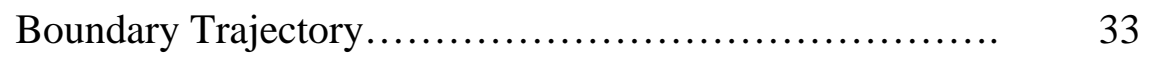

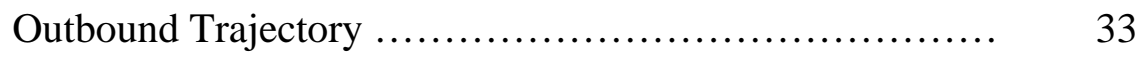

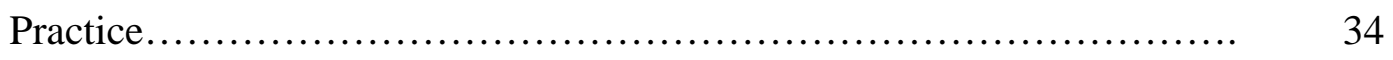

Mutuality of Practice......................................... 35

Learning in Practice............................................... 36

Evolving Forms of Mutual Engagement................... $\quad 36$

Understanding and Tuning Enterprise..................... $\quad 37$

Developing Their Repertoire, Styles, and Discourses....... $\quad 37$

Characteristics of Participation................................. 38

Participate in Resolutions to Conflict and Change........... 38

Support Communal Memory ............................. 38

Assist Others......................................... 38

Perspectives to Accomplish Goals......................... $\quad 38$

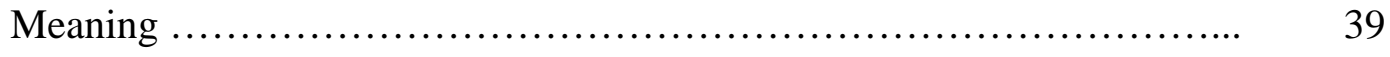

Negotiation of Meaning....................................... 40

Participation........................................... 41

Reification................................................. 42

Duality of Meaning............................................ 43

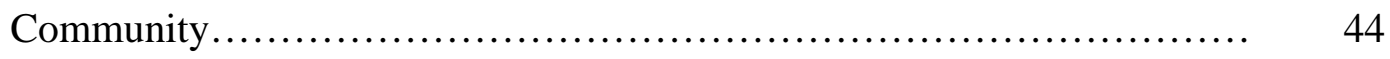

Community Membership..................................... 46

Dimensions of Communities of Practice......................... 46

Mutual Engagement.................................... 47

Joint Enterprise .......................................... 49 
Shared Repertoire....

Qualitative Research Methods.

Interpretivist Research Paradigm.

Phenomenological Approach.

Reflexivity

Data Collection Methods.

Interviews.

56

Observations

Document Analysis

Chapter Three: Methodology

Research Focus.

Qualitative and Phenomenological Approach.

Researcher and Participants.

Researcher.

Participants.

Association with Participants.

Data Sources.

Interviews

Observations.

Document Analysis.

Data Sources and Data Collection Procedures.

Timeline.

Observation of the Faculty Academy. 
Document Analysis of Educational Community Support Materials 72

First Interview with Teaching Faculty....................... 73

Observations of Teaching Faculty in the Classroom.............. 74

Second Interview with Teaching Faculty..................... 76

Document Analysis of Faculty Course Materials................ 76

Data Management............................................. $\quad 78$

Phenomenology and Data Analysis................................ $\quad 79$

Data Analysis Process.......................................... 80

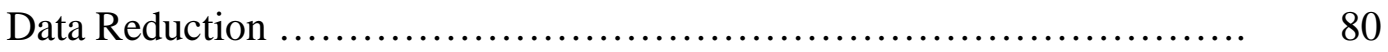

Bracketing.............................................. 80

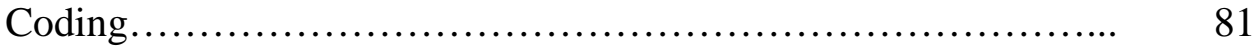

Analysis of Themes and Patterns................................ 81

Data Analysis and Synthesis................................... 83

Attempts to Reduce Limitations................................... 90

Validity in Qualitative Research............................. 90

Triangulation............................................... 90

Audit Trail............................................... 91

Thick Rich Description....................................... 91

Chapter Four: Findings............................................. 92

Overview of Chapter.......................................... 92

Review of Data Analysis Procedures for Section 1................... 92

Section 1: The College Community \& The Faculty Academy............ 94

Community’s Technology Support Center.................... 95 
Introduction to the Faculty Academy......................... 97

Guidelines for Faculty’s Participation in the Faculty Academy...... 99

Evolution of the Faculty Academy........................... 100

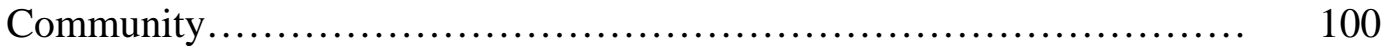

Mutual Engagement........................................ 100

Sharing Activities ................................. 100

Learning Activities that Involved the Study of Pedagogical

Practice............................................... 104

Evolution of Training Activities......................... 107

Learning about the Internet...................... 107

Learning about Communication Technologies...... 108

Learning how to Create Presentations............. 110

Learning how to Create Course Websites.......... 111

Learning how to Integrate Audio and Video........ 112

Learning how to Use Concept Maps ............. 112

Learning about University Resources.............. 112

Learning how to use the Intelliboard Interactive

Whiteboard...................................... 113

Learning about Microsoft Office................. 113

Other technology used in the Faculty Academy...... 113

Joint Enterprise........................................ 114

Shared Repertoire....................................... 115

Tools................................................ 115 
2008 Faculty Academy

Setting for the Faculty Academy

Starting in the Morning

Dialoguing about Instructional Technology.

Faculty and Technology Support Working Together

Time Management Issues

Experiencing Change and Keys to Success.

Sharing of Best Practices.

Speaking with the Retiring Dean

Showcasing of Courses.

Review of Data Analysis Procedures for Section 2

Step One: Analysis of the Individual Cases.

Step Two: Group Analysis of Cases by Teacher Positions.

Step Three: Summarizing Overlapping Subcomponent Data....

Step Four: Collective Analysis of the Three Teacher Groups

Section Two: Participant Case Studies.

Introduction to the Administrative Teachers.

Narrative 1: Nathan

Narrative 2: Elaine.

Narrative 3: Richard.

Introduction to Teaching Faculty.

Narrative 4: Ruth.

Narrative 5: Wanda. 
Narrative 6: Charles........................................ 280

Introduction to Program Support Faculty................................ 305

Narrative 7: Tanya............................................. 306

Narrative 8: Michael.............................................. 333

Chapter Five: Discussion .................................................... 361

Emerging Themes Informing the Research Questions.................... 362

Research Question 1: Identity....................................... 362

Part I: History and Path into Educational Community.............. 362

Part II: Identities Influenced as they Interact and Participate with

Technology ................................................ 363

Part III: Seamless Transparent Online Synchronous Technology ... 367

Research Question 2: Practice....................................... $\quad 370$

Part I: Knowledge and Skill Building............................. 370

Part II: Understanding of Community Mission...................... 373

Part III: Resources Developed for the use of Instructional

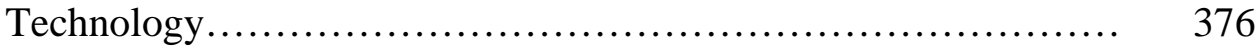

Research Question 3: Meaning........................................ $\quad 379$

Part I: Interpretation and Understanding of Community’s

Participation.................................................. 379

Part II: Interpretation and Understanding of Faculty’s Participation 383

Part III: The Creation of Policies and Tools....................... 386

Research Question 4: Community ................................... 389

Part I: The Process of Belonging to an Educational Community 389 
Part II: Adhere to Community’s Mission of Integrating

Technology 395

Part III: Shared Tools and Resources....

Discussion of Theory and Findings 402

Implications

Limitations

Recommendations.

References

Appendix A: IRB Permission Letter to Observe Faculty Academy........

Appendix B: IRB Permission Letter to Interview \& Observe Teachers......

Appendix C: Permission Letter to Observe Faculty Academy

Appendix D: Interview Protocol for First Interview.....

Appendix E: Interview Protocol for Second Interview.

Appendix F: Interview Questions for First Interview.

Appendix G: Interview Questions for Second Interview. 


\section{Chapter One}

\section{Introduction}

\section{Transformative Nature of Technology on Society}

We characterize our society as progressive as our history reflects a phenomena of social transformation through its development and interaction with technology. Our progress is not haphazardly approached as our path is accomplished through the use of tools, techniques and methods to accomplish and gain control over our circumstances in our environment. One of the distinguishing characteristics of the human race is the creation and use of technology and techniques which is represented as a combination of tools and knowledge processes utilized to develop systems, solve problems, and extend our natural capabilities (Ellul, 1964). It is the opinion of modern philosophers that the use of technology is a mechanism for organizing and creating the world to satisfy the needs of man. These actions have changed our environment to one characterized as an advanced technological society.

Our society has an expectation that we must determinedly progress as this is a natural part of our destiny as human beings. Cultural values and beliefs characterize the approaches as to the development of how technology should be carried out. Most appreciate that new technologies are involved in changing the practices and patterns of everyday life. We realize the technologies that surround us affect matters we deeply care about; the satisfactions of a working life, the character of family ties, the safety and friendliness of local communities, the quality of our interactions with schools, clinics, banks, the media, and other institutions (Winner, 1985). Technological development is more than the random accumulation of tools, techniques and organizational forms. There 
is a systematic interconnection of technology with other human endeavors and it has close ties to human knowledge, as well as an intimate connection with the organized structuring of human activities.

Idhe (1979) states that humans understand their world in terms of some focused interpretation and because humans are so existentially and necessarily related to what they perceive as their world, they bring it close so that ultimately they also interpret themselves in terms of their world. The relationship and experience we have with technology influences the way in which we perceive our world and ourselves.

\section{Transformative Nature of Technology on Being}

Barret (1978) asks the question, "how does technical man exist in relation to Being?” According to Heidegger (1977), Being is active emersion in the world; its existence is culturally bounded by history and language, which shapes us as much as we shape it. This is another example of man's use of technique. It can be said that man has become unsettled with his state of Being. The model we revere in society is not the power of Being, but the power of Becoming (Doll, 1993). We no longer represent or see ourselves as Being as we now see that Being is represented by Doing. The human has now blended into his artificial creations and becomes more impersonalized as he rationally manipulates his world at an increasing rate.

Modern man tries to satisfy his needs and expectations through the constructing of external objects, but he still finds himself living in a technical world. The expectations of humans proceeds to develop past the conditions of what nature offers to create an impossible level of satisfaction. This craving can not keep up with the appetite of modern growth. Unfortunately, man still finds himself unhappy with all of his 
innovations and continues to pursue higher and higher goals. This pursuit creates a deterministic future of continual technological development. We find that we are not free, but rather dependent upon our creations and the methods of our technology. The effects of technology are not superficial but rather deeply strewn in our ways of Being.

\section{Transformative Nature of Our Relationships with Technology}

There is a cyclical relationship society has with technology and it influences the extent to which we define our progress. Using tools entails both changing the user's view of the world and adopting the belief system of the culture in which they are used (Brown, Collins, \& Duguid, 1989). McCarthy \& Wright (2004) extend this view by stating that our involvement with technology is not just for utilization purposes, but rather technology intertwines itself into our lives, emotionally and intellectually; we don’t just use technology, we live with it. The emergence of new technologies make it difficult to comprehend how the transformations will take place.

\section{Technological Change and Social Transformation}

The rate of technological change and progress is constantly accelerating and modifying existing technologies, systems, and environments (Ayera, 1997). The impact of technological change has implications for the social, ethical, political, and cultural dimensions of our world (Ihde, 1979). This change forces us to question whether the traditional categories continue to characterize in essential ways the new kinds of Beings that modern technology creates (Ayera, 1997). Change and transformation is mutually experienced as our actions and behaviors are altered through our experience with the changed technology. McLuhan (1999) states that man is perpetually modified by his use of technology, and in turn, finds new ways of modifying his technology. 
As opinion varies for the increasing use and application of technology into our professional and personal lives, it is important to proceed with caution as the use of these technologies become transparent, invisible, and taken for granted as they become normal functions in how we live. As the use of everyday technologies is to increase the efficiency and improve our lives that were once novelty items becomes invisible in our daily habits and behaviors (McCarthy \& Wright, 2004). Heim (1994) concurs, stating that as technology becomes part of our daily needs, the technical systems seem transparent, opening up a world where we can do more, see more, and achieve more.

\section{Social Transformation and the Computer}

Many of today's technologies we experience are fairly new and it is difficult to comprehend the various was in which social transformations will take place due to the emergence of new technologies. Computers can be seen today as ubiquitous. From the mainframe to a personal computer to the Internet, the electronic computer has transformed information and human communication in unanticipated ways (Molony, 2001). To live in this milieu where the computer is so involved in our lives, Mitcham states (2007) that it transforms not just calculations, and communications, but the sense of body, self, and culture. The computer has catapulted this generation out of the daily system needs and into the free space of determining a new response to the conditions under which we live (Coyne, 1995). Laurel (1990) states that the functionality of the computer systems consists of the actions that are performed by people and computers working in concert. We are not just dealing with computers, we are dealing with people who solve problems and make decisions. Human expertise, judgment, and creativity can be supported but not replaced by computer-based tools (Nardi \& O’Day, 1999). 


\section{Transformative Nature of Technology on Education}

As we have stated here, the use of tools and computers influence the way in which the world appears to us. In the case of learning environments this means that the way in which our worlds are and how we relate to them will influence the way in which the world appears to us and in turn how we will relate to the world in general (Araya, 1997). Computing technology in learning environments develops into a much broader context of modern technology. Just as books changed the way we stored and retrieved information and enabled us to invent the modern schoolhouse, the Internet has changed the way in which we think of learning and teaching.

Education is one of the primary targets of the computer and information revolution because of the many opportunities that it offers to the introduction of computing technologies. New technology now requires new teaching methods as well as instructional strategies. Technology alone has not brought about change, but it allows us to think of new ways of teaching and learning. Learners in the $21^{\text {st }}$ Century are understood to be leading the way. Today’s students are growing up in a transitional period and they will be the first adult generation of the Information Age. Concerns for this new era in education look at the skills of the students and teachers of today and tomorrow needed to contribute to a productive society. The educational establishment is one of society's largest institutions and is one of the most deep-rooted and reactionary to technological change (Araya, 1997). Computer technology is changing the relations among students and teachers as well as the relationship to information and knowledge. 


\section{The Problem}

The integration of instructional technology and new media tools reshape the traditional contexts of professional practice of teaching and informing learners. The challenge teachers face is to integrate instructional technology methods representative of the identity and traditional context they present to the classroom, but teachers may still experience a mixture of apprehension and unfamiliarity to redesign their instructional environment with new pedagogical initiatives. The new design methodology to develop this integration requires a transformation and restructuring of not just the content, but teachers' instructional practices, as well as how they perceive their new role as instructional technology facilitators. Evidence of this transformation can be reflected through their redesigned instruction that is now digitally enhanced. A teacher's overall charge is to work collaboratively with other teachers to re-examine their professional role and responsibilities. This comes with the understanding that their instructional practices will provide the learner with opportunities to engage in digitally enhanced learning environments. The change forces us to question whether the traditional categories continue to characterize in essential ways the new kinds of educators that contemporary technology creates.

\section{The Need for the Study}

When we adopt new technologies, we face uncertainty about how our quality of life may change. The development of new technology affects the nature of our work, school, family life, commerce, politics, and war, (Nardi \& O’Day, 1999). We live with technology as observers, commentators and practitioners and we must consider the implications for our theories and professional practice. Our immersion in this cultural 
phenomenon should not prevent the need to ask questions about the consequences of technological change so we can see opportunities for evaluation, change and improvement. Although formal tools influence our practical reasoning and decision making, our personal history and social preferences shape tool use. An experiential account of technology that addresses itself to felt life, such as teaching, is still lacking (McCarthy \& Wright 2004). There is a need to attend to the experiential connectedness of the self and object, action and material, thought and feeling, and individual to community (McCarthy \& Wright, 2004). Turkle (2005) suggests that technology can be seen as an agent of transformation of traditional practices and the development of new technology is inherently a dynamic and cumulative process. The lessons learned in working with an existing technology very often provide materials, tools, and most importantly a knowledge base for the next stage of development (Nardi \& O’Day, 1999). It is critical to understand the social impacts of technological change.

Some time has passed since the initial introduction of the computers into the classroom. Teachers have had more time to adapt to their new instructional initiatives, more opportunities to participate in professional development training, and gain more hands-on experience in the classroom to employ new instructional strategies. An examination of the past decade of the computer revolution can afford a clearer picture of our experience. There is a continual need to evaluate how technology works within a given setting. We need to move beyond the human machine dyad, expand our perspective to include the networks of relationships, values, and motivations involved in technology use (Heim, 1994). What is relevant is the concept of teachers learning new ways of Being with technology in the classroom. 


\section{Purpose of the Study}

It is important to capture the experience of the transformation in educational practice as it has been changed with an increase in applied instructional technology used education. The purpose of this study is to take an exploratory look at how university teachers come to understand their experience in educational practice and their role as teachers integrating technology into their instruction using the framework provided by Wenger's Social Theory of Learning. This framework can support the examination of how technology changes teachers ways of Being in the classroom, which sees learning achieved through the context of our lived experience of participation in the world through communities of practice (Wenger, 1998). Communities of practice can provide a lens to examine some of the benefits and limitations of the change in practice with respect to technology. This provides an opportunity to examine how the meaningfulness of technology relates to social practices. The Social Theory of Learning sees an intimate connection between knowledge and activity (Wenger, 1998). Within this framework, our social engagement and participation in the world shapes who we are (identity), what we do (practice), how we interpret what we do (meaning), and how we belong (community). This theory makes the following assumptions as they relate to learning and the nature of knowledge, knowing, and what it is to know (Wenger, 1998):

1) We are social beings (identity)

2) Knowing is a matter of participating in the pursuit of various enterprises (practice)

3) Achieving meaning is our ability to experience the world \& our engagement with it as meaningful (meaning)

4) Knowing is a matter of competence with respect to valued enterprises (community) 
A Social Theory of Learning integrates these components to characterize social participation as a process of learning and knowing. These following components, identity, practice, meaning, and community are deeply interconnected and mutually defining. Table 1. displays the components and their definitions as they relate to learning.

\section{Table 1}

Components and definitions of a social theory of learning

\begin{tabular}{|c|c|c|}
\hline & Identity & $\begin{array}{l}\text { A way of talking about } \\
\text { how learning changes } \\
\text { who we are, creates } \\
\text { personal histories of } \\
\text { becoming in the context } \\
\text { of our communities. }\end{array}$ \\
\hline $\begin{array}{l}\text { community } \\
\text { learning as } \\
\text { doing practice }\end{array}$ & Practice & $\begin{array}{l}\text { A way of talking about } \\
\text { shared historical } \\
\text { resources, social } \\
\text { resources, frameworks } \\
\text { and perspectives that can } \\
\text { sustain mutual } \\
\text { engagement in action. }\end{array}$ \\
\hline $\begin{array}{l}\text { learning as } \\
\text { experience }\end{array}$ & Meaning & $\begin{array}{l}\text { A way of talking about } \\
\text { our changing ability, } \\
\text { individually and } \\
\text { collectively to experience } \\
\text { life as meaningful. }\end{array}$ \\
\hline $\begin{array}{l}\text { Components of a Social Theory of Learning, } \\
\text { (Wenger, 1998) }\end{array}$ & Community & $\begin{array}{l}\text { A way of talking about } \\
\text { our social configurations, } \\
\text { enterprises defined and } \\
\text { worth pursuing, and our } \\
\text { participation is } \\
\text { recognizable as } \\
\text { competence. }\end{array}$ \\
\hline
\end{tabular}




\section{Research Questions}

There are four specific questions this study seeks to examine:

Research Question 1: What are university teachers' reflections of their changed role now responsible to integrate instructional technology? (IDENTITY)

Research Question 2: What are university teachers’ processes and experiences of participation and engagement in delivering technology integrated instruction? (PRACTICE)

Research Question 3: How do university teachers interpret and understand their experience of integrating instructional technology into their educational practice? (MEANING)

Research Question 4: What are university teachers' processes and experiences of belonging to educational communities where they are responsible to integrate instructional technology?

(COMMUNITY)

\section{Significance of Study}

Transitional periods can be privileged positions for examination and reflection to find ourselves where we spend our lives at the interface with this machine (Heim, 1994). The awareness of the potentials for transformation during the transitional periods can guide our actions in creating and applying technology to our daily practice (Turkle, 2005). The examination of how technology is affecting our teaching methods and our instructional strategies can not be overlooked. New methods of participation integrating technology encourage a new way of Being felt both personally, professionally, and how the understandings of the communities in which we practice. The Social Theory of Learning provides a framework to examine how we understand the way instructional technology has changed the inter-working nature of our community of practice. How we come to understand our experience and negotiate the meanings of these experiences is important to investigate in the field of education. 


\section{Chapter Two}

\section{Literature Review}

This study seeks to examine how university teachers understand their experience in educational practice and their roles as university teachers integrating technology into their instruction using the framework provided by the Social Theory of Learning. The following information will explore how context plays a significant role in the learning process. This will be first explored through the perspective of the situated learning theory which sees the learning process affected by environment, people, and instruments where learning takes place. Stemming from the situated learning theory is the Social Theory of Learning, which will be used in the focus of this study. This theory examines learning through social participation in communities of practice. There are four specific components involved in this theory that inform learning which will be explained in detail; identity, practice, meaning, and community. These four components are integral to the examination of university teachers experience integrating technology. This study will seek to apply qualitative research methods to gather information about the four components of the Social Theory of Learning as it provides a framework to examine teachers understanding of technology integration.

\section{Context of Learning}

The context, in which learning takes place, plays an important role in the learning process. Over the last decade, the context where teaching takes place has changed due to advancements in instructional technology. The context in which learning is familiar, both teacher and student can relate to new information and skills more easily to what they already know than if the learning context is unfamiliar (Driscoll, 2005). When the 
context changes from learning to application or practice, learners find it difficult to transfer the knowledge they acquired in one context to the other relevant context (Driscoll, 2005). The advancements of instructional technology changed the educational and instructional context which forced teachers not only change their teaching practices, but their underlying educational theories and instructional strategies.

The landscape of the classroom transformed in the last decade with computers which provided students with learning software and Internet access. Computers, Smart Boards and LCD projectors were also provided to teachers for their instructional purposes. The subject matter and content did not change, but the manner in which it was instructed and communicated did. The voices of teachers as their own communication instrument are now shared with communication media. Chalkboards and evaluation instruments can be digitized and viewed by all students as well as other teachers. As these new tools arrived, they came with the responsibility to know how to utilize and apply them to the learning instruction and activities. The responsibilities university teachers faced not only consisted of the skill and knowledge to use instructional technology, but more importantly the challenge to appropriately apply it. Some examples of these responsibilities included how to communicate through web-based applications and email, how to develop course websites, how to develop web-based and computer based instruction, how to manage on-line chats and communication through web boards, and how to use university based course development tools. This process of change required critical thinking on the teachers' part to transform and restructure their traditional practices to represent enhanced instruction with integrated technology for their content. 


\section{Perceptions of the University Culture}

Dearlove (1997) finds that higher education communities are commonly perceived to be an ideal institution in which both the place and the people who work in it are free from external constraints. Through Dearlove’s (1997) explanation, perceptions exist that professors can choose their own hours of attendance and work, that self regulation and peer control are important to collegiality, that governance occurs through participatory democracy, and that consensus will emerge after an intellectual debate in which no hierarchies exist. This perception represents an ideal of a higher education institution more than an existing reality.

\section{University as a Community of Practice}

This study observes the university as a 'community of practice' to gain a better perspective about the context in which higher education institutions function. Barab and Duffy (2000) identify three essential characteristics of a community of practice that can be directly applied to a university community; it exhibits a common cultural and historical heritage including collective goals, negotiated meanings, developing identities and shared practices; it is situated within an interdependent system where individuals become connected to something larger; and it has the ability to reproduce itself as new members begin to engage in mature practices alongside the veteran members. Academic departments, subject disciplines and professional development networks that exist within a university can also be identified as communities of practice (Brew, 2003).

\section{University as a Learning Organization}

A university culture can be viewed as a organization that is concerned with the prospect of transforming and renewing itself through learning (Carroll, 2003). A learning 
organization is defined as one which has the capacity to transform itself as it engages in continual learning activities (Watkins and Marsick, 1993). Marsick (1997) continues by stating that when individuals learn, under the right conditions, they take what has been learned and bring it back to the system in which they work, such as a school, hospital, government, so that the knowledge can be shared, easily accessed, and utilized for a common purpose. Knight and Trowler (2001) identify the university as the central location in which faculty experience changes in their teaching practices because learning is situated within the daily practice of its community. Recent research exploring the nature of workplaces as learning environments has largely focused on industrial and commercial environments and there is a need to focus on the educational organization to examine what the teachers learn (Rowland, 2001).

\section{Professional Development}

The initiative to be a "learning organization" expressed through university mission statements can direct the focus of teachers' work, encourage the spread of best practices, and attract additional resources (Rowland, 2001). Teachers that participate in training and professional development often value the experiences, but feel an increased pressure to demonstrate the effectiveness of their training they received (Robson, 2002). Rowland (2001) states that some kind of gap between the training and the reality of professional practice is probably unavoidable.

The importance of collaboration among teachers through activities focused on professional growth and development (Brookfield 1995). Peer groups, in the context of a discussion about their training and development, may afford opportunities for enrichment, for the sharing of perspectives and for making personal and professional 
changes in a relatively safe environment (Robson, 2006). Although there may be a significant diversity of backgrounds among university teachers participating in professional development, peer group exercises tend to be highly valued, (Harkin, Clow and Hillier, 2003). Lave and Wenger, (1991) and Bathmaker, Avis and Parsons (2000) argue that the opportunities for teachers to talk and engage with one another may ensure that the communities themselves are transformed and professional identity is not simply imposed from above.

\section{Development of University Teachers Identity over Time}

The professional identities and communities of teachers in higher education are many and complex as their work in all phases of education remains relatively ill defined (Robson, 2006). University teachers are inducted over a long time into the higher education social processes, first through their own academic experiences as successful students and then as lecturing staff and researchers (Cooper 2004). Rowland (2001) agrees by stating that the work of identity for higher education teachers is not confined to a certain period of their lives or a particular setting. It is not that teachers 'become' and reach the end of a process that we have completed. Teachers are continually constructing their identities as teachers in a sense of continual 'becoming.' Zukas and Malcolm (2002) agree with Wenger (1998) in that they see the construction of teachers' identities in higher education as a process of participation rather than acquisition and that pedagogical identity as active and dynamic. Teacher identity focuses on 'potentiality' and the continual enactment of performativity (Hull, 2002). Teacher identity can be seen as a collective accomplishment from an ongoing process of learning and engaging with a community of practice, (Wenger, 1998, Bathmaker et. all., 2000). As teachers negotiate 
and continue to construct their identities, they contribute to the evolution and changes within the higher education community in which they practice.

\section{Tension Between Teachers’ Attention to Discipline Versus Teaching}

What is defined as 'expertise' in teaching compared to other professions is ill defined. Robson (2006) explains that unlike other professions a teacher is likely to regard himself or herself as an expert in a particular area and later obtain a teaching position because of the knowledge and expertise that has already been acquired in an area of discipline as a result of significant study and experience. This initial focus on becoming a content expert in their subject area overshadows the attention to their need to develop expertise in the activity of teaching as it will be their future job. Teachers may feel tension between their need to continue their development as a content expert and their need to further their skills as teachers in their subject areas. Teaching is perceived as something additional and separate from the knowledge and practice of the disciplines, (Robson, 2006). Significant to educational practice, Malcolm and Zukas (2000) argue that a critical approach to teaching and learning is necessary as the content that is taught counts as educational knowledge within a specific discipline. Disciplinary and pedagogical identities therefore cannot be separated and must co-exist within educational communities, (Malcolm and Zukas, 2000). Robson (2006) states that we should not be educating university teachers in isolation from university departments of education where pedagogical knowledge and practice already exists.

\section{Teachers Allegiance to their Discipline over their Institution}

As teachers' priority may be placed on focusing their attention toward their subject area over their pedagogical knowledge, Coldron and Smith, (1999) note that 
tensions may also exist as teachers become more attached to the practices of their discipline over attending to the imposing policies and directives from their employing university. Teachers may have a greater allegiance to their discipline and occupational group than to the university in which they practice (Robson, 2006). Tensions may arise amongst the different cultures and communities that exist within the institution and between differing imperatives and priorities associated with aspects of the teachers' work (Coldron and Smith 1999). Bleakly (2002) discusses the need for teaching to be free from an authoritarian discourse from the university institution and rather teach from a humanistic model that focuses on he autonomy of the learner. Robson (2006) notes that conferences, collaborative writing, external examining and editorial work for journals are likely to help provide a means for securing membership and negotiating identity within the disciplinary group. Research from Hyland and Merrill (2003) found that administrators involved in university management tended to see the institution as one community whereas the teachers tended to see discontinuities and breaks stating that they lead separate working lives in relation to their subject areas. Research from Henkel (2000) found similar results as administrative respondents identified their departments as a key network whereas teachers talked about their membership to their subject related professional societies which crossed the boundaries of the institution.

\section{Change in the University Culture}

Universities are now subject to more scrutiny that before (Robson, 2006) as the advent of instructional technology caused a shift in the pedagogical practices of the higher education culture. Universities are requiring an increased accountability from their teachers as they assign them the charge to develop their courses online in order to 
compete with other higher education institutions. The shift in external conditions for universities to remain competitive brought about changes in the nature of the teachers' pedagogical practices. Mayes (2002) states that technology brings about change in the organization, the delivery of training, and educational opportunities. Teachers are left with the responsibility to develop their skills and abilities to incorporate instructional technology into their courses. Teachers must also adhere to national and state departments of education mandates that preach the importance of developing teaching practices that will enable current students to be skilled and globally competitive in the $21^{\text {st }}$ Century. Robson (2002) notes that the role of the teacher is in part to induct students into discipline specific modes of thought and to teach them methods and forms of participation and inquiry, they must also teach appropriate working and cultural practices that now includes the computer and the Internet.

Instructional technology raises a number of issues for teachers as a professional group. The advent of the Internet means that expertise of all kinds is more readily and widely shared and teachers in a subtle way may be positioned differently within society as a whole (Robson, 2006). As the identity of the university has evolved and changed, so must the teachers that work within that institution. It is important to research these educational environments to examine how teachers are adjusting their efforts to sustain the universities in which they work through new pedagogical practices. As previously noted, teachers are primarily attached to their subject area and the discipline in which they teach. As their pedagogical practices and interest to adhere to university mandates come second and third to their interest to their subject area, where does this responsibility to teach with instructional technology leave the teacher? 


\section{Situated Learning Theory}

One perspective that address the context of learning is situated learning theory, which states that learning is gained through the environment, people, instruments and tools where learning took place. Situated learning shifts the focus from the individual to the relevance of the socio-cultural setting. Situated learning theory claims that every human thought is adapted to the environment that is, situated, because what people perceive, how they conceive of their activity and what they physically do develop together (Driscoll, 2005). Situated learning is stating that what people perceive, think, and do develops in a fundamentally social context.

This situated perspective is relevant in the examination of university teachers in the process of integrating technology. The traditional learning and teaching context has changed. Classrooms were built and restructured to be technology enhanced in the university environment as computer labs were added. The environment changed from traditional learning and research centers with tables, chairs, and paper-based resources to one that was specifically designed for a digitally enhanced learning that included desktop and laptop computers, T-1 Internet connections, the latest computer software, communication and research tools, and knowledgeable technology support for its successful use.

What is significant in the situated learning theory perspective is that there is no separation from what we know, being declarative knowledge and how we know, being procedural knowledge (Driscoll, 2005) . As the teaching and learning context changed, teachers practiced the combination of knowing and doing in their instructional practice learning to integrate technology as they became competent in their transformed 
instructional context. As it has been previously stated, it is important to note how context plays a role in learning. Lave (1991) states that as we become more competent and are able to exhibit more into our practices, this is knows as learning in practice. Knowledge in this theory is intended to be understood as being achieved through the lived practices of people.

The change in context forced teachers to reflect upon the methods in which they communicated, instructed, researched their content, collaborated with fellow faculty, and evaluated their students and curriculum. This change was fast, sudden, and drastic from a field that is fiercely traditional in its practices. Learning as participation shapes not only what we do, but also who we are and how we interpret what we do (Wenger, 1998). In the university setting, teachers, administrators, technology management and support, and technology integration trainers began this venture together in the instructional environment and during professional development opportunities. People from the educational community in the university worked together to begin new instructional practices. This was not only a collective professional effort toward growth in skills and practices, but a personal journey for each person as they witnessed and navigated change happening all around them. A decade later after the insurgence of advancements of instructional technology, it is important to reflect upon how we see ourselves and what we do now.

\section{A Social Theory of Learning}

The social theory of learning sees learning as a fundamentally social phenomenon and is acquired in the context of our lived experience and participation in the world (Wenger, 1998). This theory stems from the situated learning theory stating 
that learning is gained through the environment, people, instruments and tools where learning took place. Wenger wishes to extend the view of situated learning theory with its relations to the physical situatedness to an examination of how one is culturally and experientially situated in the world. This would include where people are coming from and where they thinks they are going. Wenger (1998) views learning as situated in the trajectory as a human being living in the world. The social theory of learning takes a much more complex view of the concept of situated learning. According to Wenger (1998), the primary focus of this theory is on learning as social participation.

Participation here refers not to just local events of engagement with certain people, but to a more encompassing process of being active participants in the practices of social communities and constructing identities in relation to these communities (Wenger 1998). Participation is viewed as a kind of action and a form of behavior. Learning as participation focuses attention on ways in which it is an evolving, continuously renewed set of relations (Lave \& Wenger, 1991). Learning is a co-constitutive process in which all participants change and are transformed through their actions and relations in the world, (Driscoll, 2005).

This theory has its own set of assumptions, focus, coherent level of analysis, and yields a conceptual framework to derive a set of principles, and recommendations for understanding and enabling learning (Wenger, 1998). The assumptions of the social theory of learning that relate to learning and the nature of knowledge are stated as follows; we are social beings, knowledge is a matter of competence with respect to valued enterprises, knowing is a matter of participating in the pursuit of these enterprises, 
and our ability to experience the world and our engagement with it is meaningful (Wenger, 1998).

Other research that was conducted on the application and study of the Social Theory of Learning in higher education settings included the following studies. In order to maintain consistency with the framework of Wenger's Social Theory of Learning, this research focused strictly on Wenger's review of his theory and not the interpretations of the other researchers' perceptions of the theory. There were two reasons for this decision. Throughout the review of previous research, it was found that the title of the theory being "Social Theory of Learning" was used synonymously with "communities of practice” which only represents one fourth of the components of the theory. The research on "communities of practice" does not fully represent all of the components and subcomponents of the theory as it tended to minimize or exclude the components of identity, practice and meaning. The second reason again refers to the interpretations of the other researchers' perspective of the theory which results in a separation of Wenger's original intent of the theory. As this researcher's perspective and interpretation of the theory also resulted a separation of the original intent of the theory, it was important to remain as consistent as possible to Wenger's original intentions of this theory.

\section{Social Participation in Communities of Practice}

Our social participation occurs through communities of practice which are viewed as people coming together in groups to carryout and engage in activities in everyday life. Communities of practice is participation in an activity system where participants share understandings concerning where they are, what they are doing, and what that means in their lives and for their communities (Wenger, 1998). Communities of practice are a set 
of relations among people, activities, and the world over time and the relations with other tangential and overlapping communities of practice (Driscoll, 2005). These can be networks of people and groups which can represent both formal or informal structures.

The formation of a community of practice is seemingly natural where people come together with a common interest and a level of competence and literacy necessary to engage in participation with the other members of the community. A community of practice consists of a group of people who share an affinity for a common area of interest. engaging in a common interest. Wenger (1998) states that we belong to several communities of practice and they exist everywhere; home, school, work, and hobbies.

The communities of practice is a situated learning experience for its participants and engaging members. From the social theory of learning perspective, participation in the communities of practice becomes a the fundamental process of learning toward the community's shared theme. This perspective causes a rethinking of the process of learning which of goes beyond the learning process of the individual. It can examine how the discourse, engagement, and dynamic nature of the community can affect the learning process of the participants. This perspective is especially interesting when a community is going through the process of change. Collective learning that results from the engagement in practice that reflects both the pursuit of the enterprises and the attendant social relations (Wenger, 1998). These practices are a type of asset that belongs to the community of participants who have shaped it over time by their collected efforts. The phrase communities of practice is appropriate to describe this process people participating in collective efforts toward a common theme (Lave \& Wenger, 1991). 
Our engagement in various communities of practice provides us each with the opportunity to reflect upon our interactions with an evolving world. It affords us the chance to seek answers to define who we are, what things mean to us, and how we understand our participation in our interests and relationships. Communities of practice provides us with a framework to rethink and expand upon our understandings as our communities will evolve and change over our lifetime.

\section{Components of the Social Theory of Learning}

Crucial to this theory, it is important to understand that our participation shapes who we are (identity), what we do (practice), how we interpret what we do (meaning), and how we belong (community). The social theory of learning combines these specific components to describe social participation as a process of learning and knowing. Wenger (1998) identifies four fundamental components: identity, practice, meaning, and community as shown in Figure 1. These are the components that are deeply connected to the process of learning according to this theory. There is no order or hierarchy in relation to these four components as they are simultaneously working in the process of learning. Wenger (1998) names and describes these four components as follows:

Figure 1. Components of a social theory of learning (Wenger, 1998).

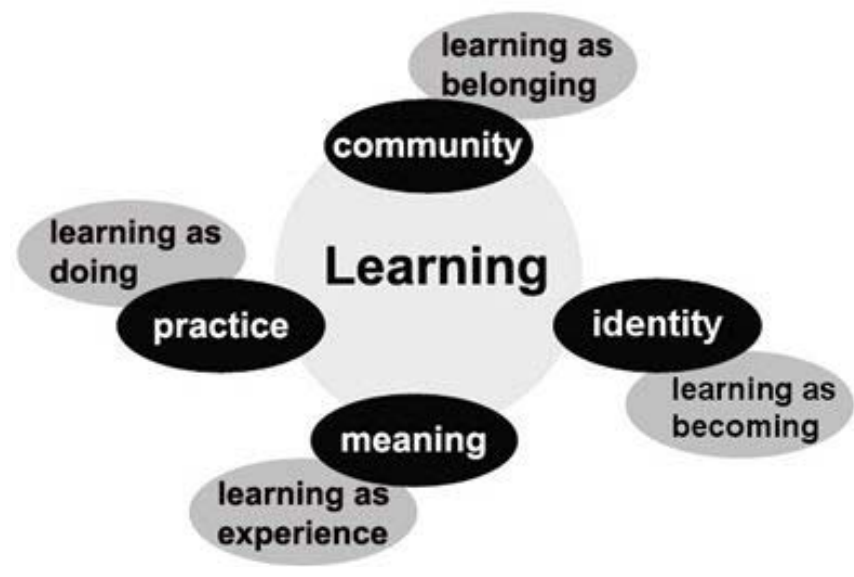


The component of identity represents the evolving self development gained through the process of learning. It is used to describe how learning changes who we are and how it creates our own individual histories of becoming and developing in the context of our communities.

The component of practice represents the act of doing and participating in the process of learning. It is the action of engagement and participation toward the pursuit of a goal which creates a collective history and resources in which people use meaningfully to continue their pursuit. It is used to explain the perspectives and mental frameworks we develop through our pursuit of learning which involve our areas of interest.

The component of meaning represents the process of coming to an understanding and learning through our experiences of living in the world. It is used to describe our ability to learn through of the lives and experiences of ourselves and with other people.

The component of community represents the coalescing nature of people coming together with common interests for the pursuit of learning. Participation with other people in the pursuit of a project or purpose create the formation of these communities.

The four components are all connected to the learning process and this theory maintains learning as its central focus. Throughout the review of the four components, there will be discussion of overlap and reference from one component to the other. They are deeply interconnected and support the development of one another. The overview of each of the four components will discuss them independently, but will indicate how one may connect to another through the process of learning in communities of practice. 


\section{Identity}

Identity is a way of talking about how learning changes who we are and how it creates personal histories of becoming in the context of our communities (Wenger, 1998). The development of our identity is a continuous process that evolves through our everyday practices. The construction of our identity occurs by negotiating the meanings of our experiences through our memberships and associations in social communities. Our negotiation for meaning occurs in how we interpret the experiences in which we participate and how we understand our selves in our social contexts. The result of these negotiated experiences is what informs our identity. The degree and level of competence in which we engage in each community of practice will influence our identity.

The development of identity can be seen as a multifaceted process that goes beyond a linear framework or a timeline of experiences. It has a temporal quality and is influenced by other factors and relationships we experience. Identity exists not as an object in and of itself, but through the constant work of negotiating the self (Wenger, 1998). The examination of identity through a social theory of learning perspective can study a person from a social perspective and analyze their process of identification in how they engage in the social structures of their communities of practice.

Identity is the result of the dynamic interplay between the individual and the community. Identity evolves through the engagement and practices in the community. Identity is influenced by the social, cultural, and historical factors of the community. As identities and communities mutually constitute each other, the communities in which we participate will jointly define who we are. 
Our identities are defined by the forms of competence we bring as members in communities of practice. Competence includes the skills, knowledge, and abilities we contribute to the communities of practice. We are aware through our experiences of the areas in which we choose to become competent and the communities in which we choose to become members. We are also aware of the areas in which we are not competent and the communities in which we can not or choose not to participate. People decide and negotiate their own level of competence. A lack of competence in a community member will be revealed over time in which that member will either work to improve his or her level of competence or to move outside of the community.

Learning can be seen as a tension between the known and the unknown. Our learning does not contribute to our identity or competence, but rather it disrupts our existing foundation (Wenger, 1998). This occurs through the exposure to a diversity experiences in a community of practice. This process contributes to the growth of the members as well as the community.

Main Characteristics of Identity. The formation of identity exists through the negotiations of the understandings we have from our experiences. It is defined through the action of our participation and the projection and connection of our reification in social contexts (Wenger, 1998). This is an active process that can be understood through the following characterizations that are described in the following sections.

Lived experience. Rather than viewing identity as a label that we wear, identity in this case is to be seen as an experience and a particular way of doing things. This characteristic of identity expresses the importance of seeing identity defined through the active and social participation in communities of practice. We see and define ourselves 
through the understandings we gain through our engagement with the world. The titles and roles in which we represent ourselves indicate the engagement and activity we have with certain communities of practice. Our identity is defined by the understandings we gain through our experiences. From this point of view, it can be understood that identity is an evolving process as we continue to live in the world and have experiences.

Negotiated experience. The construction of an identity is a continuous and ongoing process that is not limited to a particular period in time or a specific setting in which we have existed. Rather, the building of one's identity is an active process of negotiating our experiences. Our identity is uncovered and developed through the process of participation in various communities of practice. We come to reconcile a particular way of being and project who we are through the understandings we've gained from our engagement in practices. In this process, we come to use tools and artifacts that relate and assist in our actions. As we come to know the intentions of a community, we can serve its goals and missions by participating and contributing appropriate information, skills and actions. Meaning and the understanding of who we are is gained through this negotiation process and our experiences help to develop our identity.

Social-community membership. Identities are developed and influenced through our interactions with other people in the communities of practice. Our memberships to communities exist within a social context and our identity is affected by the social nature of these interactions. Our engagement is not independent of the other members' participation, but rather the engagement occurs in groups. Our membership and role within a community will be determined by our level of competence in which we 
can contribute to that community. Our identity is then defined by the memberships we make in the communities in which we engage.

Learning process. Our identities combine our past history of experiences along with our interests and intended pursuits for the future. Reconciling where we have been and where we intend to go requires us to negotiate what is necessary for us to know in the present moment for us to pursue the future. Our learning process exists within our negotiation of the past and future in order to accomplish the present moment. The meanings we gain through our past pursuits reflect our learning process. The fact that we continue to pursue various paths is evidence that our learning process is continuous and ongoing.

Nexus of multimembership. We have relations and memberships to several communities of practice all at once such as work, families, hobbies, and neighborhoods. Our identity consists of our ability to adapt and reconcile our understandings of the combination of our memberships and roles to different communities. The strength of our participation will vary among the different communities in which we are involved. We must reconcile the many forms of community memberships in which we carry. Our various roles exist simultaneously and our many memberships affect one another.

Modes of Belonging. In order to make sense of the process of learning and its affect on identity formation, the social theory of learning names three modes of belonging as they relate to our social interactions; engagement, imagination, and alignment. These three modes are used to describe the ways peoples' identities are influenced as they interact and participate in communities of practice. Each of these three modes create relations of belonging that help build and shape our identities. These modes of belonging 
provide a framework for understanding the variety and types of communities, as well as a structure for analyzing the transformations of these communities over time (Wenger, 1998). These modes help us understand the efforts required in the work of belonging. Most of what we do involves a combination of these three modes of belonging. We may be informed of the meaning of our actions if we place more emphasis on one or more of the modes of belonging. The following sections will describe in detail each of the three modes of belonging.

Engagement. In the process of engagement, members collectively become involved in activities which help form a community of practice. Relationships are formed through the members' interactions with each other which creates shared histories of learning in their practices. Through the process of mutual involvement, members try to negotiate and define the meanings of their activities. It is a continuing cycle of participating in community events and projecting their understandings through sharable artifacts and materials to build upon toward the development of the community. During this process, members' identities are transformed by their involvement and they develop a certain way of being which is defined with respect to the community. Engagement is an ongoing process as members negotiate new situations, form new relationships, and pursue the future of their mutual interests.

Imagination. The mode imagination affords members the ability to see outside the boundaries of a practice to invite new opportunities and possibilities into their practice. Wenger (1998) uses the concept of imagination to refer to our ability to expand our understandings of the self and create new images of the world and ourselves. The exploration of new visions for a community results from our own perceptions and 
understandings from previous experiences. Our imagination can refer back to our own personal events, past memories and experiences of how we belong to communities that shape our identity and relations with others.

It is necessary to remain open in this process in order to receive new perspectives and interpretations. We can create new histories as well as come to understand and project new meaning. This process will influence the way members understand their own participation and how they influence the community. It is important to note that the explorations of other possible worlds in which a community can imagine is still directed toward the shared mission and goal of that practice. Imagination involves various possibilities for the evolution of a community. Imagination affects the forming of our identities through our process of involvement and belonging to the community.

Types of Trajectories. Wenger (1998) states that as we go through continuous forms of participation, our identities create trajectories that travel both within and across the boundaries of communities of practice. A trajectory can be seen as an object moving through time and space. A person's trajectory proceeds with its own momentum and is affected by outside influences. A trajectory's path can not be foreseen nor does it travel on a fixed path or charted course. Its path relates to the concept of time because it links the present with the past and the future. Wenger (1998) further explains by stating that under the concept of trajectories, it is to be understood that as the work of identity is ongoing, it is fundamentally temporal. There is a temporary notion in relation to identity. It is influenced and defined by the interactions of multiple convergent and divergent trajectories (Wenger, 1998). Trajectories can be a way to talk about one's commitment to practice. It shapes the way members understand their participation and influence within a 
community. This process shows how members continue to negotiate with a community even as they pursue a certain path.

As a community of practice relates to a workplace, its history and its evolution shape the trajectories they construct (Wenger, 1998). These trajectories represent the history and the collective stories of the community. These are created through the members' identities and participation in practice. Experienced full members of a community can share the extensive history of their experiences. New members though may have difficulty aligning themselves with a community. Their new ideas may have to be negotiated as they navigate their trajectory and participation in a community. Just as there are different forms of memberships, there are different forms of trajectories. The following sections will discuss peripheral, inbound, insider, boundary, and outbound trajectories.

Peripheral trajectory. A peripheral trajectory refers to a person’s participation that occurs in the margin, edge, or outer boundary of a community. It usually refers to a person's participation that occurs through their own choice or by necessity. This peripheral participation can eventually lead to full participation and membership into a community, but that can only be seen over time. It is important to note that even through the participation is peripheral, the ability to have access to certain communities of practice can contribute greatly to one's identity.

Inbound trajectory. An inbound trajectory can be seen as a person's apprentice relationship to a community. It represents the trajectory of a newcomer to a community of practice with the hope and intention of becoming a full member. Examples of a newcomer could be a novice, a new recruit, an intern, a graduate assistant, or a trainee. 
The newcomer's identity is invested in the relationship with the community members and their practice. There may be hopes for a continued future relationship and participation in order to secure further participation within that community.

Insider trajectory. Change can be seen as a constant element for any organization and the evolution of any community of practice. In relation to change, the development of one's identity does not come to an end by attaining full membership to a community of practice. An insider trajectory represents a member's participation that requires new and additional responsibilities, requirements, and needs relating to the evolution of a community. This would also include the adaptation to new generations of people, the use of technology, or new ways of participation. This change presents members with opportunities to renegotiate their identity.

Boundary trajectory. A boundary trajectory can be seen as a person who finds value crossing and connecting to various communities of practice boundaries. The person in this process maintains his or her own identity, makes connections, links to other identities, and finds value for themselves and other people participating in different communities of practice. This is a difficult trajectory to travel, but some people have great skill in bringing people together from different practices which can build the potential for creating whole new communities all together. A person with this trajectory creates an identity with extensive breadth as he or she can walk the boundary of many different types of practice.

Outbound trajectory. Not all participation leads a person into a full membership of a community of practice. The outbound trajectory represents the process of leading a person out of a community. An example to understand this process could be graduating 
from school or growing up into adulthood and the ability to see the world and themselves in different ways. This type of trajectory looks toward the development of a new type of participation that enables one to seek new participation possibilities. Through the new process of participation, one develops new relationships or new roles and responsibilities with respect to a community. It is evident in this trajectory that the person's identity is in the process of evolving into a new state as change and transformation is evident in this process.

\section{Practice}

The social theory of learning classifies the concept of practice as a complex process. It can be seen as an action and connection toward the development of an enterprise. It is the action of doing in a social connection with other people and a kind of property that is creating through our shared pursuits. Through this process, we come to negotiate meanings and understandings through our participation with others. The social theory of learning uses the term participation in reference to the 'action of practice' and this study will also refer to the term participation in that format as well.

Through practice, we engage in a combined process of action and connection. Action is viewed as our participation and connection is viewed as our social engagement in participation with others. It is both a personal and social process. Throughout this process, our participation results in a shared type of property with other members and practitioners known as a practice. Examples of this understanding can be seen as a law practice, a physicians practice, or communities of practice. As a property, it is the sustained participation of members toward a collective venture. This can be viewed as the result of the collected actions of people over time. 
Mutuality of Practice. Through the action of practice, there is a mutual recognition that is achieved through our social participation. As we engage in a dialogue with others, we have an assumed awareness and recognition that there is a shared understanding between us. Through this process of engagement and social participation, we recognize in each other something relevant of ourselves. As we engage in mutual participation in our conversations and actions, we begin to negotiate meaning and define each other's experiences and understandings, thus becoming part of each other. Participants will shape and mold each other's experience to negotiate meaning. These experiences contribute to our own identities. This is a defining characteristic of participation in that there is a possibility of contributing to an identity of participation. Who we are is defined through our participation with others.

The use of the word mutual in this perspective does not reflect an equality, respect, or constant harmonious engagement of actions. As those would be ideal conditions, mutual participation to negotiate meaning with others that is unequal, conflictual, or unharmonious still provide us with an some form of understanding. Mutual recognition is meant to be seen as a process of taking part in the relations with others that reflect the same process.

The transformative potential gained through participation can affect both the member of the community and the community itself. Our participation in a community can shape our experiences and in turn, we can shape the meanings and understandings of that community. We can greatly affect a community of practice through the capabilities and competencies we can offer. Our experience of participation can also be significantly 
influenced by our ability or lack of ability to engage in these practices. If we are unable to contribute or participate due to any reason, we may take our energies elsewhere.

Our mutual participation is a process that stays with us even when we are not engaging in that practice at the moment. Our participation is not limited to the context or the specific time of our engagement, but rather the thoughts and actions stay with us where ever we go. Our identity is deeply affected through mutual participation and it stays with us and will surface in our other experiences.

Learning in Practice. As people work in their professions or jobs, their everyday interactions and engagement in tasks becomes a part of their learning experience as they are learning their practice. Wenger (1998) states that learning in practice in this case is not identified as specific activities, but rather the processes of being engaged in, participating, and developing an ongoing practice. The social theory of learning identifies three processes to understand learning in practice; the evolving forms of mutual engagement, the understanding and tuning of the enterprise, and the development of the repertoire. Wenger (1998) states that significant learning affects these three dimensions of practice and it is what changes our ability to engage in practice, the understanding of why we engage in it, and the resources we have at our disposal to do so. Learning contributes to the ongoing social development process of the community. Each of these three processes will be described in the sections below.

Evolving forms of mutual engagement. Mutual engagement describes the process of how a community of practice functions and it is the ability to learn certain ways of interacting with other people as they relate to a community of practice. For learning in a community of practice, there is a continuous development process in which 
participants learn how to work and interact with each other. It is a process of learning how to develop relationships with other people involved in the same pursuit. Participants discover and learn both positive and negative qualities about other members of their practice. This involves realizing what is helpful and productive, identifying who are the other participants, and learning the what are the various contributions to the practice.

Understanding and tuning their enterprise. This process is concerned with the process of alignment, which is through the connection and coordination of energies, actions, and practices to larger communities of practice (Wenger, 1998). Participants are concerned with orienting their energies and efforts collectively while defining their practice. Members learn to become accountable for their participation and have the expectation that other members carry the same responsibility. In this process, members try to interpret and reconcile their understandings of their community's mission and adjust their efforts for maximum performance toward that mission.

Developing their repertoire, styles, and discourses. As participants engage in a practice, there are resources that are developed and used that aid and support their sustained engagement in that practice. As this is a learning process, members negotiate the meanings of the elements that shape, facilitate, and help define that practice. Members create and adopt tools, artifacts, representations, and recall events (Wenger 1998). The evolution of a practice necessitates discourse. Communication among members includes a common language with specific terms. Dialogue among members consists of their history and stories of their practice. During this learning process, members develop routines and decide upon courses of action. The tools that we adopt and use, the conversations and dialogue we have with fellow members, and the histories 
we create over time are examples of the process of developing a repertoire. The tools, conversations and histories contribute to the strength and understanding of the community.

Characteristics of Participation. The following sections will describe some of the characteristics of participation that exist in communities of practice.

Participate in resolutions to conflict and change. Members of a community of practice plan a course of action and establish goals to navigate their way through change. As change infers that members engage in a learning process to continue their participation in the future, they may establish education or training programs. Because the world is in a continual state of flux and conditions continually change, any practice must be constantly reinvented even as it remains the same practice (Wenger, 1998).

Support communal memory. Community members contribute their individual knowledge and capabilities to collectively build a successful, productive, and functioning practice. The interdependence among members contributes to their communal knowledge allowing members not to be required to know everything. Through their collective engagement, their shared knowledge can sustain the activities of the practice.

Assist others. A necessary activity among members is that they help each other succeed in their community endeavors. This can occur through professional development sessions, opening the door to new community joiners, and providing solutions and/or resources to one another. Members can share in the new ideas and shortcuts for answers to problems or difficulties.

Perspectives to accomplish goals. As community members orient themselves to their practice, they develop and proceed with plans in order to achieve their pursuits. As 
members collectively focus their efforts, the input and shared dialogue they have with each other will be directed toward a common goal. It is not out of the ordinary that diversity and conflict arise with the various perspectives members bring to their practice. Diversity is a benefit to expand the boundaries and provide growth for a community. Even as there are differences in perspectives among members, it is known that they are all interested in achieving the intended community's mission.

\section{Meaning}

Meaning is our changing ability individually and collectively to experience life, the world, and our engagement with it as meaningful. We are alive in the world with a body and brain functioning well enough to participate and communicate with each other in social communities of practice. Our engagement in practice gives us opportunities to attach meanings to our thoughts and actions. It is the meanings that we produce through our experiences that matter. For this discussion, meaning is meant to be understood as the knowledge and learning gained through our engagement in practice. Our experiences produce new meanings. We expand our frame of reference to modify our existing understandings.

The process of meaning is broken down in the following steps. The social theory of learning states that meaning is acquired as we go through the process called the negotiation of meaning. The negotiation of meaning involves two interrelated processes; participation and reification. The process of participation represents action in our social involvement and interaction in life's activities. The process of reification represents the projections of our understandings that we place onto the world from our social 
experiences. Reifications are ever evolving representations and points of focus to help us communicate and connect socially as we engage in practice.

The two processes of participation and reification are interconnected and form a duality as they work as a pair which is essential in the process of negotiating meaning. In this duality, we participate in activities and reify our new understandings. We take these understandings and make new connections to help guide our social connections in the engagement in practice. This duality of participation and reification is fundamental to the human experience of negotiating meaning and the nature of how we engage in practice (Wenger, 1998). The following sections will explain these processes further as they describe the component of meaning as it is understood in the social theory of learning.

Negotiation of Meaning. As we live in the world, we come into contact with different experiences, interactions, activities, observations, and environments. To live meaningfully, our social activities and relations provide opportunities to have experiences in which we can learn in practice. Negotiating meaning involves a process of interpreting the experiences in our lives and resolving how they relate to our history as well as how they make us understand our future.

Our process of negotiation is dynamic and ongoing as situations and the events we are exposed to are always changing. We interpret our circumstances and make decisions from our past experiences on how to respond, think, and act. Meaning becomes the result and product of the negotiation process. We will encounter a world that provides access to opportunities as well as closed doors. As we engage in the world, we have the ability to affect our relations with other people and they can equally affect us. The process of engagement is never simple, but rather it consists of multiple factors and 
perspectives. We produce new perspectives from the collective factors in which we are presented. Throughout the process of negotiation, we come across meanings which reflect the convergence of our understandings gained from a new resolution toward our pursuits.

The negotiation of meaning is ongoing as the world and our interaction in life's events continue to change. The new resolutions we gain can only be seen as temporal and incomplete as our engagements in activities will present new information and understandings. The convergence of the processes of participation and reification are where the negotiation of meaning takes place. This is a combination of action and the concepts we create that make connections in social practice. The following sections will describe participation and reification in more detail.

Participation. The process of participation is the active involvement and interaction with other people toward a shared pursuit. Through participation with other members in communities of practice, we are afforded the ability to connect socially and form relationships with other people around mutual interests. The social theory of learning sees participation as a complex process as it carries both personal and social significance. Participation involves the totality of the individual as they use their mind, body, emotions, and social relationships in the process. This process includes doing, talking, thinking, feeling, and belonging all at the same time (Wenger, 1998).

The concept of participation in communities of practice is meant to represent our social character in our engagement with the world. As we engage in communities of practice, we have all kinds of relations with people. Our participation and engagement 
with members participating in a practice is characterized as mutual. Characteristics of participation can be seen through the following information.

Mutual relations should not be understood as being synonymous with collaboration or equality. Participation with others consists of many kinds of relationships. Members will shape and influence each other's experience as they engage in practice toward a mutual pursuit.

Our participation in communities shape our experience as well as transform these communities in which we practice. An important aspect of our experiences is the potential to affect a community's practice. Our lack of ability to participate or influence a community through our participation will also affect our experience.

Our participation in social practice becomes part of our identity and defines who we are. The meaning we gain in practice are carried with us past the time and context of the experience. The meaning we gain from our experiences will surface in our future activities. The experiences in which we participate and engage are meant to show our social nature as we engage in life's activities. These are the characteristics that the social theory of learning uses to describe how meaning is acquired through the action of participation. Participation is combined with the second process, reification, in the process to negotiate meaning.

Reification. Reification can be seen as a process of projecting the understandings we gain from our experiences onto the world. This is a process of taking what we know and creating material objects to represent the meanings of our experiences. We take tacit knowledge and make it explicit and tangible. Examples of these projections can be seen as the recordings of laws, the creation of tools, or the development of procedures and 
policies. These tangible objects are constructed and used by members of the community to assist in the productivity and organization of their practice. To refer back to the examples, laws are used to negotiate points of view, tools help members perform activities, and procedures provide guidance in community activities. The reifications we create shape and influence our experiences. We clarify our intentions of our participation with the explanations through these representational devices. As we use these objects in practice, our performance is greatly affected.

Being that reifications are the projections of the negotiation of our meanings, it is important to understand that our understandings and meanings will evolve and change. Our reifications will also evolve and change as well with our understandings and projected meanings. Reifications are never in a completed state just as living in the world is a continuous process. Our reifications will reflect our living process.

Duality of Meaning. The duality of meaning represents the alignment of the complimentary processes of participation and reification. This alignment represents a dialectical relationship of the action of participation and the projection and connection of reification. Mutual understanding and the negotiation of meaning is found among members through these two paired processes.

The balance of each process is important and it is necessary that participation and reification are in proportion to each other. If a community of practice has too much participation without enough reification, then there will not be enough points of focus for members to anchor their practice. Misunderstandings can result without enough reification which can create an unstable community structure. It represents too many different ideas of the community's mission and practice. 
If a community of practice has too much reification then the lack of shared experiences and collective interaction give little opportunity for members to negotiate their own meaning. Even though there are points of focus to structure the practice, chances for people to negotiate their own meaning is not available. The practice will consist of people who have their own understandings and do not have the opportunity to share them collectively.

These two processes can not replace each other and the various combinations of these two factors can provide for a variety of experiences of meaning (Wenger, 1998). The different balances between the two produce different meanings. Participation and reification are meant to be complimentary in their dialogue with each other. They also are negotiated continually throughout the social interaction of a community of practice.

This duality is a fundamental aspect of the constitution of communities of practice. It is important to recognize a practice's evolution over time and the relations that are made among other various practices. The identities of participants also evolve and move in and out of communities. The broader organizations in which communities of practice exist will produce initiatives for smaller branch communities to follow. The smaller communities will negotiate their own meaning that is appropriate for their practice.

\section{Community}

Through the act of social participation and mutual engagement, people come together to pursue common interests and ideas to form communities of practice. Lave and Wenger (1991) first introduced the concept of communities of practice and described it as a set of relations among persons, actively involved in the world through time and in 
relation with other tangible and overlapping communities of practice. People coming together can be for both formal and informal interests. They join in groups to participate together in their mutual interests. It is these groups that we call community. It is the act of belonging to particular groups to learn together and share experiences. There is a common interest shared by the members of the community that does not need to represent equality or harmony, but it does reflect a mutual theme. The community and the act of belonging eventually becomes the result of the mutual participation in the shared interest.

It is through our participation in these communities that we learn. Participation in the community helps inform members and provides opportunities for them to continually pursue their purpose. The collective learning results in practices which Lave and Wenger calls communities of practice (Lave \& Wenger, 1991). These communities have a familiar context to participants and members which give them the opportunity to deepen their understanding. Their participation allows them to increase their level of knowledge and skill while reflecting upon their actions that allow them to explore who they are and their understandings of the world.

Throughout our lives, we are continuously involved in communities that can range from formal communities (jobs, careers, and specializations) to informal communities (hobbies, sports, and music). The community serves as a platform for members to reflect upon their pursuit and work to advance its capabilities as it evolves. It gives the participants an opportunity to share in their stories and conceive of ideas to expand the perimeter of their practice as they look for unexplored paths that relate to their pursuits. 
Community Membership. Our membership with a community of practice translates into a form of competence which is a part of our identity. When we become a member with a community, we can participate in activities and discussions that are familiar to us. The level of competence held by each of the members is important. All members must uphold a certain level of competence to participate. Members' level of competence in the community's practice is recognized and revealed through their participation. It is necessary that one understand the social procedures of the community and interact well with others. Relations among community members share a common understanding and must meet a level of accountability. Resources are developed and made available for community members to share as they engage in community activities. Our memberships carry these responsibilities as they are necessary for the sustained practice of the community.

Dimensions of Communities of Practice. In a community of practice, there are different elements that are important. The dimensions of communities of practice are meant to connect the practice to the community. There are three dimensions that help define the relation that practice has as a source of coherence and collective participation in a community (Wenger, 1998). The dimensions of a community of practice are:

- mutual engagement

- joint enterprise

- shared repertoire

The dimension of mutual engagement refers to the aspect of people coming together to form a community to search for meaning toward a shared interest. Their coming together assists in their efforts to define who they are in their collective pursuit. 
The dimension of joint enterprise refers to the domain that is created through the participation of members as they pursue an established mission that defines their community. The dimension of shared enterprise refers to the action of sustained engagement of practice in which the community is involved. Members use stories, tools, languages, and styles to engage and work together which represents their accumulation of knowledge and skill in their practice. The following sections will describe each of these dimensions in more detail.

Mutual engagement. The process of mutual engagement refers to how a community functions and how it joins members together into a social practice. This is an important aspect because members collectively negotiate the meanings and understandings of their community. This creates patterns of relatively structured interactions among the participants that shape the culture and work of the community. Mutual engagement constitutes the community because what occurs in the practices of the community is a result of the members interactions and engagement. For members to be a part of a community, their interaction and engagement is necessary. There are three important aspects of the process of mutual engagement. The following sections will explain these three important aspects will be explained at greater length.

The first aspect is that members must create and facilitate an atmosphere that enables interaction among members and people who would like to contribute to the community. Mutual engagement is interested in welcoming newcomers into the community and will develop paths to encourage engagement among members. As this is a theory that is focused on learning, members are aware that all participants have their own needs and will facilitate engagement opportunities for the various stages of learning. 
Activities and regular meeting times are set for members to interact and communicate. This allows for discussions and opportunities for members to come up with new ideas to further their community of practice.

The second aspect is that members must also be accepting of both diverse and complementary interactions to help build upon the community's pursuits. Even though members of a community of practice come together and engage in meaningful shared activities, the identities of each member is maintained. Participants provide their knowledge and competencies collectively, but it is individually based upon each member's understandings, perceptions, and interests in the community.

The third aspect returns us the to the importance of participation being mutual. The use of the term mutual allows for the complexity and variety of participation among members as their involvement is directed toward a common negotiated activity. Relationships are developed through the awareness of members mutual interest in their practice. These relationships involve the bringing together of perspectives and ideas. Relationships also involve both harmonious and discordant interactions as there is a process of negotiation throughout the members' participation in practice. In this process, members get to know each other and have confidence in the capabilities and competencies of other members. Leadership roles and key players are known by the members as well as the rituals and rhythms of the interactions in a community. It is necessary that mutual engagement occurs for a community of practice to exist otherwise it remains a group with individuals acting independently. Mutual engagement means that people come together to interact meaningfully toward a common goal. 
Joint enterprise. The dimension of a community of practice known as the joint enterprise is meant to represent the forms of accountability in which we are able to contribute to an enterprise or venture which makes us perceive the world in certain ways and understand certain responsibilities. This is a process of ongoing participation and negotiation focused around a specific mission or objective enacted through mutual engagement.

The overall aim of a community of practice is usually determined by a larger organization or institution in which the community is a part. The community usually represents a branch or a smaller section of the larger institution. As a smaller representation, the community declares its own indigenous course of action, its identity and a defined domain. The indigenous scope of a practice is constructed through the mutual negotiation of its members. It is then reasonable to expect that the community require mutual accountability among its members to uphold its pursuit.

The community's regime of mutual accountability implies that there is a shared ownership among members as they are responsible for their own work as well as being a part of a group. We are seen as being responsible for ourselves and to be made available to assist others in this process. The shared accountability among members corresponds with the shared efforts toward the common goal as members negotiate the future direction of their community.

A shared common goal aligns the member's interest in upholding the accountability among as they navigate the future direction of their community. This instills an understanding among members that they are collectively pursuing the same path. It is important to note that different points of view are welcomed as it extends the 
boundaries of the community. The is necessary for the community's growth and development. The dimension of joint enterprise in a community of practice informs what the community is about and how it is understood among members who share in the pursuit of a common purpose.

Shared repertoire. This process describes the knowledge and capabilities that have been created through the communities of practice. These are shared points of reference that provide a common discourse and language where members can develop their own thoughts and ideas to communicate meaning in relation to their community. Members utilize shared resources that are continually developed, maintained, and renewed over time to represent the knowledge of their practice.

The resources are created from the community's established routines, belief systems, used languages, and methods of practice. The resources can be seen as both material and intangible elements such as stories, artifacts, techniques, tools, symbols, concepts, methodologies, and more. The shared repertoire is most easily recognizable as it represents the practice through its resources and materials used.

The use of resources portray a shared history of the community's practice that has been built over time and shaped by its members. The shared history provides members with a sense of identity and belongingness through the recognition and familiarity of its resources. If a community lacks a shared repertoire, then members will not have common points of reference and their practice will lack meaning and substance in relation to their mission. It is important that a community of practice build their resources and shared repertoire from which to work from in order to sustain and strengthen the practice among members. 


\section{Qualitative Research Methods}

Qualitative methods can facilitate information gathering that helps describe university teachers' experience in teaching as well as the academic community in which they practice. Qualitative research can be viewed as multi-method in focus, involving an interpretive, naturalistic approach to its subject matter as qualitative researchers study things in their natural settings, attempting to make sense of, or interpret phenomena in terms of meanings people bring to them, (Denzin \& Lincoln, 1998). According to Creswell (1994) a qualitative study is defined as an inquiry process of understanding a social or human problem, based on building a complex, holistic picture, formed with words, reporting detailed views of informants, and conducted in a natural setting. Denzin and Lincoln (1998) continue to state that qualitative researchers seek answers to questions that stress how social experience is created and given meaning. Qualitative methodologies can be powerful tools for enhancing our understanding of teaching and learning. Eisner (1991) states that qualitative research has an interpretive character aimed at discovering the meanings of events have for the individuals who experience them and the interpretations of these meanings by the researcher.

A variety of methods are employed by qualitative researchers to collect information for a better understanding of their subject area. The information and data collected from these methods provide a greater perspective of the events and experiences in people’s lives. Some examples of these methods are case studies, interviews, observations, document analysis, focus groups and open ended surveys to name a few.

Qualitative researchers examines the patterns of meanings which emerge from the data and these are often presented in the participant's own words. The task of the 
qualitative researcher is to find patterns and themes within those words and actions and to present those patterns and themes for others to examine while at the same time staying as close to the structure of the participant's environment as it was experienced.

This type of inquiry takes into account the complexity and dynamic nature of the social world and researchers seek the uniqueness and individual nature of each part of their study. A researcher listens to what people say, explores the ideas, thoughts and concerns presented by the subjects. In this research perspective, the subjects then become the experts to be studied as the researcher attempts to observe, describe, and interpret the meanings of their world.

The researcher studies and collects materials that will be used to describe routine and problematic moments and meaning in individuals' lives. This method of research attempts to make sense of a chosen phenomena from the perspectives of the people being studied in a holistic manner by preserving the complexities of uniqueness of human behavior (Patton, 2002). Researchers look for themes and patterns emerging from the information and data collected while bracketing out their own thoughts and beliefs.

It is important to capture and understand the subjects experiences being lived by the participants as they do (Van Manen, 1990). Possible methods to capture this data are in-depth interviews with people experiencing the phenomenon as well as observations to see the people living through the experience as it happens (Patton, 2002). The subjects' interpretation of their experiences becomes their reality. Patton (2002) states that there is no separate or objective reality for people as they can only know how and what they experience through their own perception that makes it meaningful. 
The way in which a researcher designs a qualitative study depends on the purpose of inquiry and what specific information will be most useful. Qualitative research maintains an emergent design framework noting that a researcher's focus and the outcomes and results of the research reflects an emergent process as well. Patton (2002) states that because the researcher seeks to observe and interpret meanings in context, it is neither possible or appropriate to finalize research strategies before the collection of data has begun.

\section{Interpretivist Research Paradigm}

A paradigm can be referred to as a theoretical framework that influences the way knowledge is studied and interpreted. The paradigm establishes the intent, motivation and expectations for research. The term paradigm may be defined as a loose collection of logically related assumptions, concepts, or propositions that orient thinking and research (Bogdan \& Bilken, 1998). Patton (2002) states that a paradigm is a worldview and a way of making sense of the complexities of the real world.

An interpretivist approach to research tries to understand the human experience through the participants’ point of view of the situation being studied (Creswell, 2003). The shared meanings of the culture is situated and related to a specific context. Reality, under the interpretivist paradigm is seen as socially constructed (Mertens, 2005). The culture of the examined participants viewed as both cognitive and affective, is their shared meaning reflecting a common language, symbols, and other modes of communication (LeCompte \& Schensul, 1999). Meanings are socially constructed and created through the interaction and participation among members of the culture. Cultural 
beliefs and meanings are not fixed, but rather negotiated and socially constructed among the multiple versions of the community being studied (LeCompte \& Schensul, 1999).

\section{Phenomenological Approach}

A phenomenological approach refers to a particular group of perspectives and methodologies for carrying out qualitative investigation. Phenomenology is an interpretive research methodology used to examine the human experience. This research study will adopt a phenomenological approach to examine the university teachers experience of how they came to understand integrating instructional technology in a changed practice through the social theory of learning framework. Phenomenology seeks to find the meaning, structure, and essence of a lived experience of a phenomenon for a person or group of people (Patton, 2002). Van Manen (1990) states that phenomenology aims at gaining a deeper understanding of the nature or meaning of our individual and collective everyday experiences. Patton (2002) states that phenomenological research focuses on the question, 'What is the meaning, structure, and essence of the lived experience of this phenomenon for this person or group of people?' Phenomenologists focus on how we come to understand the phenomena we experience to make sense of the world in which we exist. With the meaning we've created from our experiences, we then have a perspective of our world. It is the interpretation of another person's reality. Phenomenologists attempt to interpret another person's perspective through their lived experience. The researcher tries to find out how the person reconciles and makes sense of their experiences to arrive at their particular understandings. It attempts to uncover the meanings that have been created due to lived experiences. Phenomenological research requires the researcher to put him/herself in the world of the people he/she is trying to 
study to experience their reality and conditions. In attempts to collect data from the subjects, it is important that the researcher separates his or her own biases and beliefs in order to understand the phenomenon they are researching. This process is called bracketing. This method is used for phenomenological study as a tool to separate the thoughts and judgments in which the researcher approaches the study.

Phenomenology directs the focus and point of view onto the subject who is experiencing the phenomena. It is through this focus that the researcher can learn about the experience of others individually and collectively. It can examine what is distinct in each person's experience and what is common to the experience of groups of people who have shared the same events or circumstances.

\section{Reflexivity}

Patton (2002) states that reflexivity calls for critical self-reflection and selfknowledge and a willingness to consider how who one is affects what one is able to observe, hear, and understand in the field as a researcher. It is important that the researcher observe himself or herself in addition and in conjunction with the observations and interactions with others. Reflexivity implies that the researcher become aware of the ethical concerns of the access to the research area as well as understanding that he or she is part of the social world that he or she investigates (Berg, 2001). The researcher must have an ongoing inner dialogue to examine what he/she has come to know as well as how he /she became aware of this knowledge. It is construction of the researcher interpretations of experiences during the research. 


\section{Data Collection Methods}

The using a variety of data sources, a researcher can build on the strengths of each type of data collected and minimize the weaknesses of any single data collection approach (Patton, 2002). The methods to collect data to examine the university teachers' experience of integrating technology through the social theory of learning framework are described in the following sections.

Interviews. In-depth interviews present open ended questions to participants to yield in-depth responses about their experiences, perceptions, opinions, feelings and knowledge (Patton, 2002). This process gives the researcher access to the subject's world and discovers a perspective that could not be directly known or observed. In-depth interviews can be seen as face to face conversations with a selected group of people for the purpose of exploring issues or topics in detail (Patton, 2002). The use of topics and open-ended questions help guide the participant's discussion and responses about a particular subject area. The participant explores his or her thoughts, beliefs, experiences and knowledge throughout the interview in which the researcher captures quotes and discussion about the topic of interest. Rapport with the person being interviewed is important so that he or she feels content with the researcher and can comfortably answer questions. The researcher must remain neutral in their perspective as well to the content and information that is being received by the people being interviewed. The subjects must feel that what is communicated is not judged in any way. It is also important that the researcher's bias is not subjected to the participants during the interview as it can encourage the participants to provide material they feel is necessary for the research rather than their genuine beliefs or views. 
Observations. Observations are a type of data collection method that gathers information about participants in the context of their own natural environment. Observational data are used for the purpose of description of settings, activities, people and meanings of what is observed from the perspective of the participants (Hoepfl, 1997). This method to gain a better understanding of the research subjects by drawing the observer into the phenomenological complexity of the world, where connections, and causes can be witnessed as how they unfold (Denzin \& Lincoln, 1998). Passive observation is defined as the systematic watching of behavior and talk in the participants' natural occurring setting. It allows the researcher to see the participant in their natural setting engaging in the action that is being studied. Observation can lead to deeper understandings because it provides a knowledge of the context in which the events occur, and my enable to researcher to see things that participants themselves are not aware of, or that they are unwilling to discuss (Patton, 2002).

Once the researcher has chosen a setting and gained access to that setting for observation, a field guide is necessary when conducting the observation to help the researcher know what to be aware of where he or she will make record of the actions, behaviors, conversations, and interactions in the chosen setting. The researcher will take field notes that will include comprehensive descriptions of their observations which will include the context in which the observation takes place. The use of observation to study subjects is helpful when used in conjunction with other research methods such as interviewing. It can help strengthen and clarify information found through other research strategies. 
Document Analysis. Document analysis includes the study of excerpts, quotations, or entire passages from organizational, clinical, or program records (Patton, 2002). Relevant records, documents, and artifacts can provide a rich source of information to research about a particular organization or program. Other relevant documents Patton (2002) includes are memoranda and correspondence, official publications and reports, personal diaries, and open ended written responses to questionnaires and surveys. Documents and reports can provide a researcher with information that otherwise could never be known, observed, or discussed. Patton (2002) informs that program records can provide a behind the scenes look at program processes and how they came into being. The importance and advantage of gaining access to documents relevant to the research is that it can help direct the focus of inquiry and observations. 


\section{Chapter Three}

\section{Methodology}

\section{Research Focus}

The purpose of this study was to take an exploratory look at how university teachers come to understand their experience in educational practice and their professional role as teachers who integrate instructional technology into their coursework using the framework provided by Wenger’s Social Theory of Learning. This chapter describes the arrangement of research methods to answer the following questions: Research Question 1: What are university teachers' reflections of their role now responsible to integrate instructional technology? (Identity)

Research Question 2: What is the process of university teachers participation and engagement with delivering instructional technology in the classroom? (Practice) Research Question 3: How do university teachers interpret and understand their experience of integrating instructional technology? (Meaning)

Research Question 4: What is the university teachers’ process of belonging to and educational community now responsible to integrate instructional technology into their educational practice? (Community)

\section{Qualitative and Phenomenological Approach}

Qualitative research methods were used to gather data to help examine how university teachers make sense of their environment and their experience now with instructional technology. This form of inquiry assisted in examining how these faculty members understand the meaning and experience of the evolution and change in their profession. The complexity of teaching and how it is learned cannot be learned from the 
outside in (Freeman, 1995). It is imperative to learn how teachers construe their worlds, the actions they take, and the ways in which they explain those actions to themselves and to others (Shulman, 1986). It was important to grasp the teachers’ perspective from the context in which they experience their 'world.'

Adopting a phenomenological research approach, this study examined what was distinct and unique in each teachers' experience as well as what is common to the experience of a group of teachers who have shared the same circumstances.

\section{Researcher and Participants}

Researcher. Prior to becoming a graduate student to study in the field of Technology Education, my experience began eleven years ago was that of a lecturer for a graduate level distance-learning program at a northeast research university in which I taught traditional face-to-face instruction for six cohorts. It was my role and responsibility as a lecturer in this position to begin to learn how to design the courses for web-based instruction through part time graduate course-work in the Department of Technology Education. The goal was to begin to blend and eventually replace the longdistance traditional teaching format of the classes with that of web-based instruction. That position provided me with the opportunity to see a department go through the transition and change as we were tasked to change our original teaching format and begin to integrate instructional technology. This transition was felt by both adult learners as students and fellow faculty members of that department. It was important for me to learn how to prepare and assist both students and faculty with the skills needed to transition from one format to another. It was apparent to me during this time of the complex and difficult nature of changing traditional techniques and practices. In order to fully 
understand and be competent in the process of technology integration into instruction, I would need to dedicate my time fully to graduate study. Through my graduate studies, I was provided with the opportunities to develop web/computer-based learning activities and develop and maintain course websites for higher education faculty members.

Participants. Participants that were important to inform this study were college faculty teaching at a research university in a college of education who participate regularly in a yearly professional development activity, the Faculty Academy. The Faculty Academy is a yearly event which started in the year 2000, that focuses on teaching faculty how to integrate instructional technology into their coursework. A total of eight faculty were purposefully selected to participate in this study based on their regular participation in the Faculty Academy and that they all taught courses that integrate instructional technology within the college of education. This research used purposeful sampling which is a dominant qualitative research strategy in which the researcher chooses participants that can provide information-rich cases which could be studied in-depth. In purposeful sampling, the researcher selects the people, settings, and circumstances in which the processes being studies are most likely to occur (Patton, 2002).

The eight faculty chosen to participate have been involved with the college of education community in both a learning and teaching capacity for a range of 15 to 34 years. Secondary to the primary purpose of this study, the levels of roles the participants maintain within the college of education facilitated another level of understanding of the experiences of university teachers integrating instructional technology; three faculty 
maintain administrative roles, three faculty maintain primarily teaching roles, and two faculty maintain program support teaching roles.

The college of education hosts a varied group of educational departments. For this study, six participants taught for the teacher education program, one participant taught for educational leadership program, and one participant taught for speech pathology and audiology. These faculty have a high level of responsibility to provide direction and serve as role models to successfully teach with instructional technology for their students. As their students are to become involved in future educational practice, the college faculty presents them with learning experiences to see how instructional technology can provide new ways of learning and teaching.

Association with Participants. One of my graduate experiences was working as a graduate assistant where I gained contact with experienced university faculty teaching in the college of education. During the assistantship, I worked side by side with education faculty during the Faculty Academy as I helped them address instructional technology applications that matched with their methods of instructional design, provided technical training, and assisted with the preparation of instructional technology materials. Participation in those professional development experiences provided me with the access and familiarity to the teaching faculty. The informal relationships that were built through the participation in those professional development activities enabled me to approach the faculty concerning my research study as a foundation of familiarity previously built. An initial meeting was arranged with each participant in which they were informed of the intent and purpose of the study as well as the level of commitment needed from them to 
participate in the research activities, which provided information to inform the study's research questions.

\section{Data Sources}

Using a variety of sources and resources, the researcher can build upon the strengths of each type of data collection while minimizing the weaknesses of any single approach (Patton, 2002). The types of data sources use Wenger's Social Theory of Learning to inform how teachers' identity, practice, meaning, and community had been affected by integrating instructional technology included interviews, observations, and document analysis.

Interviews give the researcher access to the subject's world and discovers a perspective that could not be directly known or observed. Observational data are used for the purpose of obtaining descriptions of settings, activities, people and meanings of what is observed from the perspective of the participants (Hoepfl, 1997). Observational methods are used to gain a better understanding of the research subjects by drawing the observer into the phenomenological complexity of the world, where connections, and causes can be witnessed as how they unfold (Denzin \& Lincoln, 1988). Document analysis includes the study of excerpts, quotations, or entire passages for organizational, clinical, or program records (Patton, 2002). Relevant records, documents, and artifacts can provide rich sources of information to inform research topics on organizations or programs. The data sources chosen to inform each research question is shown in Table 2. 
Table 2

\section{Data sources to inform research questions}

\begin{tabular}{|l|l|}
\hline Research Questions & Data Source \\
\hline $\begin{array}{l}\text { Research Question 1: What are university teachers' reflections of their } \\
\text { role now responsible to integrate instructional technology? (Identity) }\end{array}$ & Interviews \\
\hline $\begin{array}{l}\text { Research Question 2: What is the process of university teachers } \\
\text { participation and engagement with delivering instructional technology } \\
\text { in the classroom? (Practice) }\end{array}$ & $\begin{array}{l}\text { Interviews } \\
\text { Observations } \\
\text { Document Analysis }\end{array}$ \\
\hline $\begin{array}{l}\text { Research Question 3: How do university teachers interpret and } \\
\text { understand their experience of integrating instructional technology? } \\
\text { (Meaning) }\end{array}$ & Interviews \\
\hline $\begin{array}{l}\text { Research Question 4: What is the university teachers' process of } \\
\text { belonging to and educational community now responsible to integrate } \\
\text { instructional technology into their educational practice? (Community) }\end{array}$ & $\begin{array}{l}\text { Observations } \\
\text { Document Analysis }\end{array}$ \\
\hline
\end{tabular}

Interviews. A list of semi-structured, open-ended interview questions were created that focused on informing the study's research questions related to the Social Theory of Learning components; identity, practice, meaning, and community The interview questions created to inform research question one, identity, shown in Table 3.

Table 3

Interview questions created to inform research question one, identity

\begin{tabular}{l|l|}
\hline \multicolumn{2}{|l|}{ Identity } \\
Research Question 1: What are university teachers' reflections of their role now responsible to integrate \\
instructional technology?
\end{tabular}


The interview questions created to inform research question two, practice, are

\section{shown in Table 4.}

\section{Table 4}

\section{Interview questions created to inform research question two, practice}

\begin{tabular}{|c|c|}
\hline Practice & \\
\hline $\begin{array}{l}\text { Research Question 2: What is the process of university teachers } \\
\text { delivering instructional technology in the classroom? }\end{array}$ & \\
\hline Interview Questions & Practice Components \\
\hline $\begin{array}{l}\text { 1. How does instructional technology affect the way you engage in } \\
\text { your educational practice? } \\
\text { 2. What is it like working with other members of your educational } \\
\text { community with the use of instructional technology? (influences, } \\
\text { contributions) } \\
\text { 3. How has instructional technology contributed to your work in } \\
\text { education and your own process of learning? } \\
\text { 4. How do you see instructional technology contributing to the } \\
\text { evolution of your educational community? } \\
6 \text {. How have you and your fellow colleagues navigated your way } \\
\text { through change with the integration of instructional technology? }\end{array}$ & $\begin{array}{l}\text {-Participate in Resolutions to } \\
\text { Conflict \& Change } \\
\text {-Evolving Forms of Mutual } \\
\text { Engagement } \\
\text {-Mutuality of Practice }\end{array}$ \\
\hline $\begin{array}{l}\text { 5. What are some your educational community's current goals in } \\
\text { relation to instructional technology? }\end{array}$ & $\begin{array}{l}\text {-Perspective to Accomplish Goals } \\
\text {-Understanding \& Tuning } \\
\text { Enterprise }\end{array}$ \\
\hline $\begin{array}{l}\text { 2. What is it like working with other members of your educational } \\
\text { community with the use of instructional technology? (influences, } \\
\text { contributions) } \\
\text { 4. How do you see instructional technology contributing to the } \\
\text { evolution of your educational community? } \\
\text { 7. With the use of technology, how is knowledge and information } \\
\text { shared among your fellow colleagues? }\end{array}$ & $\begin{array}{l}\text {-Support Communal Memory } \\
\text {-Assist Others } \\
\text {-Develop Repertoire, Styles, } \\
\text { Discourses }\end{array}$ \\
\hline
\end{tabular}

The interview questions created to inform research question three, meaning, are shown in Table 5. 
Table 5

Interview questions created to inform research question three, meaning

\begin{tabular}{|l|l|}
\hline \multicolumn{2}{|l|}{ Meaning } \\
\hline $\begin{array}{l}\text { Research Question 3: How do university teachers interpret and understand their experience of integrating } \\
\text { instructional technology? }\end{array}$ \\
\hline Interview Questions & Meaning Components \\
\hline $\begin{array}{l}\text { 1. What is your perspective about teaching and education today with } \\
\text { the integration of instructional technology? }\end{array}$ & $\begin{array}{l}\text {-Negotiation of Meaning } \\
\text {-Duality of Meaning }\end{array}$ \\
$\begin{array}{l}\text { 2. How do you come to understand the experience of evolution and } \\
\text { change in education due to the integration of instructional technology? }\end{array}$ & \\
\hline $\begin{array}{l}\text { 3. What does your experience in education mean to you now with the } \\
\text { use of instructional technology? } \\
\text { 4. How has your participation in education shaped your experience as } \\
\text { a teacher? Has technology changed your experience? }\end{array}$ & -Participation \\
\hline $\begin{array}{l}\text { 5. Are there any recent guidelines, procedures, protocol, or policies } \\
\text { that have been created for your educational community concerning the } \\
\text { use of instructional technology? }\end{array}$ & -Reification \\
\hline
\end{tabular}

The interview questions created to inform research question four, community, are shown in Table 6.

Table 6

Interview questions created to inform research question four, community

\begin{tabular}{|l|l|}
\hline Community \\
\hline $\begin{array}{l}\text { Research Question 4: What is the university teachers' process of belonging to and educational } \\
\text { community now responsible to integrate instructional technology into their educational practice? }\end{array}$ \\
\hline Interview Questions & Community Components \\
\hline $\begin{array}{l}\text { 1. How would you define your educational community now with the } \\
\text { use and integration of instructional technology? }\end{array}$ & $\begin{array}{l}\text {-Community Membership } \\
\text {-Mutual Engagement }\end{array}$ \\
$\begin{array}{l}\text { 2. How has technology affected the way members of your community } \\
\text { interact and communicate? }\end{array}$ & \\
$\begin{array}{l}\text { 3. How does technology contribute or influence the opportunities you } \\
\text { have to work with other education faculty and staff? }\end{array}$ & \\
\hline $\begin{array}{l}\text { 4. How has your educational community defined its mission and } \\
\text { overall goal concerning the use of instructional technology? }\end{array}$ & -Joint Enterprise \\
\hline $\begin{array}{l}\text { 5. Describe some of the tools, methods, or concepts that help your } \\
\text { educational community in practice. (resources or assistance for } \\
\text { example) }\end{array}$ & -Shared Repertoire \\
\hline
\end{tabular}

Observations. Observation guides were created that focused on informing the study's research question two, practice and research question four, community related to 
the social theory of learning components. The observations that related to research question two, practice, focused on individual faculty's classroom instruction that used computer and web-based technology in the classroom. Table 7 displays the observation guide criteria focused on informing the Social Theory of Learning's practice components. Table 7

Observation guide criteria to capture practice components

\begin{tabular}{|l|l|}
\hline Observation Guide Criteria & Practice Components \\
\hline $\begin{array}{l}\text { Instructional Practices using technology in teaching } \\
\text { practice }\end{array}$ & Evolving Forms of Mutual Engagement \\
\hline $\begin{array}{l}\text { Mandates/Standards relating to instructional } \\
\text { technology used in teaching practice }\end{array}$ & Understanding and Tuning Enterprise \\
\hline $\begin{array}{l}\text { Technology tools \& resources used in teaching } \\
\text { practice }\end{array}$ & $\begin{array}{l}\text { Developing Resources, Styles, } \\
\text { Discourses }\end{array}$ \\
\hline
\end{tabular}

The observations that related to research question four, community focused on faculty’s collective engagement in practice learning how to integrate instructional technology in an educational community professional development session. Table 8 displays the observation guide criteria focused on informing the Social Theory of Learning's community components.

Table 8

Observation guide criteria to capture community components

\begin{tabular}{|l|l|}
\hline Observation Guide Criteria & Community Components \\
\hline $\begin{array}{l}\text { Collective engagement learning and using } \\
\text { instructional technology }\end{array}$ & Mutual Engagement \\
\hline $\begin{array}{l}\text { Attention to community mandates that relate to larger } \\
\text { communities of practice standards; nation, state } \\
\text { standards that relate to instructional technology }\end{array}$ & Joint Enterprise \\
\hline $\begin{array}{l}\text { Community shared technology tools and resources to } \\
\text { engage in practice }\end{array}$ & Shared Resources \\
\hline
\end{tabular}

Document Analysis. The data collected for document analysis focused on informing the study’s research question two, practice and research question four, 
community related to the social theory of learning components. Documents that related to research question two, practice, included artifacts of faculty's course websites, lesson activities, and syllabi reflecting the integration of instructional technology. Table 9 displays document analysis criteria to capture practice components.

Table 9

Document analysis criteria to capture practice components

\begin{tabular}{|l|l|}
\hline Documents for Analysis & Practice Components \\
\hline Syllabi, Assignments, Discussion Board & Evolving Forms of Mutual Engagement \\
\hline $\begin{array}{l}\text { State mandates and } 21^{\text {st }} \text { Century CSOs relating to } \\
\text { instructional technology used in teaching practice }\end{array}$ & Understanding and Tuning Enterprise \\
\hline $\begin{array}{l}\text { Course Websites, Wimba, Power Point Presentations, } \\
\text { PDF documents, Concept Maps }\end{array}$ & $\begin{array}{l}\text { Developing Resources, Styles, } \\
\text { Discourses }\end{array}$ \\
\hline
\end{tabular}

Document analysis that related to question four, community included documents or plans for faculty technology use, tutorials, and community standards or mandates guiding the use of instructional technology, shown in Table 10.

Table 10

Document analysis criteria to capture community components

\begin{tabular}{|l|l|}
\hline Documents for Analysis & Community Components \\
\hline $\begin{array}{l}\text { Community mandates that relate to larger } \\
\text { communities of practice standards; nation, state } \\
\text { standards that relate to instructional technology }\end{array}$ & Joint Enterprise \\
\hline Educational community tutorials, websites, guides & Shared Resources \\
\hline
\end{tabular}

\section{Data Sources and Data Collection Procedures}

To restate, the data sources that were used for this study to inform each of the research questions included interviews, observations and document analysis. Table 11 displays how each data source was used as well as the method and number of collections per data source. 
Table 11

Data sources and collection methods to inform research questions

\begin{tabular}{|l|l|l|l|}
\hline Research Question & Data Source & Data Collection Method & Number of Collections \\
\hline RQ1 (Identity) & Interviews & Faculty Interview & 1 First Interview \\
\hline RQ2 (Practice) & Interviews & Faculty Interview & 1 First Interview \\
\cline { 2 - 4 } & Observations & Classroom Observation & $\begin{array}{l}\text { 2 Observations } \\
\text { - after first interview } \\
\text { - after second interview }\end{array}$ \\
\cline { 2 - 4 } & Document Analysis & $\begin{array}{l}\text { Evidence of technology } \\
\text { integration in courses }\end{array}$ & $\begin{array}{l}\text { 1 Fall 2008 course with } \\
\text { technology integration }\end{array}$ \\
\hline RQ3 (Meaning) & Interviews & Faculty Interview & 1 Second Interview \\
\hline RQ4 (Community) & Interviews & Faculty Interview & 1 Second Interview \\
\cline { 2 - 4 } & Observations & $\begin{array}{l}\text { Faculty Academy } \\
\text { Observation }\end{array}$ & $\begin{array}{l}\text { 1 Observation (5 days) } \\
\text { - during professional } \\
\text { development activity }\end{array}$ \\
\cline { 2 - 4 } & Document Analysis & $\begin{array}{l}\text { - resources, guides, tutorials } \\
\text { - documents from previous } \\
\text { Faculty Academies }\end{array}$ & $\begin{array}{l}\text { Any information relative } \\
\text { to the university, college } \\
\text { or teacher education } \\
\text { programs that inform the } \\
\text { practice of integrating } \\
\text { technology }\end{array}$ \\
\hline
\end{tabular}

\section{Timeline}

Data collection initially began in early month of May 2008 at the end of the university’s spring semester. At this time, teaching faculty from the college of education came together to attend an annual one week professional development activity called the Faculty Academy. Data collection at this time consisted of observing faculty as they worked together with their educational community to learn about instructional technologies and to gain skills to integrate the technology into their courses. Also at this time, documentation of the university's and the college of education's was obtained of its guiding policies directing the use of instructional technology. Data collection did not resume until the beginning of the Fall 2008 semester when teaching faculty began teaching their courses for the new school year. At this time, teacher interviews and observations were scheduled throughout the fall semester. Documents that were relative 
to the teachers courses that were observed, both digital and paper based, were collected.

Data collection concluded at the end of the Fall 2008 semester. Table 12 displays the timeline of data collection as well as the data sources collected.

\section{Table 12}

Timeline of data sources collected.

\begin{tabular}{|l|c|c|c|c|c|c|}
\hline Data Source & $\begin{array}{c}\text { May } \\
2008\end{array}$ & $\begin{array}{c}\text { August } \\
2008\end{array}$ & $\begin{array}{c}\text { September } \\
2008\end{array}$ & $\begin{array}{c}\text { October } \\
2008\end{array}$ & $\begin{array}{c}\text { November } \\
2008\end{array}$ & $\begin{array}{c}\text { December } \\
2008\end{array}$ \\
\hline $\begin{array}{l}\text { Observation } \\
\text { Faculty Academy }\end{array}$ & & & & & & \\
\hline $\begin{array}{l}\text { Document Analysis } \\
\text { Educational Community }\end{array}$ & & & & & & \\
\hline $\begin{array}{l}\text { Interviews } \\
\text { Teaching Faculty }\end{array}$ & & & & & & \\
\hline $\begin{array}{l}\text { Observations } \\
\text { Teaching Faculty }\end{array}$ & & & & & & \\
\hline $\begin{array}{l}\text { Document Analysis } \\
\text { Faculty Course Documents }\end{array}$ & & & & & & \\
\hline
\end{tabular}

The data sources that were collected to inform the research questions of this study included interviews, observations and document analysis across an eight month time span. The following information will describe the data collection procedures for this study in the order that they occurred.

Observation of Faculty Academy. The first step in the data collection process was conducting an observation of the college of education faculty engaging with their fellow faculty during an annual professional development activity called the Faculty Academy. This observation focused on faculty's engagement with other faculty as they learned technology to integrate into their coursework. An observation guide was developed to capture the following: 
- Faculty collectively engaging in an activity focused on learning and integrating instructional technology into their courses

- Influence and mention of mandates and standards affecting their use/design of instructional technology

- Shared instructional technology and resources used in the educational community The procedures that accomplished the observation of the Faculty Academy are described here. First, it was important to gain permission to conduct the Faculty Academy observation. A letter seeking permission to observe was presented to one of the leaders of the Faculty Academy and it was signed granting approval (Appendix X). The signed letter of permission was submitted along with the application to conduct research to the University Institutional Review Board (IRB). The IRB granted permission to conduct the research at the exempt and expedited levels. The Faculty Academy consisted of faculty participating in a week long, Monday through Friday, professional development session that began at 9am in the morning and finished at 4pm in the afternoon. One of the days of the Faculty Academy was Election Day in which there was no Faculty Academy was scheduled for that day. The unobtrusive observations began at 8:30 in the morning each day when faculty were arriving to the session and ended at 4:00 in the afternoon when the session concluded. An observation field guide was used while observing faculty learning and working together during the professional development sessions. Field notes were taken and recorded regarding details and descriptions of the professional development setting, the activity of the teachers learning and working, and the collective discussions faculty had discussing their educational community's practice. After each day of the observation, the researcher reflected and recorded any additional thoughts concerning the observations of that day. The access to 
observe faculty collectively engaging in practice helped inform research question four, community.

Limitations noted that could have affected the observation of the faculty academy involve the participants' knowledge and awareness that they are being observed and recorded. As it was a professional development activity in which multiple members of the educational community collectively participated, observations only captured their behavior and what was displayed externally and not their internal thoughts. Also, as it is a group environment, the data captured was limited to the perspective of the researcher and did not capture all occurrences within the activity.

Document Analysis of Educational Community Support Materials. The second step in the data collection process was to (1) collect any support or tutorial documents that helped faculty improve their skill and use of instructional technology in practice as well as (2) collect documents from previous Faculty Academy sessions. The procedures that accomplished this second step are described here. To research and collect any college of education documents that were created to help support and sustain faculty's use of instructional technology. These documents were available through the college of education's technology support center website. To research and collect previous Faculty Academy documents that were created to update and provide guidance and information about current technology integration software and practices. These were documents organized in binders marked by the Faculty Academy's individual years and were provided for review by the director of the technology support center. The access to the educational community's documents helped inform research question four, community. 
Limitations that could have affected the review of the document analysis that affected the educational community are described here. Limitations found with the first document analysis were informative tutorial materials used by the educational community which focused helping faculty use instructional technology. As computer and web-based technologies are constantly being updated and renews, the tutorial materials to keep up with these changes may not have been available or updated. Limitations found with the third document analysis were the binders and agendas from previous Faculty Academies starting with the year 2000. Not all years were recovered and years 2001 and 2005 were not available for review which didn't allow for the researcher to observe the change in community practice.

First Interview with Teaching Faculty. The next source of data was the first of two interviews with the college of education faculty who teach with instructional technology. The data captured in this first interview informed the study on research question one, identity and research question two, practice. The procedures that accomplished this third step are described here. The teaching faculty were contacted through either a phone call or in person and were informed of the research study were asked if they would be interested in participating in the research study. The teaching faculty that agreed to participate were provided with the an interview protocol that was created for the first and second interview. The faculty had the opportunity to review the interview questions in advance before the interview and had the option to agree or disagree to answering any of the questions. A time and place to conduct the first interview was agreed upon. Faculty were asked for their permission to audio record the interview. Each participating faculty agreed and the interviews were recorded. Notes 
were also taken during the interview. For the first interview, a total of 12 questions were asked, five questions to inform research question one, identity and seven questions to inform research question two, practice. The interviews lasted between an hour and an hour and a half. At the end of the interview, scheduled dates and times were agreed upon with the participating faculty to conduct classroom observations where they taught with instructional technology. After the end of the interview, the researcher reflected and recorded any additional thoughts concerning the interview. The first teaching faculty interview informed research question one, identity and research question two, practice.

Limitations that could be found from the participant interviews could have been due to the prior association and familiarity with the faculty from previous Faculty Academy experiences relating to the development of the integration of instructional technology into their coursework. The interview data collected could have been limited due to the possibility that people interviewed may have tried to please, had prejudices against the research topic being instructional technology, and they may have tried to play a role rather than be themselves. Even though each participant displayed a disposition of ease speaking with the researcher, the true thoughts of the participant may never be known. Also, by a couple of the participant's choice, some questions were not answered.

Observations of Teaching Faculty in the Classroom. The next source of data collection consisted of two observations of participating faculty teaching with instructional technology in the classroom. These observations focused on the chosen computer/web based applications as well as the instructional strategy the faculty used with the instructional technology. The first of two observations occurred after the first 
interview and the second observation occurred after the second interview. An classroom observation guide was developed to capture the following:

- Instructional practices using technology in teaching practice

- Mandates/standards relating to instructional technology used in teaching practice

- Adopted technology tools and resources used in teaching practice

The procedures that accomplished the classroom observations are described here.

The participating faculty agreed upon possible dates for the researcher to observe their classroom practices when they used instructional technology. The researcher came before class began, sat in a location that was out of the way of the classroom practice, and unobtrusively observed the teachers classroom practices. For the observations that occurred in an online teaching environment, the researcher logged on to the web-based class and assumed an observer position, not interfering with classroom practices. Field notes were taken during the observation and additional notes were made regarding any questions about their instructional technology use to be asked during the second interview. After the conclusion of each observation, the researcher reflected and recorded any additional thoughts concerning the classroom observations. The classroom observations informed research question two, practice.

Limitations relating to the classroom observations that examined instructional technology use by teaching faculty in their educational practice could have involved the use of technology because they were being observed rather than the instructional methods they would typically use. Participants could have felt that they were being observed for the quality of their instruction in which they used instructional technology. 
Second Interview with Teaching Faculty. The next source of data was the second of two interviews with the college of education faculty who teach with instructional technology. The data captured in the second interview informed the study on research question three, meaning and research question four, community. The procedures that accomplished this next step are described here. The faculty had the opportunity to review the second set of interview questions in advance before the interview and had the option to agree or disagree to answering any of the questions. A time and place to conduct the second interview was agreed upon. For the second interview, a total of 10 questions were asked, five questions to inform research question three, meaning and five questions to inform research question four, community. The interviews lasted between an hour and an hour and a half. After the end of the interview, the researcher asked each participant if there was any additional information they would like to share regarding the research study. The researcher then reflected and recorded any additional thoughts concerning the interview. The second teaching faculty interview informed research question three, meaning and research question four, community. The limitations that were discussed for the first interview apply to the second interview.

Document Analysis of Faculty Course Documents. The last source of data collected were documents related to the teaching faculty's courses that used instructional technology. Documents included syllabi, assignments, and information provided through their course websites. These documents provided specific examples of technology integration chosen by each participant. The procedures to obtain these documents are described here. During the first interview, the researcher asked permission to obtain access to the teaching faculty's university based eCampus course websites as well as see 
any course documents. Each participant granted the researcher access to their course website. In order for that to happen, each teacher had to send an email to the Office of Information Technology at the university to ask to provide the researcher access to the course. Teachers that had an additional course website that they developed and authored that was not eCampus provided the researcher with the Internet address of their course. Course documents were obtained from both the eCampus courses and the web authored courses. At the end of the Fall 2008 semester, the access to the eCampus courses ended, but the other web authored courses remained available to view. The teaching faculty had the opportunity to review their course documents during the second faculty interview. The researcher took notes on the digitized and paper based course documents. The course documents informed research question two, practice.

Limitations found from the document analysis process from the participants coursework was due to the variation in the amount of data available among participants as this would be representative of the variation in which the participants engage in their teaching practice. There was a variety of the course documents that were available from the participants' course websites which did not provide for a consistent assessment across all participants.

To summarize, multiple data gathering techniques were used to collect information concerning the four components of the social theory of learning. Table 13 displays how each data method and data source was collected to inform the Social Theory of Learning components, which are, identity, practice, meaning, and community. 
Table 13

Data methods and sources to inform the social theory of learning

\begin{tabular}{|l|l|c|c|c|c|}
\hline \multirow{2}{*}{ Data Method } & Data Source & \multicolumn{3}{|c|}{ Components of Social Theory of Learning } \\
\cline { 3 - 6 } & & Identity & Practice & Meaning & Community \\
\hline Observation & Faculty Academy Observation & & & & $\mathrm{X}$ \\
\hline $\begin{array}{l}\text { Document } \\
\text { Analysis }\end{array}$ & $\begin{array}{l}\text { Educational Community Policies } \\
\text { and Support Materials }\end{array}$ & & & $\mathrm{X}$ & $\mathrm{X}$ \\
\hline Interview & First Interview with Faculty & $\mathrm{X}$ & $\mathrm{X}$ & & \\
\hline Observations & Classroom Observations & $\mathrm{X}$ & $\mathrm{X}$ & & \\
\hline Interview & Second Interview & & & $\mathrm{X}$ & $\mathrm{X}$ \\
\hline $\begin{array}{l}\text { Document } \\
\text { Analysis }\end{array}$ & Faculty Course Documents & & $\mathrm{X}$ & & \\
\hline
\end{tabular}

\section{Data Management}

Data management are the operations necessary for a systematic, coherent process for data collection, storage, and retrieval (Denzin \& Lincoln, 1998). Qualitative research produces a large amount of data that needs organization and structure and it is necessary that a data management system is put into place before the data collection process begins.

The following data management strategies were applied for each data source collected. First, each raw data source that was collected from each participant was labeled, dated, and placed into its own individual physical folder so that it could be easily retrieved for the data analysis process. Both raw and printed off processed data that was relevant to the participant was put into the folder as well. A master code list relevant to the social theory of learning components was kept that recorded the component codes identified within the data. Future codes that were developed during further analysis of the data were kept in the master code list as well. A researcher's journal was kept for noting thoughts and insights that occurred during and after the data collection and analysis process. 


\section{Phenomenology and Data Analysis}

To restate, a phenomenological study examines the meaning of the lived experiences of several individuals about a concept or phenomenon (Creswell, 1998). The aim of phenomenology is to explicate the meanings of human phenomena and to understand the lived structures of meanings of everyday experience (Parsons, 1997). It is concerned with interpreting the meaning of the lived experience (Van Manen, 1990). Data analysis involves methods and procedures where the data shifts from the qualitative data that have been collected into some form of description, explanation, understanding or interpretation of the people and situations we are investigating (Lewins, Taylor, \& Gibbs, 2005). Data analysis can be seen as an ongoing and iterative process.

It was important to begin the data analysis process at the beginning of data collection as ideas for making sense of the data that emerge, while still in the field, constitute the beginning of analysis and are a part of the recorded field notes. The data from the observations, interviews, and document analysis were prepared for analysis through the process of transcription, which put the data into an organized text form. The transcription documents were then later used for coding, data reduction and data analysis.

Patton (2002) states that when data collection has formally ended and it is time to begin the final analysis, the researcher has two primary sources to draw from in organizing the analysis: 1 ) the research questions that were generated during the conceptual and design phases of the study and 2) analytic insights and interpretations that emerged during data collection. The next section describes the data analysis process for this study. 


\section{Data Analysis Process}

Phenomenological data analysis proceeds with data reduction, analysis of specific statements and themes, and a search for all possible meanings (Creswell, 1998). The data analysis process will be explained in detail through the following sections.

\section{Data Reduction}

Needed was a process to organize and make sense of the large amount of data that was collected for this study from interviews, observations and document analysis. Miles and Huberman (1994) describe this process as data reduction as it refers to the process of selecting, focusing, simplifying, abstracting, and transforming the data into a written form or typed transcriptions. During this process, the data was condensed and organized into manageable parts to help the researcher come to an understanding of what the data was communicating. Transcribed were the first and second interviews, the Faculty Academy observations and the classroom observations, and the documents from the faculty courses, the community policies and the community’s shared resources. With each source of data, the analysis process began by organizing and labeling each source of data as it was collected. It was important to organize the transcribed data into the related social theory of learning components, identity, practice, meaning, and community.

Bracketing. During phenomenological research, it is important for the researcher to try to remain objective by attempting to remove presuppositions and biases by bracketing out his or her beliefs about the subject area and the people being studied. For the data collected, all personal thoughts, observations and beliefs were bracketed out of the transcription to try to maintain the essential meanings and perspectives found from the interviews, observations and document analysis. Once the data was bracketed out, all 
aspects of the data were treated on an equal level during the data analysis process. True to qualitative research, the researcher becomes the research instrument and it is not possible to completely remove all judgments during the data analysis process. The use of bracketing was used in an attempt to reduce the researcher's bias.

Coding. Careful inspection and analysis of the raw data found in the interviews, observations, and document analysis was for the purpose of identifying relevant patterns, themes, structures, and categories. This study used a priori codes relevant to the social theory of learning components and research questions related to identity, practice, meaning, and community. There are sub-categories that exist under each of the four components and the a priori codes were identified throughout the reviews of the transcribed data. The a priori codes relevant to the social theory of learning components identity, practice, meaning, and community are shown in Table 14. These codes helped the researcher organize the data as well as provide a structure for the purpose of drawing connections from the research findings to the research questions.

\section{Analysis of Themes and Patterns}

After the initial process of coding the data, the next step was to organize and summarize the data. During this analysis phase, the researcher identified themes, categories, parallels, contrasting data, and irregularities from the coding process. It was through this process that the identification of patterns and themes informed the researcher. For this study, it was important to capture the emergent themes as well as identify the themes relative to the Social Theory of Learning. 
Table 14

A priori codes established to inform Social Theory of Learning components

\begin{tabular}{|c|c|c|c|c|}
\hline A priori Codes for Identity & \multicolumn{3}{|c|}{ Data Collected } & * Coded Data \\
\hline Main Characteristics of Identity & \multirow{11}{*}{ 总 } & & \multirow{11}{*}{ 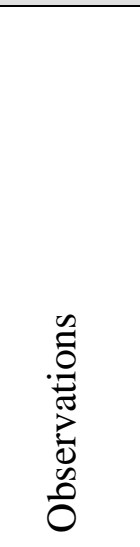 } & (n) \\
\hline Lived Experience* & & & & * \\
\hline Learning Process* & & & & * \\
\hline Social Membership* & & & & $*$ \\
\hline Negotiated Experience* & & & & * \\
\hline Nexus of Multimembership* & & & & $*$ \\
\hline Modes of Belonging & & & & \\
\hline Engagement* & & & & $*$ \\
\hline Imagination* & & & & $*$ \\
\hline Alignment* & & & & $*$ \\
\hline Trajectory* & & & & * \\
\hline A priori Codes for Practice & \multirow{11}{*}{ 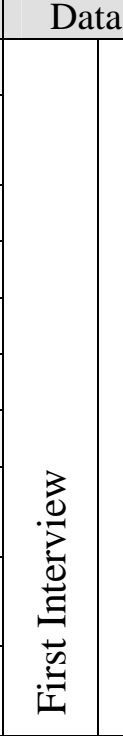 } & \multirow{11}{*}{ 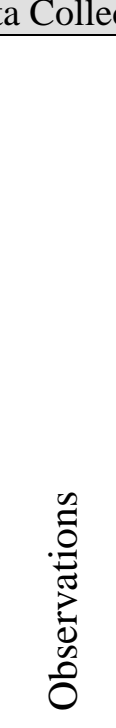 } & ected & * Coded Data \\
\hline Characteristics of Participation & & & \multirow{10}{*}{ 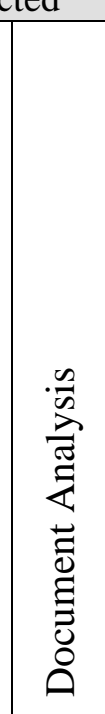 } & \\
\hline $\begin{array}{l}\text { Participate in Resolutions to } \\
\text { Conflict or Change* }\end{array}$ & & & & * \\
\hline \multirow[t]{2}{*}{ Support Communal Memory* } & & & & $*$ \\
\hline & & & & * \\
\hline Perspective to Accomplish Goals* & & & & $*$ \\
\hline Mutuality of Practice* & & & & * \\
\hline Learning in Practice & & & & \\
\hline $\begin{array}{l}\text { Evolving Forms of Mutual } \\
\text { Engagement* }\end{array}$ & & & & $*$ \\
\hline $\begin{array}{l}\text { Understanding and Tuning Their } \\
\text { Enterprise* }\end{array}$ & & & & $*$ \\
\hline $\begin{array}{l}\text { Developing Repertoire, Styles, and } \\
\text { Discourses* }\end{array}$ & & & & $*$ \\
\hline A priori Codes for Meaning & \multicolumn{3}{|c|}{ Data Collected } & * Coded Data \\
\hline Negotiation of Meaning* & \multirow{4}{*}{\multicolumn{2}{|c|}{ 号 }} & \multirow{4}{*}{ 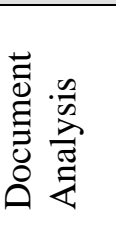 } & $*$ \\
\hline Participation* & & & & $*$ \\
\hline Reification* & & & & $*$ \\
\hline Duality of Meaning* & & & & $*$ \\
\hline A priori Codes for Community & \multicolumn{3}{|c|}{ Data Collected } & * Coded Data \\
\hline Community Membership* & \multirow{5}{*}{ 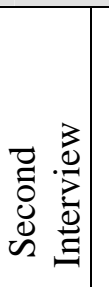 } & \multirow{5}{*}{ 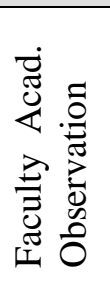 } & \multirow{5}{*}{ 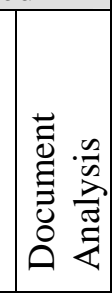 } & $*$ \\
\hline Dimensions of Communities of Practice & & & & \\
\hline Mutual Engagement* & & & & $*$ \\
\hline Joint Enterprise* & & & & * \\
\hline Shared Resources* & & & & $*$ \\
\hline
\end{tabular}




\section{Data Analysis and Synthesis}

All data that was collected to inform the research study about the individual teaching faculty that was collected through interviews, observations and document analysis was analyzed and coded by the social theory of learning components which informed research question one, identity, research question two, practice, research question three, meaning, and research question four, community. The following procedures describe the data analysis and synthesis processes that were used for the data collected from the eight teaching faculty participants.

Data obtained from faculty interviews, observations and documents were all individually analyzed by participant case. Data for each case was first organized by the a priori codes relating to the social theory of learning and then coded again to capture themes and patterns recognized within the data.

All data that was collected to inform the research study to inform research question four, concerning the education community, was collected through faculty academy observations and document analysis. The following procedures describe the data analysis and synthesis processes that were used for the data collected from the Faculty Academy observations and the document analysis.

Data that was collected from the Faculty Academy observations was coded to the social theory of learning component, community. Document analysis was conducted of the materials that related to the educational community. These documents and materials consisted of educational policies and mandates that pertained to the teaching faculty's use of instructional technology, support documents that assisted teaching faculty with instructional technology, and previous Faculty Academy agendas and binders. Both 
observational data and documents relevant to the community using instructional technology was then analyzed with the existing data from the individual participant data regarding the Social Theory of Learning component, community. Comparisons were made of the similarities and differences found between the Faculty Academy observation and the teachers interview questions related to community.

Table 15 displays the coding process to inform the four components of the social theory of learning for each participant case. Participant case narratives were constructed from the coded data. A narrative about the community was constructed from the coded data as well. 
Table 15

Coding process to inform case narratives

\begin{tabular}{|c|c|c|c|c|c|}
\hline A priori Codes for Identity & \multicolumn{3}{|c|}{ Data Collected } & * Coded Data & Case Narratives \\
\hline \multicolumn{6}{|l|}{ Main Characteristics of Identity } \\
\hline Learning Process* & \multirow{6}{*}{. } & & & $*$ & \\
\hline Lived Experience* & & & & $*$ & \\
\hline Social Membership* & & & & $*$ & \\
\hline Negotiated Experience* & & & & * & \\
\hline Nexus of Multimembership* & & & & $*$ & \\
\hline Modes of Belonging & & & .ే & & \\
\hline Engagement* & \multirow{3}{*}{\multicolumn{2}{|c|}{ 兽 }} & \multirow{3}{*}{ 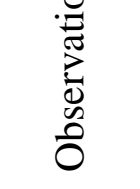 } & $*$ & \\
\hline Imagination* & & & & $*$ & \\
\hline Trajectory* & & & & $*$ & \\
\hline A priori Codes for Practice & \multicolumn{3}{|c|}{ Data Collected } & * Coded Data & Case Narratives \\
\hline \multicolumn{6}{|l|}{ Characteristics of Participation } \\
\hline $\begin{array}{l}\text { Participate in Resolutions to } \\
\text { Conflict or Change* }\end{array}$ & \multirow{9}{*}{ 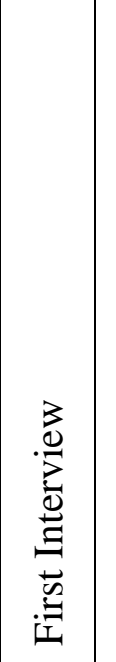 } & \multirow{9}{*}{ 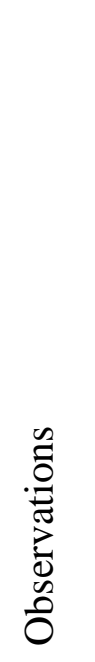 } & \multirow{9}{*}{ 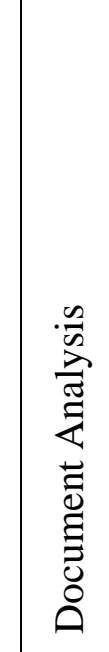 } & * & \\
\hline Support Communal Memory* & & & & $*$ & \\
\hline Assist Others* & & & & * & \\
\hline Perspective to Accomplish Goals* & & & & $*$ & \\
\hline Mutuality of Practice* & & & & $*$ & \\
\hline Learning in Practice & & & & & \\
\hline $\begin{array}{l}\text { Evolving Forms of Mutual } \\
\text { Engagement* }\end{array}$ & & & & * & \\
\hline $\begin{array}{l}\text { Understanding and Tuning Their } \\
\text { Enterprise* }\end{array}$ & & & & $*$ & \\
\hline $\begin{array}{l}\text { Developing Repertoire, Styles, and } \\
\text { Discourses* }\end{array}$ & & & & $*$ & \\
\hline A priori Codes for Meaning & \multicolumn{3}{|c|}{ Data Collected } & * Coded Data & Case Narratives \\
\hline Negotiation of Meaning* & \multirow{4}{*}{\multicolumn{2}{|c|}{ 总 }} & \multirow{4}{*}{ 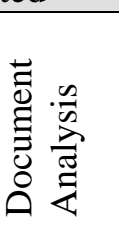 } & $*$ & \\
\hline Participation* & & & & $*$ & \\
\hline Reification* & & & & $*$ & \\
\hline Duality of Meaning* & & & & $*$ & \\
\hline A priori Codes for Community & \multicolumn{3}{|c|}{ Data Collected } & * Coded Data & $\begin{array}{l}\text { Case Narratives } \\
\text { \& Community } \\
\text { Narrative } \\
\end{array}$ \\
\hline Community Membership* & \multirow{5}{*}{ 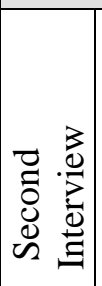 } & \multirow{5}{*}{ 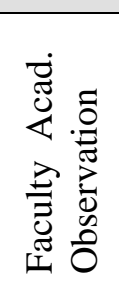 } & \multirow{5}{*}{ 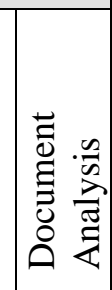 } & $*$ & \\
\hline Dimensions of Communities of Practice & & & & & \\
\hline Mutual Engagement* & & & & $*$ & \\
\hline Joint Enterprise* & & & & $*$ & \\
\hline Shared Resources* & & & & * & \\
\hline
\end{tabular}


After the data was analyzed from the individual cases and community, a second level of data analysis occurred which consisted of grouping teachers by their positions at the college of education (administrative, teaching, and program support) and then drawing comparisons of similarities and differences. These comparisons were made across all three participant groups as it related to their experiences of integrating instructional technology in the college of education. These findings provided another level of understanding as it related to the research questions, but it was not and can not be assumed that the perspectives informed by their positions are universal across all teaching positions at the college of education.

It was not the original intent of the research study to perform a cross cases analysis of the individual cases, but the three separate levels of positions within the educational community provided another level of data analysis that communicated the similarities and differences of the educational community as a whole. Table 16 displays this next level of analysis that consisted of grouping the participant cases into three levels of their teaching positions; administrative, teaching, program support. 
Table 16

Grouping of participant cases into teaching positions

\begin{tabular}{|c|c|c|c|c|c|}
\hline A priori Codes for Identity & * Coded Data & Case Narratives & \multirow{11}{*}{ 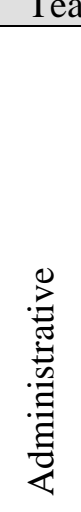 } & \multicolumn{2}{|c|}{ Teacher Positions } \\
\hline \multicolumn{3}{|l|}{ Main Characteristics of Identity } & & \multirow{10}{*}{ 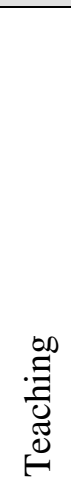 } & \multirow{10}{*}{ 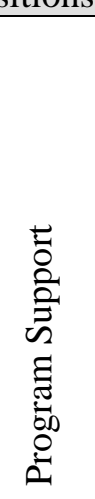 } \\
\hline Learning Process* & $*$ & & & & \\
\hline Lived Experience* & $*$ & & & & \\
\hline Social Membership* & $*$ & & & & \\
\hline Negotiated Experience* & $*$ & & & & \\
\hline Nexus of Multimembership* & $*$ & & & & \\
\hline Modes of Belonging & & & & & \\
\hline Engagement* & $*$ & & & & \\
\hline Imagination* & $*$ & & & & \\
\hline Trajectory* & $*$ & & & & \\
\hline A priori Codes for Practice & * Coded Data & Case Narratives & Tea & er $\mathrm{Pc}$ & itions \\
\hline Characteristics of Participation & & & & & \\
\hline $\begin{array}{l}\text { Participate in Resolutions to } \\
\text { Conflict or Change* }\end{array}$ & $*$ & & & & \\
\hline Support Communal Memory* & $*$ & & & & \\
\hline Assist Others* & $*$ & & & & \\
\hline Perspective to Accomplish Goals* & * & & & & \\
\hline Mutuality of Practice* & $*$ & & & & \\
\hline Learning in Practice & & & & & \\
\hline $\begin{array}{l}\text { Evolving Forms of Mutual } \\
\text { Engagement* }\end{array}$ & $*$ & & 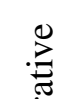 & & ڤે \\
\hline $\begin{array}{l}\text { Understanding and Tuning Their } \\
\text { Enterprise* }\end{array}$ & $*$ & &. & $\stackrel{\infty}{\leftrightarrows}$ & $\underset{\Xi}{\Xi}$ \\
\hline $\begin{array}{l}\text { Developing Repertoire, Styles, and } \\
\text { Discourses* }\end{array}$ & $*$ & & 誨 & $\underset{\sim}{\stackrel{\mathscr{J}}{\oplus}}$ & مإ. \\
\hline A priori Codes for Meaning & * Coded Data & Case Narratives & Tea & er Pc & itions \\
\hline Negotiation of Meaning* & $*$ & & $\sum$ & & \\
\hline Participation* & $*$ & & 苞 & $\stackrel{\infty}{=}$ & \\
\hline Reification* & $*$ & & 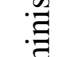 & تี & 常 \\
\hline Duality of Meaning* & $*$ & & 昰 & 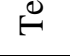 & के के \\
\hline A priori Codes for Community & * Coded Data & Case Narratives & Tea & er $\mathrm{Pc}$ & itions \\
\hline Community Membership* & $*$ & & & & \\
\hline $\begin{array}{l}\text { Dimensions of Communities of } \\
\text { Practice }\end{array}$ & & & 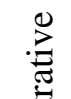 & & 离 \\
\hline Mutual Engagement* & $*$ & &. $\bar{n}$ & $\stackrel{\infty}{\Xi}$ & $\Xi$ \\
\hline Joint Enterprise* & $*$ & & 互 & త్రี & 5 \\
\hline Shared Resources* & $*$ & & U्र & $\stackrel{0}{-}$ & 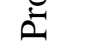 \\
\hline
\end{tabular}


For the last step, the data that was collected from the participant cases were collectively analyzed to provide a third level of data analysis which informed research questions one, two, three, and four. This final level of data reduction occurred when overlapping data was found in the sub-components of the four Social Theory of Learning components; identity, practice, meaning, and community. The overlapping subcomponent data was grouped together into three summaries for each Social Theory of Learning component to reduce redundancy in the reporting of the final themes discovered; identity has three summary sections, practice has three summary sections, meaning has three summary sections, and community has three summary sections. Discovered themes identified from the analysis of the grouped subcomponents were then placed under the subcomponent summaries.

Similarities and differences found from the grouping the participant cases into three levels of their teaching positions; administrative, teaching, program support were reported within the identified themes. Table 17 displays each research question with its relevant Social Theory of Learning component and grouped subcomponents with the identified summaries for each grouping of the subcomponents to help identify themes found in the data. 


\section{Table 17}

Summaries from grouping of the components to identify themes

\begin{tabular}{|c|c|c|}
\hline \multicolumn{3}{|c|}{$\begin{array}{l}\text { Research Question 1: What are university teachers' reflections of their role now responsible to } \\
\text { integrate instructional technology? }\end{array}$} \\
\hline Identity Subcomponents & Summaries of Identity Subcategories & Themes \\
\hline $\begin{array}{ll}- & \text { Learning Process } \\
\text { - } & \text { Lived Experience } \\
\end{array}$ & History and path into educational community & \\
\hline $\begin{array}{ll}\text { - } & \text { Social Membership } \\
\text { - } & \text { Nexus of } \\
& \text { Multimembership } \\
\text { - } & \text { Negotiated Experience } \\
\text { - } & \text { Engagement } \\
\end{array}$ & $\begin{array}{l}\text { Identities influenced as they interact and participate with } \\
\text { instructional technology }\end{array}$ & \\
\hline $\begin{array}{ll} & \text { Imagination } \\
\text { - } & \text { Trajectory } \\
\end{array}$ & $\begin{array}{l}\text { Vision for educational for future and how technology will play a } \\
\text { role }\end{array}$ & \\
\hline \multicolumn{3}{|c|}{$\begin{array}{l}\text { Research Question 2: What is the process of university teachers participation and engagement with } \\
\text { delivering instructional technology in the classroom? }\end{array}$} \\
\hline Practice Subcomponents & Summaries of Practice Subcategories & Themes \\
\hline $\begin{array}{ll}\text { - } & \text { Participate in } \\
\text { Resolutions to Conflict } \\
\text { \& Change } \\
\text { - Evolving Forms of } \\
\text { Mutual Engagement }\end{array}$ & $\begin{array}{l}\text { Knowledge and skill building, learning instructional technology } \\
\text { to participate in educational practice }\end{array}$ & \\
\hline $\begin{array}{ll}\text { - } & \text { Mutuality of Practice } \\
\text { - } & \text { Perspective to } \\
& \text { Accomplish Goals } \\
\text { - } & \text { Understanding \& } \\
& \text { Tuning Enterprise }\end{array}$ & $\begin{array}{l}\text { Understanding of community mission involving instructional } \\
\text { technology that affects how members engage in educational } \\
\text { practice }\end{array}$ & \\
\hline $\begin{array}{ll}- & \text { Support Communal } \\
& \text { Memory } \\
\text { - } & \text { Assist Others } \\
\text { - } & \text { Develop Repertoire, } \\
& \text { Styles, Discourses }\end{array}$ & $\begin{array}{l}\text { Assistance and resources developed for the use of instructional } \\
\text { technology for members to engage in educational practice }\end{array}$ & \\
\hline \multicolumn{3}{|c|}{$\begin{array}{l}\text { Research Question 3: How do university teachers interpret and understand their experience of } \\
\text { integrating instructional technology? }\end{array}$} \\
\hline Meaning Subcomponents & Summaries of Meaning Subcategories & Themes \\
\hline $\begin{array}{l}\text { - Negotiation of } \\
\text { Meaning }\end{array}$ & $\begin{array}{l}\text { Interpretation and understanding of community participation } \\
\text { integrating instructional technology }\end{array}$ & \\
\hline $\begin{array}{ll}- & \text { Participation } \\
- & \text { Duality of Meaning }\end{array}$ & $\begin{array}{l}\text { Understanding their own participation integrating instructional } \\
\text { technology }\end{array}$ & \\
\hline - Reification & $\begin{array}{l}\text { Creation of guidelines and tools that guide educational practice } \\
\text { regarding instructional technology }\end{array}$ & \\
\hline \multicolumn{3}{|c|}{$\begin{array}{l}\text { Research Question 4: What is the university teachers' process of belonging to and educational } \\
\text { community now responsible to integrate instructional technology into their educational practice? }\end{array}$} \\
\hline $\begin{array}{l}\text { Community } \\
\text { Subcomponents }\end{array}$ & Summaries of Community Subcategories & Themes \\
\hline $\begin{array}{ll}- & \text { Community } \\
& \text { Membership } \\
\text { - } & \text { Mutual Engagement }\end{array}$ & $\begin{array}{l}\text { Contribute and participate in community activities that involve } \\
\text { instructional technology }\end{array}$ & \\
\hline - Joint Enterprise & $\begin{array}{l}\text { Adhere to community missions and objectives regarding } \\
\text { instructional technology use }\end{array}$ & \\
\hline - $\quad$ Shared Resources & Shared resources assist teaching with instructional technology & \\
\hline
\end{tabular}




\section{Attempts to Reduce Limitations}

Validity in Qualitative Research. The following sections will define the methods that were used to ensure the validity in this qualitative research. Validity is concerned with the accuracy and dependability of instruments and observations in qualitative research (Patton, 2002). Validity can be found in qualitative research through the following methods. Construct validity refers to the use of multiple sources of evidence assumed to capture or measure data such as surveys, questionnaires, and interview guides as to assess if it gathers information it is assumed to capture (Schensul, Schensul, \& LeCompte, 1999). This study used interview guides, observation guides and document analysis guides to assess and ensure that the data captured was relevant to the study. Another method that was used to ensure the validity of this study was to conduct a member check where the researcher returned to the participants after the data has been collected and transcribed to ensure that the information gathered was correct, if there were any gaps found in the information, or to gather any necessary additional explanations.

Triangulation. Triangulation consists of combining two or more views, approaches, methods in an investigation in order to get more accurate picture of a phenomenon. One of the most frequently used forms of triangulation is the use of multiple sources of data; interviews, observations and documents. This research combined and compared the data taken from interviews, observations, and document analysis to ensure the quality of the data. For this research, observations provided a check on what is reported in interviews. Interviews on the other hand permitted the observations to go beyond external behavior to explore the feelings and thoughts 
teachers had about using instructional technology. Document analysis provided a behind the scenes look at the educational community using instructional technology that was not directly observable. By using these variety of sources, this researcher built on the strengths of each type of data collection while minimizing the weaknesses of any single approach.

Audit Trail. This study performed an audit trail which involved the recording of information that created the possibility to retrace the steps that lead leading to the interpretation of the data. It ensured that no alternatives were left unexamined and that no biases had any influence on the results.

Thick Rich Description. Another way the research quality was established for this study was the writing of thick, rich descriptions of the analyzed data through narrative case studies which described the participants' experience of integrating instructional technology and their environment in which they engaged in practice. 


\section{Chapter Four}

\section{Findings}

\section{Overview of Chapter}

Chapter four presents the findings from the data that was collected and analyzed from the college of education and its teachers to inform the four research questions of this study. This chapter begins with an introduction to the educational community as well as describes the technology resource center that assists faculty and students with their use of computers and software applications. This chapter is then divided into two main sections. The first section presents the analysis of data collected from the college of education that informs the study of the community's influences and engagement in professional development activities that involve instructional technology. This analysis of data informs research question four concerning community. The second section presents eight case studies from the data collected from the college of education teachers which informs all four of the research questions for this study. The following information will provide an overview and the data analysis processes related to each of these two main sections.

\section{Review of Data Analysis Procedures for Section 1}

The first section introduces the reader to the college of education community. This community will first be explored through the review of the college of education's history engaging in an annual professional development activity called the Faculty Academy from the year 2000 to 2008. Information that was collected to inform the history and current practices of the Faculty Academy included yearly binders and the scheduled agendas that guide the practices each year. Documentation from the years 2001 
and 2005 of the Faculty Academy was not available for review to include for the history of this document. The data analysis that was conducted to review the history of the Faculty Academy informs research question four community.

The first section also includes the data analysis of a week long observation of the 2008 Faculty Academy. The data captured from the observation focused on the teachers' collective engagement in practice learning how to integrate instructional technology in an educational community's professional development session. Data collection of the week long observation was coded and analyzed to inform research question four concerning community. It was also important to examine the support structures and shared technology, tools, and resources that help faculty in the college integrate technology. Table 18 displays the data that was analyzed from faculty engaging in a community activity to inform the community subcomponents.

Table 18

Data from faculty engaging in community activity to inform community subcomponents Data analyzed to inform faculty engaged in community activity Community Subcomponents

Collective engagement learning and
using instructional technology

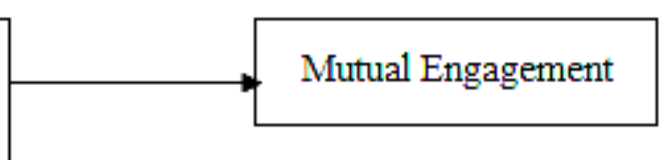

Attention to community mandates that relate to larger communities of practice standards; nation, state, university, college, teacher education, that relate to their practice of integrating technology

Community shared technology tools and resources used to engage in practice
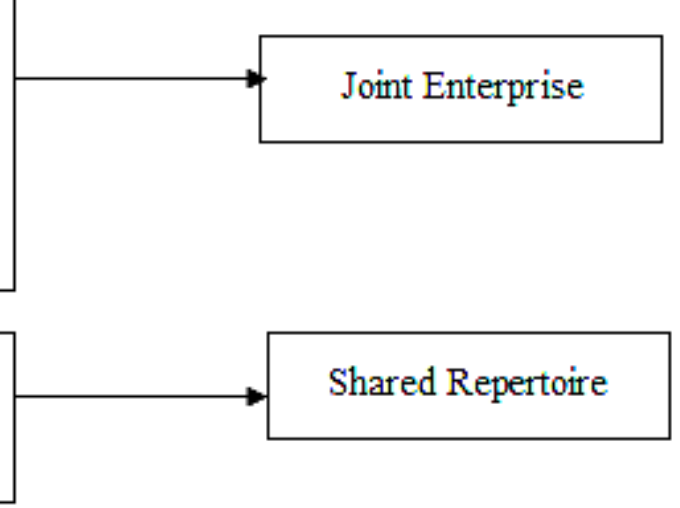


\section{Section 1: The College Community \& The Faculty Academy}

The university's college of education has a varied group of educational programs that focus on preparing educational professionals. The mission of the college of educational states the following objectives toward their educational practice:

- to offer sound and accessible pre-professional and professional preparation at undergraduate and graduate levels,

- to provide scholarly contributions, leadership, and service at state, national, and international levels,

- to contribute to the instructional, intellectual, economic, social, and cultural diversity missions of the university.

University faculty in the college of education have a high level of responsibility to provide direction, support, and apply instructional technology as they serve as role models for using instructional technology in new teaching processes. Faculty who teach for the teacher education program are responsible to represent a model for successful implementation of new ways of teaching and learning to future teachers.

In this higher education environment, faculty have access to instructional technology resources that can support their instructional endeavors with help from expert personnel, educational training and skill development opportunities, and some departmental funding to obtain new instructional technology resources to assisting for successful integration. Faculty working in the college of education are empowered by being recognized for their individual teaching practices and the show of importance of ‘ownership’ in the developmental process of new instructional materials, (ownership 
identified as an individual's right to represent and teach the content while adhering to the school's instituted curriculum established for each of the educational departments).

Faculty are enabled to develop their instruction to what they feel is appropriate to accomplish in their goals and learning objectives. Positive reinforcement and departmental support is provided through continuous community recognition through teaching awards for professional accomplishments.

Community's Technology Support Center. The technology management and support personnel is provided in a center which is located within the building that houses the college of education. This center provides both technology support and learning resources to support and assist the academic and computing needs of the education department. Within the center, there are computer lab classrooms available as well as laptops and PCs for faculty that can be scheduled for use for the semester or day as well as an audio-video lab included in the center that has specialized software for image, video and sound editing. This technology support center has both Macintosh and IBM computer labs, scanners, and printers in which the knowledgeable support staff can provide faculty with technical support. Portable PCs and projection equipment is also available for faculty to use in their own classrooms. There is also a resource center that provides a closed reserve materials collection, audio-visual and video equipment, and materials production equipment. It is important to note that this computer lab is supported solely by the college of education and is independent of the university office of computing.

All PCs in the technology support center run on Windows XP Professional Edition. The Macintosh computers run MacOS 10.4/X. All computers are installed with 
the latest version of Microsoft Office 2007. Other software applications that are downloaded to the computers include SPSS, Winzip, Dreamweaver, Adobe Acrobat, Fireworks, Flash, FrontPage, and Inspiration.

There are two main computer labs within the center. The larger computer lab is equipped with 32 Dell PCs and a teacher’s Windows XP PC connected to a projection system with an ELMO camera, DVD, VHS player and an interactive whiteboard. The smaller computer lab contains 26 Dell Pentium 4 computers running Windows XP Professional Edition with Office XP and FrontPage loaded onto the computers. This smaller room also has a video projection system connected to the teacher's computer with an ELMO camera, DVD/VHS player and an Interactive White Board.

The technology support center also contains many other resources including sample lesson plans, professional journals, and other printed materials as well as educational support equipment such as a laminator and an Ellison press. On the technology support center website, there are e-learning resources and tutorials for faculty and students to access to learn how to use the software applications available in the center.

The center has the following roles to support the education faculty, staff and students: a director, a library technical assistant, a data networking specialist, and an Elearning specialist/web developer and many knowledgeable graduate assistants. The graduate students are available to assist faculty and students with most of the software applications available in the center as well as trouble shoot. Faculty can also receive training by making a request to the center director on certain software applications. 
Introduction to the Faculty Academy. The Faculty Academy was originally created in the year 2000 as a support mechanism for teacher education faculty to learn about instructional technology tools and integration methods that were to be applied to their teacher education program courses. In May, an intensive 40 hour professional development workshop that would be conducted annually, provided hands on training and support that was intended to provide teacher education faculty a focused learning opportunity to gain the skills and knowledge of new instructional technology applications. An important component of this workshop was the emphasis on the analysis of exemplar pedagogical practices for the development of courses exhibiting best practices with the use of instructional technology.

The creation of this Faculty Academy in the year 2000 was a part of a PT3 grant that emphasized the importance of providing support mechanisms and learning opportunities concerning instructional technology equally to the teacher education program faculty and professional development public school teachers who were both working with pre-service student teachers. This three-tiered approach provided consistent learning opportunities and on-going support to all people who were involved in teacher education. This intention was to provide instructional technology training, resources and ongoing support systematically to all three parties so that the instructional technology that was used and taught in the college classroom would be recognized and utilized in the K-12 classroom by the public school teachers. The vision and intention of integrating instructional technology would unified for pre-service student teachers from the college classroom to the public school classroom. 
When the PT3 grant concluded in the year 2003, the faculty from the college of education believed that the Faculty Academy was an important annual endeavor to continue as part of the university's mission was to expand learning access to an increasingly diverse student body. Administration from the college of education put the initiative to their faculty to offer their courses either fully online or in a blended face-toface/online format.

As part of this university and college of education's initiative to reach a larger student body as well as compete with other university programs, support mechanisms for faculty to attend to this charge were necessary to stay current of the instructional technologies being utilized in both online and blended college classrooms. The continuation of the annual Faculty Academy was equally agreed upon by both college administration and faculty to be a significant support mechanism necessary for faculty to adhere to the university's charge.

When the Faculty Academy was under the direction and mission of the PT3 grant from 2000 to 2002, its focus was on providing services for just the teacher education program faculty in the college of education and not all faculty. In 2003, the Faculty Academy was then open to all faculty teaching in the college of education in addition to the faculty teaching for the teacher education program. Since 2003, the Faculty Academy continues to be open to all faculty teaching in the college of education.

The following information will explore the progression of the professional development activities that occurred during the Faculty Academy from the year 2000 to 2008. The information for the years 2001 and 2005 were not available to include for this analysis. 
Guidelines for Faculty's Participation in the Faculty Academy. Faculty who participate in the Faculty Academy have the opportunity for one 40 hour week to collectively engage with their peers without any outside distractions to gain the knowledge and skill to enhance their courses by learning about new instructional technologies and various pedagogical integration methods. Faculty who are interested in participating in the Faculty Academy submit an application to be approved by their department chair as well as the college of education's associate dean of science and technology. Upon receiving approval, the faculty receive an incentive or stipend for their required full participation and attendance to all the sessions in the Faculty Academy. In addition, faculty are then required to identify a course they are teaching the following academic year that they would like to work on during the academy to apply new instructional technology applications they have learned. As the Faculty Academy concludes at they end of the week, faculty then are to provide a draft of a syllabus from the course they have identified, in which they demonstrate how they intend to integrate instructional technology. It is common that faculty will need more development time to work on their courses as it is a two step process of learning the technology and then learning how to integrate in their courses. During the next academic year after they then teach their identified course, they are to again provide a finalized syllabus demonstrating how they integrated instructional technology. All of these Faculty Academy requirements are in place each year and faculty who attend must adhere to these conditions each year they participate. 
Evolution of the Faculty Academy. Data was collected and analyzed to inform the evolution of the Faculty Academy from the year 2000 to 2008 was coded by the framework provided by the STL component, community. Again, the information for the years 2001 and 2005 were not available to include for this analysis. Data was coded and analyzed by the STL component community, which includes the subcomponents mutual engagement, joint enterprise, and shared repertoire. The data that was collected and analyzed to communicate these findings was retrieved from the previous binders and agendas in addition to the to 2008 observation of the Faculty Academy.

\section{Community}

Mutual engagement. The following information will describe the Faculty Academy sessions that were dedicated to sharing activities, learning new pedagogical practices, and learning new instructional technologies.

Sharing activities. The following section describes the opportunities that faculty had to collectively engage in sharing activities in the Faculty Academy from the years of 2000 to 2008. When the Faculty Academy first began in the year 2000 under the direction of the PT3 grant, sessions were designed for faculty to collectively identify their needs and discuss the improvements they felt were necessary to support them and their students learn and integrate instructional technology. Professional development opportunities and enabling the availability technology resources were specifically discussed as faculty and student support mechanisms.

Faculty also engaged in sessions during the 2000 Academy where they shared their thoughts and strategies about traditional teaching practices versus instructional technology teaching practices. Throughout this session, faculty collectively would 
discuss where possible opportunities were in their courses where they could integrate instructional technology. The Academy that year would engage in frequent "temperature checks” to evaluate how faculty were feeling about their work and progress learning about how to integrate technology into their courses. Faculty could also work together during scheduled development time throughout the week to learn together and from each other about the new technology applications they were learning. At the end of the 2000 Faculty Academy, faculty collectively discussed their experience of the Academy and what they had learned. Faculty also showcased and reviewed their courses to other faculty in the end and collectively discussed what their next steps were regarding continued work on instructional technology integration with their courses.

During the year 2002, faculty were once again welcomed to another Faculty Academy. During the Academy's introductory and opening remarks session, faculty introduced themselves to each other and identified the course they would be working on to the rest of the group. At this time, faculty also collectively discussed what they were hoping to accomplish during the week regarding technology integration for their courses. During the beginning of the week, faculty had the opportunity to collectively share the instructional technology development plans they had for their courses. Faculty engaged in question and answer sessions during the time they had scheduled for course development in order to become more informed about the transition in their instructional practices. As the Academy wrapped up at the end of the week, faculty demonstrated and showcased the instructional technology choices they had made for their courses to the rest of the participating faculty. 
The 2003 Faculty Academy experienced a transition in leadership as the PT3 grant which originally started the Academy had ended. There was a strong belief among the faculty in the college of education to continue to have the Academy as they felt it was an important endeavor that enabled them to continue their efforts integrating instructional technology. The scheduled sessions for faculty to engage in sharing activities was minimized, but they did briefly share the progress of the development of their courses and collectively discussed how they could schedule for future development support in the technology resource center. Faculty also had opportunities to share and discuss their work with each other during the time that was scheduled for course development.

During the 2004 Faculty Academy, there was a small increase in the amount of scheduled opportunities faculty had to share with each other about the instructional technology they were integrating into their courses. During the Academy's introductory and overview session, faculty were able to see and discuss examples of instructional technology used in courses. As the week progressed, faculty were again given opportunities during scheduled development time to engage in collective discussion about the instructional technology decisions and choices they made for their courses. The 2004 Academy's culminating activity included a collective discussion among faculty about their plans to continue the development of their courses.

The 2006 Faculty Academy had several scheduled sessions in which faculty could engage in sharing in discussion with each other than the previous 2003 and 2004 years. At the start of the Academy, faculty were provided and overview of the week and they were invited to collectively talk about the technologies they used in the courses they currently taught. Faculty were provided with an overview of the technologies 
applications and the technology enhanced classrooms that were available for their use within the college of education building. An activity that was different from previous Faculty Academies included a session where faculty members could take their syllabi from the courses they identified to work on during the Academy and examine instructional technology opportunities with their peers. Faculty were provided with feedback from their colleagues during this activity to identify different areas in their syllabus where they could incorporate instructional technology that they may not have been aware of individually. During the 2006 Academy, faculty were provided with the usual development work time where they could work individually or with each other to provide assistance and feedback on each other's work. As a culminating activity, faculty shared the changes they made to their course syllabi to the group and identified where they would integrate technology as they continued to develop their course.

The 2007 Faculty Academy provided different opportunities for collective sharing and discussion as the beginning of the Academy provided an overview and facilitated discussions about the $21^{\text {st }}$ century learning frameworks and problem-based learning. Each day began with an overview and daily briefing in which faculty could ask questions and briefly raise topics of discussion. Each day would conclude with an "end of the day sharing and feedback" in which faculty could discuss their thoughts and concerns about what they were feeling about the Academy's sessions as well as the development of their own courses. Faculty would also officially share their feedback through the posting of surveys at the end of the Academy. Sessions were scheduled for faculty to discuss problem-based learning as well as plans and opportunities for research within the college of education. Culminating Academy activities involved faculty presenting their courses 
to their peers and providing feedback on an Academy evaluation to inform the leaders of their thoughts for the next year's Academy.

The 2008 Faculty Academy would begin each day with a daily briefings and overviews of the day's scheduled events. During this time, participating faculty could engage in collective discussion about their individual course concerns or the Academy's scheduled sessions. The 2008 Academy continued the practice of asking participating faculty to share their feedback through the answering and posting of online surveys that were constructed by the leaders of the Academy. A new tool that was constructed for faculty was an online journaling application in which faculty were encouraged to use for daily reflection of their thoughts and ideas about the Academy. At the end of each day, faculty were encouraged to use this tool to share their feedback to discuss and suggest activities they would like to do during the Academy. Similar to previous Academies, faculty were provided with development time in which they could work individually or with their colleagues and support personnel on the development of their courses. At the end of the 2008 Academy, there was a session in which faculty would showcase the instructional technology elements in which they integrated into their courses and faculty could collectively view and discuss their colleagues' instructional choices. Similar to the previous year, faculty provided feedback at the end of the Academy on an evaluation to inform the leaders of their ideas for the next year's Academy.

\section{Learning activities that involved the study of pedagogical practice. The}

following information describes the Faculty Academy's sessions from the year 2000 to 2008 that involve learning activities focused on faculty’s pedagogical practice and the change in instructional strategies from traditional teaching methods to those that 
incorporated instructional technology. In the year 2000, a major focus of the Faculty Academy was to introduce faculty to teaching strategies that they could apply to their courses that used instructional technology. During the initial sessions of the Academy, efforts were made to guide faculty through identifying strategies and activities that could use instructional technology to achieve their course goals and objectives. Faculty were introduced to instructional methods popular at the time called Activity Structures that facilitated the use of instructional technology through strategies identified as interpersonal exchange, information collection, and analysis and problem solving. In addition to the instructional strategies that would include instructional technology, , faculty were also asked to examine the levels of interactivity they would like for their courses. These instructional strategies provided a foundation and guide for faculty to use as they identified activities in their syllabi to integrate instructional technology.

Faculty were then taught how to storyboard their course in which they would graphically layout their class activities provided from the organization already developed in their syllabus and work on a plan to deliver instructional activities that would use technology. Faculty could use their storyboards as a working tool to think about and consider the instructional technology possibilities that would assist them in accomplishing their instructional goals. As they were storyboarding their courses, faculty were shown how web based activities could compliment, supplement or supplant their traditional teaching practices with a fully developed web based course. Lastly, the pedagogical sessions in the 2000 Academy, provided to focus on the examination of directed and constructivist teaching approaches and how instructional technology could support their chosen methods of teaching. 
For the year 2002 Faculty Academy, similar sessions were provided for faculty to examine their rationale and strategies for instructional technology integration as they developed their courses. Faculty were also provided with opportunities to explore other instructional technology possibilities that they could incorporate into their classes. Faculty learning new pedagogical practices that was separate from learning computer applications was a strong theme for the year 2000 to 2002 Faculty Academies. This was a critical moment for faculty that involved instructional change. It is important to note that the scheduled sessions that guided faculty through changes in instructional strategies were strictly pencil and paper activities carried out in a traditional classroom environment void of computers. It was important during these activities that faculty could identify different instructional methods and strategies before being intrigued to integrate new computer applications that did not tie into their instructional objectives. An important goal of the initial Academies was to help faculty understand that the instructional technology was a tool to accomplish their instructional objectives and not to be confused or used for instruction itself.

As previously described, Faculty Academies from years 2000 to 2002 provided the college of education faculty with sessions to learn about new instructional strategies and how to incorporate them into their courses. These sessions also gave faculty the opportunity to engage in collective discussions on their experiences of change in their pedagogical practice. Second to the importance of learning new instructional strategies were sessions that taught them how to use the instructional technology. The 2003 Faculty Academy provided faculty with a session to see examples of other web-based courses to examine other faculty members instructional strategies using instructional 
technology. The 2007 Faculty Academy provided sessions which helped faculty learn more about problem-based learning and how instructional technology could facilitate that instructional strategy. As years went on, later Faculty Academies in the years 2004, 2006, and 2008, had sessions that focused more on combining the instruction of new technology applications and suggested methods of instructional practices in which faculty could adopt for their own courses.

Evolution of training activities. The following information describes the progression and evolution of the years 2000 to 2008 Faculty Academy's instructional technology training activities. The evolution of the training activities described here involve the Internet, communication technologies, presentation technologies, webpage creation technologies and web-based course management systems, audio and video technologies, university resources, Itelliboard interactive whiteboards, Microsoft Office, and other instructional technologies that were presented for faculty to incorporate into their instructional practice.

Learning about the Internet. The following information describes the Faculty Academy's review of Internet features and applications from the year 2000 to 2008 . In the year 2000, when the Faculty Academy first started, the initial training sessions focused on learning about the functionality of two Internet browsers, Netscape and Internet Explorer. Training sessions at this time provided and overview of the browsers features such as the menu bars, toolbars, bookmarks and the portability of browser based folders.

After the review of the Internet web browsers, the training then focused on faculty learning effective search strategies with Internet search engines. During these sessions, 
faculty learned how to develop effective search strategies, the variety of search engines available, and online libraries and other sources to obtain information. Faculty also learned how to compare search engines what they could offer regarding the breadth and the depth of their searchers.

Faculty also learned about plug-ins as helper applications available on the Internet to extend the functionality of software programs they were currently using. The last Internet application that faculty learned about during the Faculty Academy in 2000 was the use of an FTP (file transfer protocol) application to post the course websites they could create onto the college server. Faculty would revisit how to FTP their course websites in the 2002 Faculty Academy. In the year 2002 and 2006, faculty learned about the use of WebQuests and how to create them.

During the 2007 Faculty Academy, faculty were introduced and were provided and overview of the Discovery Channels online application called United Streaming which provides standards based video content and support materials through the Internet to teachers and students. Another online video application that was examined that year was YouTube and the university's video streaming server. The last Internet application that was examined during the 2007 Faculty Academy was Google Earth which provides the user to view satellite imagery of the earth's terrain.

Learning about communication technologies. The following information describes the Faculty Academy's review of communication technologies and applications from the year 2000 to 2008. In the year 2000, faculty learned about the basics of email. They learned to create distribution lists, address books, and create, send and receive attachments. 
Also in 2000, web boards and chat rooms were introduced. These applications were demonstrated through WebCT, WebBoard by Oriely, and Blackboard. Training sessions involving web boards, which are also referred to in this review as discussion boards and threaded discussions, as well as chat rooms return frequently from year to year. In 2003 and 2004, the topic of threaded discussions and chat rooms were revisited for faculty to learn more about how to better manage and assess each application.

In 2004, faculty learned video conferencing which was a new communication tool included in the Faculty Academy sessions. In 2006, faculty examined best practice instructional examples for discussion boards and chat rooms. New learning sessions involving communication technologies in the Faculty Academy that year included using Adobe Acrobat as a communication tool. Another new application that was presented was a technology called Red Pencil which was an online annotation software that provides timely feedback to students' work. This application was created by a fellow faculty member within the college of education. Training sessions involving desktop video conferencing retuned in 2006 for faculty to again learn about for instructional opportunities.

In 2007, the Faculty Academy looked at the discussion boards and chat rooms available on the eCampus course management system available at the university. The use of Wikis were also reviewed that year as a collaborative tool that both faculty and their students could utilize.

In 2008, the faculty engaged in several learning sessions that involved using Voice Direct which is a live chat tool that enables a teacher and students who are connected to a course website to have synchronous communication through a chat 
application. Training sessions involving video conferencing were also a part of the learning for faculty that related to synchronous communication.

Learning how to create presentations. In the year 2000, the use of Microsoft PowerPoint was popular among faculty and learning sessions involved training faculty about the process of outlining their presentation before constructing it online as well as learning the templates that were available to create their presentation. Other training sessions using PowerPoint involved teaching faculty how to hyperlink internal files and URLs to their presentation. In 2002 and 2004, integrating and creating PDF documents was a part of faculty the training sessions. PowerPoint made a return to the Faculty Academy in 2006 and faculty learned how to use this application for other instructional options beyond its presentation abilities. In 2007, faculty were provided an overview of a handheld device called Impactica that can be used to deliver PowerPoint presentations.

In 2008, faculty learned of different software applications that they could use for their course presentations. Podcasting was introduced to faculty as another instructional presentation tool that they could use to deliver audio and/or video content they created for their courses. Faculty learned about how their student could download their created audio or video content through an RSS feed as well as regulate the speed in which they listened or watched the delivery of the content. Faculty were also introduced to Adobe Designer which can allow faculty to design XML forms quickly that can be saved as a PDF or HTML file. The last presentation tool that was new to the Faculty Academy was the software application, Flash, which was designed to create animations to display on a web page. The presentation tools presented in 2008 were new to the Faculty Academy in comparison to the previous years. 
Learning how to create course websites. In the year 2000, faculty was introduced to the software, FrontPage for the creation of their course websites. The use of FrontPage continued throughout the year 2002, but then another web page creation software was introduced to faculty called Dreamweaver. Dreamweaver became more popular and training sessions continued to be offered in 2003 and 2004. The software had an upgrade in 2003 and was now called Dreamweaver MX in which faculty were trained on the basics of its use. Faculty were taught how to define a site, create an Index page, learn about the web page properties, how to type in and change text on a page, how to add pages, how to link to other websites, how to create tables and how to insert images on to the web page.

Also during the 2003 and 2004, faculty had the opportunity to learn more about the WebCT course management system and the assessment tools that it offered such as quizzes, self-tests and grade book. In 2004, faculty were also introduced to Vista.

There was a gap between years 2004 and 2007 where there were no training sessions on web page creation software or course management systems. In 2007, faculty learned about the university's new course management system called eCampus 4. Faculty were provided an overview of the system, instructions on how to manage their content and files on the system as well as how to conduct assessments, use the discussion board and chat room available on the tool.

In 2008, several sessions of eCampus were offered to faculty. These sessions included an introduction to the course management system and an overview of the course shell and set up process as well as a review of the course management tools available, assignment tools, and assessment tools. Training sessions on Dreamweaver were again 
available for faculty to attend. Wimba Live Classroom was a new tool that was introduced to faculty in 2008 that offered synchronous audio and video technology to teach an online class. This technology was uniquely presented to faculty as a lead trainer enabled them to experience the Wimba online classroom environment and its synchronous audio and video capabilities for themselves.

Learning how to integrate audio and video. Technology that has been consistently studied during the Faculty Academy was audio and video technology. In the years 2000, 2002, 2004, 2007, and 2008, faculty learned methods to capture, record, and edit digital audio and video for the purpose of integrating the media clips into their presentations and course websites. The Faculty Academy provided faculty with both Macintosh and Windows platforms for learning about audio and video media.

Learning how to use concept maps. The study of electronic concept maps was another popular technology studied during several Faculty Academies. During the years 2000, 2002, 2007 and 2008, faculty learned about how they could use electronic concept maps using Inspiration software in their classes as well as an organizational tool for their research.

Learning about university resources. The Faculty Academy did not limit their instruction on hardware and software technologies within the college, but informed faculty of resources on the university campus. In 2003, 2004 and 2008, faculty learned about a variety of electronic resources available at the university library such as online journals and reference organizational tools available as well as distance education resources that could be used to incorporate into their e-learning. 
Learning how to use the Intelliboard interactive whiteboard. Faculty were introduced to the Intelliboard which is a digitally interactive whiteboard in 2006, 2007, and 2008. Faculty were taught how to use the interactive whiteboard as well as learned how they could use it into their courses by integrating and displaying United Streaming videos.

Learning about Microsoft Office. In the year 2000, faculty were presented with a review of Microsoft Office 2000 programs such as PowerPoint, Word, Excel, and FrontPage. In the year 2008, faculty were again presented a review of the upgraded Microsoft Office 2007 package which had many display changes from the previous versions. As Microsoft Office is a common software package used by many faculty, a part of the 2008 Faculty Academy, faculty were provided with overview sessions to review the changes of the upgraded 2007 version.

Other technology reviewed in the Faculty Academy. The following will discuss other technologies that were taught during the Faculty Academy sessions from the years 2000 to 2008. In the year 2000, faculty learned about database applications. In the year 2002, faculty learned about integrating spreadsheets using Excel. In the years 2003 and 2004, faculty learned how they could incorporate information and media from course textbook CDs into their online courses. In the year 20007, faculty learned about Global Positioning System (GPS) technologies and Geographical Information System (GIS) technologies and how they could integrate them into their courses. In the year 2008, faculty learned about using surveys in the classroom using Simple Forms and Survey Monkey for their courses. In the year 2008, faculty learned about how to use and integrate SPSS statistical software into their courses. In the year 2008, faculty learned 
about TurnItIn.com software and how to use it to assess the originality of students' written work.

Joint enterprise. The following information will describe the policies driving the initiatives to increase the technology literacy among university college of education teachers discussed during the Faculty Academies during the years 2000 to 2008. The U. S. Department of Education acknowledged the challenges facing education in a 1996 report titled “Getting America's Students Ready for the 21st Century; Meeting the Technology Literacy Challenge.” This effort launched the Technology Literacy Challenge program which focused on a vision of the 21st century where all students are “technologically literate.” The goals established focused on making modern technologies available to all students, providing both local and global interconnected classrooms, providing high quality learning resources integrating into the curriculum, and educating and supporting teachers in learning and using new technologies to improve their teaching practice. [Retrieved February 10, 2009, http://www.ed.gov/about/offices/list/os/technology/plan/national/index.html ]

The initial 2000, 2001 and 2002 Faculty Academies were funded under the US Department of Education Preparing Tomorrow’s Teachers to Use Technology (PT3) grants for the purpose of educating and supporting teachers in learning to use new instructional technologies to improve their teaching practice. The purpose of these grants were to support innovate preparation programs, provide comprehensive infusion of technology into teaching and learning experiences of future teachers, provide strong and extensive faculty development and provide opportunities for faculty to engage in joint learning activities. 
During the 2006 Faculty Academy, the college of education’s Technology Integration Plan that was established for faculty who teach for the teacher education program. For the 2007 Faculty Academy, faculty were provided with an overview of the $21^{\text {st }}$ Century Learning Framework.

\section{Shared repertoire.}

Tools. The following section will provide Tables to display the evolution of the technology tools used throughout the Faculty Academies through the years 2000 to 2008. The tool categories include Internet applications, communication technology, presentation technology, HTML creator technology and course management systems, audio, video and digital imaging technology, concept map software, interactive whiteboards, Microsoft Office, university resources available and other technology that did not fit into the above categories. Each section will be displayed separately in the Tables below for readers to observe the progression and evolution in technology tool use during the Faculty Academies.

Table 19

Internet applications taught during Faculty Academy

\begin{tabular}{|l|l|}
\hline Year & Internet Applications \\
\hline 2000 & $\begin{array}{l}\text { Web browsers } \\
\bullet \text { Netscape } \\
\text { — Internet Explorer } \\
\text { Plug-ins and helper applications } \\
\text { FTP } \\
\text { PT3 project website resources }\end{array}$ \\
\hline 2002 & PT3 project website resources \\
\hline 2003 & Nothing mentioned \\
\hline 2004 & Nothing mentioned \\
\hline 2006 & Nothing mentioned \\
\hline 2007 & $\begin{array}{l}\text { Discovery Channel United Streaming Video } \\
\text { YouTube } \\
\text { Google Earth }\end{array}$ \\
\hline 2008 & Nothing mentioned \\
\hline
\end{tabular}


Table 20

Communication technology taught during the Faculty Academy

\begin{tabular}{|l|l|}
\hline Year & Communication Technology and Applications \\
\hline 2000 & $\begin{array}{l}\text { Email } \\
\text { Web boards* } \\
\text { Chat rooms* } \\
* \text { facilitated by WebCT, WebBoard by ORiely, and Blackboard course management systems }\end{array}$ \\
\hline 2002 & Nothing mentioned \\
\hline 2003 & $\begin{array}{l}\text { Web boards } \\
\text { Chat rooms }\end{array}$ \\
\hline 2004 & $\begin{array}{l}\text { Web boards } \\
\text { Chat rooms } \\
\text { Video conferencing }\end{array}$ \\
\hline 2006 & $\begin{array}{l}\text { Web boards } \\
\text { Chat rooms } \\
\text { Adobe Acrobat } \\
\text { Red Pencil } \\
\text { Video conferencing }\end{array}$ \\
\hline 2007 & $\begin{array}{l}\text { Web boards* } \\
\text { Chat rooms* } \\
\text { Wikis } \\
* \text { facilitated by eCampus course management system }\end{array}$ \\
\hline 2008 & $\begin{array}{l}\text { Chat room - Voice Direct } \\
\text { Video conferencing } \\
\text { Wimba }\end{array}$ \\
\hline
\end{tabular}

Table 21

Presentation technology taught during the Faculty Academy

\begin{tabular}{|l|l|}
\hline Year & Presentation Technology and Applications \\
\hline 2000 & PowerPoint \\
\hline 2002 & $\begin{array}{l}\text { PowerPoint } \\
\text { Adobe Acrobat }\end{array}$ \\
\hline 2003 & Nothing Mentioned \\
\hline 2004 & Adobe Acrobat \\
\hline 2006 & PowerPoint \\
\hline 2007 & Impactica \\
\hline 2008 & $\begin{array}{l}\text { Podcasts } \\
\text { Adobe Acrobat } \\
\text { Adobe Designer } \\
\text { Flash }\end{array}$ \\
\hline
\end{tabular}


Table 22

HTML editors and course management systems taught during the Faculty Academy

\begin{tabular}{|l|l|}
\hline Year & HTML Editors and Course Management Systems \\
\hline 2000 & FrontPage \\
\hline 2002 & $\begin{array}{l}\text { FrontPage } \\
\text { Dreamweaver }\end{array}$ \\
\hline 2003 & $\begin{array}{l}\text { Dreamweaver MX } \\
\text { WebCT }\end{array}$ \\
\hline 2004 & $\begin{array}{l}\text { Dreamweaver MX } \\
\text { WebCT } \\
\text { Vista }\end{array}$ \\
\hline 2006 & Nothing Mentioned \\
\hline 2007 & eCampus4 \\
\hline 2008 & $\begin{array}{l}\text { Dreamweaver } \\
\text { eCampus } \\
\text { Wimba Live Classroom }\end{array}$ \\
\hline
\end{tabular}

Table 23

Audio, video, and digital imaging technology taught during the Faculty Academy

\begin{tabular}{|l|l|}
\hline Year & Audio, Video and Digital Imaging Technology \\
\hline 2000 & $\begin{array}{l}\text { Audio } \\
\text { Video }\end{array}$ \\
\hline 2002 & $\begin{array}{l}\text { Audio (Mac \& Windows) } \\
\text { Video (Windows) } \\
\text { Digital Camera }\end{array}$ \\
\hline 2003 & Nothing Mentioned \\
\hline 2004 & $\begin{array}{l}\text { Digital Cameras } \\
\text { Scanning to PDF \& Mac } \\
\text { Digital Video }\end{array}$ \\
\hline 2006 & Nothing Mentioned \\
\hline 2007 & Nothing Mentioned \\
\hline 2008 & Video \\
\hline
\end{tabular}

Table 24

Concept map software taught during the Faculty Academy

\begin{tabular}{|l|l|}
\hline Year & Concept Maps \\
\hline 2000 & Inspiration \\
\hline 2002 & Inspiration \\
\hline 2003 & Nothing Mentioned \\
\hline 2004 & Nothing Mentioned \\
\hline 2006 & Nothing Mentioned \\
\hline 2007 & Inspiration \\
\hline 2008 & Inspiration \\
\hline
\end{tabular}


Table 25

University resources available taught during the Faculty Academy

\begin{tabular}{|l|l|}
\hline Year & University Resources \\
\hline 2000 & Nothing Mentioned \\
\hline 2002 & Nothing Mentioned \\
\hline 2003 & $\begin{array}{l}\text { University Library Resources } \\
\text { Distance Education Resources }\end{array}$ \\
\hline 2004 & Nothing Mentioned \\
\hline 2006 & University’s Instructional Technology Resource Center \\
\hline 2007 & University's Video Streaming Server \\
\hline 2008 & University’s Library Resources (Ref Works \& EndNote) \\
\hline
\end{tabular}

Table 26

Interactive whiteboard technology taught during the Faculty Academy

\begin{tabular}{|l|l|}
\hline Year & Interactive Whiteboard \\
\hline 2000 & Nothing Mentioned \\
\hline 2002 & Nothing Mentioned \\
\hline 2003 & Nothing Mentioned \\
\hline 2004 & Nothing Mentioned \\
\hline 2006 & Interactive Whiteboard \\
\hline 2007 & Intelliboard Interactive Whiteboard \\
\hline 2008 & Intelliboard Interactive Whiteboard \\
\hline
\end{tabular}

Table 27

Microsoft Office technology taught during the Faculty Academy

\begin{tabular}{|l|l|}
\hline Year & Microsoft Office \\
\hline 2000 & Microsoft Office 2000 \\
\hline 2002 & Nothing Mentioned \\
\hline 2003 & Nothing Mentioned \\
\hline 2004 & Nothing Mentioned \\
\hline 2006 & Nothing Mentioned \\
\hline 2007 & Nothing Mentioned \\
\hline 2008 & Microsoft Office 2007 \\
\hline
\end{tabular}


Table 28

Other technology taught during the Faculty Academy

\begin{tabular}{|l|l|}
\hline Year & Other Technology Applications \\
\hline 2000 & Database Applications \\
\hline 2002 & Excel \\
\hline 2003 & CDs for e-courses \\
\hline 2004 & CD literacy \\
\hline 2006 & Nothing Mentioned \\
\hline 2007 & GPS \& GIS \\
\hline 2008 & $\begin{array}{l}\text { Simple Forms } \\
\text { Survey Monkey } \\
\text { TurnItIn.com }\end{array}$ \\
\hline
\end{tabular}

\section{Faculty Academy}

This section describes a week-long observation of the 2008 Faculty Academy. This section is organized by the following subsections: the setting, an overview of the morning and daily briefing activities, an overview of the training sessions, an overview of the end-of-the-day activities, the faculty's communication with the retiring dean, and faculty showcasing their courses.

Setting for the Faculty Academy. The Faculty Academy began the week after the end of the 2008 university spring semester, the Monday morning after faculty have turned in their final grade reports. For the university, this is the week before the first of two summer class session begins. The Faculty Academy takes place in two of the main computer lab classrooms located in technology resource center. The Academy’s day begins in the large computer lab classroom and at times breaks off to a smaller computer lab classroom.

Walking through the door of the computer-lab classroom, one is met with the size and abundance of computers. Two rows of tables line both sides of the classroom. There are five rows of tables on each side of the room equaling a total of ten tables. There are four computers to each table, equaling a total of 40 computers in all. All computers face 
the front of the classroom, and there is large flat screen monitor for each computer. Each computer has internet access with up to date versions of software. There is an LCD projector and remote controlled projection screen with a Whiteboard in the front of the room with a dry erase boards on either side. The participants use a console station placed at the front corner of the room that has the ability to control the equipment in the room. There are rows of lights above that can be controlled to allow a certain amount of light in the front, middle or back of the classroom for the purpose of using the LCD projector.

A second, much smaller computer lab is used for Faculty Academy. This computer lab, which is also used for classes, consists of two rows of computer tables that outline the side walls of the room with five tables to a row making ten tables in all. Each table houses 2 computers on the left side of the room and the right side of the room houses 4 computers to a table. There are flat screen computer monitors with a keyboard and a mouse that sit on the table and the computer tower sits below. Between the two rows of tables is a large pathway leading to the front of the room where there is a interactive whiteboard in the front of the class that is also used as an overhead screen for the LCD projector. There are two dry erase boards on either side of the interactive whiteboard. A teacher's desk sits in the far right hand side of the room along with a computer console that is connected to the internet and also displays their digital instructional materials over the LCD projector for the students to see.

Starting in the Morning. Each morning, faculty are provided with coffee, tea, pastries and donuts about 30 minutes before start of the day. Faculty indulge in the daily offerings and engage in casual conversation around the food on a table that sits outside of the technology resource center. Food and beverages are not permitted in the technology 
resource center, but that does not stop a few faculty who absent mindedly carry their cup of coffee with them to the large computer lab classroom. On the first morning of the Faculty Academy, Wayne, who is the director of the center is quick to call this rule to their attention and asks that they either dispose of their drink or finish it before they enter the lab. He is jovial in his request, but remains committed to making sure everyone follows the rules of the center. The immaculate condition of the technology resource center is a testament to his commitment.

There is a relaxed atmosphere and faculty appear to be easy going this first morning. They enter the large computer lab classroom in pairs continuing their conversations with other faculty and some faculty arrive by themselves. The leaders of the Faculty Academy speak with Wayne about the organization and events to be carried out through the day. As the time is growing closer to the start of the Academy, the large classroom lab is filling up with participating faculty and they continue to speak softly with one another. It is a positive and pleasant atmosphere and faculty have familiarity with each other. As faculty share in multiple conversations its interesting to see that they feel comfortable ribbing one another. As an observer, it is a privileged perspective to see faculty members joking with one another and "being human" outside of the formal nature they present in the classroom.

When one of the leaders of the Academy stands in the front of the room to speak, the participating faculty respectfully become quiet to listen. The lead into his discussion reviewing past Faculty Academies and how instructional technology has assisted in the practice of teaching. Participating faculty contribute to the discussion by comfortably 
speaking out about their experiences and sharing their ideas and opinions about what they hope to accomplish for this year's Academy.

The group discussion continues and it revolves around what faculty are currently doing in their courses and the sharing of their teaching experiences. Faculty provide explanations about their choices in using specific software as well as their instructional strategies. What is common is a technology literacy that is represented in the language that they speak regarding software use, courseware, and computers as well. This language represents prior experiences and knowledge gained working with instructional technology. As the conversations continue, participating faculty refer often to the help they have received by the technology support provided by the center.

Each morning begins promptly and the atmosphere continues to be jovial and upbeat. There is an informal nature among faculty and they genuinely appear to enjoy each other's company as they comfortably share in conversations about topics that do not relate to school. Faculty gather in the large computer lab first thing each morning to hear a daily briefings and overview of what will occur that day. This is a beneficial activity sets the tone for the day and provides an opportunity for faculty to focus on their task of working on their course. At the end of the day, faculty again return to the large computer lab classroom to engage in a review at end of the day review as well as fill out a survey concerning their thoughts about the Academy.

Dialoguing about Instructional Technology. During the Academy, there were occasions for the faculty to engage in discussions about their experiences integrating instructional technology. Several different topics were raised and the following will summarize these discussions. 
Faculty and Technology Support Working Together. Mentioned by several faculty was the support they received from their colleagues and especially from the staff working in the technology resource center. Participating faculty stated that they were pleased with the help and guidance that they received regarding advice and directions from people that had the knowledge along with the wisdom from their experiences working with the instructional technology.

Time Management Issues. A common theme discussed among faculty was the need for more time to work on their courses as well as methods to better manage their time throughout the semester. Common words used describing faculty's experience trying to manage were "time sink” and "struggle.” Faculty shared that teaching with technology increased their workload by “ $150 \%$ ” and feared an increase in the number of students taking their courses online.

Experiencing Change and Keys to Success. There was discussion among faculty concerning a "shifting in their thinking" about their teaching practices and the structure of what their courses would look weekly like throughout the semester. Collectively, faculty identified what they believed to be the keys to success were as they worked through the challenges of teaching with technology. Faculty stated that they believed it was important to remain "flexible and adaptable" when it came to teaching with technology. Wayne contributed to the discussion and stated that it was important for faculty to "maintain communication with their students, provide clarity by stating what specifically they are asking of their students and to remain consistent with the expectation of student assignments and projects.” The phrase "creating a learning community” was stated often among different faculty as well as their interest in collaborating and working 
in teams with other faculty for the opportunity to learn from each other's experiences. The faculty collectively agreed to share their own individual ideas by posting them on the Faculty Academy website for all faculty to see as well as generate more discussion about technology use outside of the Academy.

Sharing of Best Practices. On the second day of the Faculty Academy, one of the leaders informed the group during a morning briefing that they would like to have a sharing session among faculty to allow people see what others have done with their courses. One of the leaders explained that it would be a "flexible sharing session" in which faculty would take about 10 minutes to show their course and "talk to their teaching community” about what instructional decisions that incorporated instructional technology really worked.

The day came for faculty to participate in their sharing session and faculty appeared to be shy and not overly open to volunteer and share their courses. Without too much hesitation, four participating faculty break the silence and volunteer. One by one, each person goes to the front of the room to present their course and display it for the rest of the faculty to see through the overhead projector. As the person, their course and their instructional choices displayed in presentation is unique, there appears to be a common recognition among the group of the "experience" of integrating technology into the courses. As each faculty person presents his and her courses, faculty continue to nod their heads appearing to acknowledge their understanding of the presenters' discussion of their experiences. The group listens intently to what each presenter says and asks questions during the presentation about their experiences of the instructional choices they have made. These questions spark discussions among the group about their individual 
preferences to use instructional technology, their difficulties with technology applications, efficient methods to provide feedback to students, and how they manage the overwhelming nature of their instructional choices that use technology. As this discussion communicates diversity among faculty's instructional choices, it does infer that they view themselves on a similar unknown path that they Table out along the way.

Speaking with the Retiring Dean. On the morning of last day of the Academy, the dean from the college of education was in the room. She was retiring that year and came to speak the participating faculty for the purpose of generating informative materials about the Academy for the new incoming dean. As she was introduced by one of the leaders of the Academy, she began to speak to the faculty about how the Faculty Academy was "increasingly successful each year” and that it "kept going year after year.” The retiring dean expressed that the Academy had a "great impact on students and the faculty's progress delivering innovative courses.” The dean continued to speak about how she believed the Faculty Academy was a place to talk about "teaching strategies collectively with other teachers" and have discussions about the "start of delivering entire programs online for a number of students.” Again, for the purpose of providing informative materials to the incoming dean, she asked faculty to provide her with their comments about specific things they would like to do concerning the development of their online courses and online programs. Faculty members were not reluctant to share their thoughts with the dean and as they communicate their thoughts, an observer can perceive that there are strong feelings among faculty. Some of their important comments included the following: 
- "I would like to see what other people do, how they build their classes, put courses online so that they are visible for others to see and give feedback to learn from each other...to be able to provide a peer critique."

- "There is a misconception that online classes can equal more students, which is not true! Its easier to communicate to all the students at one time...traditional is easier...there is more time involved and it takes time to create the online courses. The time to learn to use the technology to create the courses should be considered by administration. We need support and help to teach these classes. The key element is to access the support quickly. We need help with problems with the technology. The support personnel in the technology resource center has been very helpful with the software and the courses. While I'm here working on my online courses, there are other faculty who have chosen not to do this and they are relaxing right now... while I'm working away!'

- "As I develop my course, it may make sense to me, but not to my students...and I need feedback and I don't know that at the start of the class. I would like to know before. I have talked to faculty about the trials, tribulations and successes, but I need sessions to discuss what we as faculty have learned...sharing the wisdom of our experiences.

- "Most of the technology skills and applications that are used are for the traditional face to face classes and that has a far greater affect [instructionally] than for online classes. Most skills that are learned are for face to face classes...and I'm all for face to face classes.” 
- During the semester, I can't spend time building these courses and I appreciate that the Faculty Academy gives me time to accomplish building my courses. The approach should be rethought because I can’t do it during the semester. How can this change because I need more time? Once class starts, I’m too busy to keep doing course technology work.”

The dean remains quiet and calmly leans on the table in the front of the room as she receives the comments from the faculty that communicate their needs for more opportunities to gain peer feedback, the time constraints to learn and apply the technology to their classes, their lack of development time once the semester begins, the importance of support during the semester, and the conflict over faculty who choose not to teach online. The dean then comments that she agrees with the value that the Faculty Academy provides to the faculty and states that "We need to find out how to maximize this type of activity throughout the year regarding time devoted to technology course development in the building." She then poses a question back to the faculty asking, "How do we sustain what is learned in the summer throughout the year?” She pauses and then continues to talk about the technology support that is provided for each department in the college who are the graduate assistants and fellow faculty members. The dean offers the advice to place faculty who are having trouble in groups with other more technologically skilled faculty. The message she is trying to communicate is for the college to learn how to "maximize and find support that is available for problem solving. It is important that the find balance where all the faculty work together to solve a problem." She again reiterates that these comments will be provided to the new dean as the rationale and historical perspectives to keep the Faculty Academy going. 
There is a pause in speaking among the faculty and the dean as if they are each digesting what has just been said, “...the rationale to the new dean to keep the Faculty Academy going...” Faculty then begin speaking one by one about how the Academy has provided them with the opportunity learn, but among a few faculty, there are emotions that are still running a bit high. One faculty member states almost incredulously, "What's the easiest way?! Technology is not static! We've gone through WebCT, Vista, and now eCampus! Technology is always changing and the tools are changing. The tools changed since last year! The Faculty Academy keeps us up to date for the new year. What it doesn't do is that I'm back to working with 2 to 4 online classes that I need to retool. There needs to be consideration for how much time it takes to build and retool classes.”

The dean listens to the faculty's concern and acknowledges in agreement that technology has not made life easier for faculty. She asks the group how it could be possible to "track the changes of the classes" and questions "what the consequences and ramifications are for spending time to change a course?” She felt that there was a need for faculty to reflect and assess the changes that they were making to their courses for the purposes of trying to find answers to make more efficient decisions.

Trying to neutralize the discussion, the director of the technology resource center reminded faculty that their college of education was the only college in the university with a Faculty Academy. He stated that other departments around the campus come to look to their college of education to model their technology support and professional development opportunities because their practices are successful. He reiterated that the Academy was to provide the faculty with learning opportunities so that they could 
support themselves along with the access to departmental support and technology resources. The director concluded with stating, "The Faculty Academy is a place to learn to teach ourselves, to work on a course and teach you how to fix the difficulties with your courses, and become independent, rather than just fix it for you. There are multiple ongoing levels of support.” The dean then thanked the faculty for their time and comments. Before leaving, she praised them for the work that they were doing and encouraged them to continue with their efforts developing their courses.

Showcasing of Courses. On the final day of the Academy, the last session is lead by one of the leaders who begins speaking about promoting a "learning community" among the faculty in the college of education. He tells the faculty that each person can be a teacher to someone else and that learning can occur through conversations and observations of other's instructional design decisions from their courses. He encourages faculty to continue to help each other and continue to work as a "real learning community.” As he is speaking, faculty listen intently to his comments and nod their heads in agreement.

As the leaders of the Academy stood in the front of the room, they asked the participating faculty to volunteer and share their courses with others. The room became quiet and faculty appeared reluctant and shy to share. Interestingly as faculty engage with one another comfortably, they exposure of their coursework remained a guarded and private affair. Faculty began to joke under the pressure of having to share their work by volunteering one another. In a jovial manner, one faculty member called out another's name and stated, "Bill wants to show you his class! He’s been working hard all week!” Alarmed, Bill whipped his head toward the faculty member who called out his name and 
stated, "Oh! No! Steve was the one who wanted to show you his course! Go ahead Steve, show 'em!” The group laughed at this good humored exchange and finally one faculty member volunteered to share her course. She expressed confidently that she was "excited about doing her course using the Wimba Live Classroom instead of a threaded discussion" and that this synchronous technology provided her with "fresh ideas in mind.”

Another faculty member spoke up and began talking about his course to the group. As his fellow faculty listened, he started explaining that for the online component of his class, his students select to be in groups that work together in chat rooms to discuss their course projects. He stated that the people in the class generate separate discussion boards to post the results of their work. He stated that the "different way of thinking about this instructional task was easier to accomplish online than in a traditional setting.” Faculty in the classroom listened intently as he was talking and complimented him on his instructional strategy.

One last participating faculty member spoke about how he has been working with a hybrid class for the last five years. He explained that he could now accomplish what he had hoped due to the facility of the eCampus course management system. The tools available within eCampus had enabled him to “do what he wants to do as he’s trying to construct the course.” As he was talking, faculty assertively nodded their heads appearing to communicate that they understand his previous instructional dilemmas and comprehending the instructional design decisions he has made for his course.

No one else chooses to volunteer, and one of the leaders concludes the Faculty Academy by expressing the importance of sharing, providing feedback and giving ideas 
and tips to fellow faculty. He commented that he wanted faculty to find this to be an important activity and for faculty to share their experiences of success and difficulties, learn what people tried to accomplish, and begin to relate to each other through the instructional design decisions that used technology. Acknowledging that faculty are searching for instructional solutions, he stated that the communication among faculty could help promote knowing what has been learned and seeing best practices. He concluded by stating that this was a way that the faculty within the college could continue to further each other's development of integrating instructional technology. 


\section{Review of Data Analysis Procedures for Section 2}

The following information describes the data analysis and synthesis procedures that were used for the data collected from the eight teaching faculty participants. This data analysis procedure followed a four step process that is displayed in Table 29.

Table 29

Process of data analysis and synthesis for the participant case studies
Step 1
Step 2
Step 3
Step 4
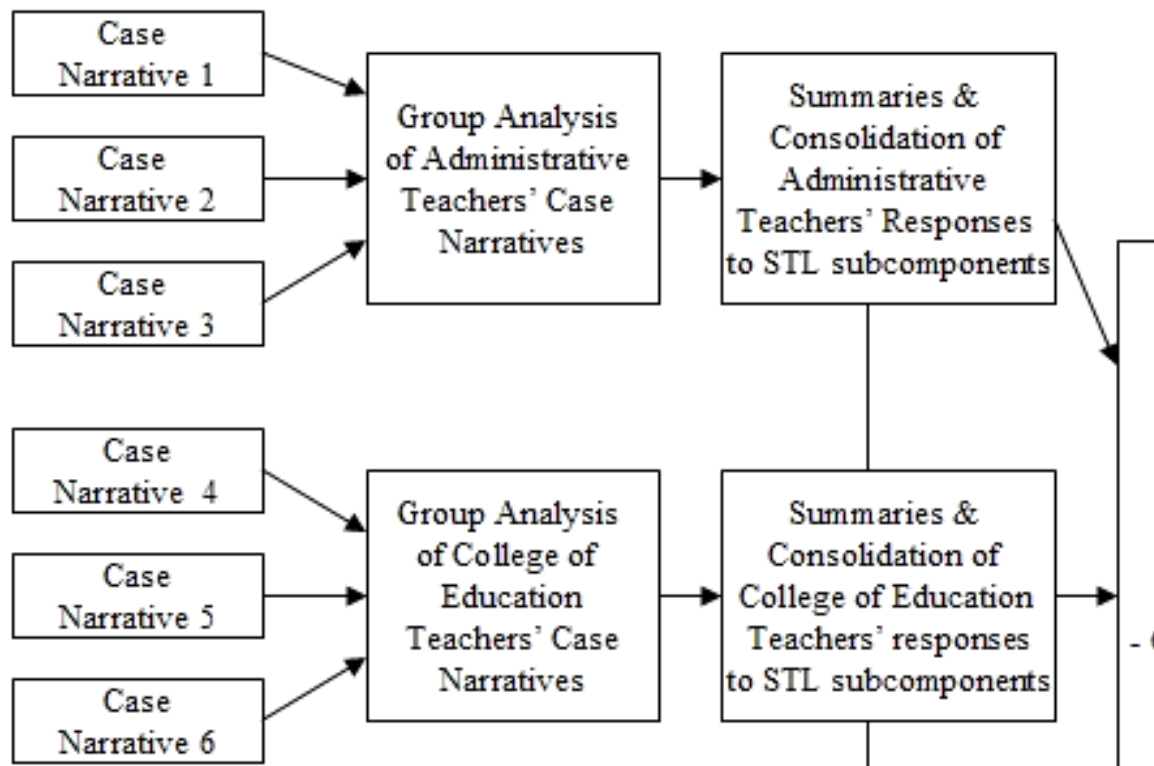

Group Analysis of Summaries \& Consolidation of all teachers' responses to STL Subcomponents

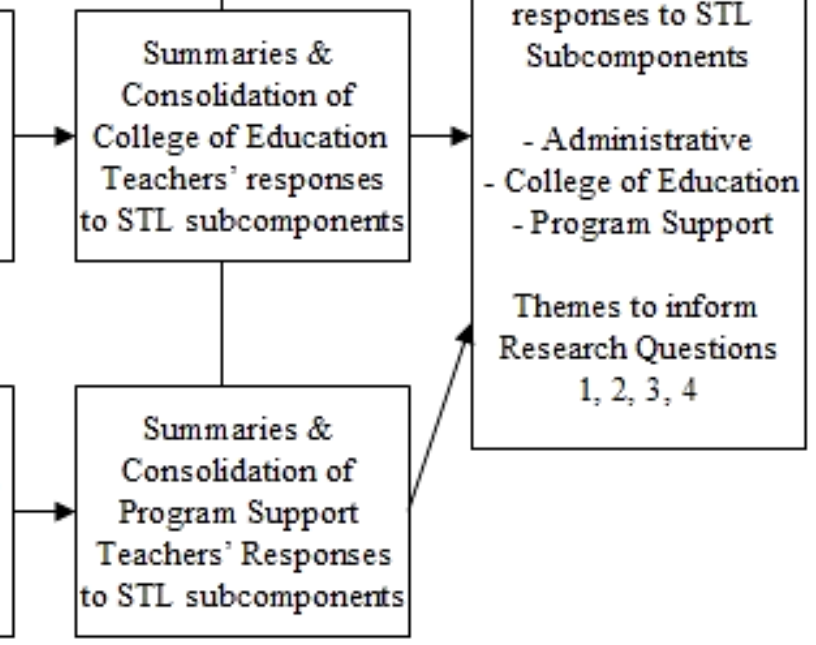

Step One: Analysis of the Individual Cases. The data that was obtained from the participants' interviews, observations, and documents were first organized by the priore codes, identified as subcomponents, listed under the four components of the Social 
Theory of Learning. The organized data for each individual participant case was then analyzed to capture recognized patterns and themes for the writing of the case narratives.

Step Two: Group Analysis of Cases by Teacher Positions. A second level of data analysis consisted of grouping teachers' case narratives by their positions at the college of education (administrative, teaching, and program support) and then drawing comparisons of similarities and differences. These comparisons were made across all three participant groups. As these findings provided another level of understanding as it related to the four research questions, it was not and could not be assumed that the perspectives informed by their positions were universal across all teaching positions at the college.

Step Three: Summarizing Overlapping Subcomponent Data. The data that was collected from the grouping of the participant cases was then collectively analyzed to provide a third level of data analysis. During this process, the overlapping data that was found in the Social Theory of Learning subcomponents was grouped together into summary sections for each of the Social Theory of Learning components (identity, practice, meaning, community). Discovered themes identified from the analysis of the summarized subcomponents of the grouped participant cases were then placed under the subcomponent summaries for the three participant groups.

Step Four: Collective Analysis of the three Teacher Groups. The last level of data analysis consisted of analyzing and making comparisons of the summaries found from the subcomponents across all three participant groups to obtain themes and patterns to inform the four research questions of the study which is presented in Chapter Five. 


\section{Section 2: Participant Case Studies}

Eight faculty participated in this study who have been involved with the college of education community in both a learning and teaching capacity from a range of 15 to 34 years. There were three levels of positions that the participants maintain within the college that included three participants with administrative roles, three participants with primarily teaching roles, and two participants with program support teaching roles.

The participant case studies were then divided into these three sections representing the administrative, teaching and program support roles. Displayed in Table 30 is information about each participating teacher concerning their roles within the college of education, their academic position, the years they been with the college and the subject area they teach. To maintain the anonymity of the participants, pseudonyms have been provided.

Table 30

Participant information

\begin{tabular}{|c|c|c|c|}
\hline Participant & Academic Position & Years with College & Subject Area \\
\hline \multicolumn{4}{|c|}{ ADMINISTRATIVE ROLES } \\
\hline Nathan & $\begin{array}{l}\text { Department Chair } \\
\text { Full Professor }\end{array}$ & 25 years & $\begin{array}{l}\text { Teacher Education } \\
\text { Education Psychology }\end{array}$ \\
\hline Elaine & $\begin{array}{l}\text { Assistant Dean } \\
\text { Associate Professor }\end{array}$ & 13 years & $\begin{array}{l}\text { Teacher Education } \\
\text { Literacy Studies }\end{array}$ \\
\hline Richard & $\begin{array}{l}\text { Associate Dean } \\
\text { Full Professor }\end{array}$ & 15 years & $\begin{array}{l}\text { Teacher Education } \\
\text { Science Education }\end{array}$ \\
\hline \multicolumn{4}{|c|}{ TEACHING ROLES } \\
\hline Ruth & Full Professor & 30 years & $\begin{array}{l}\text { Educational Leadership } \\
\text { (off-campus) }\end{array}$ \\
\hline Wanda & Full Professor & $\begin{array}{l}34 \text { years } \\
+2 \text { college degrees }\end{array}$ & $\begin{array}{l}\text { Speech Pathology \& Audiology } \\
\text { few teacher education students }\end{array}$ \\
\hline Charles & Full Professor & 21 years & $\begin{array}{l}\text { Social Cultural Foundations } \\
\text { Teacher Education }\end{array}$ \\
\hline \multicolumn{4}{|c|}{ PROGRAM SUPPORT ROLES } \\
\hline Tanya & $\begin{array}{l}\text { Clinical Coordinator } \\
\text { Teacher Education Program }\end{array}$ & $\begin{array}{l}20 \text { years } \\
+2 \text { college degrees }\end{array}$ & Teacher Education \\
\hline Michael & $\begin{array}{l}\text { Adjunct Faculty } \\
\text { E-learning Specialist }\end{array}$ & $\begin{array}{l}10+\text { years } \\
\text { working \& teaching } \\
+3 \text { college degrees }\end{array}$ & $\begin{array}{l}\text { Teacher Education } \\
\text { Faculty Technology Support }\end{array}$ \\
\hline
\end{tabular}




\section{Introduction to the Administrative Teachers}

The following information will present the three administrative teachers case studies of Nathan, Elaine, and Richard. All three administrative participants teach one or more courses in the teacher education program.

Nathan is a department chair and a full professor who has been teaching in the college for 25 years. He teaches courses in teacher education and educational psychology. Elaine is an assistant dean and associate professor who has been teaching in the college for 13 years. She teaches courses in teacher education and literacy studies. Richard is an associate dean and full professor who has been teaching in the college for 15 years. He teachers courses in teacher education and science education. 


\section{Narrative 1: Nathan}

\section{Identity}

\section{Main Characteristics of Identity}

Learning process. Nathan became most directly involved in the study of education during his undergraduate years, although his initial studies began in a different direction. Initial career plans were directed toward medical school as he majored in psychology and general sciences. After he took a couple of elective seminars from an operant psychologist, Nathan realized that this different area of study had a lot to offer. Although he was accepted into medical school, he decided to change his path toward educational psychology, because it afforded him a way of provide human services. Continuing on his new path, Nathan sought out more learning experiences and during the last two years of his undergraduate studies. He worked with a professor and other students set up a pre-school and run college courses that used Mastery-Based Learning. This instructional method provides learners with appropriate learning conditions in the classroom to help them advance through lessons only after the previous objective is mastered. Nathan was very inspired by this instructional method and got into a graduate program in applied behavioral analysis in which he focused on early language development, and further worked with personalized systems of instruction and masterybased learning. His research focused on instructing people to apply behavioral analysis practices. Nathan continues to be involved in these same areas of instructional practice today.

Lived experience. After completing graduate school, Nathan served as the director of a school program while he worked and conducted research in a residential 
setting for people with developmental disabilities. After that year-long experience, he taught a university course and decided that teaching in a university setting is what he wanted to do. He took a position at another university to take a job and after a year, he hired by the university in which he now a full professor serving in an administrative position. Nathan states "During my career here, my work has been about applied behavior analysis practices and research methodology.”

Social-community membership. Nathan serves in an administrative role for his educational community. In this leadership role, the level of competence he brings includes 40 years of experience working with teachers, parents, and educators assisting in the design of the conditions affecting the learning environment to provide for optimal instructional conditions for the students. He serves as a teacher and mentor to his undergraduate and graduate students providing instruction and guidance through their studies and research. Nathan is also a collaborator with a colleague in the development of the Competent Learner Model which he continues to work on and implement into school systems.

Nexus of multimembership. Nathan has been actively involved in educational settings since the beginning of his own undergraduate years. His current role with the university involves his administrative role in teaching undergraduate and graduate level courses, as well as serving as a mentor to graduate level students. This role has also provided him with opportunities to develop and maintain relationships outside of the university in the public schools.

Previously working with public schools during his undergraduate years, he took a sabbatical for a year from the university to become a school psychologist for public 
schools and counties in the state and also on a case-by-case basis. Describing his role, Nathan states that he "would do behavior analysis consulting in terms of how teachers and parents can deal with challenging behaviors...kids with real difficult situations.” He says that he's been doing that ever since.

A significant partnership Nathan developed 20 years ago was with a former graduate of the college who developed what is called the Competent Learner Model (CLM). He describes the CLM as “a behavior analysis, direct instruction, precision teaching perspective.” He took a permanent leave for a year to learn more about CLM and when he returned to the university, he helped integrate the model into locations in the state including the university and a nursery setting.

Negotiated experience. During Nathan's experience in teaching, he has been less than enthusiastic to adopt and use instructional technology for his courses. Nathan validates this statement by saying that he has been "drug and cajoled...pushed into using course management systems and other computer-based technologies to assist with teaching his courses.” He claims that his resistance started with the use of the computer 25 years ago, to using email in the mid 80s to late 90s, and using instructional technologies in his courses in the late 90s. He sees himself as a “...second adopter. I am not an early adopter because I would be very skeptical about my colleagues and think, why would they send an email when they could just pick up the phone and call a person?!” He was not convinced of the 'ease of use' and the 'practicality' of the technologies and states that he "would let them get more user-friendly before I got friendly with them.” He would observe and inquire with other people who used various 
instructional technologies and allowed the technology "become further refined" before he would adopt it for instructional use.

Nathan eventually began to use technology for class management to keep track through filing systems of his students' attempts at quizzes and coaching them on their performance. The technology helped facilitate the organization of the class structure to facilitate students' mastery of the units of the content. His use of technology helped him specifically with the use of the Mastery-Based Learning instructional method that he first learned during his undergraduate years and continued to apply in his teaching. As the learning principles he applied to his courses remained consistent, his application and use of technology changed.

\section{Modes of Belonging}

Engagement. Nathan's involvement in educational practice has remained consistent through his teaching, research and application of applied behavioral analysis and Mastery-Based Learning. He sees technology as a supportive set of tools and that it should not get in the way of accomplishing the goals with real people in real time. As a self-professed late adopter, Nathan mentions that he watches and interacts with his colleagues to discuss their experiences before adopting a technology himself. He will examine his set of tasks and assess carefully how the technology will help him perform the task more easily. Nathan states that it is not his usual practice to seek out the technology for his use, but will wait until it becomes available to him and sees how well one of his professional acquaintances uses the technology in practice. As he sees his colleagues doing different things with the technology, he feels that some of the new methods are "sort of awkward" such as blogging and Twittering and feels that it is not 
something he will involve himself in. Nathan likes to see how the technology enhances the practices of colleagues as well as how long it will stay in practice. He states, "When I see people trying to kind of stand on their head, so to speak, to use something, I don't want to use that. But when I see people use products that are user- friendly, with a little bit of knowledge then I'm likely to Table out a way to get them and use them.”

Even though he refers to himself as a late-adopter and second adopter several times regarding the use of instructional technology within the same sentence, Nathan acknowledges his leadership role as one who is responsible to oversee the use of technology in his educational community. For this responsibility he has participated regularly in professional development activities such as the Faculty Academy and also enlists help and assistance from a graduate assistant with the use of instructional technology.

Imagination. The vision Nathan has for his community in the use of instructional technology for his educational community involves the use of seamless audio-video technology that allows for direct communications. He mentions technologies available such as Wimba Live Classroom and Adobe Connect that provide the audio-video communication, but feels that there is a certain "clunkiness and bugginess" that still exists with these technologies. As he is aware of these availabilities he mentions, "There are still technological problems still being mediated and to me aren’t as ready for primetime...at least not for my primetime.”

He looks forward to eventually having a system where people can enter a course and learn activities that are online and monitored and participate in interactions that are almost as good as face-to-face interactions. Environmentally aware as well with the 
instructional possibilities for the future, Nathan feels this would make sense for the "planet and the pocket book" relating to the lack of required travel to meet for courses.

While discussing the visions and future possibilities for his educational community, Nathan reflects upon an early learning experience he had with the operant psychologist that influenced his career path. Nathan states, "He had us read Education and Ecstasy by George Leonard, who was kind of a futurist in the mid-to-late 1960s. He envisioned in this book a situation where students in schools would come to a place where they would sit down in front of a screen and they would log on and do things with computers that would connect them to other things and students that were doing similar things... who were in the same 'class' and they would do that for a while and go off and do projects in the real world. And so this has all come to pass.” As his new visions relate back to his own past learning experience, Nathan sees the possibility and his ability to participate in seamless audio-video synchronous communication and instruction coming to fruition.

\section{Trajectory}

Insider to boundary. Nathan views his future path and involvement in the field of education lasting another 8-10 years due to his age and what he wants to do with his life. In that time, he would like to bring the Competent Learner Model more into the state and into the field of special education as well as general education classrooms. Efforts needed in order to make this happen are the development of an online course of study that could be available to teachers during their own time. The online instruction would include synchronous audio-video technology to provide for virtual coaching for the teachers to help them as they learn to apply the Competent Learner Model techniques 
in the classroom. The teachers then would become experts themselves in the techniques and available to teach their fellow colleagues. Nathan believes that "The knowledge needed to create learning resides in the teachers, the students, the parents, and the school administrators who are right there on the spot who are witnessing what is happening moment to moment.” Nathan states that the Competent Learning Model is growing and being implemented into school systems and that one of his goals would be "for it to become a household word before he dies.”

\section{Practice}

Mutuality of Practice. Nathan views his immediate educational community and other departments in the college as charged with the expectation to use instructional technology for the teaching of their courses, for their research and for their service activities as well. He states that the majority of faculty in his department are adhering to this charge.

\section{Characteristics of Participation}

Participate in resolutions to conflict and change. As Nathan may feel overwhelmed at times with the use of technology, he states that it forces him to Table out a way to make it work efficiently or choose to cut back on the technology choices he has made. He again refers to himself as a late-adopter, but he is very aware of what other people are using and notices their successes and difficulties. He then selects technologies that he feels will help him with his goals as well as be efficient in practice. He is aware that finding efficiency through technology use can be a myth. Through discussion with a colleague who he refers to as an "early adopter" he was told that "integrating technology would not decrease the amount of preparation and teaching time, bur rather take $150 \%$ of 
the time he would normally spend for class.” He has found this to be true of his experiences. To stay current and responsible to the charge set by the university to increase the amount of distance learning courses available for students, he participates regularly in the professional development sessions as well as seeks out assistance from fellow colleagues and technology support staff.

Support communal memory. Nathan mentioned a few times that there was not so much sharing with colleagues, but that if a question or concern was raised, he would participate and join in to help find information needed. He is positive about the aspects of easier channels of web-based communication in which he uses often to stay in touch with colleagues and refers to the developed departmental web pages. Nathan also remarks about traditional methods of contact such as "roaming the halls and interacting with one another as a "nice way to share information." One problem that Nathan sees is the potential that the use of computers can isolate people because they can either be alone in their office or just interact over the Internet.

Assist others. Nathan feels he is a person in need of assistance and consults he the support networks available for faculty to help with technology integration beginning with his own graduate assistant (GA). Referring to his administrative position and the responsibility he has to include technology in his classes, he states that his GA is skillful to help him with the computer needs. Nathan states that he "calls people more than anything for help" and has a preference for traditional person-to-person conversations to discuss how to accomplish what he needs to do. He finds frustration at times with the electronic forms of help and automated systems and wishes he could just sometimes "get someone to talk to.” He recognizes that he does learn something along the way while 
solving the problem himself, but still can be frustrated with the length of time it takes him to solve the problem when an expert could rapidly fix it.

Perspectives to accomplish goals. How Nathan intends to proceed with his plans to integrate technology begins with his perspective belief that, "it needs to be useful in the future in order to be productive.” This is relative to his methods of adopting instructional technology for his own purposes, which is observant and cautious of what is available and then waiting to see the success rate of its application. Viewing technology as a supportive set of tools to assist with the task of instruction, the goal for Nathan remains to be "accomplishing the instruction with real time and real people." He believes that technology is only a benefit if it assists in this process.

\section{Learning in Practice}

Evolving forms of mutual engagement. He states that he became an educator through an "apprenticeship process through his undergraduate and graduate level of education.” The teaching practices in which Nathan participates has remained consistent in the use of the Mastery-Based system of learning methodology. Referring to one of his early teaching experiences, Nathan discusses how his past instructional practices mirrors the same techniques he uses today, only now with the technology.

Nathan reflects back to the late 70's when he assisted with the instruction of a course in the field of health sciences. Consistent in his teaching practices, he explains that the students were first instructed to read their content and then take a quiz on the reading. Upon successful completion of the reading evaluation, they would reassemble to discuss the application of their reading through case studies in which Nathan felt they were now prepared due to their prior reading-quiz activities. This instructional practice 
has an emphasis on student preparation through reading and conducting an evaluation of that reading before beginning a lecture-discussion format for the class.

He is consistent in applying the mastery based system of learning in his classes today as content is given to students in small units so that it can be mastered, quizzes of the content is administered, and then the class reconvenes for the discussion of the application of the content. Any technology that he previously applied to this process was for course administration purposes, such as keeping track of student quizzes. Nathan states that the "technology that was there provided organization of the class structure to facilitate mastery or obtaining mastery of each unit of content.” The small units of content was something that the students could master, and the frequent quizzes over time allowed students to do well on the larger exams. This is what he called his "technology of teaching” in which he is referring to his instructional technique in which he states that he was a part of early on and continues to use some version of that throughout his career.

As he is resistant to use any type of instructional strategy that "gets in the way of his teaching goal," Nathan adopted an online instructional tool that provides him with the tools necessary to enable him to teach with his mastery based system of learning instructional strategy. For one of his undergraduate courses, Nathan found a publishersupported course management system called “My Education Lab” by Pearson, a higher education publishing company. Through the use of this technology, Nathan requires his students to go to the publisher-supported course management system to join the course he's teaching and do pre-and-post tests on what they are reading for that class session. As consistent with his instructional preference, "Class is not about going over the text, but rather applying what they've learned as they achieve proficiency according to the 
standards in My Education Lab materials.” Prior to coming to class, Nathan will provide his students with the first hour of a three hour class to read, take the pre-and-post test. Students are provided with an unlimited number of attempts to successfully complete the tests, but they must complete them successfully before coming to class. Those students who do not complete the tests successfully can continue to work on them until they do or provide a written version of the lecture-discussion they have in class. Nathan states that "most of them are prepared because they don't want to have to deal with it [writing up the class discussion].”

Interestingly, Nathan's instructional methods have remained consistent and his adoption of instructional technology has enabled him to conduct his class the way that he prefers. He used to feel that the written scoring was too onerous before because they included face-to-face and paper and pencil. These traditional methods would become too cumbersome for him and he was not able to ensure the quality of instruction that he desired. For him, this facility is a great benefit because his instructional ideal has become realized through the use of the My Education Lab.

Nathan's work with the Competent Learner Model (CLM), was originally a workshop based on a course of study which later became CD-ROM-based and online. He states that he did not develop the online course, but rather that he helped with the "conceptual parts, editing, and the try-outs." The idea for the CLM was to provide programmed instruction with video examples. Now, the CLM provides virtual coaching through web-based audio-video interactions with people at a distance. Nathan states that "we can be in people's homes or classrooms in a timely fashion, because one of the problems of the old technology which was showing up at pre-arranged times which 
would not correlate with the children's behaviors [displaying them] at prearranged times.” He sees his partner, who was the former graduate of the college as an early adopter who has the CLM program to where it is today.

Understanding and tuning their enterprise. The discussion of Nathan's alignment and action of practice did not center around missions set by larger institutions of practice, but rather the goals and direction set for the people he was trying reach through the energies of his own practice. These people would include his own students in the college as well as the children in the public school. His accountability fell upon his capacity to provide sound instructional methods in his classroom and consultation using the Competent Learner Model. Equally, he held the expectation that his audiences be accountable through their participation. He found that the use of the course-based management system that mimicked his instructional strategy provided immediate feedback to students and the instructor regarding their scoring of the pre-and-post tests of the weekly readings. This immediacy of student accountability was not possible before with the administration of paper quizzes done with paper.

Developing their repertoires, styles, and discourses. Nathan sees that technology is to be used as a "supportive set of tools" used to help facilitate his instructional purpose rather than the use of technology be the goal in mind. His choices are purposeful and directly in alignment with his principles of learning. He is resistant to use instructional technology for the fear of it getting in the way of accomplishing his goals and prefers to carry out his instruction with real people in real time.

The adopted technology Nathan commonly uses that helps him in practice for communication purposes is email. He also uses instant messaging software such as iChat 
and Skype to communicate with people at a distance, which provide audio and video synchronous communication in addition to the commonly used texting. He has not integrated the synchronous audio-video into his courses though. Nathan uses the eCampus shell, which provides with the facility of tracking, grading, and monitoring of student assignments.

The technology resources that Nathan uses to aid and support his sustained engagement in practice has provided him with the facility to teach in the way that he thought was “ideal for 40 years now." Specifically, his use of the My Education Lab course management system is the technology resource he had been looking for. He is quite pleased with this software. He states, "When I have available to me already developed pre-and-post tests that students can take online and be provided with immediate feedback...I could only guess what they were doing when I had to give them paper and pencil quizzes in class after proctoring and grading them myself.” With the capability provided through this software, missed questions on the tests link students right to the place in the text in which they need to further study so they can get that answer correct the next time they take the test.

Nathan also finds great benefit in using the technology support center and also teaches one of his courses in the computer lab in that location. The support and assistance provided to the faculty and students through educational community resources like the technology support center has taken the responsibility off of faculty to teach students how to use the technology in addition to the content of their class. Nathan sees this as an evolution in their practice. He remarks, "Around 10 years ago, we were very concerned about whether people had the technology for one thing, and if they did, did 
they know how to use it. If they didn't, we made it available to them and taught them to use it.” He sees that the majority of students he has today have learned how to use the technology as well as where to go for help.

Snapshot of Instructional Technology Use. Nathan teaches his undergraduate course in teacher education in a computer-lab classroom setting. As one walks through the door of the computer-lab classroom, they are met with the enormity of its size and its abundance of computers. It is a large classroom with two rows of tables aligning both sides of the classroom. There are 5 rows of tables on each side of the room equaling a total of 10 tables. There are 4 computers to each table, equaling a total of 40 computers in all. All computers face the front of the classroom and there is large flat screen monitor for each computer. Each computer has internet access with up to date versions of software. There is an LCD projector and remote controlled projection screen with a Whiteboard in the front of the room with a dry erase boards on either side. The professor uses a console station placed at the front corner of the room that has the ability to control the equipment in the room. There are rows of lights above that can be controlled to allow a certain amount of light in the front, middle or back of the classroom for the purpose of using the LCD projector.

Nathan teaches a three hour class in which his undergraduate students studying teacher education have the first hour of class to read the chapter, log on to the My Education Lab website related to the course textbook Nathan has chosen and take the online quiz assessing their understanding of the chapter. Students have access to Nathan and the computer lab classroom for that first hour of class. On this class night observed, students have not chosen to ask for his assistance during the first hour, which he calls 
"student self-time." Nathan stands alone in the front of the room working on his own laptop on a podium, going back and forth between typing and writing things down on his own notebook. Students begin to trickle in to the classroom as the "student self-time" hour winds down and Nathan greets and says hello to each person as they enter the room. There are 30 students in his class which fills up the rows of seats easily and they turn on the computers and the sound of typing begins.

He checks to see that the students entering the room have passed their weekly online My Education Lab quiz and calls out to them if their name does not appear on the list of people who have successfully passed. There seems to be a dispute with one student as Nathan inquires where an assignment document is and the student states that she emailed it in. Nathan checks to see, but does not find the file. They go back and forth for a while on the issue and then resolve that it was "lost" or there was a "block in the system" and she would resend it.

The overhead projector screen is now showing the eCampus log-in page, Nathan attempts to $\log$ in but has trouble and quietly shows his frustration, but after another attempt, he successfully logs in and the overhead screen displays the eCampus "student view” showing many files on Nathan's eCampus course front page. He clicks on a Word document that reads "Class Activities for Chapter 5.” Nathan, looking at his laptop gives a 'thumbs up' to himself and starts to prepare for the teaching part of the 3 hour class. Students begin typing and log onto eCampus themselves to access the document so they can follow along from the overhead screen from their own computers. Nathan uses the overhead projector displaying course related documents found on their eCampus course website as a guide for the class. 
Before class officially begins, Nathan discusses the feedback he's given on an assignment and informs students that "their feedback is posted online [eCampus] and that they have been corrected for the students to see and review.” A student asks with slight desperation "Where are the assignments listed?!” and Nathan responds that they are under the "Assignments tab on the eCampus page.” The student continues her inquiry "Is there supposed to be a link?!” Nathan responds, “There is a description of it...on the Assignments page and just read the paragraph I wrote on the assignments page as you get to it."

Nathan uses the overhead projector displaying the "Class Activities for Chapter 5” electronic document found on their eCampus course website as a guide for this night. The document displays a numbered list of the class agenda for that evening. Most of Nathan's class is taught in a lecture-discussion format and he goes down the list of "Class Activities” displayed on the overhead screen. During a question and answer instructional moment between Nathan and his students, the sound of typing on the keyboard could be heard in the background. He mentions during the interview that student attention in a computer lab environment can be difficult to maintain as they work on individual things on the computer not related to the class.

Nathan continues to scroll down the list of items displayed on the "Class Activities” document and he assembles the students into groups for an in-class assignment. As the group finish with their work, they communicate their findings by writing their answers on dry erase board. Nathan leads the class in a discussion as he compares each group's work. 
At the end of class, Nathan refers to the eCampus Assignments page and shows it on the overhead for the class to see. The assignment is for students to go through the ERIC database and find articles for a topic area they are researching. At the end of class, students go up to Nathan to ask about papers they have sent to him through the eCampus email, looking for his electronic feedback and asking him if he posted certain class items on the eCampus course page yet. Nathan records the students' specific inquiries, so that he can later attend to them after class. Table 31 displays the instructional technology choices Nathan used for his course. 
Table 31

Instructional technology choices for Nathan's course

\begin{tabular}{|l|l|}
\hline Web \& Computer-Based Technology Used in Class \\
\hline Instructional Technology & Participant Choices \\
\hline Course Website & \\
\hline $\begin{array}{l}\text { Web Authored Course } \\
\text { (Dreamweaver/FrontPage) }\end{array}$ & $\mathrm{X}$ \\
\hline eCampus & \\
\hline Wimba & $\mathrm{X}$ \\
\hline Textbook Website & \\
\hline Textbook CD & \\
\hline Subject-related web resource & \\
\hline Communication Technology & $\mathrm{X}$ \\
\hline Email & $\mathrm{X}$ \\
\hline Discussion Boards & $\mathrm{X}$ \\
\hline Listserv & \\
\hline Chat & $\mathrm{X}$ \\
\hline Instant Messaging & \\
\hline Other Technology Used in Course \\
\hline PowerPoint & \\
\hline Video & \\
\hline Simulations & $\mathrm{X}$ \\
\hline Wiki & \\
\hline PDF Documents & \\
\hline Inspiration & \\
\hline Wiki & \\
\hline Microsoft Word for presentation & $\mathrm{X}$ \\
\hline Microsoft Excel & \\
\hline Online Libraries/Journals & \\
\hline Online Journals & \\
\hline
\end{tabular}

\section{Meaning}

Negotiation of Meaning. Nathan sees that instructional technology has only occurred in the latter half of his 40 year career in education and only during these 5-10 years has he "chosen to" participate in the process of using it for his teaching. The extensive history that he has in the field of education has provided him with the opportunities to work on things that he's "struggled with all along with how to be a more 
effective communicator and feedback giver.” He is pleased that he has developed some confidence in these areas as they relate to his instructional abilities prior to the more recent technologies available, because he notes that in his earlier experiences, the technology felt overwhelming and there were "too many opportunities available." As he started to use technology for his classes, he says it has allowed him in certain situations to create mechanisms to fully develop "meaning” with his instruction, and at the same time, technology use has made him question the meaning of his activities as well. As a teacher, he feels the pressure to include technology in his teaching practice and mentions that "sometimes the tail seems to be wagging the dog and people are integrating it just for the sake of integrating it.” He feels it is very important to have conversations concerning teachers' interests and thoughts about integrating technology to discuss the benefits as well as the difficulties instructors have experienced with technology, such as the overuse, logistical and ethical problems.

Participation. Nathan is aware of the possibilities computer and web-based technologies can provide for both the teacher and student, but he is also aware of the potential downfalls of adopting them. In relation to Nathan's activities and involvement with technology in his educational activities, he feels he is beginning to identify ways it can assist him accomplish instructional methods the way he always wanted to, but was too overwhelming due to the logistics involved. The technology he has adopted, in his view, has provided greater value and reliability in the quality of his instruction. Through his experience, he recognizes the time commitment of preparing instruction with technology and finds this challenging at times. He states, "it requires more effort on my part to keep up and provide for all of those experiences even though they're done or 
handled once they're set up...sometimes its more challenging." So that he still "has time to include more fun activities with his students," Nathan says that he chooses his technology-related activities wisely.

Regarding the use of communication technologies, he finds great benefit in the ability to have contact with his colleagues from a distance as they are scattered across the country. Nathan enjoys the immediacy of interaction through email, iChat and Skype, but is wary of the expectation that it brings to immediately respond. He feels at times the this expectation can not or maybe should not be met for either fellow colleagues or students because he does not have the time. As time passed, he believes that people are aware of this constraint.

One factor that Nathan does find problematic in practice with the use of technology is multitasking. He has found with teaching his students in the lab environment that they at times will have several Internet screens open while they are listening to his instruction. He feels that this lessens the quality of the task that they are doing especially when they [students] should be focused on the class instruction. Nathan remarks, "They can look at Facebook or MySpace or they text message on their cell phone when they should be focusing on class...” Referring to his students as the "multitasking generation," he finds this behavior problematic beyond the obvious pitfalls of not paying attention to class instruction. He has reviewed the research on multitasking as well and says "it is almost always problematic in terms of quality of one task over the quality of multitasking....as you may think you're getting more done, but how well did you do it?” As he teaches in the computer lab, he makes the effort to walk around as he 
lectures to try to discourage students from engaging in that behavior, but realizes that he can only do so much.

Reification. One of the plans developed by the university to help provide direction to the educational faculty concerning the integration of instructional technology that Nathan mentions is a policy regarding annual peer review of their work. Nathan states, “About 10 years ago now, there was an expectation that we would get credit for showing how we integrated technology into our teaching or other activities, but particularly into our teaching which influenced us.” With the incentive incorporated in this policy, Nathan began to seek opportunities and look for ways to include technology into his own teaching. He states that it is a policy that departments share and the structure of the university system started to put in place in the last 10 years made it more useful to be involved.

Another guiding policy that Nathan mentions concerns the area for privacy and safety with Internet postings for the students who are putting together electronic portfolios containing images and videos of children they are teaching in their classes. The posting of the student portfolios brought up numerous discussions among the educational community around how to use the new technology but also protect and maintain the security of these children that were shown during a lesson. Adjustments made to tackle this issue centered around a permission procedure to make sure that the parents of the children were aware of the photographing, videotaping and posting process.

The technology that Nathan has adopted to help him work in practice are the eCampus shell provided through the university and Pearsons My Education Lab. For 
communication purposes, he uses email as well as iChat and Skype for synchronous audio-video communication.

\section{Community}

Community Membership. The relations that Nathan has to educational communities spans several levels from teaching and working with faculty and students in higher education, to consulting with public schools and parents to help children with behavior disorders to collaborating with his partner on the Competent Learner Model applying his expertise concerning the mastery based system of instruction to schools across the country. He maintains a high level of competency in each area as he has worked professionally in each field as well as sought after opportunities for learning experiences through a sabbatical and permanent leave for a year. Nathan also engages in research and service activities in which he maintains contact with the people in his educational community as well as people outside the community where his knowledge and expertise can be applied.

\section{Dimensions of a Community of Practice}

Mutual engagement. As Nathan is in a leadership role for his educational community, it is important to him to have open channels of communication available to his community as he does not want to see people isolated by the technology. One possible way that faulty can communicate is through the created department wiki. Nathan confesses that even though this has been developed to facilitate the joining together of faculty to discuss departmental agendas and goals, it has not "caught on" just yet. This was created as a way to prepare people for discussing issues at faculty meetings as well as share what they were doing with the rest of their colleagues. Nathan states, 
"people can look at the wiki before we come together at a meeting or post their meeting agendas for everyone to see.”

Another avenue Nathan mentions that helps provide structure to his department as well as people outside his educational community is the use of the department web pages. He feels this is a way to continue to facilitate the connection as well as bring in future colleagues to the department.

The Faculty Academy is mentioned quickly as he notes that it has had positive impact overall and a way for people to start to relate to one another. Nathan states that even through their courses are different, the ability to see and get to know what people are developing is a great benefit. Continuing along this thought, he says, "you get to see people that you haven’t seen before in that light and not know what they were doing...or had the expertise." He is pleased with this knowledge because it provides him with more knowledge about his colleagues and a possible resource to call upon to discuss technology possibilities.

Joint enterprise. One of the goals that Nathan attends to for his department is the effort to acquire the enrollment of highly qualified applicants. Through the use of web- based communication and information systems, the ability to access and provide instructional services to a larger audience through online instruction. Nathan sees this as "broadening the scope of the audiences that we can approach by the use of synchronous and asynchronous methodologies and software technologies to make it possible to serve people without being face to face.” The department has made efforts to make themselves accessible to reach a greater audience by purchasing what is known as "sponsored links" through the search engine Google. When potential applicants are searching to enroll in 
higher education programs, the sponsored link will appear within their search if their search criteria is relevant to the university's program. Nathan views this as a positive step for both the applicant as they are finding a program that can be available to them without having to come to campus as well as the school to have hopefully a greater number of more highly qualified applicants to access the program.

Shared repertoire. When discussing the resources shared and used by his educational community, Nathan reflects upon a shift in the intention and use of the technology support center. He explains that initially, about 10 years ago, that there were some colleagues in the community that made efforts centralize the work and organization of the technology support center and that a small number of people who were in charge of managing it. Today, he views the technology support center as "almost totally decentralized" as it opened up its efforts to serve the entire education community school and students. Nathan finds great value in the center when it comes to support as he can “just call down anytime and someone will come up and help me or have me come down and be shown how to do things.”

Nathan continues to discuss the technology support center as it has been home to the Faculty Academy for nearly a decade where faculty can come together to further their knowledge, practice and capabilities. Nathan has been a part of its history as it has allowed faculty to become more familiar with the setting, people and assistance available to them along with their tangible resources available in the lab; computer and internet access, up to date hardware and software, technical assistance and expertise. 


\section{Narrative: Elaine}

\section{Identity}

\section{Main Characteristics of Identity}

Learning process. Elaine’s early college studies began in field of physical education where she had a focus on exercise physiology and adult fitness. With the completion of her undergraduate degree and teaching certification in physical education in the late 1970s, she continued to pursue her masters degree, in physical education with an emphasis on adult fitness and cardiac rehabilitation. Nearly a decade later, her interests changed and she returned to school to obtain an elementary teaching certification, augmenting her physical education teaching certification she earned during her undergraduate years. After some time teaching in the classroom, she returned to school in the early 1990s and completed her doctorate in the area of Language and Literacy Studies.

Lived experience. After the completion of her undergraduate degree in the late 1970s, Elaine returned home and began working in a human performance lab at local university where she was an exercise test technologist using technology to record human performance measures. She became the director of a health promotion project in the early 1980s at a local hospital. After she finished her masters degree she administered fitness assessments with computer programs and conducted paper surveys that she later key punched into cards to run through a computer statistical analysis program. As a director, Elaine became involved with a physiology department at a university medical school working on research projects in which instrumentation data from research subjects were recorded on computer programs for data analysis. 
Later in the mid 1980s, she moved to a new location and returned to school to change her physical education teaching certificate with an elementary classroom teaching certificate in order to begin teaching. She called this a "transition certificate.” During this time, she worked for a science education faculty person who had the first Macintosh computer that she used to "write and merge letters with databases as well as create lesson plans and units.” In 1986, she got a job teaching in a public school and taught for the next 4 years. Elaine returned to graduate school to work on her doctorate in Language and Literacy Studies, which she completed in 1996.

She came to the university community one year prior to completing her doctorate in 1995 as an assistant professor and obtained the position of associate professor in 2001. Elaine maintains her associate professor position in the college as well as works in an administrative capacity as an assistant dean for teacher education.

Social membership. In her leadership role as an assistant dean, Elaine works to support the teacher education programs in the college by attending to accreditation issues, maintaining connection to other educational communities such as the state department of education and looking for teacher professional development activities. As a teacher, Elaine instructs both undergraduate and graduate students, works with public schools, and engages in research and service activities in literacy education. Elaine also serves as a mentor for her undergraduate teacher candidates in their teaching activities, as well as her graduate level students as they conduct research toward the completion of their masters and doctorate degrees.

She states that when she thinks about the kinds of communities in which she finds herself in, she says that she "likes being connected to and around people who are 
innovators and who are leading the way.” As she finds that there is great benefit from their innovation, she is keenly aware of how important it is to acknowledge and support their efforts. Elaine recognizes that the "innovators" value the encouragement and reinforcement of being told how members from the community were able to apply what they have learned from their leadership.

Nexus of multimembership. As Elaine talks about her relations and involvement in different educational communities, she is surprised to realize that there are numerous commitments. When she starts thinking about them, Elaine identifies the different focus and intention of the communities by saying, "some of them are content-focused, some research-focused or some are process-focused.” Elaine first mentions a few of her colleagues who are involved in teaching and working in the college that focus on literacy and then refers to a professional organization that relates to literacy studies. This professional organizations that relates to her background is the National Reading Conference and she explains that is primarily made up of "reading researchers from higher education who also discuss issues around teaching as well.”

Starting to think of other communities that are relevant to higher education and teacher education, she talks about being a member to a community that "crosses institutions.” Explaining further, Elaine mentions that she is a trustee on an educational foundation board who provides scholarships to students annually for their student teaching semester as well as $\$ 30,000$ annually in grants to teachers for professional development or student enrichment projects. Elaine states that they currently have been involved in writing letters to the grantees and in this process she and other trustees are sending and revising these letters back and forth to each other. In discussing this process 
of contact with her fellow trustees, she says, "You know it allows that kind of opportunity to stay connected in work across states...and I'm involved in that.” She also notes that she is involved in working on projects with the state department of education.

Elaine identifies awareness and connections to the different levels as an important factor for the community memberships and relations involved working in the teacher education program. She states, "there is the institution level being higher education, there are teacher education programs, there are the teaching faculty, and there are public schools and public school teachers.” The communities that she referred to earlier that "cross institutions" refer to the efforts to support these different levels.

Elaine also feels communities have changed based on instructional technology and that "communities are not just local people who are in your building, but you can maintain communication with people with whom you've worked with in the past.” Through the content or process-focused communities using listserv technologies, Elaine feels that she is able to stay current and be aware of what people are talking about as they share what they're doing. She also notes that she is then able to go to or contact those people more directly because she knows of their work or interests more specifically.

Negotiated experience. Elaine's participation and involvement in the sciences during her early educational experiences and career provided her with opportunities to get involved to come to know the range of uses for the computer and technology. From her first years in college, she used technology to record human performance measurements, cardiac rehabilitation assessments, and adult health and fitness levels. Elaine used an IBM computer for word processing, generating graphs and tables, as well as and running off data and statistical analysis from the research. She was introduced to the process of 
developing a computer program for research purposes through her work with cardiologists of a fitness facility who were interested in developing a computer program to provide an analysis and calculations of cardiac fitness assessment data.

Elaine's use of computers for work and school continued as the direction of her career interests began to change. She returned to higher education seeking a transition certificate to become more involved in the field of education. She worked for a science education faculty person who had the first Macintosh computer. The previous experience she had with the IBM computer helped her be familiar enough to do newsletters and work with databases with the Macintosh. She also created her lesson plans and units on the Macintosh in 1985-1986. When she got her first job teaching public school, she bought her first Macintosh computer and had 2 Apple 2E computers and had her students working on them doing problem solving and skill-based programs, and popular programs such as "Where in the world is Carman Santiago?” When she began teaching right from the beginning, all of her lessons were on the computer, in addition to keeping an electronic grade book. During her public school teaching years (1986-1990), she supervised the school yearbook, as well as the graphics, word processing, desktop publishing and data management. Elaine comments that using the computer to do these types of activities was something she did all the time.

When she came to graduate school in 1991-92, she was still using her computer. Elaine states that this was around the time that the Internet was introduced and she got a modem and got "hooked up." When she came to the university in 1995, Elaine got in contact with a person who was a leader and an early adopter with instructional 
technology in the college. He helped her select the first computer that she got here as well as a laptop she could take with her to work at home or for travel purposes.

Referring to herself as an early adopter, Elaine feels like she's always been involved with technology by stating, "I feel like I’ve come along [using the technology] as the technology has emerged.” She recognizes that she can not stay as current with the new advancements as she once did, but feels that with her high comfort level with computers and her willingness to problem solve will always be there.

\section{Modes of Belonging}

Engagement. Elaine has come to have a certain way of being that has been defined by her history of technology use, first in her sciences community and then later in her educational community. Having a deep background using technology in her work, she feels fortunate to have had those opportunities as she believes that it was not normal for people in her age bracket to have. She states that she has "developed a keen interest and a willingness to explore and Table things out with technology.” Elaine states that she “can’t even imagine not using technology on a daily basis or not having technology as a part of my personal life as well as my professional life.” Her interests of technology go beyond fondness as she mentions that she is interested in thinking about "how it serves the purposes of her tasks, communications all what she would like to accomplish in her life.”

Projecting her understandings of instructional technology use, she has presented in professional educational conferences such as the Society for Information Technology and Teacher Education and the National Reading Conference. She has also worked and served as chair for doctoral students' committees who studied instructional technology in 
the late 1990s. Her cycle of participation in the educational community events that involve the use of instructional technology has waned slightly as she states that she is not teaching as much as she did before. This causes her to feel "exposed and not as current with the technology advancements" that appear "more vast" to her than they once did. Last year, Elaine admits that last year was the first time that she did not attend the Faculty Academy. Her change in role reduces her participation less than she would like, she "tries to stay connected" and looks for ways to be in contact with these types of professional development efforts.

When discussing her ongoing process of negotiating the use of technology, she examines her role as a faculty member and questions, "How do I get appropriate instructional technologies to forward the goals and learning objectives of the learning outcomes from our students?" She feels that this question is a small but complex piece of how instructional technology is affecting the life and work of public school teachers and higher education faculty. Cognizant of her different educational intentions for the educational programs in which she is involved, she examines "how she should use technology” for her graduate students in the masters in reading program. Comparatively, for the teacher education program, she also examines "how she should model the kinds of uses of technology for instruction and learning that is appropriate for teaching in the public schools.” She is aware of her responsibilities to serve as a model for appropriate teaching for the teacher education program and tries to demonstrate the use of primary school technologies that could be used in a public school setting. Elaine notes "this may be certainly different than what I would be doing if I was simply teaching.” This awareness refers back to her earlier comments concerning the multiple levels of influence 
higher education has on teacher education programs as it trickles down to the public school setting.

When thinking about her teaching, she finds tremendous value with traditional face-to-face interaction, but realizes that the use of instructional technology provides alternatives and possibilities that traditional methods can not offer. She has a realization that as she and her fellow colleagues, "who have known other ways are growing older and are moving out and those who are brought up knowing these different ways of coming together through technology...those become the norms and they can make it work." Elaine is speaking of the evolution of instructional practice and how she will also be a part of this change. Even though the methods of how people come together may not be the personal and face-to-face interaction that she values, she is aware and willing to participate in the change.

Imagination. When Elaine thinks about the vision and possibilities she would like to have for her educational community, she reflects upon capturing the teachable moments in the classroom so that they could be viewed and examined multiple times. Explaining further, she states, "The live things are too fleeting, but it would be so useful to have those kinds of technologies where you could peek inside a classroom for teaching purposes. That would be useful."

Another possibility she would like for her community concerning teacher preparation would be the opportunity to be able to conduct focused observations and practices of her students in both the teacher education program and the masters reading program. Capturing observations could be later analyzed and used for coaching purposes to help student gear their efforts toward best instructional practices. 
As she is thinking, she mentions the possibility of having live streaming connections to the public schools so that the pre-service teachers instruction could be captured and reviewed with students. Elaine finds great value in the ability to capture, illustrate and then reviewing instructional practices in her class as it demonstrates the application of what they are learning in the classroom. To be able to see and review real instructional moments as it relates to her topic area would help students view best practices and engage in conversations about the instruction that may be otherwise lost in the classroom. The possibility for these materials to be available for students to return to and review, in Elaine's mind, could be very helpful as it would give them time to later engage in conversations after they've been able to mentally process what they are learning.

\section{Trajectory}

Insider. Elaine's trajectory with her community continues on an insider path as she gains more responsibility in her leadership role. In this role, her contact and engagement with other educational communities grows, as well as her ability to contribute and influence her own community.

\section{Practice}

Mutuality of Practice. Elaine's conversation concerning the mutuality of her community's practice centers around the transformative potential instructional technology has on the expectations of faculty to develop and teach online courses, of departments to reach a broader student base and of the college to provide professional development to practicing teachers. 


\section{Characteristics of Participation}

Participate in resolutions to conflict and change. When discussing the learning process to advance her knowledge with the use of instructional technology, she first mentions her history with the Faculty Academy in which she was a part of since the year 2000. In her leadership role, Elaine states that she is working to get to get faculty to complete their work electronically rather than in paper-based form. Rather than wait for faculty to transition their skills, she states, “we're pushing them” even though she acknowledges that there is still some resistance to change.

She then begins to think about what she can personally do to "stay on the cutting edge” to provide information and knowledge to her students. Exploring the use of commercial technology products has always been a valuable exercise to Elaine as she feels that she and her students should know what is available to the public as it concerns instructional technology. Talking about her previous involvement, she states, "in the late 90s, I spent a lot of my discretionary money to buy technology - to buy CDs and software and things like that are commonly available in public schools.” She would look for products that could be used in "work stations, small groups for children to do an activity, or rotating children through a learning experience using the computer.”

Elaine includes the search for available instructional technologies as an assignment in her courses so that the exploration process does not get forgotten. Students are assigned to find an instructional technology, use it and review it and write up a review of it. Elaine finds at times that her students may comment that they do not see the value in the activity, but she is well aware that parents are quite active and interested in the learning activities of their children. For Elaine, being aware of what technology is 
available for young learners, is important activity for teachers so they can stay connected to the best learning opportunities for their students.

Support communal memory. When discussing how members of her community work collectively to build a successful practice, Elaine mentions that she and her colleagues are really working on examining ways to use technology that are going to inform them how to make program decisions. Specifically, one of the efforts Elaine mentions is the building of an infrastructure to support the collection of data taken from the students in the dual degree teacher education program. This data will keep a record of students' academic performance while they are in the teacher education program as well as their performance for the first few years teaching in the public schools. Elaine states that significant efforts are being made to transition the paper-based information collected from students" "forms" to "eforms" which will be entered into a Sequal Server. As Elaine is explaining the process, she makes mention of her effort to state it correctly with the "technology language." She states, "from what I understand, the data will go to an Access front database with a Sequal Server in the back.” Currently, Elaine mentions that she and the people working on how they can download the data that will be entered and make it manageable. These efforts are geared toward making program decisions that help improve the teacher education programs teaching and learning practices.

Assist others. Elaine is quick to mention the help and assistance she receives from her fellow colleagues and the technology support staff in the technology support center when talking about her efforts to integrate instructional technology. She offers an interesting perceptive about the human condition as it relates to the process of helping one another. She is keen to note the internal drive teachers may have to provide 
information and knowledge to another person in need of help. The internal benefit teachers receive from being helpful comes from connecting to an audience equally interested in their teaching efforts. Elaine is aware of this reciprocal dynamic and is sincere with her gratitude and interest with a few of her close colleagues in her department that "keep her in their circle” with their knowledge of instructional technology advancements. She feels that she is very fortunate that they continue to involve her in their conversations and explorations of new technology to apply to the classroom.

Similarly, what is very helpful to Elaine when it comes to learning new software is the opportunity to have a 'template' created in which she can learn from. The ability to get beyond "the blank page" and be able to work with a structure that already contains content gives her the chance to explore and proceed working with new technology.

As she engages in conversation about instructional technology with ease due to her rich history of working with computers, she is not immune from feeling apprehensive about applying a new technology to her classroom. She mentions how she has benefited from a knowledgeable new faculty person whom she says "knows all about these things that are on the web that I don't know, but she talks about them with such ease and makes them sound so simple...So it plants a seed with me that makes me think I can do that too!”

Perspectives to accomplish goals. As Elaine thinks about how her educational community develops and proceeds with plans that help it achieve its pursuits when it comes to technology, she focuses on her own efforts first. Recently, Elaine says that she overheard one of her students in her classes talking about how “she didn’t like computers 
in the classroom and could not imagine having her students using computers in the classroom for learning." This came as quite a shock to Elaine as she immediately thought, "Here's a young lady who is texting, she has a cell phone, she uses computers herself, but she can't...she hasn't seen it used effectively in regular classrooms?” She felt that her consciousness was raised hearing this remark, and she made attempts to discuss the use of computers in the elementary classrooms. As she discussed with her students that there were elementary schools currently that had a laptop for every student, she was met with disbelief, “they couldn’t fathom it?!” What Elaine took from this experience was the perspective that she as a teacher "falls short in actively, regularly, systematically seeking ways to have technology be more prevalent in my own instruction,...in my classes.”

On the other hand, as she is interested in making instructional technology be a part of her regular teaching practice, she is quite clear in stating that its use will be purposeful rather than "digitizing the information." Elaine is discouraged when she sees technology being used in an uninformed way and hopes to serve as a better model for her students.

\section{Learning in Practice}

Evolving forms of mutual engagement. When thinking about the developmental process of her educational community as it involves technology, Elaine comments on her instructional practices, the connection and communication with her colleagues, and the learning processes of her students. Elaine has an extensive history with the involvement and use of computers and technology. As she talks about her experiences and involvement in educational practice, she refers back to her days of 
teaching in the public school before she came to the university setting. She felt very comfortable using her own IMB computer when she taught in the public schools as well as used the computers in her classroom to for problem solving and skill building instructional purposes.

Elaine has remained very quite interested with learning and applying new instructional technology to her classroom practices and has been involved in professional development activities such as the Faculty Academy since its inception in the year 2000. Currently, she is teaching one course that meets in a traditional face-to-face format, but extensively uses the eCampus online course site for accessing important course documents as well as communication purposes. One of the resources she uses in class are instructional video clips which provide students with the ability to review and discuss instructional best practices. Elaine states that she tries to integrate technology meaningfully and will not include it if it not purposeful toward the instructional objectives.

Elaine is teaching her first blended web-based course in the next semester and admits that she is a bit apprehensive, as she has a few concerns about teaching in the different format. She worries about her students who may be somewhat novice learning in a web based environment and laughs to herself and humbly mentions that she may be the one who is more novice. Areas of concern she has with web-based instruction involve the increased time commitment for both teacher and student. She mentions that she is sensitive to the amount of work that she requires them to do outside of class. Elaine is not convinced that escalate their workload through additional reading activities, postings to the discussion board, and projects her students are already working on will 
advancing their knowledge. The learning experiences she would like to provide for her students that include instructional technology are ones that "engage them in the learning experiences and practice experiences rather than just providing dictation through PowerPoints on the web.”

An important factor Elaine mentions as it relates to instructional technology available in the public school classroom, is for her students to have an "awareness of what is happening in popular culture and in the home as it relates to elementary instruction.” She is speaking of the continuing the effort to examine what commercial options are available to teachers, schools and parents for their children who are struggling with learning or who need enrichment activities.

Another area of concern for Elaine is the change from the traditional face-toface teaching format to the blended format which will consist of both face-to-face and web based connection with her students. As she values the face-to-face interaction with her students, she is aware of the successful experiences of that her fellow colleagues have as well as the strong connections with students even under the web-based format.

When thinking about the developmental processes of connecting and communicating with her fellow colleagues, Elaine has noticed a change. She begins to discuss where there was once the expectation that her fellow faculty would be required to be on site and attend meetings is now changing. She notices a transition and an evolution in practice as people are now engaging and participating in activities through desktop video conferencing. She notes that even though there may be limitations to these types of communications, that "we are in a transition time and we learn to work with that environment.” Mentioning that the technology can support the exchange and 
collaboration on documents as well, that people learn to complete projects in different ways. She finds that as she may have an internal struggle with this change as she "puts on her administrative hat" she is cognizant and respectful of the transitional practices of her educational community.

Understanding and tuning their practice. Discussing issues of teacher accountability, Elaine refers to the International Society for Technology in Education (ISTE) and the new National Education Technology Standards (NETS) that are set for teachers and administrators as well as for children. She explains that there are three levels, "what teachers should be doing with kids, what teacher preparation educators should be doing with teacher preparation candidates, and what teacher education principles should be doing with principle education.” She continues to state that the courses that are taught through university are supposed to be addressing the appropriate ISTE standards and that people are very aware as they are discussed frequently.

Developing their repertoires, styles, and discourses. There were several computer and web-based resources Elaine mentioned that she uses to aid and support her engagement with her educational community. For her own course use, Elaine has been active in her use of eCampus which she refers to as WebCT at times as that was an earlier name for the course management software used by the college. Referring to the courseware as WebCT has happened frequently with other faculty who were interviewed. The organizational structure and design of the web pages is helpful to Elaine as she likes being able to specifically refer her students to course information she has posted. She states that she uses the eCampus as a "repository" over the last few years for the particular course that she is teaching for students to find additional information. She 
notes that she keeps the course up-to-date with the course materials, such as handouts and the syllabus. One of the eCampus functions she uses is the online grade book which is reflective of her previous practices when teaching in the public school. She is skilled at using the web board for threaded discussions and the chat rooms, but comments that she has not used this feature the last few times in teaching the course. Although there is an online interactive calendar function in eCampus, Elaine prefers to use the Google calendar although she admits that she "hasn’t gotten everyone signed up on it yet."

Elaine uses a variety of computer and web-based software for instructional and collaboration purposes. For a couple of semesters, Elaine mentions that she uses the Adobe Acrobat audio commenting feature for her students' work as well as with her colleagues on research projects.

One resource in which Elaine finds value an uses in her classroom are illustrative video clips that helps students practice skills such as "record keeping and using a coding scheme” in the assessment of children's reading skills, which can usually only be learned through authentic practice. Elaine finds great value with the ability to provide her students with authentic assessment activities for them to practice in the classroom. Students can watch the clips repeatedly, discuss their findings in a group setting and have the guidance of a seasoned and skilled instructor.

Elaine mentions that the college is implementing the use of Survey Monkey that as a survey assessment tool to collect data across the different programs in the college. Never far from Elaine's mind is the awareness of the influence and the connection of multiple levels in her educational community. She is learning how to use the software at the institutional level, she also thinks about how she could use it in her own classroom. 
In addition, she shows her students how they could use Survey Monkey with their own students for the possibilities of obtaining information from the parents of the children.

Important web-based technology relating to the teacher education program, Elaine mentions that "the institution has purchased and is piloting Web Folio software" that the faculty will be evaluating. As the portfolio is an important culminating project for the teacher education program students, the ability to have a software that allows students the ability to upload materials and create their portfolio online is a great advancement. Elaine notes that the faculty in the program are trying to identify what the specific uploads will be and how they will evaluate those required uploads. She finds that, "there's this concert between really working with our faculty and working with our students as we're trying to use technology in your practices and just pushing everything forward."

One last technology that Elaine mentions is Ning, which is a social networking software she just became aware of through her membership to a national organization. It caught her off guard initially because she had not heard of it before, but it appeared to be very well known by some of her colleagues. Wanting to stay current with her knowledge to the latest technology available, she continues discussion with her colleagues about to see how she may be able to apply the social networking software to her own classroom.

Snapshot of Instructional Technology Use. Upon entering the room for Elaine's course, one is reminded of a grade school classroom. The room is filled with books, tables, drawings, counters, and bookshelves. The walls are painted in a pastel yellow and taped to the walls are several rows of children's colorful magic marker drawings of decorated cupcakes, fish bowls, trees, and peace signs. Five round tables 
that appear to be children's tables are used for the class that seat four to five students. Students crouch down to sit bending their longer legs so their knees can fit under the table. There is enough room between the tables for one to walk around easily.

A teacher's desk is in the front left hand side of the room housing a computer with a flat screen monitor that is connected to the internet. A control console is also located in this front left corner by the teacher's desk for easy access to control the LCD projector which displays on the remote controlled overhead Whiteboard screen. The screen is located in the front center of the room and large dry-erase boards sit on each side of the screen. An overhead projector sits in the front left corner of the room.

As the students get settled and before class formally begins, Elaine reads an email from Richard discussing new changes concerning the library system that students should be aware of. Students receive the email news with nothing more than a few nods and Elaine continues on with the class direction for the day.

Midway through class, Elaine asks student to go to the back of their textbooks where a CD is provided. This textbook CD provides students with evaluation forms and charts necessary for their teaching profession. In addition, there are short videos providing observation examples for students to sharpen their skills with reading evaluations which can only otherwise be found through live experiences in the classroom. Elaine describes these experiences to be fleeting and the videos give students the opportunity to view and practice these reading evaluations sessions over and over again. These are evaluation skills necessary for their profession.

Elaine dims the lights, inserts the CD into the computer located in the front of the room and plays the video for the class to collectively see and discuss. As Elaine is using 
this CD for class use, she comments that "they [students] can use this resource at home and play the video again and again to learn to become more familiar with picking up the listening skills they need in order to evaluate young readers with learning difficulties.”

Each student takes an evaluation form Elaine previously passed out to their tables in to complete as they watch the video. These evaluation forms will be used over and over again in students professional practice. Students can access these forms from their eCampus site for the course as well as on the supplemental CD provided by the textbook. Elaine states that students can use them in class for practice and later use them in their own classrooms for student reading evaluations.

Elaine plays a video from the CD of a young boy reading to a teacher and he frequently makes mistakes in his reading. This activity is for students to build their skills of hearing the young reader's mistakes as he is reading so they can correct it in the moment. This video provides students with a tool as they can have several chances of capturing the young reader's mistakes that can otherwise only happen in the classroom, which is a limited amount of time and opportunity. Elaine uses the videos for the use of class discussion and learning.

After Elaine plays the video, she gives students time to gather their thoughts and make decisions on their evaluations sheets. She plays the video again so that students can assess their responses and add or change any marks that they first put down. Elaine puts the lights up and the students discuss their answers at their tables. After she gives the students a moment, she dims the lights and plays the video one more time (EFME). Students again check their work with the third playing of the video. 
At the very end of the third playing of the video, nearly all students recognized something that they missed in the two earlier viewings. With each new playing of the video, the students appeared to pick up something new that they didn't notice before. Having access to the video clips which can be played and reviewed repeatedly for student practice helps build their listening skills critical to their profession. Elaine states that "provided on the $\mathrm{CD}$, there are several different videos with different young students reading for more practice with student reading evaluations.” For this activity, Elaine uses the handout and the $\mathrm{CD}$ together.

Elaine's chooses to use the CD again for another purpose. She plays a different video to her class to show her students 'reader work stations' and teachers helping other teachers to help with reading and to talk about testing. Elaine instructs that she wants the students to record key ideas they found as they watched the video. Elaine would play a portion of the video and then stop and discuss with her students what she felt was important and then would continue to play the video. After the video is finished playing, Elaine reviews what she feels is important and helps the students view different classroom tactics of how to organize practice time for the students. Through the viewing of the video clips, students were provided an opportunity to see how a work station project was modeled and discussed by other teachers. This video also provided students to see teachers performing best practices in their content area.

During Elaine's review of the video clips, she makes note of the state's standards and the $21^{\text {st }}$ Century Skills her students must keep in mind as they will conduct work stations in their own future classrooms. Elaine discusses examples found through the video clips of what students can put into their future practice. Elaine states, "I'm trying 
to show you that teaching doesn't have to be an isolated activity. You can work with other teachers and focus on your state's standards and other outside experts in the field”. Elaine discusses how to evaluate their students' work station performance through a rubric that was provided on the eCampus course website. Elaine reminds the students that the evaluation forms are available on the CD as well as on the eCampus course website.

She dims the lights one last time, and working from the console in the front of the room, goes on to her eCampus course webpage. She shows students where to access the evaluation forms. Elaine shifts her class's attention to their upcoming assignment and clicks onto the Assignments link on the eCampus site. She uses the web pages on the overhead screen to walk the students through their next assignment. Under the Assignments link, she clicks on a Word document and displays it so that she can discuss it with the students. Referring to the Word document on the overhead screen, she refers to it, reads through it, talks about their assignment, discusses what they will need to do, and provides them with examples and a snapshot of what their assignment will look like. The students ask questions as she explains their upcoming assignment and she uses the displayed Word document as a guide to walk them through their task.

The class is coming to a close and Elaine clicks off the eCampus website. She turns the lights back on and tells her students, "You can email your assignment, hand it in as a hard copy or send it to me to look at...all versions are fine with me.” Table 32 displays the instructional technology choices Elaine used for her course. 
Table 32

Instructional technology choices used for Elaine's course

\begin{tabular}{|l|l|}
\hline \multicolumn{2}{|l|}{ Web \& Computer-Based Technology Used in Class } \\
\hline Instructional Technology & Participant Choices \\
\hline Course Website & \\
\hline $\begin{array}{l}\text { Web Authored Course } \\
\text { (Dreamweaver/FrontPage) }\end{array}$ & \\
\hline eCampus & $\mathrm{X}$ \\
\hline Wimba & \\
\hline Textbook Website & $\mathrm{X}$ \\
\hline Textbook CD & \\
\hline Subject-related web resource & \\
\hline Communication & $\mathrm{X}$ \\
\hline Email & $\mathrm{X}$ \\
\hline Discussion Boards & $\mathrm{X}$ \\
\hline Listserv & \\
\hline Chat & $\mathrm{X}$ \\
\hline Instant Messaging & $\mathrm{X}$ \\
\hline Other Technology Used in Course \\
\hline PowerPoint & $\mathrm{X}$ \\
\hline Video & \\
\hline Simulations & \\
\hline Wiki & $\mathrm{X}$ \\
\hline PDF Documents & \\
\hline Inspiration & \\
\hline Wiki & \\
\hline Microsoft Word for presentation & $\mathrm{X}$ \\
\hline Microsoft Excel & \\
\hline Online Libraries/Journals & \\
\hline Online Journals & \\
\hline Online Grade Book & \\
\hline
\end{tabular}

\section{Meaning}

Negotiation of Meaning. As Elaine reflects on the history of her work

experience, she states "It is interesting to think about how my life has been touched by

technology.” She acknowledges that her previous work in the sciences launched her into the use of technology and made her feel at ease to explore how it could be used in her educational practice. Technology plays a large role in Elaine’s personal life as well as 
her professional life and she sees herself using it on a daily basis. She does have concerns though about the blending of work into one's personal life as she states that she witnesses this occurring more than ever before. The positive side, she mentions, is the flexibility to be able to travel or visit with family where before that may not have happened due to one's educative responsibilities.

What Elaine interprets from her experience of integrating technology is that she "finds great value of the possibilities in using it to enhance learning skills, practicing skill, evaluating the facility of the practices, as well as provide opportunities to coach at a distance." She would like to "break the boundaries" of the classroom and believes that what is available to her learners is better than ever before by being able to communicate with people at a distance as well as access resources and materials.

She is equally cautious as she is enthusiastic in her view stating that she is aware of the potential and power surrounding the use of instructional technology and that educators must be attentive to their decisions to use it in their classrooms. Sensitive to her colleagues and students who may share a different perspective, Elaine recognizes that it can be "frightening for a lot of people because its changing on so many fronts." She states that at times she can feel "mixed," because she "loves the instructional technology" but feels it is important to integrate it meaningfully.” 
Elaine is left with many questions when she thinks about integrating instructional technology. Throughout her discussion of the interpretations and understandings she's gained through her experiences using technology, she is left with many questions that relate to her engagement in practice. She asks:

- How do I keep learning more and well enough to make it easy to use to show my students?

- How do you use technology to provide feedback and to store iterations so that you can watch papers grow, analyze them and use them in research?

- How do we select the right kinds of software programs and hardware to provide us with information that is going to help us make appropriate decisions?

- How do I Table out how to use technology for instructional purposes? How do I do that myself with my students and try to think about what is appropriate for them to be thinking of doing with their students?

These are issues that she continues to grapple with and the concerns she has in mind as she is a teacher modeling instruction to future teachers.

Participation. Elaine has concerns about how technology may affect the instructional relations and connections with students specifically as she begins to teach online. It is her preference to be able to have face to face contact with her students, but realizes that this may change once she does not see them in the classroom. She shares her concern with her colleagues that have experience teaching online and they try to provide her comfort by telling her that "they do absolutely have connection" and that she may "come to know those students in ways that are deeper than what she normally would in class." As she is provided with a lot of testimony that she will have access to more detailed conversations with students, she shrugs her shoulders and says that she will "wait and see what happens.” 
Elaine examines the significance of her ability to model appropriate technology use for instructional purposes for her college students as well as provide examples of what would work well with public school children. As some of her students have spoken out about not seeing the promise of technology use, she examines her role as an instructor and intuitively sees that as a sign that they are not seeing it used enough in practice.

In addition to modeling the technology use, Elaine finds it critically important to explore and find resources that could be available to the public schools. The responsibility is twofold as she would like to have the knowledge of technology available, but also have the ability to use them well enough to show her students how they can be use for the learning purposes. What adds to the difficulty is the appropriateness of programs relating to a variety age differences as she explains, "what is appropriate for a third grader is different from what is appropriate from an eighth grader.”

Taking the time to locate and find practical applications Elaine believes is a necessary and valuable activity. She recognizes and struggles though with her own schedule to fit in the time to search for resources and feels it's a commitment to stay current. As she states, "because there are so many things, one can't know everything, but its important to find out what is there and sample resources more.” She recognizes and acknowledges that it is a continuously evolving practice and that she must "be comfortable with that and be willing to stay with it.”

Reification. Discussing the procedures that help provide guidance to Elaine's educational community regarding instructional technology, she states that it can be challenging to set priorities on what the most critical issues are around the appropriate use of instructional technologies. The most prominent policies standing out in Elaine's 
mind are the ISTE standards that she feels are "pushing the way forward and they are probably doing that through the support and help of national organizations such state departments of education.” She states that the state departments have adopted the ISTE standards as requirements for courses and program approval. When Elaine thinks about her International Reading Association standards, which are used in the masters of reading program, she states that there is one section of their five major strands that addresses the appropriate use of technology.

The tools that Elaine mentions that help her perform her activities range from communication technologies, eCampus course management systems, video clips from CDs and DVDs, Adobe Acrobat Professional edition, and most currently survey development software. The communication technologies that Elaine uses most often for teaching and being in contact with her colleagues and professional organizations are mainly email, web-boards, listservs, and an instant messaging technology. She finds value in using the eCampus course management software provided for faculty for each of the registered courses. She again states that she mainly uses this as a "repository" but does find facility with the options and functionality available with it such as the grade book, web-board, email and chat features. Recently, Elaine has been using the audio commenting feature provided through Adobe Acrobat Professional edition to provide feedback to her students work. She finds functionality as well with this feature as she is working collaboratively with her colleagues on a research paper. The CDs and DVDs that she uses in class are for the purposes of showing her students video clips of captured instructional moments. The option to review and play the clips repeatedly for student 
observation and class discussion is a learning opportunity that could only be done otherwise during a live observation.

Currently, for departmental purposes, she is learning how to use Survey Monkey which creates online surveys for her fellow faculty and students to provide information into a database for the 5 year teacher education program. These are all tools that Elaine uses on a frequent bases and are included in her professional practice.

\section{Community}

Community Membership. The competencies that Elaine reveals through her participation with her educational community has included the roles of a leader, teacher and researcher in addition to the memberships she has to several university, statewide and national organizations. Regarding her participation in teaching and researching, she has received the college's award for outstanding teacher twice and the award for outstanding research once.

Elaine's relations among community members is that of both a leader and a learner. As she has administrative responsibilities to the college, she learns side by side with her fellow faculty. She participates actively in professional development activities focused on instructional technology as well as maintains connections and learns from her colleagues who have high technology skill level.

She assumes the position of accountability equally with her colleagues in the area of learning to apply and model the use of instructional technology in her classroom. She looks forward to the task, but proceeds with her own questions in mind when it comes to technology. Elaine as well seeks communication with the members of her community to proceed through this process of instructional change. 


\section{Dimensions of a Community of Practice}

Mutual engagement. As Elaine thought about and discussed how her community in higher education created patterns of relatively structured interactions, she mentions “As long as I’ve stayed connected to my professional organization and what people are doing in the way of teaching and research, it has helped me stay more current than what I would otherwise be.” When thinking about examples of how her community provides knowledge and competencies collectively, Elaine describes a research project that she and a team of colleagues collectively worked on that examined a web-based iterative commenting program that one of her colleagues in the college developed. Through the process of researching a new technology, Elaine found it very educating as well to be exposed to different forms of feedback a teacher could provide to her students. Activities such as this provided an opportunity for faculty to work and learn together in the area of instructional technologies they could use in their own teaching practice. She notes that she and her colleagues at times work collectively on the same document where “everyone is contributing to the work simultaneously and we send it as an email attachment to each other.”

Elaine views the key players and people who have a role in leading the charge with the use of instructional technology as two of her "good colleagues" with whom she shares the same educational background. These key players are defined as leaders to Elaine in the fact that they have a high level of skill integrating instructional technology and they are enthusiastic to support other members of their community with their knowledge and experience. Elaine describes one of the two people as a "model of leading the use of technology in instruction.” Due to this colleague’s interest in using 
technology, Elaine talks about how she would spend a lot of time exploring and tried new things that came along. She states, "she would try it and make it her own... and then she would teach others...Like me!" She notes that the first colleague was the "leader" and that the second colleague was a step behind her. Elaine describes herself as several steps behind the both of them, but is very grateful that they would be "so generous to take the time” to communicate and show her what they were learning. Enthusiastically, Elaine says “They would say, 'hey look what I’m doing now! They would invite me in and I always felt like it was an invitation to come along with them. They never saw me as someone who was sort of a stick in the mud and they were always willing to give it a go.”

What Elaine notices change though among the members of her community that has been built upon more traditional practices. With the use and development of online classes, she notices that the "community with your colleagues is really altered and transitioned. The people who are doing the most web-based courses may be seen the least.” As a person who finds great value in the face-to-face contact with students and faculty, she views technology as "changing the workplace and changing the classroom certainly.” Reflecting upon this change, she states "at the university level more and more students are preferring more web-based classes due to travel expenses and they find that they're more comfortable in their own work space.” Elaine again has questions of how technology is affecting her community and asks "What does it mean to be in higher education?”

Joint enterprise. Examining the overall aim and objective for Elaine's higher education community, Elaine discusses "that for a land grant institution like this university, it is part of our goal to reach citizens in all counties.” She is referring to the 
use of instructional technology that can provide access to students outside the university location.

To uphold the levels of accountability in teacher education programs, Elaine mentions the state department of education adopting the ISTE standards as requirements for courses and requirements for program approval. She states that for teacher preparation programs, the accountability and accreditation have changed because of technology. One specific requirement she mentions for teacher preparation programs is that the higher education learning institutions have electronic technologies available that would be similarly used in the classroom.

To note the responsibilities of the teacher education program, Elaine talks about the accreditation report and visit scheduled for the Spring of 2011. This institutional report will be submitted electronically as well as the "exhibits” must be submitted electronically. Previously, a conference room within the college would be considered the exhibit room in which it would become filled with "files, books, and all sorts of hard copy items.” Now, with the new accreditation cycle, all exhibits will be digitized and made electronic. This step requires members of the education community to make electronic copies of all materials, documents, meeting minutes, graphics, syllabi and more that is linked to their educational practice. Elaine says that the requirement of submitting the reports and exhibits electronically is partially due to the accrediting agencies, but the benefit Elaine states is that is "streamlines the process" as well as provides the ability for people to access it without being on site.

Also necessary documentation in these reports is the number of programs and classes that are technology-based. Elaine describes "technology-based" as courses which 
are $50 \%$ or more, which is what "most reporting agencies would consider being a webbased class when the content is done in this non-traditional way.”

Elaine describes that in the strategic plan for her educational community, which is part of the college's indigenous courses of action, that they will use instructional technology in their practice to offer as an advantage to their students. Specifically, she says, that there are sections within the strategic plan that refer explicitly to what kinds of technology will be used in the college.

One last thing that Elaine discuses as it relates to forms of accountability that contribute to the educational community is the requirement to address and report upon the professional development that is provided for faculty to keep them current of the latest technologies available to assist them in practice to the state department of education on an annual basis.

Shared repertoire. As Elaine discussed the resources available to her and her community to share knowledge collectively, she referred to the created and use of wikis in the college, the teacher education program, the Faculty Academy and the state department of education. She feels that the people in her community are using the technology well to communicate. The use of the web-based technologies provides Elaine with the facility to stay in contact with her colleagues as well as provide her with the opportunity to learn more about it through its use. A common online resource Elaine mentions that she and her colleagues use to work together on documents is Google Docs. She says that they can create, edit, provide iterations, and track the changes of a document they work on in a group. She finds that this makes the process of collaboration on documents much easier and helpful as the document can be shared. 
In addition to the use online resources that assist her community in their practice, she finds great benefit in being able to learn and share information and knowledge with her fellow colleagues. She feels that this has been quite influential on her practice as well as improving the collective capabilities of her educational community. 


\section{Narrative: Richard}

\section{Identity}

\section{Main Characteristics of Identity}

Learning process. Richard had always been interested in being an educator since the age of 23 when he decided that after the completion of his bachelors degree that he would return to school to obtain his teachers certification and masters degree. Richard completed his doctorate in curriculum and instruction with a science education emphasis.

Lived experience. Richard's states that his work in education began with opportunities to student teach. His initial work experiences involved "human health work" and he says that his first job was in public health which "had an education component” as he was employed as an "education specialist - training coordinator.” Later in his career, he became responsible for “doing a lot of in-service teaching for K-12 teachers.”

In 1995, he came to the university and began work for an organization that continued his experiences in the health sciences, but introduced technology as a necessary component for communication and instruction. It was his responsibility in this position to maintain communication with 50 to 60 teachers in remote locations around the state. He began the process of building websites so that both he and the teachers would have the option to communicate, conduct "in-service” functions and "weekend workshops and instruction.”

As Richard continued his work with the health sciences and technology organization, he later began to work and teach in the area of teacher education. Due to his previous experiences and higher skill level in applying instructional technology, he 
states, "as a teacher, I became more and more involved with giving more professional development” to his fellow faculty members.

As a full professor continuing to balance the health sciences and technology organization, teacher education and now providing professional development in 2002 he was asked to serve in an administrative capacity as the Associate Dean for Research and Technology. In 2005 he resigned from his work with the health sciences and technology organization and in his administrative position became more involved with "coordinating and working with other faculty and technology experts in the department with instructional technology professional development.”

Social membership. Richard serves in a leadership role as Associate Dean for Research and Technology, and the high level of competence he brings his community lies within the 30 years that he has been involved in various areas of higher education. The content areas Richard has mostly been involved in are the fields of health and science as well as using technology to enhance instruction.

Richard's initial exposure with instructional technology began when he started working at the university and learning how to apply instructional technology in 1995 in order to reach teachers around the state. He began his experience using technology for his classroom teaching and gained a reputation among his fellow faculty as a highly skilled member of his community integrating technology. Fellow faculty members participating in this study mention his high level of skill and knowledge in technology use and compare their skill level to his. One peer states, “Now I'm no Richard, but I learn as I go...” Another peer exclaims, “I don’t have Richard's skills, but I do okay.” Richard's proficiency with instructional technology has provided him with opportunities 
to lead and collaborate with faculty in professional development sessions for his fellow faculty such as the faculty academy.

As Richard is both a teacher and a mentor to undergraduate and graduate students in the curriculum and instructional fields, he has provided assistantship and research opportunities for his students through funding obtained through the Center of Disease Control for the health science and technology organization as well as funding obtained from the National Institutes of Health as a grant writer and Project Investigator (PI). He is a collaborator with his fellow faculty members as well in areas of research and grant writing.

Nexus of multimembership. When examining the membership and relations to the multiple communities in which Richard is involved, his participation provides him with a variety of roles and functions in each. Richard's various community activities include teaching and mentoring to students but also include involving them in his funded research projects in which he obtained funding with grant writing. As Richard serves as a teacher-leader to students, they serve as learners and collaborators in their projects. The same can be seen with his fellow colleagues. As Richard is working in leadership roles with professional development activities for faculty and working in developing research projects, they will collaborate in professional development activities as colleagues, collaborators and professional development partners in grant writing, research and the publishing of articles. These activities require a delicate balancing and multitasking of all of these activities.

Richard discusses the time in his career where there were several communities at once engaging in significant activities. In 2002 the health sciences and technology 
organization, in which Richard was involved, received funding from the Center of Disease and Control (CDC). During this project, Richard involved graduate students with web page design experience and provided them with graduate assistantships for the development of an informational and community-based-research website. Richard states, “The biggest project I ever did was from 2002 to 2005 where there were a total of six separate 'higher end' research projects.” The health and science technology organization website still remains on the CDC website and even though the project has been over for some time, the website still remains.

There was additional funding from the National Institutes of Health (NIH) in which Richard received for an additional research project. Richard states, "they [CDC and NIH projects] were going on at the same time and we were able to 'marry them' a little bit and also do a tremendous amount with technology.” From this research project, his students built project websites, develop PowerPoint presentations and then shared them over the Internet. Richard states that from the websites the students built, "they were able to share a lot of things - a web interface and evaluation designs for example.”

Additionally, Richard comments, "some of the teachers who were taking graduate classes at the time became involved as a part of that grant...The teachers would work on the research project and obtain course credits by taking a graduate course for their work.” During the interview, he noted that a few publications emerged from that project and a manuscript from this time was on his computer screen that was due that day of the interview. The article showed the students working with clients and participants in their programs doing some counseling and setting up walking tracks in their school. He found this to be very exciting. 
In 2003 Richard became increasingly involved in the college’s Faculty Academy. He states "There were a few thrusts going on at the same time...there was the coincidental launching of the Faculty Academy in 2003 and the health sciences and technology funding and project going on from 2002 to 2005.” As Richard reflects upon his role as a teacher, he states that he has become more involved with giving professional development directly. As he began to attend to his administrative role, he notes that he has become more involved in coordinating professional development activities "with other faculty and technology experts” who are also participants in this study along. Around 2005 he said he had to back out of the health science and technology organization and became more involved working with the Dean's office of Research and Technology. The review of Richard's involvement to various communities at once reveals also his evolution of his various communities in their stages of development as well his evolution in professional practice.

Negotiated experience. Richard's use of tools to assist and accomplish his teaching goals started with his use of computer programs. His teaching area was focused much more in human health work. He used body composition analysis and nutritional intake computer programs for "analysis purposes and to provide students and clients with results and not for direct instruction." He explains "I was an educator...so I would have my students use the computer for self discovery...to see nutritional intake for three days and then ask 'How does that look?'” Richard's interest was what information could be provided from the use of the computer programs, and he did not explore much else beyond those programs. 
As Richard came to the university in 1995, he was faced with the task of reaching his cohort of 50-60 teachers throughout the state to provide in-service for them from the university, and “especially all at once!” The model that was in place at the time would have required an inefficient and energy-intensive process of accomplishing this task. Richard felt he had to learn how to accomplish this goal "the right way.” Richard states that these conditions forced him to ask the questions, "How do we communicate with them [teachers]? How can we keep in touch? How could we start to form a community of learners?” For the first time in his teaching career, due to the circumstances of remote teachers, there was the chance to develop instruction on the Internet.

Recalling his initial trepidation with the process, Richard remembers seeking out assistance to help him learn how to accomplish this task. Richard recalls "I remember sitting down with a person who was very helpful to other teachers at that time begin this process of putting instruction online way back in 1998. She was showing how to use this stuff and I was struggling, but you know, I got it to work!” From his efforts, he developed a blended course, mostly online, and had some teachers for a class weekend workshop, while the rest were online.

As Richard thought about his own feelings of that time, he questions his own enthusiasm and believes that it was not his own motivation that initiated his work with web-based instruction. He states that his “job motivation to do it and be able to network with his teachers was necessary.” Looking back, Richard questions whether he would have pursued learning web-based instruction otherwise.”

From these experiences, Richard feels that he and his fellow educators have become a part of a "knowledge worker society...producers... and how to use 
[technology]. As a teacher, I have learned to be more of a facilitator now and that's great.” It is pleasing to him if he can motivate his learners to harness what is available to them through the Internet and feels that it is the "single biggest advantage" concerning the integration of instructional technology. Concluding his thoughts on the topic he states “That's how technology has changed my experiences. I feel like I've been more of a professional educator with helping people to learn to teach better.”

\section{Modes of Belonging}

Engagement. As Richard discusses how his identity has been transformed through his engagement throughout the cycles of his participation in the educational community's events. He comments on his involvement with the Faculty Academy. "As a teacher,” Richard states, "I’ve been giving more professional development directly.” The "ultimate" in Richard's estimation of engaging in his educational community's professional development activities has been the Faculty Academy. Since its inception, Richard states that he heavily participated first as a "learner" and then in the second year, as a learner and instructor "helping out a lot," and says that he "just continued doing so" year after year. Now in an administrative role, his involvement in the Faculty Academy has increased and he explains that his responsibilities now include "being in charge of it with a team of people coordinating it and working a lot with other faculty and technology experts in the college.”

One of the biggest accomplishments that Richard is pleased about is that he feels the Faculty Academy promotes interdisciplinary activity and allows people from different fields within the college to work together. Prior to the Faculty Academy, Richard says that he gave workshops that were more related to the health area and not workshops on 
how to be a "better educator." "Because of the technology," he has "done a lot more of that [workshops learning technology].” Thinking about the effects of how technology has affected the members of his educational community. He feels that they have all become more of a "knowledge worker society and producers in how to use the technology.”

Thinking deeper into how technology has affected his role and how it has changed his teaching experiences, Richard feels that it has had a "tremendous impact on his position as an educator" and feels that he has "become more of a professional educator with helping people learn to teach better.” Richard states that as a teacher and his methods of teaching, he feels that he has "learned to be more of a facilitator now" rather than teaching with a "direct instructional approach.” Richard finds great advantage and possibility with the access to information for the "motivated individual." Richard states, "if I can motivate that individual to harness what is out there, that is outstanding and the single biggest advantage to this whole technology thing!”

Through his efforts to integrate instructional technology, Richard feels that he's "had to become a bit mechanical" as compared to his previous teaching efforts in that “there wasn't the challenge previously to learn how to use the technology in order to teach....more specifically, how do you get interaction?” In referring back to his initial challenge to communicate with a cohort of 50-60 teachers around the state, he believes he was not enthused or motivated to integrate technology into his classroom. He did have what he refers to as "job motivation" to network with these teachers across the state. Even though a solution was found with the technology, Richard states that it is difficult to say what he would have done otherwise or if he would have made the same decisions. 
He jokes as he shares a humorous insight comparing people's different levels of ease and use of learning and adopting new instructional technologies. He notes that "maybe there is a genetic reason or possibly a certain environmental background that helps people understand new technology...or a child growing up with a father who was a handy man! Man, oh man! Are those people who can really get at it! My father was an undertaker...okay? So I have none of that!”

Reflecting on his technology use over his lifetime, Richard talks about going from using his manual typewriter to having a complete online environment to do his work. He is amazed with the pace of technology and that "its moved quicker than what I've thought and especially over the last few years, which has been difficult for me.” This is comment coming from a person considered by his community to be a "frontrunner" in the use and knowledge of instructional technology.

Imagination. Themes of "student empowerment" emerge frequently throughout Richard's discussion of the visions he has for his educational community. He would like students to feel more empowered in the classroom by providing a structure that helps students develop into "main contributors to the class" and to ultimately build, in Richard’s words, “a full learning community...Yes! A learning community!”

Richard explains his vision and he includes how the use of instructional technology would help accomplish his goal. When he thinks about teaching online, he would like to be able to sit in his office and provide demonstrations with the ability to shift his attention from student to student. He mentions using an application like Blackboard to help in this process, because he feels that "there are really good reasons for using that still.” 
Richard discusses how he would like to construct a classroom format in which students participate by each taking on different tasks of a project. Richard explains "We could divide one week's topic into five principle concepts that I've modeled a few times how I would like them to be presented using technology. But then every other student has a chance to do that each once or twice during the class." Richard explains, "As students become more empowered they can say, 'Hey, I can make something, I can do some research-library research...' They can try things out in my class as an in-service teacher and share with others in an enthusiastic manner as a participant in the course, not as a teacher in the course.”

Richard provides another example involving the use of reading resources and articles, and students sharing and presenting their reading assignments to the class. Feeling that it is a "simple concept," Richard explains that as the class would be taught online, students would share their articles with the class and at the same time, each student and teacher at their own location could access that article on a split screen. Enthusiastically, Richard states, "It could just bang-bang-bang and set that right up and we can use. It would be a set of things a student would have ahead of time. They would know they have to have "this, this, this, this" ready to go. That's the kind of thing I would like!” As Richard discusses his ideas, he notes that he does not intend for students to become the "teacher" of the class, but as "main contributors" through "sharing products, teaching other students in the class using their products, and to hopefully be enthusiastic about the process.”

Reflecting upon his visions and ideals for teaching with instructional technology and is reminded of his previous experiences with instructional technology. He finds 
some applications to be "still too cumbersome" and would like the technology to become more "transparent." Richard makes specific reference to desktop video conferencing and Wimba Live Classroom and he is motivated to make the experience teaching with it become more "seamless and because its affordable it can be available to folks." Other technologies that are a part of his goals involve the GPS and GIS units that are a part of a recently acquired grant that he is using for teachers.

\section{Trajectory}

Insider - boundary. Currently, Richard maintains an insider trajectory in his administrative leadership position for his educational community and feels that he has another eight to ten years left before retirement. Considering his future path, Richard states that eventually he will decrease his administrative role in technology in education and begin another path on a boundary trajectory. He will focus his efforts on his main interest which he describes as "the aspects of humans and environmental health...how connected they are from an educational standpoint..” This boundary trajectory has already begun, as he and a colleague just received an NSF grant in which technology will play a role. Richard explains that "this research will use new GIS software program called My World GIS and that they are going to use that software in conjunction with the GPS and use it to study watershed dynamics.”

\section{Practice}

Mutuality of Practice. Richard is involved with a multitude of educational projects and has the opportunity to work with different educational departments within the university. More specifically, Richard is involved in collaborative work writing grants and conducting research projects with other faculty and subject matter experts 
from other colleges in the university and has become aware that the interest and practice of technology integration "cuts across disciplines.” Richard states, "its use [instructional technology] is interdisciplinary! The applications and software used for the research projects are integrated and used in the different educational fields...especially STEM [science, technology, engineering, and math]. Richard also mentions are the links to health science and education.

Richard finds "great diversity in the college and there is a great deal of sharing and each of us get excited and there’s a good feeling when you go home.” Richard feels that the sharing and participation with others is a positive experience and that he and other faculty are learning to integrate technology and that "they are enthusiastic to share with each other.” Through the learning experience of integrating technology, he has been on both ends of the learning process being the learner and also helping people learn new software.

\section{Characteristics of Participation}

Participate in resolutions to conflict and change. Richard was quick to mention the Faculty Academy as he talked about the course of action and learning process he and members of his community engaged in each year to further their technology integration knowledge and skills. Richard and some of his fellow faculty first participated in the Faculty Academy in the year 2000, which was under the direction of a PT3 grant and continued annually for three years. After those three years, whether the yearly Faculty Academy would continue or not was up to Richard and his fellow faculty. Richard states clearly, "When the grant ended, we really needed to fill that void and we needed to be very specific about what we were going to do.” He and other faculty 
decided upon a planned course of action for the Faculty Academy in 2003 to "launch the development of online courses" and that "we needed to compete with other university's online courses.” As Richard holds an administrative leadership position, he is aware of the mixed opinions shared by his fellow faculty, but says "I know that some people just don't want to do it online, but we have to make some movement here." So, the established goal of the 2003 Faculty Academy as Richard described was to have participating faculty to develop an online course. Explaining the requirements of what constituted an online course, Richard mentions that faculty did have the option for the course to be "blended, but the major goal was to have the course $75 \%$ online." He states that the Faculty Academy that year had a small participation of ten faculty participants.

Although the participation in the 2003 Faculty Academy was small, in 2004 the participation doubled to over twenty faculty participating. Richard states "In the year 2006 we were up to a huge number of 32 to 33 ! That's a lot of faculty...that was almost beyond what we could really handle!” Providing a description of the Faculty Academy learning process, he described it as a "seven day working institute with the understanding that the faculty would receive compensation that was to be used in the summer as they continued working on and developing their course and they were required then to teach that following school year."

Support communal memory. Richard spoke about ways in which he has contributed his own individual knowledge and capabilities to his educational community. He has given more professional development sessions involving instructional technology now as an educator than ever before in his career. Specifically, one of the examples is his is his involvement in the planning and leading some of the sessions of the Faculty 
Academy. When it comes to activities in which faculty can collectively engage and share their knowledge, Richard has also been actively involved with the educational departments' monthly brown bag lunches and weekly colloquia sessions. These opportunities provide another avenue for faculty and students to collectively learn from each other and discuss important topics concerning their educational community.

Assist others. As he is regarded as having a high skill level when it comes to knowing and integrating instructional technology, he makes reference to the support available through the technology support center. Richard views the technology support center as a significant resource for both the faculty and students and mentions that he will direct his students there if they need additional technology assistance. He feels that this is especially important as students begin registering for class to become aware and skilled with the technology requirements of the class and that they do have help available to them if they need it. Richard remembers how he was assisted by the technology support available at the university 13 years ago when he was building his first class management system, TopClass. He states that this help was essential in enabling him to accomplish his task of teaching teachers at a distance across the state. Making note that "at times learning and teaching with instructional technology can be a struggle”, he expresses that the "technology support provided to the faculty and students is essential."

Perspective to accomplish goals. Richard spoke previously about the change in leadership after the PT3 project ended and made a specific point to begin its new directional goal of having more movement toward faculty developing more of their classes for online instruction. He realized that this was a "push" for some faculty, but again commented that it was necessary to move in that direction. On a much larger scale, 
Richard speaks of having two masters degrees now from his department that can be earned online which is a tremendous leap from just a few courses from an educational program. He states that "Some of our goals are to have complete majors online and masters programs online...those are part of our goals.” In stating these goals, Richard mentions that he is aware that there is a "threshold that we all reach" and makes a sarcastic reference to an older belief falsely filled with the hopes of financial gain saying “we're not limited by the classroom anymore...put more students in your class! You can handle that!" He broke the sarcasm with the reality of "being buried by emails" and the incredible difficulty a large online course can be for faculty. So as he discusses putting complete program majors online, he concludes by saying "we have to be careful."

\section{Learning in Practice}

Evolving forms of mutual engagement. In the later 1980's, Richard started to become interested in the use of computers as a part of the "broad educational picture" as he began to examine the possibilities of its instructional use. He makes note that this was a time before he had a PC to use for his teaching as well as a time before its use was "user friendly." His initial use of computers for teaching purposes focused mainly on analysis programs that provided students with results from nutritional intake and body composition data.

Later, during the early 1990's, Richard began to use the computer for communication purposes through email "quite a bit" but notes that before coming to the university, he did not use technology to deliver instruction. His use was mainly for learning himself, but admits that his "knowledge at that time was limited." This would 
change when he came to the university in 1995 charged with the task of communicating and teaching to an off-campus cohort of teachers located across the state.

As he began to look into building a website for this class to solve the problem of distance between him and the students, he enlisted assistance from the people at the university to help him build a blended course. Richard states that his course website "wasn't much," and that he used "the ol' Top Class" which was a course management tool that provided an online presence and structure for teachers to use. Noting the history of change and evidence that he has been a veteran of the university's use of different course management systems, Richard says, "this was before we had WebCT and so we used TopClass and then moved to WebCT....and I did chat rooms.” He became interested in researching and analyzing the dialogue captured by these communication tools. He incorporated the use of discussion boards into a couple of studies that were then published and states that he "did quite a bit of that in the late 1990s up until 2000.”

One significant interest that is still today "very important" to Richard is the use of concept maps. Richard mentions “I hadn’t really thought about it this way, but that concept maps is one reason why I became interested in instructional technology more so, because it was available, the concept maps, electronically!” Describing the difficulties of making a concept map by hand, he states "who likes to erase all the time?! And whoa! This is wonderful!" Richard states that he "immediately got into using electronic concept maps" and that it was one of the "biggest draws" for him. He soon got to using Inspiration, which is a popular electronic concept mapping tool and that it has become "advanced and that there is a tremendous amount that a person can do with it." The use of Inspiration electronic concept mapping for him was one of its "biggest draws." 
The next step that Richard took with his use of instructional technology was the process of website building. He would use the web-authored sites he created for his courses rather than the use course management tools such as TopClass or WebCT that he used before.

His interest in website building started with the beginning of the PT3 grant that provided a two week Faculty Academy. Richard states "I really liked that and I learned a lot of that [web site development] through the grant... So that had a tremendous impact on me.” The website that he created for his science education course in the initial years of PT3 grant in the year 2000-2001 is still working and functional. He still maintains and uses this website for his course. "Its really functional, but its kind of embarrassing is that I have not updated it and so compare mine to a person’s who has just been building them recently and I mean, mine looks archaic!” He states that the site still works really great, but due to a lack of time, he has not been able to update it. Richard feels that this course has "history and functionality" and from the experiences and learning he gained through the PT3 grant, he was able to build a course website for the health and technology organization.

An important step for Richard working with his students using instructional technology is that he wants them to feel empowered. He notes that he feels he is "making small steps" in that area and "what I'm able to do is when we have a common assignment where the students could use technology and in some cases where I've put them together, they've come up with a lesson, they'll post it, they'll get up in the front of the class and they'll tell us." 
Richard continues to develop instructional technology, "moving to a higher end now, I have a web-based course.” He explains that last summer was the first time he taught a fully online course and only had them face-to-face for a week. During this course, it was the student's task to put together the results of what Richard describes as a "robust investigation" and then construct a PowerPoint presentation in which they would present it online from their different locations using Wimba Live Classroom with each one of the PowerPoint presentations available for each student to see. Again, striving to provide empowerment to his students, Richard states that he "gave them the teacher's role and circulated giving presentations.” As he reflects on the experience, he recalls that they had problems with the Live Classroom technology, but that it was quite successful.

Richard also created a "fully approved" online graduate course that he has taught three times. The graduates do a good deal of work with Excel and online national databases.

His most recent example with graduate students was that "graduate students gave PowerPoint presentations of a project they developed for their own future students using GPS and GIS.” Through a threaded discussion, the students took the whole class through their PowerPoint presentation showing an example of what might be a one of their student's work and then "harnessing other internet sites while they were presenting this." Richard felt that this type of presentation was "sort of powerful" in that "the students could initiate their own threaded discussion, give their presentation on the internet, while using other internet sites to add depth to their work.” Richard reiterates that one of the students' tasks is that they initiate their own threaded discussions. 
One of the last instructional technology applications Richard talks about trying to incorporate is the use of Horizon Live Classroom "as an expert.” He explains "The first time I used it, it was a disaster...but the second time, it was $100 \%$ better, but still not very good.” Having the initial frustrated experiences with the application, he continues to believe that this is a valuable tool.

While thinking about the positive and negative qualities that instructional technology has provided his university, he returns to his environmentally conscientious roots. He notes the initial estimate that the use of computers and the Internet would save paper was a "tremendous miscalculation!" Richard notes that as an instructor, he tries not to print out too much, but states "I get burned out looking at the computer screen so much that I say, 'I’m not going to correct another assignment online!....and then I just print 'em!”

When Richard thinks about his progress and use of instructional technology, he reflects that his earlier days of teaching did not necessarily require technological competence. “I feel in some ways less competent than when I didn’t have the technology. When I did not have the technology, I felt very competent. Now, I have to be competent with the technology as well with my teaching.”

Understanding and tuning their enterprise. Richard's alignment and coordination of energies to larger communities of practice is represented through his actions of writing, being awarded, and carrying out grant activities. The science and health grants that he has received have been from national organizations such as the Center for Disease and Control, the National Science Foundation and National Institutes of Health. The funding provided by these grants have afforded Richard, his colleagues 
and students, learning opportunities and the ability to help the university community further define, interpret and reconcile their understanding of their community's missions and goals. The knowledge and information gained through the grant activities are published in peer reviewed journals to communicate the findings to larger educational communities of practice. Some of the grant activities have included the development of desktop video conferencing for educational communication purposes, website development for health and science education, as well as learning GPS and GIS applications for instructional development. Richard states frequently the importance of receiving funding from the grants as it has provided learning opportunities for his educational communities that they would not have otherwise. These learning opportunities help further Richard's educational community’s missions and goals and help it further define its engagement in practice.

Developing their repertoires, styles, and discourses. The resources that Richard uses to aid and support his sustained engagement in practice for his science education courses are plentiful. He cites technology applications that he uses in his teaching with his students. He is quick to mention his use of the Internet and feels his is knowledgeable in finding "reliable websites” for resourceful information. An online resource that Richard expresses great interest in is the National Academy of Services Press E-Books and states that "it is a goldmine of books that you can read right online and there are other resources associated with that!” What he finds surprising is that each new group of students that comes through each year is unaware of it and has never heard of this resource. 
Another valuable online resource is the Environmental Health Perspectives from the National Institute of Environmental Health. As Richard describes the enormity of resources available from this source, he mentions that there are students sites available as well. With enthusiasm, Richard continues, "I could espouse on and one about all of these resources and I still wouldn't cover all of it!” Stating that he had a science methods resource website available for his student teachers and he "still could not cover the number of sources available.” He wanted his students to harness these online resources and other sources like them for their own use in the classroom.

During professional development leave in 2006, he was able to learn how to use geographic information systems software, or GIS. He jokes by calling it "the granddaddy of software" but is serious when describing how difficult it was to learn. "I thought Dreamweaver was complicated and it can’t hold a candle to GIS! It was very difficult, but nevertheless, I was determined and I was going to learn it!”

Richard views GIS as being “robust” technology. Students can take the application outside to gather readings. The readings can be quickly transformed into an understanding of the differences in their environment. Richard feels that it is a tool that can "create knowledge on the spot as they can see the differences displayed in the GIS readings!” Its use can also be used across educational disciplines. Specifically, "It can be used a tremendous amount in geography and geology as well as in the health disciplines. Both of these are very useful in civil engineering and in non-motorized transit studies.” As an educator showing other faculty how to use the GIS software, he influenced peer faculty to incorporate it into their own education class. Richard's use of 
GIS will continue in the future with a grant from the National Science Foundation he and a colleague worked on together.

Richard cited the importance and value of live demonstrations available on the Internet for science descrepent events. Descrepent events are demonstrations and experiments where something occurs differently than what students cognitively would expect, and can lead to questions and further experimental interest. Richard views the live demonstrations as "rich learning environments" where students have the access to the demonstration as well as the safety from the experimental elements. His primary interest would be for students to have hands-on access to these experiments. He also acknowledges that student safety is always a priority, and they may not have access to the materials in which the viewing the demonstration on the Internet is beneficial.

Another technology resource that Richard has incorporated into his science education courses is the Globe program that is NASA-based. Globe is a science education program originally developed in 1995 for grades 5 and above. The Globe program enables the young students to take data that they have collected from one of their lessons in the program and upload it to a Globe national database. It comes with a binder full of educational units, lessons, materials, activities and a website in which teachers can use in their classrooms. Richard became very interested in the Globe program even though his students were kindergarten through grade 4 pre-service teachers. Three years ago, Richard made arrangements for the Globe program to be used in his classroom "because of the technology more than anything and the information that a student could link to.” The Globe program has been updated and now starts with Grade 1 and above. The educational are extensive and Richard feels it is unfortunate that he can 
not use all of the contents of the program in his course, but finds that it is a wonderful resource for students to see and potentially use in their own future classrooms.

Richard finds the use of Excel for his science education course. Believing that there is great potential in Excel, a spreadsheet application, Richard explains that it is a technology that "cuts across disciplines” as he uses it in a course for science and math educators. He says that Excel could also be used as well with geology, geography and math education. He notes “I learn a little bit of it and I want to do more, but I don't have the time."

In addition to Inspiration, Richard mentions using PowerPoint presentations for an online class in place of teaching as he does not believe it is quality instruction. Although he does see its value in the use of presentations, he becomes wary when it is used as another tool to convey information. Comparing PowerPoint to a lecture, Richard states, “I do not believe that PowerPoint is superior to a lecture. Although I don’t believe a lecture is the best form of instruction, the lecture can be spontaneous... and I can react to a student. If I'm teaching along and someone has a question and I'm just in the zone of clicking through my PowerPoint... I don't feel that instructional method is superior.” He discusses the developmental process of creating a presentation and states that it is important to be cautious in how much time is spent creating the aesthetic quality of the presentation rather than the instructional components. He says, "I know I’ve gotten caught up in the look of the presentation and spending way too much time trying to make it look good."

Another technology application that Richard questions is the use of Podcasts. As he is aware of their popularity and their increasing use in education, he makes reference 
to the use of PowerPoint presentations and states that the Podcast instructional method is similar in that it is a "one way" information providing technology application. He notes that he realizes that folks are excited about its use, but he currently remains skeptical about its use.

Richard mentions the use of EndNotes as a useful technology tool, which is an application that works as a database for the storing and categorizing of articles and information for research purposes. He was interested in getting EndNotes for his fellow faculty and providing training sessions for them. Training sessions for this application also occurred during the Faculty Academy. Richard talks about his own experience with using EndNotes by saying that "I started my professional database on a couple of topics and got enthusiastic about it and for about two weeks I kept it up, but that's it... only for about two weeks.” He expressed his disappointment explaining that due to time constraints, he had to refocus his efforts toward his previous commitments.

Lastly, Richard quickly mentions the use of email and stating that he and his colleagues email back and forth quite often. He felt that the email use was a benefit in that it helped reduce the amount of time "chit-chatting." As he states that he enjoys talking with his colleagues, but that it is "really easy to lose time" and email provides an advantage to overcome that.

Different from the technology tools and applications mentioned above, Richard discusses the tools that help him and his fellow faculty engage in practice. Richard first discusses the use of eCampus. His comments reflect his own history and experiences of the process of getting a course website supplied by the university. Richard states, "No longer does your department need to have a contact person that has to list your course and 
let you know that you want it online...No! They're automatically generated! The shells are generated!” As every course taught in the university has an automatic online shell available for use, Richard is quick to mention that this was a tremendous incentive for faculty to use and was pleased that the university "has come far enough along that we can afford to do that for everybody.”

Many years prior to the development of eCampus, faculty could create their own websites from software such as FrontPage and Dreamweaver and have their course websites uploaded to display from their department's server. When the Faculty Academy was under the direction of the PT3 grant, website templates were developed and provided to faculty for the facilitation and use toward the development of their own websites. Richard was a participant in the initial Faculty Academy run by the grant. The course he developed at that time is still being maintained and used for the same course today. He found the templates to be quite useful and expressed his delight in being able to provide the templates with other faculty. Believing that the templates were tools that helped facilitate the development of faculty websites, he states that "this is a process that we have continued." Believing that there was potential in the availability and use of the templates, Richard talks about making them available to faculty on a CD in which they could take and build their own website. He hoped that with their development, they could then share their work with their fellow colleagues and it could inspire other faculty to think, "She developed an online course...I think I could try do that!"

A tool that Richard has frequently incorporated into his instruction for his students as well as provided informational sessions to his fellow faculty on how he uses this tool in the classroom are the use of rubrics. Richard explains that "rubrics can be a 
tool that can assess how someone else constructs information to present to others.”

Richard saw the opportunity to use rubrics to conduct peer reviews online. He found that this saved time in class by pairing up students to review each other in class and then providing his students with the rubric online.

He was quick to mention the opportunities faculty had during the Faculty Academy each year. There were also "brown bag lunches and colloquiums" scheduled throughout the semester that provided faculty and students the opportunity to see and talk about each other's work and specific topics of discussion. He said that he wished there where more opportunities for faculty to talk and share with each other what they were doing in the classroom.

Richard cited wikis and threaded discussion could contribute to the sharing of information among his fellow faculty. Richard explained that he and colleagues share "a tremendous amount of information on the preparedness of a course" mainly through the use of email. He then began to say that he could do more communication through blogging or contributing to a wiki, but that at this point in time, curtailed this undertaking. Although many of his colleagues already used threaded discussions and that it would be a benefit to have a discussion board, the lack of time available again limited his participation.

Snapshot of Instructional Technology Use. Upon entering the classroom where Richard teaches, one becomes immediately aware that there is an educational science element. The room is very crowded with large metal cabinets lining the one side of the room, and elementary science educational posters decorate the cabinet doors and the walls of the room. There are long connected tables where students sit in the shape of half 
circle. A teacher's table sits in the front of the room. Several chairs outline the long tables and the teacher sits at the head of the class. All students can see each other as the students are essentially sitting in a circle. An Internet-connected computer control console is also located in this front left corner by the teacher's desk for easy access to control the LCD projector which displays on the overhead screen. The screen is located in the front center of the room and large dry-erase boards sit on each side of the screen. The room is crowded as students take every seat around the tables. Their attention is facing toward the front of the classroom where Richard sits among them at the head of the class.

Richard is on the computer and is having trouble pulling up his website. Barely audible, he quietly asks himself, "Is the technology working?!” Continuing to work with the computer he finally has success accessing the website that he created for this course in 2000 he and continues to update. Pulling down the overhead screen and turning off the lights, Richard uses his website as an overhead to go through and talk to his students about a classroom activity. Richard goes to the computer and returns to the course website and displays a different online page titled The Learning Cycle.

The webpage displays a circular chart that includes writing and pictures. Richard asks a technology skill related question about the chart before beginning his discussion about the instructional elements of the chart. Pointing to the chart, Richard asks, "Why must you save this as a jpeg?” He is asking about their knowledge and skill of the software that is used to create the chart. The room is silent as the students do not respond to his question. He then asks, "Who has not used Inspiration?” referring to the software used to create the chart. The students turn to each other and nod their heads indicating to 
Richard that they all have. He confirms with them again that they know how to save the chart as an image and then moves on in his discussion. Richard explains that the Learning Cycle chart displays the "big picture” of the students' created educational models. Richard's example of the Learning Cycle provides an example of an educational activity that uses concept map software necessary to complete it. The technology software provides the students with the structure and capability to organize their Learning Cycle educational model.

Richard moves onto another technology-related question and asks his students if any of them have posted their Learning Cycles to the eCampus discussion board, which is also available for this class besides Richard's own course website. This task would include the knowledge necessary for students working with concept maps. They would need to have the knowledge to save the concept map as an image, and they would have to have the knowledge to save the concept map with any text, pictures, audio or video files included. Richard is interested in their technology skills to accomplish this task, but is also interested in using the discussion board as a way for students to share their work and development on the Learning Cycle to their classmates.

Richard then discusses the topic of using rubrics for evaluation purposes. As he mentions evaluation, he works on the computer in the front of the class to display an online rubric through the overhead projector. The students refer to papers in their notebooks as they have the rubric webpage printed off. Richard walks through the online rubric, while the students take notes as he provides examples of what students can do with the rubrics. Richard would like his students to see how they can use this rubric as a 
tool in their classrooms to evaluate their instruction on science education related principles.

Returning to the topic of concept maps, Richard begins to discuss how it can be used as a tool to develop instructional models, which relates directly to the Learning Cycle project. Richard once again returns to his course website from his computer and displays a webpage from a section titled “Technology Supported Course Components” and selects a hyperlink titled Concept Maps. As the website displays on the overhead screen from the LCD projector, students can read from the concept map website that is rich in description concerning the educational theoretical background of concept maps, as well as hyperlinks describing its use. He describes the robust nature of the tool for their use, as well as how they could be used for their elementary school students.

Richard emphasizes how concept maps can be used to promote visual literacy skills of the learner. To display a hands-on version of creating a concept map, Richard picks up a large portable dry erase board from the floor and places a pile of different colored sticky notes on the desk beside him. Facing the class with the board in front of him, he asks his students to give him a word so that he can begin to show them the development of a linkages and connections that can be made in a concept map. Richard remarked that this is an "older form of concept map development," and that they were going to spend the last part of class in the computer lab working with Inspiration software to create their own concept maps for their Learning Cycle project.

The students collected all of their belongings and went out the door one-by-one to the computer lab which was next door in the technology support center. It is a smaller computer lab that commonly holds classes. Students again take a seat behind a computer 
and drop their book bags on the floor beside them. They turn on the computers and Richard walks to the front of the class to the computer console to bring up the Inspiration software. Richard has switched instructional modes as he initially was working with his students on science education instructional concepts and now was focusing his attention on teaching his students how to use a concept mapping software in a computer lab.

Richard has a concept map fully developed for instructional demonstration purposes that includes text, pictures, audio and video files. As Richard talks, the students all have Inspiration opened and displayed on their computer screens and some are experimenting with the options available on the software. He walks the students through his concept map example and the students are engrossed in their newly created concept maps. Every single computer screen is displaying the Inspiration software and no one is tempted to go off task to check their email or surf the internet. The room is very quiet other than clicking, but the computer screens are very colorful and displaying concept maps unique to each students' ideas for their Learning Cycle.

Students spend the last part of class working on the software in the computer lab and have access to Richard if they have any questions. He walks around the room and examines their work row by row commenting on Internet sites where the students can access images and videos for educational use. There is still no discussion among the students themselves, and they use the entire time they have left to try to work on their projects. As class begins to wind down, Richard asks his students that they keep their young learners in mind as they develop their Learning Cycle. The instructional technology Richard chose to use for his course is displayed in Table 33. 
Table 33

Instructional technology used in Richard's course

\begin{tabular}{|l|l|}
\hline \multicolumn{2}{|c|}{ Web \& Computer-Based Technology Used in Class } \\
\hline Instructional Technology & \multicolumn{1}{|c|}{ Participant Choices } \\
\hline Course Website & $\mathrm{X}$ \\
\hline $\begin{array}{l}\text { Web Authored Course } \\
\text { (Dreamweaver/FrontPage) }\end{array}$ & $\mathrm{X}$ \\
\hline eCampus & \\
\hline Wimba & \\
\hline Textbook Website & \\
\hline Textbook CD & $\mathrm{X}$ \\
\hline Subject-related web resource & $\mathrm{X}$ \\
\hline Communication & $\mathrm{X}$ \\
\hline Email & \\
\hline Discussion Boards & \\
\hline Listserv & \\
\hline Chat & \\
\hline Instant Messaging & \\
\hline Technology Used in Course \\
\hline PowerPoint & \\
\hline Video & \\
\hline Simulations & \\
\hline Wiki & \\
\hline PDF Documents & \\
\hline Inspiration & \\
\hline Wiki & \\
\hline Microsoft Word for presentation & \\
\hline Microsoft Excel & \\
\hline Online Libraries/Journals & \\
\hline Online Journals & \\
\hline
\end{tabular}

\section{Meaning}

Negotiation of Meaning. As Richard reflects upon his experiences with

instructional technology, he begins his discussion commenting on how quickly computers and the Internet became an important part of the educational process. He views the use of instructional technology in education taking a "big jump from where it was previously 
just progressing along for years with the computer and then rapidly accelerating with the introduction of the Internet.”

He sees the Internet as a wealth of resources and information that is "untapped” in which his students and other teachers could benefit. This information in Richard's opinion, is one of the biggest advantages to educators, and he would like to see "students harnessing the power of the Internet and use it to present to their colleagues.”

Richard believes that the use of technology will increasingly be used to solve problems not just in education, but also in areas of health and the environment. As he thinks of his own role as an educator using technology, he clarifies his intentions by stating that his "major interest is not toward a specific piece of technology, but the solving and working toward the solutions to problems... and that will certainly have to do with the use of technology.”

He believes his colleagues view instructional technology positively. He and others attend professional development sessions, because they are interested and enthusiastic to learn and share with each other. "Folks are realizing how much they can do online, but it is important that they test the waters first.” Richard's enthusiasm is mixed with caution as he comments on the larger workload comes with the integration of instructional technology.

The use of technology can sometimes be viewed as synonymous with efficiency. Richard realizes that the use of instructional technology does not lesson one's workload, but creates much more and time management is essential. He says "we're on this electronic leash as educators” reflecting on the need for educators to establish boundaries between work and home life. More specifically, Richard refers to the need for "adult and 
family time” as well as setting guidelines for students expectations concerning his availability or lack of availability out of the classroom and on weekends. Expressing serious concern, Richard says that he recognizes the stress that the use of computers and the Internet has had on his fellow colleagues. He sees "a lot of people handling three times as much work as what they would have if not more...and it just goes on and on.” He is cognizant that he and his faculty have a threshold and limit to the amount of work they can do and feels this is the one disadvantage of the use of technology. Richard remains positive in his conversation about the opportunities that technology has afforded his educational community, but he proceeds integrating technology with caution.

Participation. Richard discusses what he finds to be beneficial in working with student teachers learning to use and teach with technology. They can come back from public schools and share their experiences with their peers. "They'll try some stuff with their kids, and some will work and they'll come back and be real excited!” This accomplishment he believes is not enough. Richard feels that there are a "tremendous number of opportunities to access information and use it in an empowering way especially when teaching online.” Richard hopes that working together with his students and providing access to quality information will create a better educational experience for everyone.

Again, mixed with Richard's enthusiasm is a note of caution. Acknowledging the considerable acceleration in the technologies available to education, he notes that at times his educational community has "embraced the technology instead of the learning, as we've become so enamored with the technology.” He finds that it is easy to become "swept away" with the technology only to realize later that he has become "overloaded," 
which can lead to a "loss of time in the classroom." In his experience, Richard states that he did not want to lose any more class time and needs for his teaching time to be "automatic." He does not want the "teaching moment" lost with the delay or clumsiness of an instructional technology, but rather that the flow of the teaching process be "automatic.”

Richard says that keeping up with the newest technologies can become burdensome at times. When he makes instructional decisions, he compares the use of new technologies to his current teaching practices to evaluate if there is a benefit in using the new technology. Richard feels pressure that "people want you to always use technology for learning,” but he admits that he “can’t always see adopting it versus to what he is doing already.” Richard wishes he had more time to read his professional journals so that he can be more helpful and "stay current" with his doctoral students who want to do research. Referring to a large stack of articles on his bookshelf, he states "I should be reading this so that I can help them in meaningful ways and to keep current.” Richard finds that even though he may have "flex time," he feels that he does not have time he previously had before to read his professional journals and would like one uninterrupted afternoon of his work week to be devoted toward that activity.

Reification. Richard states that he is unaware of any guiding policies directing his educational community's practice toward the integration of instructional technology, but he does mention that there are "incentives" for those who participate in the Faculty Academy. Richard explains that “we've set forth incentives and stipends provided to faculty attending the Faculty Academy that have been put in place for a number of years now even back to the PT3 grant.” Faculty who attend the Faculty Academy and receive a 
stipend are then required to develop and teach a course that is $50 \%-75 \%$ online to completely online for the next school year.

Beyond and policies or protocols, Richard feels pressure that "people want you to always use technology for learning,” but he admits that he “can’t always see adopting it in place of what he’s doing already.” Expanding upon this point, he remarks, “we're feeling stressed to incorporate the better technologies, the things we learn through the semester and we need time to learn the technology as well as how to incorporate it.”

Being aware that the university does have "guidelines in terms of privacy and plagiarism, safety and terms of use and intent,” Richard again states that he does not know of any specific protocols relating to the use of instructional technology. Richard carefully chooses which tools to adopt for his teaching practices and he discusses what guides his decisions of which instructional technology to use for his classroom. A large part of his instruction incorporates activities such as scientific experiments and live demonstrations. He prefers for his students to learn through authentic hands-on experiences, but internally he struggles with the issues of safety. Richard states "we live in such a litigious world that we must be very careful to what we expose our students to.” He is aware that he can find his experiments and live demonstrations online, but questions the quality of the learning experience in comparison to hands-on activities.

One example of a technology that provides a hands-on experience is pleased to begin incorporating in his instruction is the use of GPS and GIS technology that has infrared sensors for collecting ground surface temperatures. These tools provide preservice teachers and their young learners with instant data to compare environmental temperatures in their immediate surroundings. "You can take them out and they can 
compare the temperatures of the blacktop parking lot to a grassy lot and instantly see the difference. These are very teachable moments!”

Admitting that he has strong feelings about the "environmental mission," Richard says that he knows teachers are not supposed to transfer their beliefs onto their learners, but as an educator, he would like to have some affective changes. He likes to see that it makes the teaching fun for the teachers and also it "gets the kids excited to learn."

Technology such as PowerPoints and Podcasts do not appeal to him. He finds that although these two technologies do "convey information, the instructional component is missing."

One tool that Richard would like to become more familiar with is Wimba Live Classroom. He states that when he was first introduced to it at a time when it was Horizon Live Classroom, he says that "it was one of those AHA moments!" As that experience was two years ago, he became more familiar with it through the aid of another colleague who he coins as an "expert" because of her familiarity and use of it. Richard is pleased with the possibilities Wimba provides, but finds that this technology is "just not seamless enough" to where he feels comfortable and confident using it for his classroom. He states, "for me to be savvy with it, I'll have to use it like 10 times in a row." Currently, Richard feels that there are still some problems with it and "too many layers" but he does see the possibility in its use.

For his own classes, Richard uses a combination of Dreamweaver for his own course website as well as eCampus for the email, discussion board and posting applications it provides. For instructional purposes, Richard incorporates the use of Excel and Inspiration in his classes. Richard also uses the campus email provided to 
faculty, students and staff to communicate with his colleagues and students beyond the eCampus email which is strictly for the use of specific courses. As Richard is an advocate for the use of instructional technology, he carefully selects which technologies provides the most appropriate learning experience for his students.

\section{Community}

Community Membership. Richard maintains a leadership role in his educational community, especially in the field of technology. He also serves as a teacher and mentor to both undergraduate and graduate students in the fields of education and curriculum and instruction,. He quite often is the Principle Investigator on a number of grants from national organizations as he is involved with other educational communities within the university through collaborative grant writing activities. Richard is regarded by his peers as being highly skilled and competent in his knowledge and use of instructional technology and leads his educational community in professional development sessions as well as the Faculty Academy. Richard is a believer in professional and educational accountability and has developed, demonstrated the use of and utilizes rubrics often in his educational practice to evaluate his own teaching practices as well as his students.

Mutual engagement. When describing activities that his educational community engages in to provide knowledge and communication collectively, Richard discusses his active involvement in collaborative grant writing activities with other colleges within the university. He finds this experience to be "wonderful" as it enables interactions among educational programs so that there can be a greater degree of contribution to the larger educational university community. Currently, two of the three grants that he and the another college worked on have been accepted and he awaits the result of the third. 
Richard notes that the ability for him and the other college to work together and collaboratively share and develop documents has been "facilitated by technology." He says, "I'd hate to think how we could accomplish this without being able to transfer the documents back and forth with technology!”

Another grant from the National Science Foundation in which Richard collaboratively wrote with other colleagues and is currently engaged in, involves working with elementary school teachers throughout the state using GPS and GIS technology. For this grant, the teachers will "become leaders" in the use of this technology along with other software and the use of probeware.” These teachers will become knowledgeable with the instructional use of GIS and GPS technology, and to teach other teachers.

When discussing how people from his educational community come together to work toward a goal that involves the integration of instructional technology, he is quick to mention the Faculty Academy as a professional development experience for his colleagues. Richard discusses that he joined the Faculty Academy planning community and states that "for the last three years, we have formed a community in terms of planning our Faculty Academy and we've worked throughout the whole school year planning for it.” He notes that this activity has had a significant impact on his colleagues. In addition to the Faculty Academy, he notes again that there are scheduled "brown bag lunches and colloquia sessions" throughout the semester in which faculty and students can collectively come together and learn from each other.

Richard discusses that he feels that a stronger educational community exists on more of a professional development level, and that he does not feel too much a part of an educational community that uses technology at the course level.” Explaining further, 
Richard says, "We have multiple sections of an undergraduate methods course and we really have to consider ourselves as faculty members a part of that small community.” He describes that this course has had graduate assistants and adjunct faculty teaching these different sections of the methods course in the past. What is unfortunate is that those are people who will eventually transition to other work opportunities which results in a constant turnover of teachers for that course. The educational community for this methods course is constantly changing. Richard notes that his "ideal circumstances for this methods class would be to create four to five sections in which instructors could work as a community and contribute equally." Declaring that he "is usually the one that has tried to build this small community," he admits that "there has not been a whole lot of community effort.” Richard is aware of an example of this working for another group of faculty in which a peer is a part of and wishes that he could create the same kind of community for this methods course.

Joint enterprise. Richard states that his educational college's overall mission "very simply is to provide high quality instruction to their students." Turning his comments toward his own subject area, he says that the science education mission is to "focus on graduating more STEM teachers," which will teach in the subject areas of science, technology, engineering and math. It is more of a "mico-mission" of his department, Richard states that it is part of the big picture because the STEM education is currently a large national educational focus. Richard is encouraged to work toward that mission as well as being aware that there national organizations that will provide grant funding to realize this mission. 
Richard also mentions that the college has a strategic plan that is in line with the university’s mission toward using instructional technology in their courses. "In fact, I had it up [on his computer] right before you came in!” Richard was working on linking the college's strategic plan to a grant proposal he was currently working on. "When we work on a grant proposal, we want to articulate how the focus of the grant is related to the strategic plan we have for our own college and university.”

Quick to mention, Richard discusses that the external funding provided from grants from larger national organizations has given his educational community opportunities to work toward his own educational community's goals. He feels that the monies received from these organizations such as the CDC and NSF is extremely important toward the forward progress of his community’s own missions.

Shared repertoire. As Richard discusses the resources that are available to his educational community, he initially mentions the Faculty Academy as well as the technology support center. "We have three experts that work in the technology support center full time, as well as graduate students who are willing to help us at any time!” Noting that these are people who do not do the work for faculty, but rather they are valuable to the educational community for areas of "trouble shooting." He feels that the "human" resources available is an important part of his department and that they provide structure as well as support a location [technology support center] where people can come together to learn from each other.

Richard also mentions that he feels fortunate that his college hired a new faculty person who he finds is a "very knowledgeable person in the area of instructional technology" and a "wonderful resource" that he works with during the Faculty Academy. 
He mentions as well that this is a person who is "very interested in helping other members of his educational community learn more about how to use technology for their own classes.”

Another resource that has been created for Richard's department is a wiki to provide another place for faculty to share and communicate in hopes to build an online learning community. Richard finds that the intentions of the department wiki are for faculty to "update each other and work like a little community." Richard expresses that he is "beyond his threshold right now" and regretfully has not participated, although he feels that this is a good attempt for faculty to have another place to learn from each other. 


\section{Introduction to the College of Education Teachers}

The following information will present the three college of education teachers case studies of Ruth, Wanda, and Charles. Only one of the three teacher participants teaches one course in the teacher education program. The other two teachers teach courses in different areas in the college of education.

Ruth is a full professor who has been teaching in the college for 30 years. She teaches off-campus courses in educational leadership. Wanda is a full professor who has been teaching for the college for 34 years. She teachers courses in speech pathology and audiology. Charles is a full professor who has been teaching for the college for 21 years. He teaches courses in teacher education and social cultural foundations. 


\section{Narrative: Ruth}

\section{Identity}

\section{Main Characteristics of Identity}

Learning process. Ruth believes she was motivated to become a teacher in the $3^{\text {rd }}$ grade. She and a few other students in the third grade were asked by 2 of their teachers to sit with the first graders while the teachers had their lunch. Ruth exclaims that there were three of the them who would be in charge of the first grade classrooms at different times. She realizing later in life that it was really more about control and disciplining the first grade students than it was about teaching. This was a significant experience in her life, it ignited her motivation later to become an English teacher. She received her undergraduate degree in education to teach English. She later went on to get her masters degree in curriculum and supervision and then later her doctorate in curriculum and supervision. She studied teaching in both programs. She states that not only was she trained as a teacher, but she learned how to study her teaching through her graduate work.

Lived experience. As Ruth began her career in teaching English in a junior high school over 30 years ago, she decided that she wanted to become a graduate student assistant to gain experience teaching in higher education. She co-taught with several faculty members, and Ruth feels that this inspired her to want to eventually work in higher education. After she graduated with her doctorate in 1981, she thought it would be a good idea to start to practice interviewing for a job. Her first interview was with the university and she laughs, “I decided to take the job...so I guess I didn’t have to practice 
interviewing anymore!” Ruth works as a full professor in the area of educational leadership studies and has been with the school ever since.

Social membership. Ruth has been a member of this educational community for over 28 years, serving as a full professor in educational leadership studies. She maintains a high level of competency in the areas of school law, teacher evaluation, and supervision of instruction. These are areas that she explores extensively in her research, service and teaching activities. Her teaching role is significant as she provides a "connection" to the graduate students who are enrolled in the college through off-campus locations. Through this connection, she serves as a mentor and committee chair person to the doctoral candidates she helps guide through the doctoral program.

Nexus of multimembership. The position Ruth holds as a teacher for her educational community is unique in that she provides a link to the off-campus students to the college. She works with colleagues within the walls of the school, but also serves as the 'educational program's identity' as she teaches outside the walls of the school to those students who are taking class from off-campus sites. The responsibilities she has to the student body outside the college is different in that her efforts must represent what students would normally have if they attended on-campus classes. This relates to not just courses that students take, but also administrative responsibilities. Her efforts to make connections with these students is beyond the role of just a teacher for classroom instructor.

This dual role creates a different dynamic when it comes to relating to the faculty who teach on campus courses. Even with continuity is in an educational program, there is a slight disconnect felt by the instructor from the program as their students are different 
from the on-campus students and the conversations may not be relevant to the off-campus sites. Ruth expresses that she feels that her off campus students and cohorts are her “community."

Negotiated experience. Upon first meeting with Ruth during the Faculty Academy, she posed a question to her colleagues, "I know this learning is for the technology, but what about the attention to pedagogy as it applies to the instructional technology?” Her question speaks to a common concern about the use of technology overriding the importance of the instruction. As Ruth is quite familiar with the use of instructional technology in her classes, she at times struggles to appropriately apply it to her instructional practice. "We don't have the instructional design help to make decisions about what or how we want to envision our course and what our pedagogy is how we can more systematically match the technology with the pedagogy. We kind of have to learn through trail-and-error of 'what works and what does not work' for us and what is consistent with our teaching philosophy.” But as she discusses these concerns, she is quick to mention “but we're in the school of education if we don't know things like that, nobody else will.” Speaking to her role and responsibility as an educator teaching in a teacher education program, she sees herself responsible to learn the practice of integrating technology purposefully for her classes.

\section{Modes of Belonging}

Engagement. Ruth sees herself as an "avid learner" and that she engages in learning activities for the purpose of increasing her instructional abilities. She became motivated to try teaching with technology as it would help her learn to teach her courses in a new way. Ruth talks about the influence computers had on her professionally "The 
use of computers even in my own research revolutionized the way I thought about research and writing about research. I learned to think in a non-linear way with computers.” Specifically referring back to her traditional instruction methods, she describes her teaching was a "very careful sequencing of the delivery of instruction."

Using the computers expanded how she thought about the possibilities for teaching. One is the opportunity to provide real-world examples through the use of case studies so that the students can engage collaboratively in high-level critical thinking. The design of her instruction ensures that "the students aren't regurgitating the information, but they're taking the information and applying it.” The lessons and cases Ruth presents are based from actual events and could possibly relate to issues her students may face in their career.

Ruth also states that the more she learns to use the computer for teaching, the more information and knowledge she can provide to her students. It is important for Ruth to serve as a model to help her students to "help them be more efficient and help them think through their work.” During an interview she was helping her doctoral cohort in a face to face conference learn how to type up APA references for their dissertation as well as performing a search through EBSCO host. She demonstrated these activities through both a PC laptop as well as a MAC laptop. As a teacher, Ruth feels that she has high expectations of her students and she would like her instruction to be "high touch." She feels that although she is asking a lot, she very much wants to convey "I care about you."

Imagination. Although Ruth did not go into great detail discussing the visions she had of her educational community as it related to instructional technology, she did make continuous reference to "authenticity" relating to the connection and learning 
experience with her students. Specifically, she would like to explore "how to build a community of learners online in an authentic way.” As her students are located offcampus, she is sensitive to include and schedule gatherings that are both social and educational in nature. Her efforts are to strengthen and maintain the bond she has with students, as well as provide them with an event that brings them together physically as a group. Three or more times a semester, she schedules a meeting time where she and her students will get together. After reviewing Ruth's transcripts, it should be noted that authenticity is a common theme in her instructional practice, as it is consistent in her instructional choices using case-studies and the scheduled off-campus meetings. Her efforts to build and create authenticity are evident in her efforts as well to provide "high touch” mentoring and advising to her students.

\section{Trajectory}

Insider. The evolution of Ruth's trajectory continues to be focused and committed toward the demands of the new generations of learners, as well as methods of practice that include the computer and instructional technology.

\section{Practice}

Mutuality of Practice. Ruth attends to her educational communities efforts to use instructional technology by committing to its use in her classes and participating in professional development activities such as the Faculty Academy. She serves not only as a teacher, but also as a representative of the college for her educational department. It is important for her to make strong connections with her students and gears her efforts toward their success. Ruth defines her "community" as the one that she creates with her off-campus students and does not feel the connection as strongly with the members of her 
immediate educational community in the college. From her previous experiences, she has felt a disconnect and a lack of support from the college as it related to her participation in practice attending to distance learning efforts prior to the use of the computer. Although she may feel slightly "silo-ed" from members of the university educational community, she continues in her efforts to practice and uphold the rigor of scholarly work.

\section{Characteristics of Participation}

Participate in resolutions to conflict and change. Recognizing her educational community's charge to apply instructional technologies to their practice as well as place their courses online, Ruth participates in professional development opportunities such as the faculty academy, but also explores her own self-directed learning activities to improve her skill and ability integrating technology. She has a mixture of self interest and feeling pressured by the university when it comes to learning and integrating instructional technology, but she again mentions feeling overwhelmed and cautious not to exceed her threshold level.

Support communal memory. Relating specifically to her community of offcampus students, Ruth applies the knowledge she’s gained from her service experiences as well as the information she gathers at events such as speaking at the State Capital about No Child Left Behind. The university's eCampus course management system provides her with the facility to upload one of the resources she received from this event for her students to see. She likes to design her instruction around real-world issues on policies and laws in education, she was able to create an assignment from this source. She asks her students to post discussion after they read their unit and the source she 
provided. She asks them "If you were asked to speak to your state representative, what would you say? Apply what you've learned to talk about federal policy?” Ruth makes the effort to apply her service experience and knowledge to her students learning activities.

Assist others. One example Ruth observes collaborating with other members of her educational practice involved her days of teaching with a satellite broadcast. Ruth sought out opportunities to help others with satellite teaching. In this experience, Ruth worked with public school educators who had their own evaluation systems, which is one area she is quite knowledgeable. Wanting to promote the educators, she got them involved in the satellite broadcasts as well at another university in the state.

Ruth talks about the help she receives from others and quickly mentions the technology learning center and one staff person who has been "instrumental" helping her learn and apply new instructional technologies to her classes. "He provides me with guidance in terms of how to think about things instructionally and helping me if the technology doesn't work and tries to help me Table things out.”

Perspectives to accomplish goals. Attending to the university's charge for faculty to use instructional technology, Ruth has become familiar with the amount of workload that can accompany its use. She finds that when she uses instructional technology, it becomes more time intensive and time demanding. "I constantly have to struggle to better manage the time and carve out space for things that I need to be doing besides teaching like writing and research.” She experiences both a weekly and daily struggle to find ways to make the technology benefit her work and not consume more of her time. 
One example is providing feedback to students. "Just for this week, if I have 40 students, I have 40 pieces of work. If I get 2 discussion posts (on a web board) from each student, that's 160 discussion posts!” She has developed strategies, however. She does evaluate what they are doing if they have two sets of work, such as discussion posts on web board. To describe her methods, she says "the students that most need the feedback right away on the first post, I go to them first. Then on the second set, I'm not going to duplicate it (her same feedback to the same student), I'm going to do the ones I didn't do but if there's someone who needs it (second set of feedback) then I need to double it.” Ruth says that her workload has "multiplied exponentially because of its delivery" and feels that she "is not doing a fair job unless her students get feedback." Thinking back to days when students just handed in hard copies of their work, she felt it was easier to provide feedback and discuss their work with them face-to-face. Finding the traditional methods much easier, she refers back to today's practice by stating that now she has to use extra technology to mediate the feedback.

To ease her workload, Ruth states that she has come up with methods for group feedback rather than each person individually so that she’s "not always behind.” Ruth refers back to days not using technology. “In my traditional sense, I didn’t have to have periods where I catch up, but now when I'm teaching online so that I'm not always behind, I have to build in space to breath which I don't know whether anyone talks about.”

She is unsettled with what she hears about the methods of her colleagues to attend to these types of issues. Although she is reading every discussion post and making demands on her students similar to what she did when she taught in a traditional format, 
her colleagues have told her that they may not attend to every post. What she interprets from the discussions she has with her colleagues is that they may not be asking as much from their students and may be "teaching less teach through the medium." She finds herself in an instructional predicament in that she is trying a find a way to do less or ask her students to do less, but questions if she will "still get the same sense of what they are doing.”

Create a habitable atmosphere. Ruth makes great efforts to connect and maintain a sense of community with her off-campus cohorts for the purpose of providing them with teaching experiences that will better prepare them to be competent in their professional lives. These are students who gather from a distance to earn a graduate level degree, Ruth schedules face-to-face and online meetings with her students beyond the regular course meetings, so that they can collectively share in discussions that relate to the responsibilities and tasks of their degree. Specifically, she would hold a class oncampus three times during the semester on Saturdays, so that they could be in touch with her concerning their courses and also dissertation work. She also rotates the meeting location around the state so that the off-campus students can take turns meeting closer to their home location. These meetings are an important occasion for Ruth beyond the scholastic obligations. They meet in one person's home for lunch or dinner and can collectively discuss their school work over a meal. These plans relate to her intention of providing "high touch" to her students along with what she calls "high tech" referring to the use of computers for teaching. "People really appreciate that" as she likes to cook and be attentive to her students. She acknowledges that she has high expectations of their 
school performance, but still wants to communicate "I care about you" throughout their engagement with each other.

\section{Learning in Practice}

Evolving forms of mutual engagement. Ruth was involved early in the efforts to reach learners beyond the university campus. She gained experience teaching through Satellite TV. In the early 1980's the university was just beginning to experiment with TV and satellite broadcast for the delivery of instruction for various off-campus sites around the state. Ruth explains that there was a period of time where she and other faculty would have to drive across the state to teach and the technology was a convenient way to be present with students without all of the time and expense of driving.

During this period, she purchased "no-glare" glasses and would choose the colors of her clothing to accentuate her appearance and try to match well with the background of the TV studio. She noticed that she "was the primary way that the content was delivered...We mediated the content."

She continued to be quite involved with satellite broadcast for instruction. She applied for grants and received a small amount of money for course developmental purposes. To her surprise, she states, "I found no support from the college level...people saw it as I was being paid to teach through satellite and that I didn’t need merit for advancing technology for instruction...I was told that!” This was alarming and disheartening to Ruth, which contributed more to the disconnect she felt with her educational community. She then stopped teaching with the satellite TV and a colleague of hers began to teach with it instead. Later, she continued to look for other distance learning technologies she could use to again reach people at a distance. Ruth currently 
uses Wimba Live Classroom, which is an audio-video synchronous communication technology for distance learning purposes.

Ruth talks about how her teaching practice has evolved and "broadened” due to the use of web-based technologies. She finds there are greater opportunities to explore online resources relevant to her courses, as well as to have access to subject matter experts to participate in discussion with her students. Ruth feels that this is a great benefit to her students as they can "have a larger network of people and access to information all over the country." With greater access to information, she encourages her students to seek additional resources, which then provides more flexibility for her students to provide their own input to the class. As Ruth teaches through Wimba using the audio feature so that she and her students can communicate with one another. Her students prefer to hear her talk instead of sharing in the dialogue.

Talking about her teaching, she was never one to give multiple-choice tests, but now she chooses problems and case studies for each of the chapters her class is covering to examine real life situations. As the case studies are very complex to examine, she is interested in providing high-level, critical thinking activities for her students to improve their level of skill to identify specific concepts and law as it relates to their reading. "They do reading in a text and there are words that they need to know, concepts, I want them to learn the importance and significance of these terms.” The use of case studies provides her students with opportunities to see how they would evaluate real situations and examine what courses of action they could take. This activity is meant for students to have the opportunity to "walk in slow motion and think through a problem." 
She finds that group discussion of these cases is profitable to the class as they can collectively engage in dialogue as one person may note one important factor while another student notices something different. Some of the activities she designs for her courses reinforces collaboration, and she will try to use the technology to have them work together in a group.

Using the technology to teach has provided Ruth with a way to evaluate her students work that was not available in a traditional setting. Using students' assignments and discussion posts, she is better able to examine where the students errors are or where they have missed a concept in the case study. These activities revealed to her "how students think about a case study problem.” She finds that she is more flexible with her interpretation of the answers and tries to Table out how to correct and help students make progress with how they are thinking about the problems. Her goal is trying to Table out how to improve upon her teaching so that her students can see the concepts and important factors in the case studies. She states that she was never able to examine her students' work as clearly as she can now with the technology.

Understanding and tuning their practice. A large part of Ruth's professional practice with teaching as well as writing and research has to deal with the studying school law and policy. She participates frequently with larger communities of practice beyond the university such as the state department of education as it deals directly with the development and creation of school laws and policies. She is a subject matter expert in this area and she participates in service activities that deal directly with the state's department of Education as well as the state superintendent to enhance her own 
knowledge. She takes what she learns from these engagements and provides information and knowledge for her own students to help them become accountable as well.

Developing their repertoires, styles, and discourses. Ruth finds that she can provide her students with more learning resources now that she has access to more information online. As she integrates more resources for her students to use, she feels that her teaching has changed. "I teach more relational because of the computer." She is quite pleased with being able to provide her students with more information beyond the course text. They can consult other resources as they work through their course objectives. One example she provides was that she uses case studies as a vehicle to examine school law. Students have the ability to consult other state laws and policies in addition to the federal government policies. In addition, she posts information that she receives from her service experiences to her online classes for student view and access.

Ruth has found great use of Wimba features in eCampus to teach her online classes. With this software she is able to "connect" with her students, as she uses the head-set connection and speaks with them through the audio feature. She uses Wimba for other events such as gathering her doctoral students to meet and having guest speakers talk to her students. She likes that the Wimba provides each student with an identity and finds that it is helpful for teaching over a distance. There are additional features that are available to her through this software and she intends to "try something new each time" she teaches. 
Snapshot of Instructional Technology Use. Ruth teaches her off-campus course in a synchronous online classroom that can be accessed through her eCampus course website. Students must log onto Ruth’s eCampus course. The course’s homepage displays an icon labeled "Live Classroom.” After selecting this icon, a window opens up inside the eCampus window notifying the user that they have entered into the Wimba Live Classroom as its title appears in the front left hand side of the window.

After students successfully run the Wimba wizard for the first time, the student clicks on the button "Enter this room” and a new window opens up on the screen. One large rectangular cell on the top of the screen serves as the main visual space for students to see any media presented by the teacher or other students. This cell takes up most of the space for the Wimba Live Classroom. A still photo of the instructor holding a large grey cat is placed in the third cell and communicates something personal about the instructor.

In the cell at the bottom of the screen labeled "People,” students can be seen entering the Wimba environment as names continue to appear. A total of 17 students enter the "classroom." Within a text box at the bottom of the screen, text confirms when a student has successfully connected and that the student's "audio ability has been enabled.” In this online class both teacher and students have the ability to communicate through synchronous audio and the students are able to text. The instructor has chosen this feature. For the students to speak to the instructor, they must press a button clearly labeled "Talk," which is located above the text box.

Nearing the time for class to begin, a PowerPoint presentation appears in the main screen with a list of items that Ruth intends to cover in the class. Ruth formally begins class, right on time, by briefly greeting them. She reviews her class agenda and talks her 
about an assignment due the previous week. She provides advice and tips to about the work they have posted on their eCampus discussion board. She was pleased with their work and attempts to provide them with feedback that can assist them for future similar assignments. A good deal of the students' work is to review case studies and identify certain factors within the cases. She revealed in her earlier interview that her comments and advice to her students is focused on helping them improve their critical thinking skills as they work and review through the cases. She has provided each person with feedback on their assignments on the discussion board. She talks to the class about what she found to be excellent work as well as places where they could improve.

After this brief discussion about their assignment, she confirms the next Wimba session and informs her students on the specific time and date in which it will occur. Ruth also reminds her students of the due date of their midterm project and that they will have the weekend to work on it. Even though both students and teacher have the audio option available, the students remain quiet and just Ruth's voice is heard.

The next item on her agenda discussing a case study. She presents a new slide with a short paragraph that summarizes one of the reading assignments. Certain words are in blue which contrast with the typical black color of the text to visually bring the students' attention to certain words within paragraph. Ruth uses a yellow arrow to point to these words as well. Students see the words in different color and are aware of her instructional direction as she points to the words in the sentences. She also informs her students of relevant factors they should know from their readings that will help them answer questions about these readings. Her intent here is to communicate "ways of 
thinking” to her students as these cases serve as preparation activities that will be relevant in their future professions.

Ruth reviews three cases this way and she smoothly moves through her instruction of each case. There is a certain level of multitasking that she must engage in order to instruct through this medium successfully. As she is talking to her students she is manipulating and controlling the media displayed on the Wimba screen. To this point, only Ruth is heard and the students have not communicated through text or audio. She calls out to students that she "does not want to overwhelm them," but she feels if they have the opportunity to walk through a few cases together, then it may become more clear to them what she is expecting with their future review assignments.

She asks her students by showing a "raised hand," which is an icon feature of Wimba if they prefer her to talk or if they would like to share in the discussion more. She would like them to communicate, but they prefer to talk to her with a "raised hand." The students do not hesitate and unanimously all select a "raised hand" to inform her that they would like her to talk instead. She goes along with their preference and continues on with her instruction.

Ruth changes the slide to continue with her agenda for the night. The slide contains questions from an assigned chapter reading. For each question, she uses a yellow arrow again to direct the students attention to the particular question. These are questions that relate to a policy in which students must be aware if the issues are covered under a certain policy or not. As she reads through the question, students must indicate in the text box their answer for one question. For the next question, she asks that they provide a "check mark" to indicates a "yes" response and an "X" to indicate a "no" 
response. The students easily follow along with this type of question and answer. Ruth reads through each of the questions slowly and after she receives the students' answers, she provides the students with an answer and explanation. Most students provide the same answer as their peers, but a few provide a different response. Ruth notes that some of the responses are different and provides an explanation along with the answer.

The class time is coming to a close and Ruth again asks if the students have any questions and reminds them that they can return to this Wimba archive to review the case studies that they went over in tonight's class. Ruth reviews the assignment that they have due later that week and asks that they submit it to the discussion board. Asking her students one last time if anyone has any questions, she pauses and then wishes them a "Good night!" and asks that they log off. Students quickly respond in the text box with “Good bye!” and “Thanks! Good night!” The instructional technology Ruth chose to use for her course is displayed in Table 34. 
Table 34

Instructional technology choices for Ruth's course

\begin{tabular}{|l|c|}
\hline \multicolumn{2}{|l|}{ Web \& Computer-Based Technology Used in Class } \\
\hline Instructional Technology & Participant Choices \\
\hline Course Website & \\
\hline $\begin{array}{l}\text { Web Authored Course } \\
\text { (Dreamweaver/FrontPage) }\end{array}$ & $\mathrm{X}$ \\
\hline eCampus & $\mathrm{X}$ \\
\hline Wimba & \\
\hline Textbook Website & \\
\hline Textbook CD & \\
\hline Subject-related web resource & $\mathrm{X}$ \\
\hline Communication & $\mathrm{X}$ \\
\hline Email & \\
\hline Discussion Boards & $\mathrm{X}$ \\
\hline Listserv & \\
\hline Chat & \\
\hline Instant Messaging & $\mathrm{X}$ \\
\hline Other Technology Used in Course \\
\hline PowerPoint & \\
\hline Video & \\
\hline Simulations & \\
\hline Wiki & \\
\hline PDF Documents & \\
\hline Inspiration & \\
\hline Wiki & \\
\hline Microsoft Word for presentation & \\
\hline Microsoft Excel & \\
\hline Online Libraries/Journals & \\
\hline Online Journals & \\
\hline
\end{tabular}

\section{Meaning}

Negotiation of Meaning. Referring to a metaphor that relates to how she interprets her experience of integrating technology, Ruth states, "I am the 'plate spinner' but the technology is that is the plate that's wobbling the most that gets most of my attention because they need more spinning. So the technology plates are bigger and they wobble more.” Ruth is speaking about her "struggle to better manage her time," as she 
finds using instructional technology is more demanding than her previous teaching practices. She realizes that she may need assistance with her tasks, and she will need to factor in time for that as well. The time that technology demands is causing Ruth to shift her priorities and established expectations she has for herself. Noting the level of her own threshold, she is willing to seek other future directions if the demands become "too tedious" or "too intensive and controlling."

Ruth has difficulty discussing her interpretation and perspective of her teaching over time. Initial attempts by the researcher were made to further clarify the intention of the question as it related to the concept of the negotiation of meaning in the social theory of learning. Noting that there appeared to be a degree of discomfort of the topic, which could have been due to the quality of the question or Ruth's sensitivity to the topic area, attempts to further clarify were ended. She commented on her lack of ability and opportunity to "critically examine" her teaching over time or the "tools to think of myself as a learner, only the ones I invent along the way.” Ruth also states that she has not paid very much attention to her teaching other than going from semester to semester. Her learning environment does not provide her with the tools to pay attention to where she is on a continuum. She feels that there is the assumption that teachers will use and continue to learn how to use technology to pay attention to student learning needs even in isolation, which is how she feels in her community. These statements seemed contradictory to the way she critically thought about her work and her methods of teaching.

Participation. Ruth discusses the understanding she gains from her participation and social involvement teaching her student community with instructional technology. 
She says that she is careful not to overwhelm her students with the amount of work she requires for her classes. Issues from teaching online knowing what students are learning when she is teaching as they do not ask questions. Ruth believes that this is because the students feel it will reveal to the rest of the class that they do not know something. "If its not cool to ask questions, I will have to develop a lot of trust with them so they will ask the questions."

Another concern about student learning is not just the appropriate use of instructional technology, but finding a method that is familiar to students and one in which they can succeed. She is sensitive to the fact that not every student learns best through an online medium, but as teachers, she feels they are making the assumptions that they can. "Students want to perform well in class, but if we're not giving them choices [for style of learning] and if they aren't seeing me because I'm teaching online, that's a problem.” Concerning the lack of choices that students may have to take classes online or come to campus, she questions what she should do as a teacher to help the students make the best choices for their learning experience.

Connecting and building student-teacher relationships through online communication, Ruth is aware that a lot of what she says in her communication can be lost or misinterpreted and is careful not to joke because "that could be deadly." Ruth has come to understand that there is a learning curve with her students ability to learn, communicate and be a part of an online community depending upon their previous experiences working with online technologies. For the students who do have experience, she finds that they are less apprehensive in being a part of an online community “however you construct it.” On the other hand, she says that "students with less 
experience learning and working with online technology, at times try to ignore they problems they have with technology hoping it will go away, and it doesn't."

Regardless of students' skill level, she finds that the element of an "online community" does not equal collaboration and rather it is an assumption that the "togetherness" shared by people will build "community." Ruth pursues trying to build a community among students online, "but in an authentic way," but is not quite sure how to do it. Creating and authentic connection with her students is a strong theme throughout Ruth's conversation.

One significant factor Ruth brings up is the issue of ethically assessing someone she has never met. She is speaking of her students that she instructs online. This problem comes to her attention when she finds a student receiving a high grade on an exam, but yet does not display active online communication through discussion board posts or participation communicating during the online class. It is a question of consistency in their behavior leading up to the exam that causes her to question whether it is really the student's work or not. It makes her uncomfortable to not have verification normally found through face-to-face classes and have to "take things on faith."

Reification. By chance, during one of the interview sessions, a colleague of Ruth's came to her office to inquire about an office memo sent by their department chair discussing a required technology course that would be included into their students' course schedule. She and her colleague had discrepancies about the meaning of the technology mandate mentioned in the memo as well as frustration with their lack of understanding of what they would eventually be responsible for in terms of technology integration. As her colleague tried to clarify his understanding, it left Ruth with more questions. They 
decided that a meeting would have to take place to discuss the matter further. After her colleague leaves, Ruth exclaims "Life should be easier...one phone call never clears it up, never.”

Duality of Meaning. Several times throughout the meeting with Ruth, she mentioned the lack of "community" she felt with her colleagues as well as the lack of opportunity to share and discuss her concerns specifically about the pedagogical implications of instructional technology. Ruth states that "this may be the first time I am articulating the complexity that instructional technology presents because we don't have a community to talk about our design.”

\section{Community}

Community Membership. Ruth has been working in higher education for 28 years and her competencies as they relate to her area of expertise are revealed through her participation in service activities such as going to the state capital to speak on issues such as No Child Left Behind and participating in state department of education meetings that discuss issues such as the development of higher level content standards.

In addition to the application of her expertise and knowledge to service work, Ruth has been teaching in a distance learning capacity for the same amount of time. She has become involved in learning technology applications for distance learning throughout her career with the university and continues to participate now with computer and web based technologies.

\section{Dimensions of a Community of Practice}

Mutual engagement. It is important for Ruth to schedule structured interactions for the classes that she is teaching at a distance as well as her doctoral cohort to engage in 
conversation about their dissertation research. As her main connection with these offcampus students may be through phone calls, email, discussion posts, chat rooms, or Wimba Live Classroom discussions, it is necessary that she facilitates an atmosphere in which both can have interactions. Currently she is experimenting with two different classes that she teaches from a distance. In one, she uses the Wimba and the other she does not. She has found that she has a greater connection and sense of community with the use of Wimba. The engagement that Ruth has with her classes are different depending upon the content of the class. For one of her classes where she has students working on independent studies, she uses only the eCampus in which they post on the discussion board. She is aware that not all students' learning styles are suited for learning online. She has met with off-campus students on campus individually to provide better support for their learning.

Ruth discusses an interesting observation she had while attending a meeting at the state department of education where the state superintendent was presenting information about new state’s standards for public school students, specifically the higher-level content standards. This was an important meeting where people came together to learn and discuss important affecting both higher education faculty and public school teachers. She noticed that many people had their laptops out and they were multitasking rather than listening to the presentation. Even though it was mentioned to the teaching audience that it was okay that they could be on their laptops working, it was alarming to her as she witnessed people "checking their email and composing memos." She thought that "what was more interesting that in an important meeting, the technology was used for off-task behavior!” The technology as she explains was not used for the focus of the meeting, but 
rather to do something other than the meeting which she found as a major contradiction to the intentions of the meeting.

Joint enterprise. Regarding the educational community’s overall mission concerning technology integration, she begins to shake her head "no" and says that she is “unaware of any written policy,” but believes that it is "an unspoken...enacted policy.” She stated that faculty can pick and choose the technology they would like to use to deliver their instruction, and they will be provided technical support. Ruth mentions that there is more of a 'techno-rational use of technology rather than the use or creation of a constructivist learning environment...it's more of a mechanical use..." She believes that there is more of a preoccupation with making sure the school can provide service to students over a distance, but not a policy or institutional consideration about faculty as learners trying to use technology for their instruction.

Ruth comments on another overriding policy concerning a "constant focus on generated student credit hours...that's a major policy. So the more students you have, the department is judged on how much revenue you generate. So in a sense, that is the overriding policy.”

Going into more detail, Ruth discusses that a department's obtained credit hours for certain semesters are "judged" more than others such as is done with the fall semester. The excess revenue received from the credit hours provides extra funds for the department. Ruth states that "those are the two unwritten college policies that drive the decisions and what gets done.” Ruth turns to think about the public school setting. She finds a contrast in relation to number of mandates they are accountable and evaluated on their use of technology. She feels that the public schools may be driving the use of 
instructional technology more than higher education due to her understanding that they are evaluated and that members in her educational community are not.

Shared repertoire. Discussing the resources available to her educational community, Ruth discusses that the technology will be available to her and her colleagues if they need it. She says that "the college has been very good about that." She also mentions the personnel available to her through the technology support center and goes there for both technology assistance and to discuss instructional options using technology. 


\section{Narrative: Wanda}

\section{Identity}

\section{Main Characteristics of Identity}

Learning process. Wanda has an extensive history with the university in which she now practices, beginning with her own learning pursuits. She accomplished both her bachelor's and master’s degree in Speech Pathology and Audiology. Her pursuit for her doctoral degree in Communication Disorders took her to different educational university community. All three of her higher education degrees are in the area of Communication Disorders.

Lived experience. Wanda's choice for work brought her back to the university educational community where she began her own learning process in Communication Disorders. After she completed her doctorate, she returned to her alma mater, the initial university community where she accomplished her undergraduate and graduate degree, and obtained the position of assistant professor. Continuing her work at the university, she gained the title of full professor in 1986 in the same college in which she received her first two degrees and has maintained that position for 34 years. Wanda reflects that she’s been in the field of Speech Pathology and Audiology a long time.

Social membership. As a full professor, Wanda maintains a high level of competency and knowledge for the curriculum and course content. She has taught every course in her department, but one. This high level of competency is not felt, however, as she integrates and applies instructional technology into her courses, "I know from the [Faculty] Academy, I know how sophisticated those people can get and I just go 'Oh!'...but I'm simple, I do it at my level. I don’t profess to be any expert at all.” She 
maintains continuous involvement and interest in professional development opportunities to improve upon her level of competency, skills, and abilities concerning the application of instructional technology.

Nexus of multimembership. Wanda adopts a combination of roles in her work, in which she shares time between teaching in the classroom and applying that knowledge to the clinical setting. Wanda provides clinical services in which she assesses, evaluates, and treats people from birth-to-death who have communication disorders. “That's our role. We're clinical people.” She states that her department works in a clinic and see patients. When they are in the medical setting, they see patients and when they are in their own setting, they see clients.”

Negotiated experience. She states that as she relies more on the technology to teach and that technology has changed and shaped her role as a teacher. "As a teacher, I do have a little bit of dilemma between having my entire personality there every day versus not being there. I do miss that component and I really do miss it. I still want my personality there and I'm missing a little of that with the totally online [class].” In lieu of the dilemma concerning the separation between teacher and student, Wanda has adopted and used instructional software that provides synchronous audio and video communication.

\section{Modes of Belonging}

Engagement. Wanda states that her identity and role as a teacher has been heavily influenced in educating her students because she states technology has changed the way she has taught. "Its influenced my entire focus on my classroom teaching as well as my online teaching. Its interesting and I enjoy using the technology because it adds 
breadth to the class, even when I'm lecturing." The degree and level of instructional technology integration utilized in her classes range from $0 \%$ used reflecting a traditional face-to-face instructional approach, to 50\% using a blended approach sharing both traditional and online instruction to $100 \%$ online instruction. Wanda uses Wimba to teach her lectures in a synchronous environment. Wimba provides real-time interaction among teacher and students through audio and video. Wimba also provides a learning environment to share content, use applications to display content such as PowerPoint presentations, Adobe PDF files, and the display of HTML pages. She's pleased with the use of the Wimba software, because with the use of audio and video, she feels it will make a difference for both teacher and students to see each other. "I can do the personality because at least the voice is there and I could do camera, but I haven't gotten that brave.” Wanda professes that she does enjoy and looks forward to new instructional technology to apply to her classroom. "I don't know what's next, but I use every bit of it that I can. Its interesting and I enjoy doing it and I just keep adding to it.” Wanda’s statements reflect an apprehension for the unknown but yet an enthusiasm and excitement for the future possibilities for her classroom.

Imagination. Wanda envisions the use of digital video to visualize communication disorders that students will have in their future clinical role. Wanda finds value in the ability to use visual applications such as digital video clips specifically for her the introductory course she teaches. She sees the potential of online digital video for classroom instruction as well as an archive where students can return to continue their studies. Wanda would like the ability to use specific segments of a video clip in her teaching rather than VHS tapes, which she currently uses to show a small amount of 
information. Access to online digital video clips would allow the students remote viewing, rather than visiting the learning center on campus. Wanda mentions the production time necessary for the transferring the VHS tapes to digital video. "I know that would take so much time because you know there is every disorder - they've never seen every disorder. Now we use the old fashion video tapes and we need a whole tape when you just need to show different segments.”

She would like to continue to advance her instructional practices with the use of instructional technology, as well, it relates to the clinical field. Wanda reflects on her visions and future thoughts for her teaching and educational community. "There are instructional technologies and practices we were envisioning years ago and a lot of it is here now." She feels it is important to provide equal access to the technology for everyone.

\section{Trajectory}

Insider. Wanda has an extensive history with a university educational community and her intentions are to continue on her current path concerning her future involvement with this community. She is aware, enthusiastic, and optimistic about learning how to evolve her own instructional practices necessary to maintain the membership of an evolving learning community.

\section{Practice}

Mutuality of Practice. Wanda feels fortunate that her fellow department faculty share an understanding of the importance of advancing their skills and abilities with instructional technology. Reflecting this process, she states that all have been involved in various levels of using instructional technology for their courses. People from her 
department have been heavily involvement and participation in professional development activities involving instructional technology including the Faculty Academy.

\section{Characteristics of Participation}

Participate in resolutions to conflict and change. Wanda states that she and her fellow faculty members have navigated their way through change by updating themselves constantly through the professional development opportunities such as the Faculty Academy. She is also pleased with the college for providing workshops and 'bag lunches,' which are monthly colloquium sessions discussing various professional education topics and presentations given by fellow faculty members in the college.

Support communal memory. Wanda intentionally uses the eCampus course shell provided by the university so that she can place content and her expertise for the students to access. "So all of that is there so they can go back and review." She is pleased with the archiving functionality of the Wimba live classroom so that if the students happen to miss the class time, they have it available for their review.

Wanda looks to members from her own educational community as they collectively share their knowledge on building successful online courses. During a Faculty Academy, she was aware that one of the newer colleagues in the college was using the Wimba Live Classroom. Wanda sought out this person's help to make the new instructional technology "less mysterious" and to sit down and run through it with her. She states that her fear of integrating technology is diminished if she knows that help is only a phone call away. Even though the instructional path may be unfamiliar to her, she will apply the technology knowing she has support. 
Wanda sees collective engagement and shared knowledge among members of her educational community through a number of means. She receives administrative support from the college, technology support facilities housed in the building where she teaches, instructional technology experts to assist both faculty and students and from graduate assistants and fellow students. Administrative support in her view occurs through the training and teaching sessions available to faculty, and from the technology support center. "If I have a problem all I have to do is just go downstairs!” Wanda finds great value in the people and expertise available from staff from staff members in the center. "We have people! We have real people! That's a huge push!” Mentioning the Graduate Assistants (GAs) that work in the technology support center, Wanda discusses how they have been available to help both faculty and students. "The GAs are really jumping right on it. They're really comfortable with eCampus cause a lot of us use it up here and all of that technology that goes with that.” She is quite pleased with the support provided by the technology educational community in the building and feels that the educational efforts could not be possible without this collective assistance.

Assist others. Wanda discusses how members from her community assist and provide resources for each other in their endeavors to integrate instructional technology. "I'm always getting help from anybody." She finds comfort in the mutual support from other members of her educational community to be able to talk, share ideas and help each other in new instructional activities. The ease of access to support is very valuable to her as she feels her enthusiasm and efforts to learn to apply new instructional technologies may not be as speedy without help being readily available. "You can run down to the lab or email. Or they'll come up! [to her office]" She is quick to mention 
how fortunate she feels about a fellow colleague in her department who has a instructional technology background. She discusses how this colleague helped her with her current Wimba Live Classroom course by saying, "Dr. [name removed] is involved with the class, she's my support you know when I teach this semester. I don't really need her much, but you know, if something goes down, she's an educational technology expert! And so she's there - and again, she pushed me to use Wimba and I love it! I wouldn't have used it if she didn't really push it this far." Wanda would like to 'bounce ideas' off of her fellow colleague and felt comfortable asking her how to do certain tasks. This colleague though is retiring and her trajectory is moving out of the educational community.

Wanda also assists and open doors to new community joiners. Currently, she has submitted and was awarded a grant by the state Department of Education that would support the hiring of a graduate assistant and could also pay for this person's tuition. Wanda's intent for this position is to support working professionals in her field who have returned to school.

Perspectives to accomplish goals. Wanda's intentions technology integration involves placing one of her classes completely online so that she can have working professionals access the class. She mentions that she has received several calls from former students about a particular course that is currently blended, containing both online and traditional, requiring face-to-face contact. Placing this class online would provide these working professionals access to the course resulting in a high enrollment for the class. 
The topic of using digital videos is brought up again as a goal for Wanda's courses. Wanda can use Wimba to show DVDs and video and break down specific segments for instructional viewing. "I've been wanting to do that for years to say 'In this segment, we're seeing this!' I haven’t been able to take the time to learn the technology.”

\section{Learning in Practice}

Evolving forms of mutual engagement. Wanda teaches graduate students, but she does teach a few introductory courses; one for majors and one for non-majors. She recalls that previously, her department did have students who majored in education taking their courses, but with the introduction of the teacher education program, education majors lack the additional time and ability to take courses outside their program due to the rigor of their program. "With the bulk of my teaching to graduate students with a smattering of introductory courses, I have the babies and the older ones... and I love it! Because I see these 'babies' [students as they take the introductory classes], but then I don't see them again for the next two to three years and then they're back again when their 'adults' ... and I remember them. I see them after they've matured, so it’s a good feeling." As the department has evolved in its ability to offer online courses, students who have graduated from their program have returned to take additional courses, and she is "able to see them again move through their professional lives."

Wanda's exposure to the use of instructional technology for distance learning began over a decade ago. Teaching through satellite broadcast was one of the earlier advanced technologies used by the university to reach students at distance locations or off campus cohorts. In 1997, Wanda was would have to go to another building in the university and was televised in a studio to teach a statewide class. She recalls that it was 
a very cumbersome process as the off-campus students would use telephones to call in and reach the instructor with questions with a speaker. Wanda would respond to their questions then through the television. Recalling some of the difficulties of this process, Wanda remembers that phone connections would sometimes be cut off. For students that did not attend 'class', she would have to send out a video tape of the recorded lecture. "I just got into it in the beginning....and I saw the evolution of the traditional classroom. So I don't know what's next. I can see it making things easier or more real as we move forward." She still describes herself today as more of a novice and one that uses the instructional technology 'simply.' She actually has been in the forefront of using instructional technology to reach students at a distance for over a decade. She has gained significant experience in the transition of teaching practices with the earlier distance technologies such as satellite broadcast.

She makes comparisons from the satellite broadcast experience to the online Wimba instructional technology which she currently uses. Each lecture using Wimba can be archived for students to return to fore class review. "I still keep them in a text box and I don't let them talk because it's too much. So I let them text back and forth and then of course they can answer the questionnaires that I put up.” Wanda is referring to the ability for students to communicate through text and/or use audio and video through Wimba. Through the administrative controls of the Wimba virtual learning environment, Wanda can choose the level of student interactivity she prefers for her online class. She is only comfortable with the texting function and is not quite ready for shared audio or video communication through the Wimba learning environment. 
Wanda also uses eCampus for her courses, which is the university’s web-based course management system. The university has evolved as the web-based course management systems using WebCT to Vista to eCampus. “In terms of evolving, I’ve gone from the old Vista to eCampus 3 and 4 ... or whatever we're on.” Wanda's comment reflects the rapidity in change and evolution of the various course management systems that faculty must keep up with. Updates and changes in newer 'versions' of course management systems usually occur each year. Changes must also be made to their online courses due to the updates in software. She admits that she "can do a lot and can Table out a lot more now than I used to" but she is still in need of support due to the rapidity of change with the instructional technology. “I don’t want to get stuck in Vista 4 you know?! I don’t want to get stuck there because when they change it, I want to be able to learn that, too!”

Understanding and tuning their practice. Wanda stated that she was unaware of any written policy instructing her educational community toward the use of instructional technology other than an "unspoken charge" for faculty to place their courses online.

Developing their repertoires, styles, and discourses. Wanda reflects upon the evolution of tools available to her educational community referring to "just a classroom and a chalkboard.” Because the technology changes so fast, she says her educational community must continue with the evolution of their practice as well. Wanda finds access to online content useful if she feels there is something missing from the textbook. Resources such as anatomy images and video clips can be used and placed in her PowerPoint presentations or Adobe Acrobat files which she posts online to her eCampus 
course shell. She likes that the students have the ability to access class presentations and information, which then affords them to be 'present' during the class instruction and pay attention to the lectures. She states, "Versus taking a million notes, I can tell them that my PowerPoint or PDF is right online and they can go get it.”

Wanda states that because its $100 \%$ online, Wimba is the only direct interaction that she has with her students. She also invites guest lecturers and online postings.

Snapshot of Instructional Technology Use. Wanda teaches her course in a synchronous online classroom that can be accessed through her eCampus course website. Students must log onto Wanda's eCampus course and it will bring them to the course's homepage which displays an organized set of specific icons for the class; course outline, assignments, handouts, help documents, specific content reference materials, and Live Classroom. One of the help documents listed on the homepage is titled "Introducing Live Classroom.” It is a one page document that assists students in the process of accessing the Wimba Live Classroom. The document instruct students to first log on to the class homepage and secondly to click on the icon for Live Classroom. A small photo of the instructor, but it provides a face to the voice that comes through the screen.

Before class officially begins, Wanda informs her students that a fellow instructor that she co-teaches with, will be joining them shortly online environment shortly. This peer works with Wanda in the same department and is highly skilled with integrating instructional technology. This person assists her colleagues frequently with technology and is helping Wanda in this class with Wimba.

As the students are waiting, Wanda uploads her PowerPoint presentation to the main viewing screen. Only Wanda's picture is on the bottom of the screen, but it 
humanizes the instructional process as it provides a pleasant photograph of her smiling to her upbeat and enthusiastic voice. Wanda indicates that she is waiting for two more students who have not logged onto Wimba. She then formally starts the class by stating, "Hello, I guess the other two people will show up when they can.” Wanda will be the only audio voice that will be heard in class. She reminds the students that the presentation and the archive of this night's class session will be available on the eCampus course website.

Wanda talks to her students about the assignments posted on the eCampus Discussion Board and that she would like them to respond to by a certain date. She tells students about the locations within eCampus they can find directions about their assignment. The presentation slide then changes on the screen and Wanda informs the students that this is an outline agenda of what they will go through tonight.

Wanda uses the PowerPoint presentation as a guide to facilitate her lecture. The presentation is a mixture of organized information displayed through bullets, definitions, examples and detailed graphics and images. As Wanda talks to her students, her speech flows easily even though the subject matter is complex. She’s easily conversant and discusses the history and development of the content, the progress and evolution of the professional organizations that established the content and explains how the topics are applied in practice. Wanda uses detailed content-specific graphics and tells her students about the source of the images. In her interview, she would like her students to watch and listen rather than take notes, because she would like them to receive all of the information available throughout her lecture. As she walks her students through the graphics, Wanda attempts to direct the students' attention to specific locations on the 
image through the use of a yellow arrow. Wanda continues to discuss the graphic referring to theorists and previous educational beliefs about the content revealing evidence to the depth of her knowledge and experience in the subject area.

Throughout Wanda's presentation and lecture, she introduces other learning activities for her students. She provides the class with a hyperlink on a presentation slide and transfers the students' viewing area to a visual simulation. Wanda explains the simulation and provides more examples to assist students with their understanding of the content, which includes a content topic and its application to professional practice.

Wanda uses a simulation to engage them in a question-and-answer interaction, so that they could take a break from the lecture and give them practice working with the Wimba components. Wanda changes the screen that displays a text question along with a text box available for students to fill in their answers. Wanda speaks to the students' individual experiences and provides an opportunity for class discussion. Wanda asks students to type in their answers. She tells them to enter an answer even if they don't know so that they can proceed with the class. The student responses are displayed on the screen and Wanda discusses the answer.

Wanda return to the presentation and is now using the yellow arrow to direct students' attention. She flows easily through the slides and her lecture continues to expand upon the presentation by providing an explanation of the application of the concepts she has been presenting.

Wanda switches the instructional activity again to display a multiple choice question for her students to answer. Students select the answer they believe to be correct and click on a "submit" button. Wanda asks her students to think about their reading 
assignments to help them remember where they would have come across the material. Student responses show up slowly and it cannot be known if it is a delay that is human related or technology related. Wanda keeps up the pace and reveals the answers to her students along with a brief discussion on each question. Wanda then returns to the PowerPoint presentation and displays the key concepts.

Wanda again engages her students with an open-ended question to reply to in the text box. This time after asking her students a question, their responses arrive very quickly. Wanda reads off the responses and discusses each one. She reminds them that they have the ability to review these questions throughout the night's class using the archival feature.

As Wanda finishes her presentation, she informs her students of upcoming assignments. Wanda directs her students where to look for the next Wimba online classroom using their eCampus website. She asks if they have any questions before she hands over the instructional position to her colleague. Students respond with silence and Wanda assumes that they do not have any questions.

During the last part of class, her colleague asks open-ended questions using the text box. These questions are used to create discussion among the students, and each answer speaks to their individual professional experiences. Students answer the questions quickly by typing in the text box 1-2 sentence answers. Her colleague closes the question and answer session asking if any of the students had trouble logging on to the Wimba classroom. Most students answer with a quick text of "no" and two other students communicated that they had made errors or were confused, but Tabled out what to do. 
Wanda returns through the audio feature. She thanks and expresses her appreciation of her colleague and the colleague responds with "my pleasure.” Wanda says thank you to everyone for attending the night's class and working through the technology. Each student responds with a positive text response expressing their appreciation in return by saying, “Thank you,” “Good night! This was great!” Wanda closes the class by saying “Thank you all and have a great evening! Good night!” The instructional technology Ruth chose to use for her course is displayed in Table 35.

Table 35

Instructional technology choices for Wanda's course

\begin{tabular}{|l|c|}
\hline Web \& Computer-Based Technology Used in Class \\
\hline Instructional Technology & Participant Courses \\
\hline Course Website & \\
\hline $\begin{array}{l}\text { Web Authored Course } \\
\text { (Dreamweaver/FrontPage) }\end{array}$ & X \\
\hline eCampus & X \\
\hline Wimba & \\
\hline Textbook Website & \\
\hline Textbook CD & \\
\hline Subject-related web resource & X \\
\hline Communication & X \\
\hline Email & \\
\hline Discussion Boards & \\
\hline Listserv & \\
\hline Chat & \\
\hline Instant Messaging & X \\
\hline Technology Used in Course & \\
\hline PowerPoint & \\
\hline Video & \\
\hline Simulations & \\
\hline Wiki & \\
\hline PDF Documents & \\
\hline Inspiration & \\
\hline Wiki & \\
\hline Microsoft Word for presentation & \\
\hline Microsoft Excel & \\
\hline Online Libraries/Journals & \\
\hline Online Journals & \\
\hline
\end{tabular}




\section{Meaning}

Negotiation of Meaning. What Wanda says that her experiences of integrating technology provides improvement and efficiency in the delivery of instructional content due to ability to show much more than before . she says that the best learning opportunity she could provide before using web-based or computer-based resources would be to conduct a live demonstration or show a video. Wanda states, "It affects me where I came from, you know, with a blackboard, maybe a video and you stand there and lecture. Just to have taken some of my classes with the technology that's now available would have been so helpful.” The access to information and the ability for her to share content with her students has been very helpful. The integration of instructional technology has affected the variation of course information that she can provide to students, the way she can engage in her teaching practices, and also the tools she can use for to course administration duties such as evaluation and grading. If it wasn't helpful to her educational practice, she says she would not use it.

Wanda acknowledges the importance of professional development opportunities available for her educational community, such as the Faculty Academy. She feels that it has facilitated her ability to apply instructional technology into her classes and without it that she could not do what she is currently doing.

Wanda considers the prospect of acquiring professional skills from learning on the computer to having the readiness to go directly into professional practice. Pulling at her, though, is her desire to "be there" and have contact with the students especially in terms of evaluations. She feels her presence can provide help to students and the live interaction available with Wimba eases the concern of connectedness. She admits though 
that she prefers contact with the students and that "it's a personality thing...I love to be in the room with the students and so it is a give and take.” Wanda enjoys the feedback from the students as well and likes to go through the learning process "with them."

Participation. Wanda's found that her experience teaching with Wimba was surprisingly similar to her traditional teaching experiences. When the Wimba software was initially shown through the Faculty Academy though, she felt it was too intimidating and doubted whether she would use that software for her own courses. Gaining more experience with the software though, she found that she started to have more comfort with the virtual teaching practices and began to develop her own courses to use the virtual classroom software. She finds similarity in using the Wimba live classroom with her previous experience teaching through satellite broadcast by stating, "Its just like doing a video conference, except you get feedback right there.” As mentioned earlier, Wanda chooses to use one-way audio to talk to her students and the students can provide text feedback. She doesn't feel comfortable yet with the live video interaction, but provides a visual for her students by placing a picture of herself on the virtual classroom.

Wanda has found that preparation is needed ahead of time before teaching with the Wimba live classroom and that it can be difficult at times to manage. From her conversations with fellow colleagues, she is aware that other people have had difficulty with the software, but feels fortunate because she has had success teaching with it so far. She notes that she integrates instructional technology a "bit at a time" to her courses so that she can successfully manage the changes.

Reification. To assist in the productivity and organization of practice, Wanda feels that there is a lot of 'urging' under the new community administration to put courses 
online. This push in her view falls under the charge to "bridge the gap" and broaden the community's reach to more students. She recognizes her community’s charge through the requirements posed upon them who participate in the Faculty Academy. As they work on developing their courses through the academy, they are then required to teach that course integrated instructional technology.

Wanda reflects upon the procedures and policies guiding online instructional practice. The classroom policies that she followed under the traditional teaching format are again followed for the online format. Wanda mentions social justice and social discrimination policies found in the course syllabus as well as stating the importance of being aware what is on the computer screen being presented.

\section{Community}

Community Membership. Technology use competencies are revealed in Wanda's educational community through faculty's development of courses and their participation in professional development activities such as the Faculty Academy. She says that "not everyone teaches online," but that a lot do in her department and they are using the instructional technology skills in their classroom.

\section{Dimensions of a Community of Practice}

Mutual engagement. She is quick to refer back to the Faculty Academy when speaking about opportunities to work with fellow faculty concerning the use of instructional technology. Another collaborative activity Wanda is working on a poster for a convention. Through email, they work on and send revisions to each other. "Back and forth...we're just working as we go and emailing sections. Well here it is, right on my screen!” She reflects and compares previous collaborative activities that she and her 
colleagues would need to complete and have their project "post marked" by a specific date. Today, they get together online, collectively work on the document and send the document through email or by an online form by a certain cut off time. She chuckles, "I always laugh because my colleague will email me and tell me that even though the cut off time of 12 midnight has passed, its still open and it’s 12:30!!" They monitor how long they can actually send in the document online past the cut off time. She concludes her story by saying, "Oh its a different life!”

Wanda sees members of her department providing knowledge and competencies collectively as she believes that the majority of her fellow colleagues use instructional technology heavily in their classrooms. Recognizing that competency levels vary among the faculty outside her department, she realizes that not all teach their courses online or use the eCampus shell. This does not stop her or these other community members from "sharing and talking with each other."

Leaders in the process of integrating instructional technology in the educational community are well known and appreciated for their skill level. Wanda abruptly states, "Now, I'm no Richard, I can't do the things he does or some of the other guys." She feels that she is at a basic level and uses the instructional technology at a "functional level.” Mentioned previously in helping her with her own coursework in practice, Wanda identifies the retiring faculty member in her department as a key person who has led the charge in technology integration. "She’s always been helpful and I like to bounce ideas off of her." She feels fortunate to have had this in her department who had the background in technology education. This person's assistance has been valuable to advancing Wanda’s own technology integration. 
Joint enterprise. When Wanda thinks about the educational community's specific mission toward integrating instructional technology, she feels that the college has pushed it due to the barriers, both geographic and accessibility, found in the state. She discusses the matter further by saying "it used to be called 'bridging the gap."' She says that the charge to have this kind of technology involves having an abundant number of online classes so that people can access them from where they live.

Shared repertoire. When asked about how her community has changed its established routines methods of practice, Wanda refers to communication, course administration and the availability of information and resources online. She states that email wasn’t used as much in the beginning, but then it had changed so much, "Everything has gone to email...when do you think to call somebody? They never say telephone anymore.” Wanda mentions that methods have changed in course administration and that the use of paper is not as common. Duties such as the grading of papers, methods to conducting research projects, and administering tests and quizzes have changed due to instructional technology. Wanda concurs with the methods adopted by her community of practice by saying “it’s just so easy and everything is online now...” 


\section{Narrative: Charles}

\section{Identity}

\section{Main Characteristics of Identity}

Learning process. Charles is a full professor working and teaching in an university educational community, but he was not formally trained as a teacher. His early undergraduate study experiences consisted of majoring in sociology and minoring in science and chemistry. The science and chemistry background peaked his interest to possibly go to medical school and after college, so he decided to work in a lab environment in a medical community. His thoughts and interests changed, and he began examining the area of Social Foundations as he wanted to study humanities and social science. In 1986, he applied and was accepted into a doctoral Social Foundations program which he said took an interdisciplinary approach that allowed him to "dabble in history, sociology, and philosophy." He sees this moment as to "how he got started.” Charles worked for 4 years and completed his Ph.D. in Social Foundations, which provided him with a background in social theory and educational history, which ties the history and philosophy together.

Lived experience. Earning the Ph.D. in Social Foundations contributed to his decisions to work in a higher education setting and teaching in that field. He joined the university community in 1990 and has been here ever since. Charles is a full professor working for a program in social cultural foundations and is a specialist in educational theory and historical research. In addition to his teaching, a large part of his work includes writing and publishing for professional journals. 
Social membership. As a full professor, teaching and working in the field of social and cultural foundations community for 20 years, Charles maintains a high level of competency and knowledge for the curriculum and course content. As he refers to himself as an historian, he came to this higher education community predominantly to teach history of philosophy of education classes and views that as his role in education. He is a teacher for both undergraduate and graduate level students and was awarded the college's outstanding teacher award. Furthering the development of educational programs for the college, Charles is also a part of the recent development of a new interdisciplinary Ph.D. program.

Nexus of multimembership. Charles must reconcile his teacher role with the varying level of students in his classes that range from bachelors to masters to doctoral level, and "that is a very different intellectual group to appeal to and it's a hard group to mediate." He feels he is doing as well as he can do with the variation of students in a class setting, but he is perceptive enough to understand their different needs. He sees the undergraduate students concentrating more on obtaining their teaching certification for graduation and the graduate level students "wanting to get more into the deeper intellectual theoretical discussions.” Charles is interested in nurturing and accommodating the intellectual needs of his students regardless of academic level, but believes that he must be attuned to their varying levels of interests and abilities. Instructional technology in his view is a tool that can help facilitate the varying level of needs for his students and he tries to design his courses with this understanding.

Negotiated experience. Although Charles uses instructional technology to accomplish his teaching goals, he makes it quite clear that he "sees technology as a tool." 
He states that he does like to learn about how to use technology to enhance his role as a teacher, but does not see being a "technology expert” as a part of his role. He explains his view further by saying, "I'm the subject matter person. My job is to teach them about the history and philosophy of education. The technology appears to have been somewhat successful thus far, but I'm not the technology person...so that's a problem sometimes.” He is persistently searching for the best way to make the connection between the subject matter and the best pedagogical practice in order to make the information more accessible to the learners. Charles feels that instructional technology can contribute to and enhance his capabilities of getting subject matter across to his students, so he is interested and enthusiastic about its opportunities.

\section{Modes of Belonging}

Engagement. Charles describes his view of an educational community member's process of mutual involvement with students by stating that "any true teacher is always looking to improve how they do things and again, we're here to teach certain things.” Through a teacher's involvement in the process of education, Charles views how a teacher's identity is transformed through their involvement of teaching by recognizing that teachers are always trying to learn and convey their own learning experiences to the students. "You are always the student and you're always trying to learn and trying to convey your own learning experiences to the students.”

Charles believes a possible benefit can be found in creating a certain niche, purpose or role as a way of being defined in respect to the educational community and to be seen as a person known for a particular expertise. He cautions that a specialty in skill or knowledge could also result in unexpectedly "silo-ing” one’s self off from the 
community. Charles feels that he can relate to this occurrence as he is the only educational historian in his department and must seek out connections with other members of his community. His engagement with members of professional educational organizations and specialty interest groups provide possibilities for engagement with people with similar backgrounds and communication technologies provide that opportunity for connection.

Imagination. The use and access of historical resources as well as archived documents and film are critical to Charles's instruction especially for the teaching of his history classes. Most of the archived documents are located in Washington D.C. where a person could take a trip to view them. With the advent of the Internet and the digitization of historical documents, more and more access to archived information has become available for classroom use. Charles states that not all documents and film are accessible, but there has been a tremendous increase in availability from what it once was a decade ago. Charles's vision for his educational community would consist of a "virtual kind of school where teachers and students could see and do things...or take them to a philosophy class where he could show them all of these historical documents.” He states that he is unaware of the current possibilities, but would like to see these opportunities for both teachers and students in the future. 


\section{Trajectory}

Insider. Charles has a long history with the university community and his intentions are to continue on his current path concerning his role and future involvement with this community. He remains cautious, but optimistic about the developments in instructional technology possibilities available to him for his courses and scholarly research.

\section{Practice}

Mutuality of Practice. Charles feels that the members of his educational community have a shared understanding in their commitment to further their instructional technology capabilities. They appear to him as invested in the process of learning and applying the skills necessary to integrate instructional technology for their academic activities. This is apparent through their continuous involvement through professional development activities such as the Faculty Academy. He notes though that even though the instructional technology is constantly changing, faculty are still willing to make an effort and an investment and work for two weeks collectively toward the development of their classes.

\section{Characteristics of Participation}

Participate in resolutions to conflict and change. Charles feels that he and his fellow colleagues have navigated their way through change by participating in the Faculty Academy. Without being asked, he lists names of some of the members that have consistently gone to the Faculty Academy and interestingly, he mentioned five out of the eight faculty members that are a part of this research study as "ancestors of the PT3 grant.” What he found helpful with the Faculty Academy was that the professional 
development activities also involved tools to help them with their own research and writing in addition to those involving instruction. He feels that "the faculty here in the college have done a good job” in relation to designing an opportunity for faculty to collectively engage and follow a learning path together toward technology integration.

Support communal memory. Through the transition from the previous dean of the educational community last year to the new dean this year, Charles feels that both have supported the faculty's efforts to continue with professional development efforts.

Assist others. Charles feels fortunate to have come in contact with a graduate student who shared the same subject area background with him and was skilled in web course development. He felt that it was quite beneficial to him because she shared both skills of teaching as well as design for technology integration. She has since graduated and left the college, but was working with Charles while she was here on his online course development. Also mentioned is the help found with Michael who is familiar with his class and has helped him in the past. He says, "Michael knows my stuff well enough now where he can help me Table out things and things can get into the eCampus better.” Charles notes the difference in expertise and specialization found in people with a technology background in comparison to faculty's subject matter expertise. He finds the technology assistance very helpful, but feels that sometime they "speak a different language and their world is different...they may think we know more than we do.” He is appreciative for the assistance given to him by people helping him with the technology in his courses. As previously mentioned, assistance that would be ideal to Charles would be to have a person who is both skilled in his subject matter as well as in integrating instructional technology sit in on his class to help him make instructional decisions. 
Perspectives to accomplish goals. Charles's mentions that "his fundamental goal is to get the subject matter across" and that is what he is trying to do and the "technology is a possible tool to help him do to that." His participation in the Faculty Academy provides him with the resources, learning opportunities, and assistance in helping him integrate technology into his courses. He notes that the time spent during opportunities to learn the latest instructional technology are usually spent toward understanding the software rather than learning about pedagogical possibilities. He says, "learning the new software was not necessarily tied to prior instruction." Charles felt though that the exposure to learn and use new technologies was a great benefit and provided an incentive to apply it to his existing courses. Charles feels that he and his department are meeting the charge to learn and integrate instructional technology. He

notes that his colleagues "want to do well in their classes and you can tell because a lot of them won teaching awards. So they are there because they want to do better.”

\section{Learning in Practice}

Evolving forms of mutual engagement. Charles discusses that his developmental process, where he has learned how to work and interact with fellow colleagues and students using technology for communication and course development purposes, began in the year 2000, when a PT3 grant was awarded to the education department. This three year grant brought learning opportunities to the university education faculty and public school teachers around the state. He does not believe that he was involved with technology for teaching any time before that. Computer and internet based technologies Charles uses for instructional purposes consist of the eCampus shell, his own developed course websites, digitized video clips, PowerPoint presentations, and 
asynchronous and synchronous communication technology such as web boards and chat rooms.

Charles has spent a good deal of time developing a website for his one history course. For the instructional purposes of his history course, he uses both the options available on eCampus and his course website. He feels that his other eCampus courses are not as "slick" as the history course, but he recognizes that he has spent a great deal of time on the development of that course. He states that he has spent years developing his history course and would find great benefit to have someone who was not only skilled with technology integrated instructional design, but to be an expert in his subject matter as well. He says, "If someone could sit down with you and tell you what the appropriate technology possibilities would be for your course knowing the subject matter, that would be a big help.”

The selected technologies Charles uses to communicate with his students and fellow colleagues are through email, posts on eCampus web boards, and chatting. He states that the postings to the course web-board are going well as students will post their interpretations of their class before class. This provides students access to their fellow classmates' interpretations of the readings as well as access to Charles for review. Chatting is another activity that he regularly incorporates in his courses and includes only about five to six people in each session as he prefers smaller groups for better manageability. Charles uses PowerPoint presentations regularly for courses and also makes them available for his students through eCampus. Included in the PowerPoint presentations are hyperlinks to embedded video clips to provide students with direct access to visual representation of important events rather than just reading about them. 
Charles confesses that the video clips can be difficult to find as well as upload depending upon the size and length of the video. In an attempt to acquire more video clips, he searches through sites like PBS and does find some, but not as much as he would like.

Charles develops relationships with other colleagues involved in the same pursuit by participating and staying connected to opportunities for professional development within the educational community and staying in touch with people outside the colleges in professional organizations. Most recently, he has been in contact with a person outside of the college for consulting purposes to assist with the development of the interdisciplinary Ph.D. program.

Charles’s perspective, gained from his experiences using instructional technology, offers a realistic point of view as it reflects the benefits and also some of the difficulties. He feels that his department has become quite technologically savvy and much more than he has witnessed from other university history programs. The accessibility of digitally archived resources as well as the assistance and expertise to upload the resources for student access has been a great benefit to Charles's instructional practice. Difficulties he has experienced revolve around barriers for eCampus access, time issues, and support for technical problems. Wanting to share his resources with fellow professionals and doctoral students, barriers are put in place so that outsiders who are not enrolled in to access eCampus courses can not access them. Outside technical assistance is necessary and this is perceived as an inconvenience. Charles is also aware from his experience that teaching with the technology takes up a large amount of time. A specific example is his use of chat for a class of twenty-five people, with five people in each one hour chat 
session; thus requiring five hours to complete. This does not include the instruction for the class, but rather a class communication activity.

Another difficulty revolves around the support available when the system crashes. In summer courses, his students like the convenience of being able to chat in the evenings due to work obligations. What is unfortunate is that if the chat system crashes in the evening, there is no technical support available to help as their offices close at 5pm. Charles's provides concrete examples of some of the benefits and difficulties experienced with technology integration. His intentions and interest are to "keep doing it" and continue to apply what he's learned in his instructional practice. Charles feels that the improvements in technology and the ability to communicate with students offer a lot of possibilities.

Charles is aware that some students may be more accustomed to traditional higher education teaching practices and may to perform better or prefer a traditional classroom setting. To accommodate this need, he provides a traditionally taught class in the fall semester and an online class in the spring. The online spring class also helps with safety issues concerning bad winter weather in which students can access the class without having to drive.

Understanding and tuning their enterprise. When discussing the community’s mission as it concerns the integration of instructional technology, Charles is quick to note the expectation of his community to adopt instructional practices associated with the state's department of education's adoption of the $21^{\text {st }}$ Century Learning framework. He notes that he is not as directly involved with that expectation, but is aware that his fellow colleagues, "mostly methods people, are being pushed and feel some pressure to engage 
in that.” Noting that it really isn't something of a surprise, he states that he and some of his fellow colleagues have already adopted and are applying the $21^{\text {st }}$ Century Learning framework practices.

Developing their repertoires, styles, and discourses. The resources that are developed and used to aid and support Charles's engagement in instructional practice involve the use of information found in educational websites, digitized historical documents and digital video. The ability to create course websites through Dreamweaver as well as having the eCampus course shell as a place to upload course resources have contributed to the strength of Charles's ability to convey information to his students. Website templates created by the department for design of an educational course have also been found to be helpful so that he has initial structure to begin to place his content. His focus is on continuing to "improve his websites for the ability to get information across in the best and clearest fashion for his students.”

The exercise of exploring educational information available through educational websites also assists in his efforts to provide additional information to students if they choose to pursue a topic further. Going to the media center and library at the college to seek out available digitized archived documents and videos is very valuable resource for Charles. This is still learning process as some videos are too long and too large in size to upload to his course websites. He is cautious as well that there is the possibility to run into copyright issues as he is in the process of digitizing the videos. This is an area that he is still exploring as the value of the video to his content is too great to dismiss as they directly apply to the courses primary source readings. It is noted that this is a continuous process as he discusses the items slower to become digitized. He finds that there is still 
too much microfilm and even though there are available resources in the media center at the college, there are still more documents that one would have to travel to access.

Blogs enable Charles’s larger educational community to share in dialogue and educational discussion of practice. He has found that he looks through them, but hasn't yet created or contributed his own at this point, but is interested in looking into it a bit more.

Snapshot of Instructional Technology Use. Charles’s course is an evening graduate level course exploring philosophy in education and taught in a traditional classroom that has been technologically enhanced. There is a control console located in the front left side of the room that is connected to the Internet, which is used by the teacher to display digitally relevant instructional materials and information through the overhead LCD projector for student viewing. There is remote controlled lighting which can selectively dim and brighten the lights in the front, middle or back of the classroom, enhancing the visibility of the LCD projection. Teachers can use the screen on the console to view and connect to the internet, display their PowerPoint presentations, illustrations, videos, PDF documents or other digital information. Teachers can also connect their own laptop computers through the wireless internet access in the building.

The traditional aspects of the classroom remain with chalkboards in the front of the room and student chairs with a table top for writing accommodating both right and left handed students. In the front of the room there is a long wooden table with a portable podium placed on top of it. The medium sized classroom and has a good number of students filling the classroom, 18 in all with a mixture of both males and females. 
As Charles walks into the classroom with his laptop and books carried at his side, he is quiet, easy going, and speaks in relatively soft, but distinctive voice. He is met with greetings from students as he enters the room and returns their acknowledgement with nods and a smile saying warm slow "helllllooooo..." Placing his books down, he and his students exchange brief comments to each other from prior conversations. He shuffles and organizes his papers and books as he talks preparing for the night’s class.

Before class begins, Charles goes to the console and begins logging into his eCampus course and obtains the PowerPoint presentation that he's created for this night's class. All PowerPoint presentations, digital videos and documents have been created for the entire course and are available through the eCampus for students to access and download to their own computer. The presentations he has created are rich in detail as they include digitized historical documents and photographs relevant to the content area of the course. These are items that he has taken time to access and obtain through various libraries and archives both on and off campus.

Charles formally begins class focusing on the week’s scheduled topic area. His teaching style in this course is lecture-discussion format, sharing dialogue with his students. Although the manner in which the class is taught is deceptively relaxed, it becomes quite obvious that one must be well versed and knowledgeable in the subject area in order to participate.

Charles uses the PowerPoint presentation during the first half of class through his lecture-discussion format to go over the week's content. Dimming the lights and bringing the remote controlled overhead screen down, Charles stands at the control console to begin his lecture supplemented with the PowerPoint presentation seen through 
the overhead projector. Rich in detail with photographs and digitized archived historic documents relevant to the content, the PowerPoint presentation is used as a background guide by Charles as he discusses the week’s topic in significant detail. The presentation includes hyperlinks for students to access the digitized historic documents in greater detail when they access it themselves through eCampus.

Charles presents the second handout of the night to students that displays a historic cartoon, expressing the debate the view of religion versus science involvement in American education. After going through the explanation of what the cartoon is trying to communicate, he participates in a hearty dialogue with his students about the various different points of view. As it is a debate that still exists today, the class discussion veers off and makes reference and connections to current events.

Charles returns to the control console to prepare to present an historic film that has been digitized of John Dewey, produced by the Center of Dewey Studies. He comments to his students not to take notes during the film because he has already done that and will give it to them at the conclusion of the film. Again bringing down the overhead screen and dimming the lights, the movie begins. It is a longer movie, around thirty minutes in length.

Charles extends the film's content through class discussion and a question-andanswer session with his students. Some questions asked by Charles are hypothetical and most require higher level critical thinking. Charles's questions about the film's content encourage student discussions among themselves as quiet conversations relevant to the subject area can be heard in the background. There is a comfortable dialogue between the students and Charles as students express their thoughts with confidence and clarity. 
Charles has students engage in group work where they quietly read the content among themselves and then discuss their thoughts about the answers to the questions. Bringing the attention of the students back to the class from their group work, Charles begins the discussion by summarizing the main focus of the chapter. Bringing the subject area of school reform into today's context, Charles inquires about the comparison of the topic's current relevance to the happenings in the PDS schools in the state. Students are sitting alertly in their seats continuing the discussion with Charles as he finishes reading through the an outline that he created to guide the discussion. He informs the students that the outline is available for the students to access through the eCampus course site. He concludes the night's class with a brief overview of the next week's content and students begin to collect their belongings to leave. After he clicks out of his eCampus on the console, Charles gathers his papers and has brief discussions with a few students as people begin to leave the room. The instructional technology Charles chose to use for his course is displayed in Table 36. 
Table 36

Instructional technology choices for Charles' course

\begin{tabular}{|l|c|}
\hline \multicolumn{2}{|c|}{ Web \& Computer-Based Technology Used in Class } \\
\hline Instructional Technology & Participant Choices \\
\hline Course Website & $\mathrm{X}$ \\
\hline $\begin{array}{l}\text { Web Authored Course } \\
\text { (Dreamweaver/FrontPage) }\end{array}$ & $\mathrm{X}$ \\
\hline eCampus & \\
\hline Wimba & \\
\hline Textbook Website & \\
\hline Textbook CD & \\
\hline Subject-related web resource & $\mathrm{X}$ \\
\hline Communication & $\mathrm{X}$ \\
\hline Email & \\
\hline Discussion Boards & $\mathrm{X}$ \\
\hline Listserv & \\
\hline Chat & \\
\hline Instant Messaging & $\mathrm{X}$ \\
\hline Technology Used in Course & $\mathrm{X}$ \\
\hline PowerPoint & \\
\hline Video & \\
\hline Simulations & \\
\hline Wiki & \\
\hline PDF Documents & \\
\hline Inspiration & \\
\hline Wiki & \\
\hline Microsoft Word for presentation & \\
\hline Microsoft Excel & \\
\hline Online Libraries/Journals & \\
\hline Online Journals & \\
\hline
\end{tabular}

\section{Meaning}

Negotiation of Meaning. Charles claims that he likes learning new things and has always had an interest in the possibilities instructional technology could offer to his teaching even though he admits that "it can be overwhelming at times." As he sees technology as a “tool,” he’s trying to “use the technology in the best practice pedagogically,” even though he feels he does not always do so. He feels that technology 
has the ability to enhance the delivery and convey the subject matter better to his students. He is cautious in his use though and feels it is easy to become "too gadget fixed" and feel the pressure to use technologies for his classes as there is a greater demand for faculty to put classes online to reach students beyond campus boundaries. The benefits technology affords Charles is access to historical documents, especially in the area of history education. digitization of archives from the Library of Congress is now available. He questions why the technology has not taken a hold in field of history of education as much as it has in other areas. He states that "it makes it a lot better to do the work so you don't have to travel there” to access and view the archives.

Participation. Concerning how instructional technology affects the interaction and social involvement in his courses, Charles says that "there is still something to be said for just sitting around and just talking," as he notes that there is not any need for technology to accomplish that activity. He is aware though and does use chat technology for this same activity to reach students at a distance. He says that even though the technology is evolving, that is not necessarily true of the pedagogical practices. He recognizes that students seem to like the chat sessions in which he perceives their preference is more about the convenience of the communication rather than the instruction of the topic area. Charles states that he can see the students' point of view and says "Sometimes it is nice change to sit and work in his own environment." Charles speaks of the practical benefits of having communication technology and an online course as it can be helpful to overcome hazardous weather conditions during the spring semester. 
Charles teaching decisions with technology use revolves around success as he will discontinue the use of a technology if it becomes a problem or gets in the way of his teaching. An example would be an experience he had with the difficulty in the use of the digital whiteboard as the pen that it uses became too erratic and hard to use. He did try a few times more times, but found that it got in the way of his teaching and has not returned to using it. Problems that he see associated with occurrences like these that go beyond the class activity and the time spent learning the new technology while other faculty responsibilities such as grant writing get pushed back. Another concern that he has been made aware of from other faculty is that the difficulties experienced in the classroom can translate over to poor teacher evaluations.

The benefit to an abundant amount of information available can be beneficial and frustrating for Charles as a teacher working within a sixteen week semester. He would like to help his students discover and review the large amount of information available and feels that he "just scratches the surface especially for those global kinds of classes like philosophy and history.” He hopes that he has stimulated his students' interests enough that they begin to pursue and look further into the content available.

Reification. When discussing tools that help members of his educational community perform activities, Charles finds value in the use of PowerPoint presentations as they can be another way to enhance the visual elements of the content during his lecture. The technology allows him to hyperlink to important information to explore various archived documents that otherwise he would not be able to do. He also connects students' visual learning style with the display of digital archived documents and videos and affirms that "Many of them learn visually and I learn that way too." Although he 
feels that the PowerPoint presentations can be tedious at times, he hopes that the students find value in the ability to explore these resources.

The global community of members involved in the history and philosophy of education are contributing to the productivity and organization of their practice by making the archives more accessible to people in education and reducing the expense of travel. Charles states that "at least the government is doing that some," but he also finds that some institutions do want people to come and spend money to access archived records and documents. He feels that historians try to access the documents without having to travel or pay for access.

Charles summarizes his view of how meaning has evolved and changed concerning the use of instructional technology by stating "In a large way its probably a personal evolution, pedagogical evolution, and always trying to deal with the change. Education's not static in any way, so you are always trying to deal with how instructional technology changes and then you use a tool to convey that change.”

Duality of Meaning. Charles participates in professional development activities such as the Faculty Academy and reifies his coursework and instruction to include instructional technology. Through the nine years that he has been involved in the Faculty Academy, he has constructed and continually updates his course websites, builds PowerPoint presentations for course lectures, scans, produces and uploads Adobe Acrobat documents, and uploads video clips for class access and viewing. He also seeks assistance from technology experts working in the technology support center to help him with the instructional technology development of his courses. 
Too much reification without enough participation. Charles believes that the university’s initiative for faculty to integrate instructional technology into their courses began in the last decade. He states that his educational community members felt that the university administration was pushing them to develop their courses for online instruction in order to be competitive with other higher education institutions for the purpose of gaining higher student enrollment. According to Charles, this push was intended for financial gain rather than for the improvement in pedagogy. The Faculty Academy is the primary opportunity for education faculty to come together collectively to learn and have hands-on assistance with the development of their courses. The value of the Faculty Academy is felt by Charles, and without the availability to participate in that learning opportunity, he believes he would not be as involved with technology integration. The time necessary for the development and creation of online courses takes more than the two weeks offered in the Faculty Academy. Charles is frustrated with the administration for their perceived lack of understanding of that barrier constraint. Charles perceives the administrative expectation placed faculty to integrate technology is difficult without the necessary opportunities to participate and collectively engage with other faculty in this process in addition to the Faculty Academy.

\section{Community}

Community Membership. Charles feels that relations among community members usually revolve around their various disciplines and not necessarily around the use of instructional technologies. He explains that the educational communities are more research and scholarly based and not pedagogically based. Charles says that "In terms of educational community, the Faculty Academy is about the only time I can think of that 
we all get together from different departments.” During the Faculty Academy, community members' competencies for integrating instructional technology are revealed through the event showcasing their courses and instructional activities. Fellow colleagues can view each other's work and how they've integrated instructional technology in their courses.

\section{Dimensions of a Community of Practice}

Mutual engagement. Charles discusses how community members associated with his discipline create patterns of relatively structured interactions with each other by participating in traditional activities such as professional organizations and meetings. Web-based interactions and connections consist of "voting online when an issue comes up" in his field, posting an online newspaper and writing in blogs. He sees that some of the special interest groups like AERA have blogs to facilitate community interaction. As Charles reviews these community interactions, he still questions whether technology is contributing to the evolution of educational communities as well as the notion of being an "educational community.”

Educational communities in the area of history and social and cultural foundations Charles feels are "not really leaders in the integration of technology" and that "historians have been kind of slow" in their involvement to adopt technology for instructional purposes. He mentions that good connections and networking possibilities to members to various "affinity groups" are available through communication technologies. Charles is interested in going to members of his History or Education Society to inquire as to how many people are doing online course work. "They may use technology to do things like 
eCampus or put their syllabus or reading materials up, but that's not the same as when you're teaching totally online.”

Specifically in the area of learning about instructional technology, Charles sees the Faculty Academy as the prominent activity in which members of his educational community can come together to work toward the common goal of integrating technology. As he reflects upon the genealogy of the Faculty Academy, he says that a good number of the people who participated then still do now. Other than this professional development activity, he feels that he and his colleagues "do not work together unless we go and seek them out.” Charles notes that this a problem as he sees that faculty are silo-ed in higher education. Charles mentions that he does see collaboration and technology used among a few faculty who teach together or share subject area background. "See, I'm kind of still by myself by myself doing some of that...and So they can kind of feed off of each other...where its a little bit more difficult I guess for me to do that.” As the only education historian in the college and feels he “does not have a community per-se.”

Charles mentions Richard as he refers to people in his community who have been leaders in the charge of integrating technology. Viewing Richard as a person he would feel comfortable going to for help and assistance, Charles states, "he knows the ins-andouts of a lot of different things so I could probably go ask him stuff and he'd probably help me.” But he does not want to take time away from the things Richard needs to do for his own work.

Joint enterprise. When discussing community members' forms of accountability that contribute to their practice, Charles is not aware of any official declaration requiring 
faculty to integrate instructional technology. He says that it is the faculty's individual discretion as to how they feel best to teach their own classes. Some he notes are quite advanced technologically speaking and "some don’t do it at all...” In terms of his own accountability, Charles states that he is not evaluated on how technology is integrated into his coursework, but rather his work is reviewed by history departments and content experts who examine his scholarship in a very traditional way. He is not reviewed for his ability to integrate instructional technology under those reviews.

Mentioning the teacher education program, Charles is aware of the ISTE standards and the $21^{\text {st }}$ Century Learning Framework that K-12 students and teachers must apply to their teaching methods. He states that there is pressure felt by education faculty and they are being motivated to participate and construct their coursework to educate students about these teaching standards.

Discussing this teacher education program, Charles believes that they have done a pretty good job of linking technology to its overall goal and mission through its "technology strand” in which this educational community focus efforts on students integrating technology in their coursework and also applying it into the classroom. Charles mentions the "Technology Integration Plan” which is one of the educational community's indigenous designs for technology integration in the coursework for the 5 year education program that was created by members working in the educational community. Charles states, “This is an educational community, I've been involved with that has probably done more than anybody else, at least tying it [technology integration] to their mission.” 
Shared repertoire. Information, knowledge, and shared points of reference among Charles's history of education community only involve occasional papers provided at conferences that may deal with teaching about a particular subject matter. He admits that it seems rare in his field though in his field to talk about instructional technology as most discussions revolve around historical or philosophy issues. He feels that the history department in this educational community is pretty advanced technologically speaking in comparison to other history departments.

Concerning methods of practice and established routines as it relates to technology integration for this educational community, Charles notices that even during professional development activities such as the Faculty Academy, faculty's focus concerns "how I can use this tool for me and not about how I can use this tool for group purposes." He states that this does not occur as much with methodologists as they are seen working and teaching together, but largely the focus of technology use revolves around how an individual will use it for their own purposes. Admitting that this describes his technology use as well, he does consider collaboration and the ability to sit down with other community members important to discuss possibilities for teamwork.

Charles feels the people who have provided technological assistance have been the community's most valuable resources. He is quick to recognize Wayne and Michael as well as their staff working in the technology support center is extremely helpful and feels it is imperative to have their assistance. He mentions that most departments have "somebody to rely on" for support with their classes. A woman in his department has also been available to help fellow faculty as he says, "people are always in another teacher's office about this, that and the other.” A previous graduate student was also 
instrumental in helping him construct his web based class. Assistance to learn how the technology works and support for faculty to continue to integrate instructional technology is critical to Charles. 


\section{Introduction to the Program Support Teachers}

The following information will present the two program support teachers case studies of Tanya and Michael. Both program support participants teach one or more courses in the teacher education program.

Tanya is a clinical coordinator who has been teaching for the college for 20 years. She teaches courses in teacher education. Michael is an adjunct faculty member and an E-learning specialist who has been teaching and working for the college for over 10 years. He teachers courses in teacher education. 


\section{Narrative: Tanya}

\section{Identity}

\section{Main Characteristics of Identity}

Learning process. The focus of Tanya's early learning experiences began in the field of education as she accomplished her undergraduate degree in Elementary Education in 1977 at the same college of education in which she now works. She decided to come back to the same college to complete her masters degree in Library Science. This graduate degree provided Tanya with the exposure and opportunities to learn various instructional technologies used at that time. When thinking back to her coursework, she reflects upon one of the courses in her program, Instructional Material Development, which taught the design and construction of earlier instructional technologies. Her exposure to the design and use of instructional technologies began early in her learning experiences.

Lived experience. Tanya began working in the field of education as a teacher after the completion of her undergraduate degree in elementary education. She taught mainly social studies to $3^{\text {rd }}$ and $4^{\text {th }}$ graders for seven years. In this role, she "taught in a self-contained classroom and did not take on or seek out any additional roles at that time.” Decisions to have a family took her out of the classroom as she stopped teaching for a period of time to care for her young children. When her children began to get older, she started looked for a part-time position that would get her reconnected to the field of education. What she found to be a perfect match was a graduate position requiring only twenty hours a week of work where she could be involved in education. On a humorous note she adds, "In addition to this position, I would have to choose and begin a graduate 
program with the school!” noting that the graduate assistant position required a twenty hour work week plus a full-time course schedule. The graduate assistant position involved the teacher education program where she helped the Professional Development School (PDS) coordinator. After she graduated, she stayed with the program and worked with the teacher education program. She continued to do the coordinating work that she had done previously in her assistantship and was doing a lot of communication with the professional development planning with the PDSs. She has been with this program since 1989 and currently serves as the Clinical Experiences Coordinator.

Social membership. In her role as the Clinical Experiences Coordinator, Tanya states that even though she is "not a traditional faculty member," she is aware of her ability to "interact with her colleagues on a somewhat level playing field" which she finds "fairly unique" for a higher education environment. This accessibility and mutual respect she receives among her colleagues means a great deal to her. She believes this mutual respect is due to the collective understanding that "we are all novices in this world and you come together as a community because you have a need to know.” These sentiments are reflective of the program's belief statements in which she plays a significant role. Her colleagues respect and accessibility could also be due to the high level of competency she brings to her role as she has been a part of this teacher education program for twenty years and part of the college community for even longer.

Nexus of multimembership. When reflecting upon the roles in her current position, Tanya thinks back to earlier experiences as an elementary school teacher, and says that she did not take on many other roles other than her teaching. She ponders 
whether this was her decision or due to a lack of opportunities, but would like to believe the latter as she was a "young person in her career, getting married and having children." Jumping to the present day, in her role as the clinical experiences coordinator, Tanya must serve a combination of roles. She coordinates and communicates efforts among the university faculty who teach courses with the 5 year teaching program. She also works with the professional development public schools and the pre-service teachers in which she places in the professional development schools for their student teaching experiences.

To describe the efforts of her relations more specifically, Tanya facilitates successful partnerships between the professionals working in the colleges relating to education within the university community to the professionals working in the public school community, all for the improvement of the teacher education practices. She says, "It was part of my role to make sure that the folks from the colleges within the university are all working on the same page.” She must coordinate the thirty professional development schools network in the state for the purposes of professional renewal and teacher education. Tanya must also serve as the program coordinator for the teacher education program in which she coordinates clinical experiences for pre-service teachers. Pre-service teachers are placed in professional development schools in which they have the opportunity to be exposed to "best practices" and mentored by a professional development teacher. In her role, Tanya must "actively coordinate and communicate to thirty schools and about 360 students any given semester.” She uses technology, such as, email as a communication device to simultaneously connect with these groups of people. 
Negotiated experience. When Tanya thinks back to the use of instructional technologies in her earlier teaching experiences in the public schools, she states, "The Internet wasn't invented yet and for a teacher in the late 1970s, early 1980s, the technology most commonly used were film strips, movie projectors, opaque projectors, and overhead transparencies.” She remembers that as a teacher who taught in the classroom, she did not really explore professional development activities at that time and what she learned about how to learn to use technology, she learned from other teachers in her public school.

When she returned to get her graduate degree with the university, she had to pursue another specialization beyond elementary education. It was at that point in which she began to learn about computer technologies and the integration of those technologies into teaching. She states, "It became a different focus of my work.” Tanya remembers that as a graduate assistant, she had a Mac computer which she used in her work coordinating the professional development schools. "It was one of those all in one's that had discs and you could do word processing. We all used it in that way [work purposes and word processing] not in teaching when I first started.”

Relating to today's use and integration of instructional technology, Tanya believes that she and her fellow teachers "will have to make adjustments in how they think of themselves as teachers.” She wonders how educators will now fit into the world of computers and technology as it is still a learning process without a known conclusion other than it is one that is still progressing. "I think it has affected that we can all acknowledge that we're learners and so that changes how we can communicate about it that its okay not to know.” Tanya is sensitive to the competencies and skills necessary to 
teach with instructional technology and how this destabilizes teachers' level of confidence in their professional position.

\section{Modes of Belonging}

Engagement. Tanya saw that instructional technology had a great influence on how her fellow colleagues perceived the change felt in their professional role. To be more specific, the responsibilities for faculty to be content experts and impart their knowledge with traditional teaching practices was no longer sufficient as their role had grown to incorporate instructional technology in the design of their courses. She felt that this had a huge impact on her role because professional development was a focus.

Imagination. Tanya is sensitive to empowering the capabilities of all members of her educational community and one of her visions would be to have the capability for instructional technology to provide a "seamless environment where we were all kind of on the same page.” This would include all members of her community being her fellow faculty, the professional development schools, as well as her students. She feels that there could be great benefit to be able to observe her students teaching in real time at their professional development schools locations. Tanya is envisioning the possibility to shape the students' teaching skills through the ability for direct observation and feedback from distant locations. She feels that this is an obvious aspiration as the benefits would be enormous. Faculty from the college could view all of their students, provide feedback and assistance, and discuss the students progress directly with the PDS host teachers.

Tanya also has ideas and visions about a specific task required of the pre-service teachers. She mentions the students' digital portfolio as she sees it now as a "showcase summative" document, but she can imagine it being "so much more robust." She would 
like to see this project become more formative than summative. Possibilities she mentions for the digital portfolio would include a place where "students could deposit things and have it be a repository over time where they could revisit their work.” This vision may come to pass as the college is looking into technology possibilities for students’ portfolios.

\section{Trajectory}

Boundary. Tanya follows a boundary trajectory in her work as her professional role dictates the connection and coordination of different communities of practice, the colleges of education at the university, the professional development schools and the students. The success of her work depends upon the ability to bring together these three communities of practice.

Insider. Even though Tanya's trajectory focuses on the harmonization of relationships between communities, her action of practice is focused on the renewal, continuation, future development and advancement of the communities capabilities.

Outsider. Although her trajectory is not outsider or outbound yet, Tanya feels she is nearing retirement age and ponders the opportunities that may be available to her as a person who “doesn’t want to work full-time forever, but is still quite interested in working on special projects." She is excited to think about the possibilities to be able to pick and choose to work on a learning goal with the chance to work with different people and making different connections. 


\section{Practice}

Mutuality of Practice. The use of instructional technology affects the practices of both university faculty and public school teachers to be responsible to integrate technology and model 'best practices' for the teacher education students. Traditional professional development practices usually are directed and led by the university community to teach the public school community how to advance in their teaching practice. Tanya witnessed that as the use of instructional technology became more important in education, both university faculty and public school teachers had a "need to know," which affected the university community equally as it did the public school community. This "need to know" changed the traditional dynamic of professional development participation where now public school educators were coming in and offering professional development to the university faculty. Tanya saw this as a great opportunity for people from the public schools to lead sessions in the Faculty Academy as well as come into the faculty's courses and show how they are using instructional technology in their public school classroom. One example she offers is the use of the digital whiteboard. The public school teachers could come in to a methods course at the university and show both the faculty and teacher education students how they use it in the classroom. Tanya mentions it has been important as well that she work with the professional development schools to make sure there is a match between what the students are learning and what they're getting when they go out to the public schools.

\section{Characteristics of Participation}

Participate in resolutions to conflict and change. As Tanya has navigated her way through change, she feels that she has been fortunate that her college has been 
"resource rich" and has compassion for those schools that do no have the resources to meet the change. In order to improve her own skill level concerning instructional technologies, she participated heavily in the Faculty Academy where she would be introduced to different technologies. She says, "I really made and effort...I would come back to infuse those into the assignments.”

Support communal memory. When discussing how members individually contribute and share their knowledge collectively to their community, Tanya thinks back to collaboration between college faculty and PDS teachers in professional development activities. She refers back to what she thought was an interesting change in a traditional dynamic, that the PDS teachers were now instructing the college faculty on their use of instructional technology.

She talks about another instance where the college obtained the services of a PDS teacher for a year, titled the Professional Development Fellow. Tanya states, “This person provided another bridge between us [college] and them [PDS teaches] and technology was often a focus of that.” Specific initiatives that were included during that year included the $21^{\text {st }}$ Century Learner model and how to integrate the pre-service teachers' learning of that model into their courses.

Assist others. When discussing how her community members help each other with technology integration, Tanya refers back to the Faculty Academy, which included different educational programs so that faculty could interact with people they would otherwise not work with normally. Tanya recalls mentors being assigned in the Faculty Academy who was from a different college and a person “she didn’t have many reasons to interact with.” The person Tanya was assigned to was also reported in this research 
providing assistance to Wanda as well. Tanya feels fortunate to be able to have a mentor who she could meet with to help her integrate the technology with whatever she was working on. She was quick to say that she feels privileged to have access to the resources, professional development and help from a person for an hour, whereas the public school teacher may not have those options or the flexibility to sit down and get assistance with technology integration.

Perspective to accomplish goals. Tanya took a deep breath before discussing how members of her community experienced diversity and a mixture of direction as they developed plans to achieve their goals concerning instructional technology integration. She began by mentioning the 'Technology Strand' guiding the objectives of the teacher education program and the Technology Integration Plan guiding that strand. "We thought we had a plan, it was a living plan, we liked it, we thought it was difficult to make sure everyone was constantly included and updated and working together [toward technology integration].”

The state department of education, who is equally as concerned that new teachers have the skills and abilities to integrate instructional technology as they go into the schools to teach after they graduate, sent out a new mandate for higher education schools in the state offering teacher education programs to require a 3 hour credit course mainly focused instructional technology integration. Tanya says, "For those of us who are in the teacher education program, it was a bit of a blow because we felt like we were doing something that was organic and pervasive.” The indigenously-developed technology integration plan mapped out the use of learning opportunities for instructional technology integration skill building throughout the teacher education program's curriculum. A 
three-hour course would not be as comprehensive or provide the learning experiences of integrating technology for pre-service teachers in the same manner that the technology integration plan would. Tanya and her colleagues must find a way to fit the course into the full course schedule in order to adhere to the mandate.

\section{Learning in Practice}

Evolving forms of mutual engagement. As Tanya discusses her participation in an ongoing practice, she reflects upon her early years of teaching in the public school remembering that her experience was "very traditional with 25 students in the classroom using textbooks...I didn’t have a computer and the internet wasn’t invented yet.” Comparing that experience with the capabilities technology can afford her today, she states that the Internet has had an incredible influence on her ability to communicate quickly and for everyone to "to hear the same information, at one time, in the same way." Communication and coordination is a large part of her role, the facility technology has provided has been important to her.

As her instructional practices continue to evolve using computer and web-based technologies, Tanya is keen to include the themes and missions promoted by the Collaborative in assignments and class activities. An example of her efforts to educate students on acknowledging the contributions other participants such as the PDS schools and teachers have had on their learning and contribution to teaching, Tanya used what she learned about chat rooms to facilitate discussions among fellow students. She saw this as "planting a seed" with students as they are now skilled with the technology. They may now have collective discussions with their host teachers and include them as part of the conversation. 
Tanya considers the effects that instructional technology has had upon the children in the public schools and thinks about what the necessary developmental processes and skills she, her colleagues, and her students must have in order to meet those learners' needs. From her perspective, she sees children being "bombarded” with technology and feels that the evolution of teaching practices must match up with the needs for deep learning experiences of the students. The expectations of teachers, in turn, are to customize their instruction to fit the individual needs of their students as well as design instruction that provides immediate feedback. Tanya views the reality of that expectation happening requiring a tremendous amount of work.

Tanya thinks about the positive and negative experiences people have as they go through change as well as the developmental processes of learning how to work and interact with each other in a community. Observing transitional processes in practice such as these, she sees that sometimes people have competing interests surrounding technology. Due to the state of instructional change, technology has caused her to question how a community defines their practice and how training should occur to support it. Tanya sees a responsibility in the teacher education program to try to negotiate among the competing views for an acceptable outcome serving the best interest of the community.

Understanding and tuning their practice. Tanya mentions several efforts that guide the charge and goals of integrating instructional technology for their teacher education program. The first goal is the "technology strand." Tanya explains that through the teacher education program, there is an importance placed in the areas of technology, diversity and special needs, and these three areas are known as the 'strands'. 
Tanya states that it is important that students gain knowledge in these three areas in teacher education as well as experience. Tanya states, "These focus areas are so important that they are imbedded in all the experiences, and all coursework using instructional technology so that even from the design of the program which happened back in the early 1990s, it was there.” These strands are spread throughout the curriculum and taught in the teacher education program. The technology strand emphasizes the designed efforts in the curriculum for students to learn instructional technology skills and applications in class as well as see them modeled and applied in the PDS schools for better student preparation when they are in the classroom. This goal involves collective efforts, accountability and expectation of the faculty in the teacher education program, the host teachers in the PDS public schools, as well as the students to all learn and apply instructional technology to their pedagogy.

A second effort Tanya discusses in which is the teacher education program's Technology Integration Initiative in which places importance of applying instructional technologies to pedagogical practices for the benefit of the learning experience. Under this initiative, an indigenous strategic plan was developed by Tanya and her colleague to help collectively guide teacher education faculty and students in the use of instructional technology. Tanya mentions, "We tried to make sure again that you have this whole group cohesive plan about how are we interacting in this environment of instructional technology in a way that is going to be meaning for PDS teachers and for the pre-service teachers.” For the teacher education program, this is a proposed technology integration timeline that guides students' progress through the teacher education program to appropriately apply computer and web based technologies coordinated with their 
coursework. Again, this then places responsibility not only on the student to become competent in using the various technologies, but also on the college faculty to teach and model the use of the technologies and also the PDS host teachers to model and then apply the technologies in practice.

After the development of the technology integration plan, the state's department of education sent out a mandate requiring teacher education programs to include a threehour credit course in instructional technology. Tanya felt that this was a "blow" to her department as they had already developed the technology integration plan which sought the learning, development and use of instructional technology occur throughout the teacher education program versus a three-hour credit course to adhere to the charge of pre-service teacher technology integration activities.

A new initiative important for K-12 education in the state as well as higher education teacher education programs is the $21^{\text {st }}$ Century Learning initiative, which has established new content standards for K-12 educators to follow as they develop their lesson plans. Tanya states that the latest plan for the $21^{\text {st }}$ Century Learning program is "for us all to take a breath and really work to go into those content standards because they are up and available for people to apply to their lessons.”

Developing their repertoire, styles, and discourses. The web-based technologies that assist Tanya in her teaching and work revolve mainly around communication and information providing technologies. The ability to use email, listservs, and distribution lists to communicate to her students and the PDS teachers has been very helpful to her. She states, "It has allowed me to get information to them 
quickly when they [students and teachers] may not have access to me.” She mentions that the PDS teachers have their own listservs with their own groups of teachers.

Tanya refers to other web-based technologies, such as websites, wikis, and blogs, that have been helpful for students to communicate information. She states that websites have been very helpful to provide "bulks of information," but she does build in face-toface time so that all connections are not through the web. She feels that this technology "pushes" pre-service teachers to use a tool for collaboration as one more way to communicate with their fellow students, their college teachers and their PDS teachers.

Tanya was interested in doing "something different" with her classes. For a class project, she implemented the development and use of wikis as a way for students to provide information and connect them to the PDS school websites. Tanya recognizes that the activities provide students the opportunities to learn the various technologies as well as apply them to something meaningful in their school work. Blogs were another technology that caught Tanya's eye for students to use weekly to talk about their experiences as a pre-service teacher teaching in the schools stating "Okay, my life as a teacher this week...” Tanya sees that PDS teachers and the college faculty can comment on the blog to assist the students in their teaching experiences. She is very interested in applying what she has learned about instructional technologies from professional development to help the pre-service teachers learn and wonders how many of her students will take what they've learned and apply it to their own classes. Tanya is hoping that students will consider this idea that, “Okay, here's how my teachers have integrated PowerPoint presentation and Inspiration into my learning...now am I going to take that and what am I going to do with it with the learning of my children in my PDS?” 
Tanya discusses another example of how she adopted the use of computer and web-based technologies to help her in practice. Previous to Tanya's use of computer and web-based resources for class, at the beginning of every semester, she created a packet for students that included a set of forms and information they would take to their PDS and host teacher. She viewed this as a tedious activity and through the Faculty Academy, she leaned how to place those forms on a website for student and host teacher access.

Thinking about the evolution of her practice, Tanya discuses the methods of trying to help students begin to think about and reflect about their experiences in a different way using photographs and music that may not have been considered before. A software tool that the teacher education program will be using soon will be e-portfolio software that the college just purchased. The use of software for students to develop their portfolios has been discussed in the past, but Tanya and her colleagues felt that the quality of the technology available did not meet the colleges needs. Now, Tanya feels that this new technology will be useful for students concerning the portfolio project.

Snapshot of Instructional Technology Use. Tanya's teacher education seminar class is taught in the small computer lab classroom that exists on the technology support center. Tanya is sitting at one of the computers on the tables before students are entering the classroom. Trying to finish sending emails to her PDS host teachers before the class begins, she greets her students as they enter the room with an enthusiastic "Hello!" and shares brief conversation as they drop their book bags and take a seat. The students in this class are teacher educators that spend their day teaching in the classroom and then later attend their university classes in the late afternoon and early evening. 
For this class, students are working on a teaching video assignment where they must create a digital 2-3 minute video that provides a sample of their teaching in the classroom. The students must create a digital video, which is a requirement of their teacher education program set by the National Board of Professional Teaching Standards. According to this organization, the video will "allow National Board assessors to view how they interact with their students, the climate they create in the classroom, and the ways in which they engage with their students." The video will also "convey to others how the students practice their profession, the decisions they make, and the relationships they have with their students.” This digital video will be included in their electronic portfolios displaying their work to future employers. The creation of this video also demonstrates their skills in working with instructional technology, and capturing and editing digital video.

Tanya's instructional choice for the class includes the involvement of support personnel, Chris, from the technology support center to assist students in the process of learning video editing technology. Tanya provides the content-related instruction to the students as it pertains to their video assignment and she chooses the technology support available to help her students learn how to use the technology to complete their task.

Tanya has created her own website for this course as well as uses the eCampus shell. She tells the students that they can access the assignment they are working on tonight through the website created for class through the Assignments hyperlink named Teacher Video. Under this hyperlink, they can also access PDF tutorials titled, Transferring Video to Computer; Video Editing Instructions - Narrating Your Video to help guide them through the process. Tanya tells her students that they can see a good 
example of the teacher video located on the eCampus Discussion Board. Tanya further explains, “Although its only 2-3 minutes long, it’s a good example of some of the skills that you'll need to learn to edit your video. Each is individually different.” Reassuring her students, Tanya tells them that there are a few seminar sessions that they can attend and that the support personnel in the technology support center is available to help them through this process.

For this assignment, students must take the twenty minutes of video they captured from teaching in the classroom and edit it down to two to three minutes. This two to three minutes of video will incorporate the display smooth transitions and variations of from one video section to another video section, add audio narrative voice over of what is displayed through the videos, and add text onto the video for clarity and emphasis. Three weeks ago, these students worked trying to get their video down from the 20 minutes to the 2-3 minutes required. Tonight, they will take their two to three minutes of video and work on the rest of the editing objectives. Tanya states to her class that initially they were not going to do voice-overs, but they are going to now. As students learn more about the process of video editing tonight, they will have to continue working on this project after class is over.

Tanya speaks to her students about the video criteria and reviews the requirements of the video. There are specific "Video Analysis Questions” provided from the National Board for Professional Teaching Standards that students must use as they edit their videos. Students need to represent the answers to these questions on their videos and they help guide the students in their editing process to capture elements of their teaching skills. Students can access these questions from the course website that Tanya created. 
Tanya reviews and discusses each of the questions. The students' task is two-fold as they must attend to the scholastic rigor of the video analysis and representation and they must also attend to the skill of video editing.

Tanya steps to the back of the room and sits in one of the computer stations and allows Chris to provide video editing instruction to the class. With the lights slightly dimmed and Chris calls out a question to the class, "Who has their video edited down to 2-3 minutes?” as this task is supposed to be accomplished up to this date. There are a few student hands that go up, but not all. He assesses the response with a nod and proceeds on with his instructional agenda. Using a completed teacher video as a guide, Chris discusses items of working with Microsoft Movie Maker video software, adding effects and titles to the videos, variations of video clip transitions, adding audio to the video, and narrating with a microphone and headphones. Chris also briefly reviews the process of storyboarding and timeline for students to help them through an organizational process of creating their video. Also added into his instruction are valuable key time saving points such as “[Microsoft] Vista doesn’t play nicely with Movie Maker.” Chris explains to the class, "Do it all with [Microsoft] XP or all in Vista. There are complications with the programs.” As he concludes his instructional session, he shows the students the process of how to save their videos from the computer back on to their flash drive. There is language that the students must be familiar with in order to understand. Chris instructs, “Once its [video] saved...” then he backtracks, "be sure to save it back to the My Videos folder, and THEN to the Flash Drive.” Students are following the procedures and exploring their video editing options. Chris concludes with stating that he is available for questions as they work. The lights go back on and Chris 
sits at the console table and Tanya walks around the room answering individual questions for students. They are anxious to show her some of their clips and inquire about requirements of the video as it relates to what they have already edited. Tanya answers specifically to their questions as each video will be unique to the student.

As students begin to work individually on their own videos after the informational session, they put on their headphones and the room becomes very quiet initially other than the sound of clicking. Each student is focused, leaning forward into their monitor, working on editing their videos. Their computer monitors all display a screen full of video clips and pictures. As they work, students would ask their questions out loud to Chris who was sitting in the front of the room at the computer console. He provides valuable and time saving knowledge gained through his experience to the students new to the process of video editing.

Students continue to work on their videos with headphones and some begin to speak out loud to themselves. One student, while shaking her head, continued to face her computer monitor and spoke possibly to her fellow students, but mainly to herself "I don't know what I want in it? What strategy I want in it? I need to sit down, think about it and then do it. I'm just trying to go through the process...it's a process.” Another student let out a huff as she viewed her video and exclaimed "Look at that! Those students aren't even listening to me!” Without missing a beat, Tanya acknowledges the student's awareness with a deep "hmmm-mmph!" in which one could translate as saying “Yeah...I know what you're talking about!” This comment made by the student has humorous irony as the university teachers participating in this research have remarked about the very same difficulty in maintaining the attention of their own students. These 
students are now experiencing it for themselves. Students later began to talk amongst themselves about their video work and a few get up from their computers to go help another student with a part of the editing process. The students have continued class time to work on their videos and also have help from Chris.

As the class is about to end and students are saving their work. Some students stay seated working on their videos. Tanya assures them that through the contemplation and working on their teacher video editing, there is help and assistance available. Table 37 displays the instructional technology choices Tanya used for her course. 
Table 37

Instructional technology choices for Tanya's course

\begin{tabular}{|l|l|}
\hline Web \& Computer-Based Technology Used in Class \\
\hline Instructional Technology & Participant Choices \\
\hline Course Website & X \\
\hline $\begin{array}{l}\text { Web Authored Course } \\
\text { (Dreamweaver/FrontPage) }\end{array}$ & $\mathrm{X}$ \\
\hline eCampus & \\
\hline Wimba & \\
\hline Textbook Website & \\
\hline Textbook CD & \\
\hline Subject-related web resource & \\
\hline Communication & $\mathrm{X}$ \\
\hline Email & $\mathrm{X}$ \\
\hline Discussion Boards & $\mathrm{X}$ \\
\hline Listserv & \\
\hline Chat & \\
\hline Instant Messaging & $\mathrm{X}$ \\
\hline Other Technology Used in Course \\
\hline PowerPoint & $\mathrm{X}$ \\
\hline Video & \\
\hline Simulations & $\mathrm{X}$ \\
\hline PDF Documents & $\mathrm{X}$ \\
\hline Inspiration & \\
\hline Wiki & \\
\hline Microsoft Word for presentation & \\
\hline Microsoft Excel & \\
\hline Online Libraries/Journals & \\
\hline Online Journals & \\
\hline
\end{tabular}

\section{Meaning}

Negotiation of Meaning. Tanya's interpretation experiences of integrating technology is significant as she says, "To me, technology was the great leveler.” This statement reflects her perception about the level of skill and ability teachers had integrating instructional technology, from higher education to public schools. No longer was there the traditional dynamic of higher education communities handing down instruction and direction to public school communities, but rather all teachers had to 
come together to learn to how to teach with technology. Tanya states that the most profound aspect of technology is that it brought together public school people and higher education people in which she says is "the heart of my work... and that allows us to have that common experience.” Tanya states clearly as a teacher that, "we are all novices in this world with something to learn." She feels very fortunate to be with the people in the college who are united in their commitment to learning about instructional technology.

She feels that the importance of computer use must be placed on helping us be better learners. More specifically, she discusses the notion that technology itself should not be the goal in mind, but rather "the vehicle" to help us be critical thinkers and good collaborative team members. Extending this view, she ponders the potential of using different methods to "help us [teachers] get to a deeper level of reflection that involves more aspects of the learner; the visual learner the auditory learner.” Tanya sees that we have a long way to go but "there are a lot of wonderful things that can happen, we just haven’t fully enacted them yet.”

Participation. Tanya's perspective concerning education's use of instructional technology is that it provides educators opportunities for learning that would not be available without the technology. She remarks that even though the teaching public may have a "love-hate" relationship with email and the Internet, the benefits of immediate contact to people and information cannot be denied. She is delighted by the ability to connect socially and form relationships with people surrounding the same interests. She discusses how technology has helped broaden her educational community by further by saying, "It has helped include people in your community that maybe would not...had it just been without the technology.” Of specific importance to Tanya is the ability to 
"reach all of her constituents rather than just a few people and that is critical to me." Examining how technology affects the relationships students have with other people, Tanya feels that it allows and pushes pre-service teachers to use a tool for collaboration which would not have been available before.

The personal and social significance Tanya believes she and her colleagues feel of integrating technology is that they must make adjustments in how they think of themselves as a teachers when comparing traditional face-to-face instruction versus online instruction. Her bias is to still have face-to-face interactions with her students and questions the appropriateness of the disconnection with students with an online degree in teaching. She feels that she still has a bit of reluctance to fully embrace the notion that the quality of instruction could still be the same. She reflects that maybe she has not had enough experiences with expert teachers using technology to be fully comfortable with the notion of an "online degree.” Tanya certainly believes in the possibility, but states clearly "Without intense professional development, you cannot succeed.”

She is sensitive to the learners' needs and feels that she and her colleagues must evolve in their instructional practices to meet their needs. Even though Tanya views this evolution forces teachers to be "reactive" in some ways, she feels that the need for learning to integrate instructional technology has helped invigorate and renew her teaching practices. She states, "now the pedagogies and strategies that were tried and true might need to be changed even though there may be kernels there that are tried and true,...but when you have to use this new technology, there are going to be some significant changes that we have to make.” Specific references she makes toward the "digital learner" is that of a "multitasker" in which she questions the push of technology 
and whether it is leading the "digital learner" in the right direction. Feeling the pressure and expectation to meet the learners' needs, Tanya finds teachers' challenges overwhelming to be able to capitalize on the experiences students already have with the technology. Contemplative in thought, she does have concerns with how teachers are going to help students learn who are going to be "in such a different world."

Reification. Some of the more prominent policies and procedures that provide guidance and structure to Tanya's 5 year teacher education program are driven by a few different entities including the state department of education, $21^{\text {st }}$ Century Learners Framework, the teacher education technology strand, and the Technology Integration Plan. These networks, policies, and plans that are never static in nature, but are regularly updated and negotiated for teacher’s "best practices.”

Tools that have been created and adopted to help Tanya perform in practice are more communication oriented web-based technologies such as course websites, blogs, Wikis, email communication, and listservs. These communication and information providing activities were once performed traditionally, such as face-to-face communication, mail, and paper/form packets to name a few. Computer and web-based technologies have provided Tanya with more efficient options to connect with her PDS teachers and pre-service teachers.

\section{Community}

Community Membership. The introduction of computer and web-based instructional technologies in the last decade has affected Tanya and her colleagues because, she felt "We all had to come together as a community because we all had a need to know and we can communicate about it.” The opportunity to have connections, 
different partners and mentors in her community she felt was unexpected, but it helped all of them realize that they are and will always be in a state of learning. The idea of community (both the college and the public school teachers) is important to Tanya because she sees the pre-service teachers caught in the middle as their experience leads them to learn from both ends. The skill level and instructional technology competencies of the faculty, PDS teacher and the pre-service teacher will ultimately be revealed through their participation in teaching.

\section{Dimensions of Communities of Practice}

Mutual engagement. When Tanya discusses her community members who teach in the teacher education program, she sees efforts faculty make to provide knowledge and competencies collectively and sees that they are all trying to integrate technology responsibly as well as participating in learning opportunities. She states, "We're learning together in those Faculty Academies.” Other structured interactions in which her community members, both college and public school teaches, engage include events organized by the state department. These events would provide opportunities for each community (college faculty and public school teachers) to be aware of what the other was doing. Tanya had other occasions to interact and collaborate with people from other higher education institutions in the state focusing on teacher education programs who she also considers part of her community. When discussing how people in her community come together to act meaningfully toward a common goal, she directly refers to teachers who are trying to work around and meet the needs of $21^{\text {st }}$ Century Learners.

Joint enterprise. When discussing the overall aim of her community of practice

Tanya notes that the college clearly has a focus on instructional technologies and refers 
to her practice being guided by the NCATE Unit Standards and Conceptual Framework. Tanya explains, "Every unit for NCATE has to have what they call their conceptual framework. The unit standards now have the technology piece in them, "Integrate into Technology Appropriately,” as part of the conceptual framework. They [NCATE] are imbedding those ideas into the content standards so that all teachers have to teach from because those are the standards that children will be tested on for the state tests.” She states that this isn’t necessarily a mission statement, but it is pretty close. In addition, Tanya again refers back to the Technology Integration Plan as the education community’s indigenous course of action as a guiding mission for integrating instructional technology.

Another guiding factor Tanya mentions is the state's initiative concerning the $21^{\text {st }}$ Century Learning, which is going to be a focus for the whole department of education to help teachers become better in their practice for $21^{\text {st }}$ Century Learners. Tanya continues to say, “From the state superintendent's emphasis on 21st Century Learning to our own strategic plan in the college, I think the good news is that people are kind of getting it in that we're thinking of instructional technologies as a way to get at learning goals.” As the $21^{\text {st }}$ Century Learners framework is a rather new initiative, she feels that both faculty and pre-service teachers need time to explore and understand them and that this will be a focus for new teachers. Being in contact with a state department liaison, she is aware of other educational initiatives that are happening around the state and states "a lot of them are dealing with technology and instructional technologies...its just constantly growing.” 
With all of Tanya's discussion surrounding the goals and aims of the education community, the collaboration and coordination of energies from the state department to the college to the PDS teachers to the pre-service teachers is in the forefront of her mind. Tanya mentions, "Working on these efforts to reach this goal [technology integration], you have people sitting side by side in the same room learning together and that was an incredible opportunity for us at the collaborative to feel like we were all equals."

Shared repertoire. Tanya discusses web-based shared points of reference for her community being the department and course websites, as well as the communication technologies such as email and listservs. Talking about the resources she and her colleagues use in the building in which they teach, Tanya states, "We are assigned classrooms and I think this building has become upgraded and technologized and there's still a lot of vying for those resources.” Tanya notes that as students and teachers work between the college and the PDSs, people must be aware of technology issues concerning compatibility. In addition, what the college may have as far as resources may not be the same as what is available out in the PDS. Significant to Tanya's work is also the support staff such as Wayne and Michael available to her and her students whom she recognizes as working toward helping her community accomplish their goals. 


\section{Narrative: Michael}

\section{Identity}

\section{Main Characteristics of Identity}

Learning process. Michael’s initial educational undergraduate pursuits began in the field of computer science, but after he graduated and worked in that field, he became unsatisfied with the career options that came with that educational background. He began to do some volunteer work tutoring and working with "troubled kids" and he began to think about pursuing a masters degree in the fields of either social work or education. Michael decided upon studying the field of social work in the same higher education community in which he now works. After one semester, he felt that he did not have the disposition needed to handle the difficulties that come with social work and switched his masters degree pursuit to special education. He graduated with his masters degree in special education and certified in learning disabilities. As he was working on his masters degree, he utilized his background in computer science to work within the computer lab now referred to as the technology support center. Being in this position, he was exposed and had the opportunity to work with people who were studying education and instructional technology. From this influence, he decided to obtain his second masters degree in computer education. A faculty member who used to run the computer lab that he worked in and who was involved in the educational department of curriculum and instruction contacted him and asked him if he was ready to work on a doctoral degree. Michael felt he was ready and completed his doctorate degree in curriculum and instruction. Laughing to himself, Michael states that his mother always jokes that as a child he hated the thought of going to school, but once she got him there, no one could 
ever get him out. Michael chuckles and said, "I guess you could really call me a life long learner...I’ve never truly left!”

Lived experience. Michael's initial educational background in computer science led him to careers in computer programming and systems administration. After 6 years of working in those fields, he wanted to examine different fields of work, obtained his masters degrees in special education and computer education, and then began working for a non-profit agency as a consultant working with assistive technology. He would train, evaluate, and help people with varying disabilities become appropriately matched with assistive technology devices. Michael again returned back to his alma mater to complete his doctorate degree in curriculum and instruction. He then went to a university out of state to teach in a faculty position for three years. Wanting to return to his alma mater for work, he came back and was employed as a server administrator for a health sciences and technology department. This position allowed him to work and provide training with schools who were looking into utilizing technology in their classes. This position led him to work on a grant for social work that reconnected him with some of the people he knew from school when he completed his masters degrees. The grant provided him with the chance to teach distance education through two-way audio and video conferencing to social workers. Michael then worked for an instructional technology resource center at the university initially as a database administrator for their online course management system which was WebCT then and now eCampus. He then changed positions in this department to become more involved in helping university faculty with their teaching as an instructional designer. After his position as an instructional designer, he once again returned to the educational college where he obtained his graduate degrees and serves as 
a teacher for the teacher education program as well as providing support services for faculty in their use of eCampus and instructional technology.

Social membership. Michael plays an important role for the college of education. He shares his professional duties between teaching for the teacher education program and providing instructional technology support services to educational faculty Michael's capability in both areas of computers and teaching in education has been gained through his work experience at the university and the completion of his higher educational degrees. He is referred to by his fellow faculty members as an "expert" in working with computers and instructional technology and he maintains a high level of competence as well with the application of his two masters degrees and a doctorate degree in curriculum and instruction that is applied to his teaching.

Nexus of multimembership. Michael shares his professional duties between two communities. In the college of education, Michael divides his responsibilities between teaching undergraduate and graduate students in teacher education and supporting faculty with the integration of instructional technology. For his teaching responsibilities, Michael teaches one course helping students with instructional design and one course helping students to implement instructional technology into their teaching and learning practices. For his responsibility to support faculty with their integration of instructional technology, he works both one on one with faculty as well as in a training capacity in the college's professional development activities. He also serves on committees that help plan and provide training to faculty for the faculty academy. 
Negotiated experience. Although Michael’s computer science background anchored him with secure employment, his desire to work in education in an instructional capacity kept him jumping from job to job until he secured his position teaching for the university in which he obtained his two masters degrees and a doctorate degrees. Beginning his undergraduate education in computer science leading him to jobs working with computers, Michael recalls that it was nott a conscious decision and teaching was always something he wanted to do. Michael stated that he did no like being isolated working as a computer programmer sitting behind a computer coding and programming all day. He longed for a position that was more people-oriented. As Michael contemplated his future career path, he stated that he felt he needed to do some soul searching in what he wanted to do. When Michael initially returned to graduate school, he wanted to pursue interests that were involved in the field of education as school had always interested him. Michael states, "I felt like I have the technology background, but pairing that up with the field of education and to look at the impact of teaching and learning really enabled me to bring my interests together in a meaningful fashion. I like working with faculty and I like working with my students.”

\section{Modes of Belonging}

Engagement. Michael's work involves him with both faculty and students and he feels fortunate to be a part of different situations and experiences in which he can influence them and they intern influence him. Michael is a teacher for both undergraduate and graduate level students in teacher education. Michael also is involved in the committees and meetings that are examining new technology applications that will support the teacher education program and their professional activities, such as new 
eportfolio software for the students and the development of a database for the college. In Michael's support role, he also is very much involved in the professional development activities for the college such as the Faculty Academy, the symposium series that brings faculty and students together to discuss different matters that affect the college as well as help faculty through workshops that focus on specific computer applications.

Michael pursues both his roles of teaching and supporting faculty with a strong interest in examining the process of learning. Explaining further, he is interested in learning more about the designing of conditions to create better educational environments in which people can experience a deeper level of learning. Michael says that his main goal is to help faculty and students to explore how technology can be used effectively to achieve their instructional objectives.

Imagination. Michael feels that computer technology has tremendous potential to create conditions under which people can experience a deeper level of learning. Although he is quick to express that he believes technology may not be a better way to learn, Michael feels that it can provide meaningful educational experiences beyond what can be created in a traditional classroom environment. Continuing on this line of thought, he states that schools may not yet be taking full advantage of what is available on the Internet for instructional purposes. Michael would like there to be a greater focus on the application of learning theories and the process of learning when it comes to creating digital education environments and experiences.

Michael then speaks of the use of the Internet in education to go beyond a medium for information dissemination and would like to explore the collaborative abilities made possible through Web 2.0 technologies. As Web 2.0 does not refer to any 
change in technology with the Internet, but rather refers to the behavior in which people are using the Internet. Web 2.0 refers to social networking applications on the internet which are dynamic rather than static web pages to collectively create and share content in a virtual community environment. Michael says, 'I think what is fascinating is the notion of the grass roots efforts in terms of people who are beginning to move in the direction of the idea of taking authority within rather than relying on others for the authority and direction. People have access to the world's information and knowledge and what we do with it is ultimately up to all of us and the potential for education is great.”

\section{Trajectory}

Boundary. Michael's membership to his educational community follows a boundary trajectory as his work is shared between supporting faculty and teaching preservice teachers. The knowledge and experience he has with computer technology and teaching in the classroom gives him with the opportunity to work with both faculty and students.

\section{Practice}

Mutuality of Practice. Michael believes that faculty are excited about the possibilities and the potential instructional technology can bring to the college of education. He feels that there is a shared vision among the different departments and that it can be seen through the "energy and synergy found through the professional development activities like the Faculty Academy.” These activities enable faculty to have dedicated time working together and Michael feels that it is important for faculty to continue to engage in shared experiences. 


\section{Characteristics of Participation}

Participation in resolutions to conflict and change. Michael discusses how he and other faculty are navigating their way through change integrating instructional technology. He states that he is "not making fast changes" and it becomes more difficult to keep up with the technology advancements. Michael looks to see how he can improve upon what he's currently doing and tries to incorporate technology where he feels it would be appropriate. It is Michael's objective to use technology only if it enhances his instruction and he focuses on being successful with one or two instructional technology approaches before looking to incorporate more. Recognizing again that he serves as a model for his own students, he states, "Its my intention to show them a good example of using technology so they can recognize the benefit and then hopefully see ways that they can integrate technology for their own classes.”

Acknowledging that there is an effort to take the K-12 schools into the $21^{\text {st }}$ Century, Michael hears from his student teachers that they are limited in what is available in the schools. He notes that it is his job to teach students how technology can be used to meet their instructional objectives, but he finds that the schools in the state are still behind in terms of what technology they have available.

Michael talks about the opportunity that he and other faculty have to engage in so that they can continue their ability to teach students about technology. Other than the Faculty Academy, Michael mentions the Symposium series as an occasion in which the teacher education program and the curriculum and instruction program can discuss the new state's standards and try to make the connections between the standards and technology applications. 
Support communal memory. When discussing how members of Michael's educational community contribute to their practice, he first states that he feels that he and other faculty could be "doing a better job of sharing their work with each other." His interests are shared by other faculty members who gave similar feedback at the faculty academy stating that they would like more opportunities to share and learn about the instructional technologies other faculty are using in their classrooms. Michael notes that from this feedback, he and other members who coordinate and plan the Faculty Academy will try to incorporate more time for faculty to share their work. Lastly, Michael mentions once again that there is a growing recognition among the faculty that a database in which they can access information from one another could be a critical tool to help members contribute to their practice.

Assist others. As Michael is regarded as having a high level of skill and knowledge about instructional technology, it is common for other faculty to go to him for assistance with their courses. He is quick to mention Richard and Wayne who are helpful to faculty as well. Noting the support available in the technology support center, Michael mentions the graduate assistants who can also provide support if anyone in the college of education is in need of help.

Perspectives to accomplish goals. Michael discusses how he and other faculty proceed with plans in order to achieve their pursuits for their educational community. He says, "The goal for ourselves is to understand and learn how to use technology so that we can teach our students to learn how to become more adept at the learning process,...but then they [student teachers] have to also apply that goal for their own teaching to their K12 students." Noting the state department of education made a commitment "to bring the 
$21^{\text {st }}$ Century Learning to the K-12 schools,” Michael states that at the college he and other faculty are asking students to create $21^{\text {st }}$ Century lessons.” He continues though stating that "they don't have $21^{\text {st }}$ Century tools and resources in the classrooms to support these lessons.” Michael remarks, "The state is not providing the support or the resources to these schools to enable the $21^{\text {st }}$ Century learning to happen!”

Sharing a perspectives felt by some of his fellow faculty, Michael says that some of the members are "wrestling with the idea that they will not be provided with compensation for the extra time and effort they have spent developing and teaching an online class.” Another controversial subject Michael discusses is the debate over the number of students allowed to be enrolled in an online class. He continues, "It's a money maker and a boundary has to be put into place. It is not the objective to burn out teachers!” Michael finds that this problem is now more well known among the members in the college and a practice not practiced as it once was when courses first were put online. On a positive note, Michael notes that it is part of the college's goal to connect to more people and instructional technology can provide the opportunity for those living in the rural areas in the state the ability to attend online classes.

\section{Learning in Practice}

Evolving forms of mutual engagement. Michael's interest and desire to return to the field of education changed his career path as he came back to work at his alma mater. After Michael completed his doctorate degree in curriculum and instruction, Michael formally began his work as a teacher as he obtained a faculty position in the field of education at another university. He longed to return to his alma mater though only after a few years of being away and took a few different positions within the university 
that combined both is knowledge of technology and teaching before he settled into his current role.

When he first returned, one of his positions at the university was at a health science and technology academy at the university which he states "at the time had a strong bend toward collaboration with the K-12 schools around the state.” Part of his position entailed that he would teach to these schools through distance education practices. This included teaching through two-way audio/video conferencing as well as travel to the school locations in the state. Recalling that the teaching through the two way audio/video technology seems rudimentary compared to today’s technology, Michael states that it was an impressive way at the time to connect to people at a distance. He remembers feeling "comfortable teaching through the audio/video conferencing system," as he was familiar with the technology, but he is quick to mention that this method would have certain difficulties. Michael explained, “As prepared as I could be, there would be connection issues on our part at the college or at the schools location...hic-ups that were unforeseen made me realize that it was important to always have a Plan B!” Michael would later work at another location within the university as an instructional designer that helped faculty integrate instructional technology. After a brief period of working in that position, Michael then returned to the college of education where he now works in his current role.

Michael recalls that he began his relationship with the university's college of education fifteen years ago. Describing his evolving participation in the university, he states, "I've been involved with this school for a long time, as a as a student, a graduate assistant. I was a faculty member teaching for another university and then I came back to 
this college. Now I teach and also provide support to faculty.” The background and teaching experience Michael has in the field of education enables him to teach for the teacher education program. The knowledge and experience he has working with computers also enables him to serve in a support role for the college. Feeling that he has "found a niche," Michael expresses that the combined areas computers and education are a "logical fit." He states that he can take his interests in the "process of education and intertwine it with the pursuit of how technology can aid in the understanding of how people learn.”

Michael describes the position that he and his fellow faculty have in the teacher education program as "complicated" as they work toward a common goal of integrating instructional technology. He states that they all share an interesting perspective in that there are "multiple levels.” Michael explains that "he and other faculty are in higher education teaching future teachers who will then teach their own students in the K-12 schools."

Currently, Michael teaches an undergraduate course and a graduate level course in teacher education program. One course focuses on helping students with instructional design and one course helping students to implement instructional technology into their teaching and learning practices. Michael's role in working with the undergraduate students involves teaching, assisting them with their action research projects as well as guiding them through the observations of their student teaching in the public schools. For the students who will be teaching in the schools, Michael comments that they are just becoming familiar and learning teaching methods they can use in the classroom. He would like them to realize that technology can provide an option for teaching and would 
like them to be "discriminating and use the technology when it is appropriate...not just use for technology's sake.”

Michael currently uses eCampus for both of his courses and feels "mostly comfortable" teaching with the instructional technology applications he has chosen. Michael mentions that he approaches technology integration initially with a basic list questions:

- What am I trying to achieve?

- What are my teaching objectives related to this activity?

- What teaching strategy would be appropriate for this situation?

- What technology would relate to the chosen teaching strategy?

- How will I evaluate whether the chosen technology was helpful achieve the teaching objective?

Michael explains that he applies these questions for the development and teaching of his own courses, for his students to follow as they develop instruction for their K-12 lessons, and for the support of the faculty as it relates to their college courses. He comments, "Becoming competent in teaching with technology is a work in progress." Michael feels that even though he has the knowledge of the technology applications, he says that he "learns something new because each experience teaching with the technology in the classroom is different.”

Michael explains his interest in new software applications to improve upon his teaching practice. One of the applications is social networking software, which in Michael's estimation, “can provide collaboration opportunities among students, public school teachers and faculty." He feels that it is "important because it is an activity that many of the students engage in" and he has not had the chance to explore its instructional 
possibilities. Another area of interest to Michael are applications such as TurnItIn.com that deal with online learning and dishonesty. Michael expresses that as he and other faculty are requiring students to do more work online, he would like to ensure that the work they are turning in is their own. "As a teacher," Michael states, "I want to know that I’ve done my best to prevent that type of behavior.” For his own classes, Michael notes that he is sure to include multiple types of assessments to evaluate the quality of the students' work. Lastly, Michael mentions that he stays current with professional journals and publications to learn what other professionals in the field of education are saying about their experiences with instructional technology.

Understanding and Tuning of Enterprise. Michael discusses the efforts directing the teacher education program's mission to include instructional technology into their curriculum. The first thing that Michael mentions is the state's department of education's standards. These standards were recently revised to incorporate what the state saw as essential knowledge and skills necessary for students to become competent and productive in the $21^{\text {st }}$ Century. Michael remarks that he and other faculty will have to become more familiar with the changes that have been made to these standards as well as doing what they can to "meet and apply them into the methods courses." He agrees with this mission that, "The $21^{\text {st }}$ Century learning effort is partially technology and partially skills. The skills that these students will need to advance and be successful in the $21^{\text {st }}$ Century are higher order thinking, collaboration, problem solving and creativity.” Michael also notes that the teacher education program's goals for the use of instructional technology are guided by the National Education Technology Standards for Students (NETS-S) that was established by the International Society for Technology and 
Education (ISTE). Michael says that as he is aware of the state standards, but he is unaware of any university policies concerning faculty's use of instructional technology. He states that it is necessary that the college of education's faculty become skilled with technology use as they must serve as role models for future teachers.

Developing Their Repertoire, Styles and Discourse. When Michael thinks about the evolution of his educational community's use of instructional technology, he is pleased and surprised to see faculty members who were once averse to adopting technology, now embrace it and include it in their teaching. He states, "If you would have asked me 10 to 15 years ago if some specific faculty members would be using instructional technology, I would have thought not a chance. There has been so much change and growth concerning technology use.”

Michael credits the college of education and their continued interest in providing faculty with technology support and resources such as the technology support center. He also mentions that there have been people hired to help faculty and support them in their efforts to integrate technology. As Michael at times helps faculty with their courses, he mentions new developments and applications and describes that these "fall outside the realm” of his abilities.

He explains that one of the new developments currently being constructed is a database that would collect information from the teacher education program with the intention that it could help inform their future policies and practices. Michael believes that faculty are realizing the potential that collected data from their teacher education program could have. As he feels that the program will have to hire a full-time person who has database development expertise in order to see this vision come to fruition, 
Michael describes that the database will have a web-based interface so that faculty can easily upload and access information with a secured back-end database. This project in Michael's view is a significant example of how the college is evolving as it relates to instructional technology.

Snapshot of Instructional Technology Use. The class is taught in the small computer lab classroom that exists on the technology support center which is the same room used by Tanya. At the start of the class, Michael directs his students' attention to the list on the board. On the left hand side of the dry erase board, Michael has written bulleted instructions items for the class's agenda. The first bulleted item starts with a reflection activity and reads, “Reflections: Describe an instance when you've been able to successfully use technology in a teaching or learning situation.” He refers to the "Reflection" item and he describes that he would like them to write about a successful experience they have had using instructional technology in their teaching. Students will later have these journals that they have the option to later put them into their electronic portfolios.

Using the Journal feature on eCampus, the students have a shortened time period for this activity and the students begin typing. Michael uses this journaling activity as a warm-up and focusing activity in the beginning of class as well as an opportunity for students to reflect upon their experiences. The sound of the typing is nothing short of thunderous as all students are typing vigorously all at the same time. He leaves them to this activity for a few minutes and then tells them that they can finish their activity later and to put their last thoughts down. Michael explains later during an interview that through the weekly reflection, he can see the development of students as they go from 5 
hours to 14 hours teaching in the school and he can later address any concerns when they meet in the classroom. Michael explains, "The journaling provides them with a mechanism to process their experiences teaching in the classroom and to write down what they are going through.”

After the journaling activity, Michael works through more of the bulleted list of the class's agenda. His topic for this class focuses on the ways that students can use instructional technology to bring real world current events into the classroom. Michael goes to the console in the front of the room and begins a to pull up an educational website containing videos that teachers can use in the classroom called TeacherTube. Students sitting at their computers go to the website themselves and share their attention between what Michael is displaying on the screen and what they can manually control on their own computers. Students start to search the videos past what Michael is showing. As Michael displays on the videos to the class, he instructs his students on planning the process to include instructional technology. Proceeding to show the students the video, he discusses the educational and technical factors of integrating video into their instruction. He instructs students to “take small steps...don't try to do everything at once” and "to make sure the use of instructional technology focuses on their objectives and not on the technology itself....to use the technology as a means to meet the learning objectives.” Students nod as Michael is speaking and appear to understand the message he is trying to convey concerning the appropriate use of instructional technology in the classroom. Michael stops and starts the video displaying from the LCD projector, interjecting comments concerning media literacy skills and the use of displaying videos in the classroom. 
Michael goes to the console and logs into the eCampus course website and clicks on the Web Links hyperlink located on the website toolbar. He asks that his students follow along with him on the eCampus site and most click off of what they are doing and go back to the eCampus site, following his direction. As the class can observe what Michael is doing through the LCD projector, the Web Links website page lists a significant amount of education related websites. He scrolls down the list and stops and makes specific note of the links titled Technology Videos, Technology Video: Integrating Technology, Research and Problem Based Learning, United Streaming, and Discovery Education. Michael selects the United Streaming website as a resource where students can access more educational videos and tells them that he has created an account. Picking up a marker, he goes to the right hand side of the overhead screen to write his username and password on the dry erase board. Pointing with the marker to the board, Michael turns to the students and tells them that they can access the site with his username and password. As an activity to do outside of class, Michael asks that the students go and log onto the United Streaming video. He discusses the importance of incorporating video clips that contribute meaningfully to their lessons.

Asking if the students had any questions so far, Michael proceeds on reviewing the other hyperlinks provided in the Web Links page on the eCampus course website. The list is long with educational websites such as NASA Quest, National Geographic, Explore Learning, KidsClick, and PBS Teachers to name a few. One student mentions to Michael that their schools may have different technology resources available and Michael commends this student for making the insightful point. Further discussing this matter, Michael stresses the importance for students to be sure that the classes in which they 
teach are technologically equipped to use their lesson plans that include instructional technology. In addition, that they again have a "back-up plan ready in case a problem occurs.”

Michael goes on to talk to his students about the importance of evaluating website resources and to be sure that what they are showing in class is not incorrect or a misrepresentation of the topic area. On the overhead screen, Michael then moves on to talk about the use of rubrics as a set of guidelines to evaluate the videos. Michael shows samples and models of rubrics and what is involved in their construction.

He reminds the class that their $21^{\text {st }}$ Century Lesson Plans are due in 4 weeks and for the last part of class, he would like them to work on this task in their groups. The student groups will present their lesson to the class and will provide feedback to their classmates on the delivery of this $21^{\text {st }}$ Century Lesson. As there has been a large amount of class activity displaying instructional technology resources, Michael has emphasized to students that should look at technology as a possible teaching strategy or approach to design and evaluation of their lesson plan. The instructional technology Michael chose to use for his course is displayed in Table 38. 
Table 38

Instructional technology choices for Michael's course

\begin{tabular}{|l|c|}
\hline \multicolumn{2}{|c|}{ Web \& Computer-Based Technology Used in Class } \\
\hline Instructional Technology & Participant Choices \\
\hline Course Website & \\
\hline $\begin{array}{l}\text { Web Authored Course } \\
\text { (Dreamweaver/FrontPage) }\end{array}$ & \multicolumn{1}{|c|}{ X } \\
\hline eCampus \\
\hline Wimba & \\
\hline Textbook Website & \\
\hline Textbook CD & \\
\hline Subject-related web resource & \\
\hline Communication & $\mathrm{X}$ \\
\hline Email & \\
\hline Discussion Boards & \\
\hline Listserv & \\
\hline Chat & \\
\hline Instant Messaging & $\mathrm{X}$ \\
\hline Technology Used in Course & \\
\hline PowerPoint & \\
\hline Video & \\
\hline Simulations & \\
\hline Wiki & \\
\hline PDF Documents & \\
\hline Inspiration & \\
\hline Wiki & \\
\hline Microsoft Word for presentation & \\
\hline Microsoft Excel & \\
\hline Online Libraries/Journals & \\
\hline Online Journals & \\
\hline
\end{tabular}

\section{Meaning}

Negotiation of Meaning. Michael states that he is "fascinated with where computer technology and the Internet are taking the field of education” in terms of providing mechanisms for students and teachers to approach the task of learning in new and more effective ways. Mentioned repeatedly, Michael believes that technology offers significant potential and opportunities to open doors to valuable resources and information that would otherwise not be accessible. In terms of teaching and learning, he 
finds that it is important to determine how to best utilize these tools that are available in education to enable learners to meet their goals.

Teaching future educators in the teacher education program, Michael states that he and his fellow faculty are responsible to be role models to present and demonstrate strategies that incorporate instructional technology so that their students can effectively model its use in their own future classrooms. Michael thinks about what skills will be necessary for his students to have in order to navigate through this "wild world that is developing” and believes that technology will play a "critical role in supporting their efforts toward working on solving global problems.” Continuing on his thought, Michael feels that the world's problems will increase and it is important to prepare students through activities that work to enhance their critical thinking skills. He feels that it is important to provide students with activities that engage them with real world problem solving projects and the use of technology can support their efforts.

Along with his belief that there is great potential for education with the use of technology, Michael feels that it lags behind other fields and that it has not yet taken full advantage of the resources available especially in the K-12 schools. Michael quickly mentions that the lack of financial resources available for the K-12 schools could also contribute to reason why education is not meeting technology's potential. Michael further expresses, “We're just not there...we're not meeting it [educational goals] with technology and I don’t think we're meeting it without technology” talking about standardization for K-12 schools.

Michael is cautious but also enthusiastic about the use of technology in the classroom. He states, "Technology should be used purposefully and as an effective 
tool...not just be used for the sake that its technology, but how does it enhance the instruction?” Michael finds that he struggles with seeing technology not being used in an informative way and warns that teachers should remained focused on "student learning" and that "technology itself should not be the main focus."

Participation. As Michael shares his perspective on using instructional technology, he does not call attention to any specific computer application or technology that he uses in his classroom. Rather, as a teacher, he expresses his intentions behind his instructional decisions to use or not use technology. He feels that his primary role as a teacher is to provide information and teach students how to think within their discipline through meaningful learning experiences. Michael states, "Each discipline has its own way of thinking, way of looking at knowledge and working with that knowledge. It is my belief that my teaching role is to engage students in that process."

Michael's intentions for his own instructional practices are not initially focused on what technology can offer his students. Michael clarifies his thoughts by explaining, "In higher education especially, there are people who have used effective instructional methods for years that don't include instructional technology and if its effective, there's nothing wrong with that.” Michael states that as he prepares for his classes, he focuses on instructional strategies that will help him achieve the goals and objectives of the course. When it comes to making decisions about whether or not to use technology, Michael says that "if technology can serve as a mechanism to do that, then I will incorporate it into my class...if not, then I won't."

Although Michael's testimony communicates that he is wary of the inappropriate use of instructional technology, he is enthusiastic about its educative possibilities. 
Michael's comments turn to the Internet and he feels that education has just begun its process of tapping into the "network of resources available that can enable and provide teachers with mechanisms to engage students in deeper levels of learning.” He would like to find new ways to effectively manipulate the information to create new educational possibilities for his students. He asserts, "We have an information explosion and we need to turn it into a knowledge explosion!”

Michael, again expressing caution in the approach of integrating instructional technology, warns his own students not to use the computer and the Internet in “uninformed ways.” He hears stories of the computer being used as a "reward” for students in the K-12 schools and regards this as "disappointing and a poor approach.” Michael comments further by saying, "Technology should not be used for the sake of using technology. It should be regarded as another instructional tool, but not to be used in place of instruction.”

Reification. As Michael thinks about his own college of education, he is aware of other universities creating policies that require students to purchase laptops for the use in their classes. He expresses that he feels there is a "recognition system that has been put into place regarding the evolution and use of instructional technology where educational institutions are concerned.” Stating further, Michael comments, "Its almost necessary that there is a recognition of efforts to develop innovative instructional practices using technology for higher education institutions to stay competitive.” Within the university and in his own college, Michael comments on the educational programs that are currently being put completely online. He notes the differences among these program models as some are completely online while some schedule face-to-face 
meetings on the weekends. He finds these different system configurations intriguing and remains indecisive about how he feels about online programs.

When the college has meetings with major computer companies to negotiate the use of their brand of computer applications, Michael is often included in the discussion and decision making process offering his knowledge and expertise. He finds these meetings to be "illuminating" at times, as the technology applications being discussed are found to be sophisticated, while the accompanying instructional strategies to be used with these applications are not. Expanding further upon this thought, Michael expresses that he finds himself “conflicted at times” as the instructional examples provided with the computer application at times represent poor instructional quality. Michael states, “Sure,...they [computer application] represent the dissemination of information, but its not engaging or quality instruction.” He comments that he feels strongly about this issue as he sees himself as a "role model for future educators" and that "showing poor quality instruction for the sake of using a cool gadget is not what using technology is about!” Michael focuses specifically on the use of podcasts capturing lectures as he speaks on this issue. He states that he can recognize the appropriateness of the use of podcasts to capture the lectures for introductory classes, especially those with a large number of students. Michael clarifies his thoughts by saying “Technology can provide more instructional options and variety. The dissemination of information provided through the digital recording of a long lecture and then delivered through a podcast is not instructionally superior!” 


\section{Duality of Meaning}

Reification without participation. As he feels that there is pressure from the university to teach more classes online, Michael states that he and other faculty members are seeking opportunities to share in collective discussion about integrating instructional technology. Michael refers to the feedback received at the Faculty Academy in which faculty felt that there was not enough dialogue to explore each others’ work and talk about their experiences. Michael states, "If we have a lack of chances to come together as a community, we miss out on collaborative discussion.” From his perspective, he feels that people in the college have a tendency to become isolated and more dialogue among members could help provide a integral perspective on what faculty feel their purpose is as it relates to instructional technology.

\section{Community}

\section{Dimensions of a Community of Practice}

Mutual engagement. When Michael talks about how members of his educational community engage with one another through their pursuit of learning to integrate instructional technology, he begins his discussion with an interesting awareness. He finds that he is in a "diverse sort of college" in that there are many different areas of study that exist under the college’s roof. In saying that, Michael states that "there is a common ground in their pursuit of learning how to use instructional technologies and determining how technology fits within the goals and objectives of their instructional practices.”

Michael sees that activities like the Faculty Academy and the Symposium series facilitate the bringing together of the faculty that teach in these different programs. 
Stating more specifically, he says, "You've got people sitting side by side that are on different floors on the building that don't have opportunities to talk to each other...and they'll share with each other during these activities and instructional technology is the focus.”

Through these activities, Michael explains that the faculty have the ability to see how technology influences other faculty in other areas of study that they would not be aware of otherwise. By seeing different technology and the variation of uses, Michael notes that faculty can then try different things for themselves. He finds this information sharing and viewing to be a "cyclical activity.” Michael explains, "As faculty see a different technology application that they would like to incorporate into their courses, they have the ability to try it, learn from it and come back next year to discuss their experiences... where they may help another faculty member learn about it.”

Michael would like to see that the energy and synergy of faculty sharing continued throughout the year rather than just being experienced through the faculty academy or symposium series. Believing that it is a pretty common phenomenon for people to retreat back to their departments and continue working individually, Michael would like for faculty to keep working together through "brainstorming sessions or just plain dialogue.” Through the faculty’s feedback acquired at the Faculty Academy, he finds that the faculty feel the same way too. He feels that there is clear evidence that the college values the use of instructional technology and provides mechanisms like the Faculty Academy for faculty to have a week of focused time with effective resources and training to work on developing their courses to integrate technology. 
When thinking of other mechanisms the members of his educational community had to communicate and share with each other, Michael mentions that some faculty are working with a Microsoft computer application called SharePoint. Michael explains that it is similar to a listserv and acts as a collaborative workspace that faculty can share and manipulate documents and information. Michael also mentions a wiki that was recently developed for the teacher education program. He discusses that the director of the teacher education program was looking for an innovative way and different tools to promote interaction and collaboration among teachers.

Joint experience. As Michael discusses what he believes his community’s missions and goals are for the use of instructional technology, he mentions that he is "unaware of an explicit policy, but there is definitely implicit that technology is valued in the college." He feels this is reflected in sentiments communicated to the faculty by the new dean of the college, the new director of the teacher education program and the department chairs. Michael states that he believes that more people within the college are aware of the expectation to integrate technology, but also that they understand that technology can provide meaningful learning experiences for their students.

Michael notes that there is an expectation on the new generation of faculty coming into the college to skilled at using technology. He states, "In the selection process of the new hires, they will be asked what they have done and what can they do with instructional technology as well as how do they view instructional technology playing a part of their instructional practice.” Continuing on this line of thought, he finds that the new faculty coming into the college usually have a higher level of skills when it 
comes to technology use and they have a willingness to readily adopt instructional technology.

As the new faculty come into the college, there is a university-wide "new faculty orientation session.” Michael states that the college has an orientation session for new faculty as well that they are encouraged to attend where they can learn specific information about the eCampus course management system, the university campus email systems, and learn where the technology resources, assistance and support is available. Michael plays a major role in these sessions helping new faculty learn about the technology available in the college.

Shared repertoire. As Michael talks about the resources available to his educational community, he first mentions the expertise provided by other faculty members in the college. The people he discusses are also teaching faculty like him who have a good working knowledge with different instructional technology applications. These folks also help plan the professional development sessions for their fellow faculty members.

Michael then mentions the resources available through the university, but is quick to mention the significant amount of technology hardware, software and support services available through the technology support center housed in the college of education. He states, “Faculty and students don't feel that they have to travel outside of the building to get support when there are people available to come up to their location and provide the help they need.”

Michael mentions that their college of education is perceived in the university as having an effective "model” of practice when it comes to providing support and 
professional development opportunities for faculty. He is pleased to mention that people from different colleges in the university have come to the technology support center to learn more about the college of education's system.

Michael states that this community is benefited by the technology fee that students pay for each semester as that money is fed back into the college to help pay for the upkeep of current and purchase new technology. He concludes by saying, "To have these tools and resources available, it allows us to work at a higher level and enables us to continue to move forward.” 


\section{Chapter Five}

\section{Discussion of Findings}

The purpose of this study was to take an exploratory look at how university teachers come to understand their experience in educational practice and their professional role as teachers who integrate instructional technology into their coursework using the framework provided by Wenger's Social Theory of Learning.

University faculty who teach in a college of education that integrate instructional technology into their courses were important to inform this study. Data relevant to understand university teachers’ understanding of their experience integrating instructional technology was collected and analyzed from 1) faculty’s engagement in an annual instructional technology professional development activity and 2) eight participants. Data that was collected from the faculty's engagement in a professional development activity included a week long observation, binders that chronologically described the history of the professional development activity, the college's current technology support structures, and shared resources that help faculty in the college integrate instructional technology. Data collected from the eight participants to inform the case studies included interviews, observations, and the review of the participants' courses from one academic semester that displayed instructional technology integration. The data was analyzed and coded by the framework provided by Wenger's Social Theory of Learning to identify emergent themes and patterns that informed the teachers' understanding and experience of their role responsible to integrate instructional technology.

This chapter includes the following sections: (1) results, (2) discussion of the results, (3) implications, (4) limitations, and (5) recommendations for future research. 


\section{Emerging Themes Informing the Research Questions}

\section{Research Question 1: What are university teachers' reflections of their role now}

\section{responsible to integrate instructional technology?}

\begin{tabular}{|c|c|}
\hline \multicolumn{2}{|l|}{ Identity } \\
\hline Identity Subcomponents & Themes \\
\hline \multicolumn{2}{|c|}{ Part I History and path into educational community } \\
\hline $\begin{array}{l}\text { - Learning Process } \\
\text { - Lived Experience }\end{array}$ & $\begin{array}{l}\text { Theme 1. Learning background in field of education } \\
\text { Theme 2. Pursued work in university community setting } \\
\text { Theme 3. Leadership roles in educational community }\end{array}$ \\
\hline \multicolumn{2}{|c|}{ Part II Identities influenced as they interact and participate with instructional technology } \\
\hline $\begin{array}{l}\text { - Social Membership } \\
\text { - Nexus of } \\
\text { Multimembership } \\
\text { - Negotiated Experience } \\
\text { - Engagement }\end{array}$ & $\begin{array}{l}\text { Theme } 1 \text {. Early adopters plus late adopters equals all adopters } \\
\text { Theme } 2 \text {. Increased demand on teachers' pedagogical identity } \\
\text { Theme } 3 \text {. Responsibilities to multiple communities inside and } \\
\text { outside the university }\end{array}$ \\
\hline \multicolumn{2}{|c|}{ Part III Vision for educational community for the future and how technology plays a role } \\
\hline $\begin{array}{l}\text { - Imagination } \\
\text { - Trajectory }\end{array}$ & $\begin{array}{l}\text { Theme 1. Seamless transparent online synchronous technology to } \\
\text { connect to students } \\
\text { Theme 2. Student capabilities empowered through technology } \\
\text { Theme 3. Creation of authentic experiences }\end{array}$ \\
\hline
\end{tabular}

\section{Part I: History and Path into the Educational Community}

Theme 1: Learning background in field of education. The majority of the participants in this study began their interest in the field of education during their undergraduate studies. Only two of the participants began their focus on the field of education during their graduate work. It was found that participants have remained with the same or related subject area of interest that they studied during their undergraduate and graduate years at school.

Theme 2: Pursued work in university community setting. The participants in this study have been involved with the university setting and the college of education from a range of 15 to 34 years. The majority of the participants sought to work in a 
university environment after they completed graduate school. Only two of the participants worked in other fields prior to working for the university.

Theme 3: Leadership roles in educational community. Participants in this study carried progressive leadership roles and are actively involved in their educational community. This was identified through their unique participation in various educational activities. A sample of their participation included the development of learning models placed in public schools, involvement with state and national educational organizations, writing and managing of grant related projects, teaching off campus students, knowing and teaching every course in an educational program, receiving teaching awards, collaborating with public schools and teachers around the state, having expertise with instructional technology and supporting the educational community to increase their own level of skill and knowledge. In addition, all of the participants regularly engaged in professional development activities that helped improve their level of skill and knowledge integrating instructional technology.

\section{Part II: Identities Influenced as they Interact and Participate with Instructional Technology}

Theme 1: Early adopters plus late adopters equals all adopters. It was common for participants to refer to themselves as "late adopters, early adopters, and second adopters," as they communicated their experience and decision making process learning to integrate instructional technology. Participants who were self-professed late adopters stated they were initially skeptical and less than enthusiastic about experiencing a change in their instructional practice as they were not convinced of technology's practicality or ease of use. It was their choice to not seek out instructional technology, 
but rather observe and discuss their colleagues’ experiences and base their decisions from their successes and difficulties. Another part of the late adopters' resistance was due to the awkwardness they felt teaching with technology and they did not want to lose important class time due to their "fumbling" with technology. Through participation in professional development activities where they could learn more about instructional technology and dialogue and support from their colleagues, the late adopters became adopters and began to assess carefully how technology can assist with their instructional tasks. These participants continue to assert that technology is just a tool and not to be viewed or identified as instruction.

In comparison, participants who were early adopters described themselves as 'avid learners' and eager to pursue and engage in learning activities for the purpose of increasing their instructional abilities. Their early adoption behavior was due to partly to previous work-related experiences where they were responsible to use computers as well as their internal enthusiasm and interest to exploring how instructional technology could enhance their teaching. These participants also sought out participation in professional development activities concerning instructional technology and learned side by side with the self professed late adopters.

Since ten years ago with the initial Faculty Academy, these participants are still attending and are actively involved with participating in professional development activities that involve instructional technology. All participants utilize the eCampus course management or have developed their own course website and teach using instructional technology. Even though the initial interest in using instructional technology varied among these participants, they are all using it successfully. 


\section{Theme 2: Increased demand on teachers’ pedagogical identity due to}

technology. Participants commented that their traditional teaching practices were viewed as being no longer sufficient, because their role as teachers was growing to include instructional technology. It was important to these participants, in their role as teachers, to look for new ways to improve upon how they currently taught their courses and the instructional practices in which they conveyed their content to their students. Participants felt that the expectation to integrate instructional technology heavily "influenced" their role as teachers. This expectation influenced and increased the demands placed upon teachers’ pedagogical identity rather than the content-expert aspect of their identity. Participants viewed this to be an change in their perceived competence as teachers as they felt more assured in the knowledge of their subject matter. Priority was now placed upon their pedagogical knowledge and ability to impart that knowledge to their students.

This shift was evidenced by participants in their comments about serving as role models and being able to demonstrate appropriate teaching practices for teacher education students. Participants felt that the more they learned to use the computer, the more information and knowledge they could provide for their students, which would help increase students' abilities to think through their work. Other comments about the change in their role as teachers included being more "facilitators of knowledge," and becoming a “knowledge worker’s society” and “producers” in how to use technology. These participants reflections about their role as teachers in turn reflected on parts of their teacher identity that were pedagogical in nature rather than their identity as a subject matter experts. 


\section{Theme 3: Responsibilities to multiple communities inside and outside the}

university. All participants of this study mentioned their involvement and responsibilities in a multiple number of educational communities that were both inside and outside the university setting. Participants explained that the focus and intentions of these educational communities varied as could be content-focused, research-focused or process-focused. Most participants revealed their surprise when they began discussing their various roles and responsibilities and expressed that it was difficult to balance all activities at once. As the participants are identified as teachers, they share that title with the roles they have to other educational communities.

Memberships in educational communities outside the university setting involved discussing research and teaching issues in content related professional educational organizations, providing scholarships to students and grants to teachers from educational foundation boards, working with the state department of education, and integrating learning models in other university and public settings. Memberships in educational communities inside the university setting included collaborative grant writing and research between colleges in the university, coordinating leading and training for professional development activities, working within a clinical setting, and coordinating and communicating with teacher education faculty and with public school teachers. Their membership and relations to various educational communities were influenced had changed due to communication technology. Communities are not just local people who are in the college as they could include people from previous work or learning experiences. 


\section{Part III: Vision for Educational Community for the Future and how Technology Plays a Role}

Theme 1: Seamless transparent online synchronous technology to connect to students. Participants witnessed learners transferring from the classroom to the workplace and they longed to remain connected to their students as they made this transition. Participants wanted to be able to provide "real-time" guidance and direction for their students as they began their working experience in the public school classroom and clinical settings. They felt that the "real-time" feedback that they could provide would assist their in having a successful transition. As participants longed for this ability, the most commonly mentioned technology-related vision that all participants talked about for their educational community was a seamless transparent online audio-video synchronous technology system where they could observe and coach their students at a distance in the public school and clinical settings. Their vision could enable them to enter the setting from a distance, participate in the interactions, conduct focused observations and guide their students’ efforts toward the best instructional practices. Participants added that the ability to capture these moments could also provide the opportunities to review students’ work and instruction so that students were able to mentally process their performance in the work setting. Participants thought that this kind of technology could enable them to see and guide their students' efforts as it was occurring which was otherwise lost in the classroom or clinical setting.

Other purposes stated by participants about this type of technology was to be able to enable students to see relevant subject matter materials and documents and connect with other experts in their field. Other abilities participants wished for using this type of 
technology was the ability for both teachers and students to display instructional materials to share and see at all times.

Participants acknowledged that Wimba and Adobe Connect were two technologies that could enable this vision because they were affordable and available to both the college and the public school. The facility provided with these technologies, they felt they did not provide the seamless connection they hoped for. They described their experience using each technology as “buggy, clunky, and still having technical problems.” This perception did not deter their belief in the technologies as they felt these were problems that would eventually be solved through new versions and updates of the products.

Theme 2: Student capabilities empowered through technology. Participants wanted to be able to empower students in the classroom. They felt it was important to create a learning community environment where students could be the main contributors to the class sharing and teaching other students in the classroom. Through the use of communication and synchronous technologies, participants wanted to provide their students with a platform to network, creatively share their content and have the ability to develop their own grass root communities. Participants wanted equal access to technology was provided to all of their learners.

Theme 3: Creation of authentic experiences. As participants talked about their visions for the future of their educational community, they discussed the use of technology to create authentic learning experiences. They did not want technology to get in the way of their teaching or disconnect them from their students. It is their charge to develop and teach their courses online and it was important to participants that they feel 
connected to their students. They prefer face-to-face contact in the classroom and hope that the future of online classes will not separate them from the learner.

Participants were enthusiastic about their ability to provide their students with authentic learning materials that were relevant to the subject matter of their courses. Through the use of video clips, simulations, and digitized archived documents, participants wanted to provide the best learning experiences for their learners. 
Research Question 2: What is the process of university teachers participation and engagement with delivering instructional technology in the classroom?

\begin{tabular}{|c|c|}
\hline \multicolumn{2}{|l|}{ Practice } \\
\hline Practice Subcomponents & Themes \\
\hline \multicolumn{2}{|c|}{$\begin{array}{l}\text { Part I Knowledge and skill building, learning instructional technology to participate in } \\
\text { educational practice }\end{array}$} \\
\hline $\begin{array}{l}\text { - Participate in Resolutions } \\
\text { to Conflict \& Change } \\
\text { - Evolving Forms of Mutual } \\
\text { Engagement }\end{array}$ & $\begin{array}{l}\text { Theme1. Learn instructional technology through participation in the } \\
\text { Faculty Academy } \\
\text { Theme 2. Evolving methods of practice using instructional technology }\end{array}$ \\
\hline \multicolumn{2}{|c|}{$\begin{array}{l}\text { Part II Understanding of community mission involving instructional technology that } \\
\text { affects how members engage in educational practice }\end{array}$} \\
\hline $\begin{array}{l}\text { - Mutuality of Practice } \\
\text { - Perspective to Accomplish } \\
\text { Goals } \\
\text { - Understanding \& Tuning } \\
\text { Enterprise }\end{array}$ & $\begin{array}{l}\text { Theme 1. Shared understanding among faculty concerning the } \\
\text { importance to use instructional technology in their courses } \\
\text { Theme 2. Attend to the university's charge for faculty to use instructional } \\
\text { technology } \\
\text { Theme 3. Proceed to use instructional technology, but its use must be } \\
\text { purposeful } \\
\text { Theme } 4 \text {. Understanding the comprehensive revision of the state } \\
\text { department of education's content standards and objectives } \\
\text { Theme 5. State department of education's requirement of } 3 \text { hour credit } \\
\text { technology course }\end{array}$ \\
\hline \multicolumn{2}{|c|}{$\begin{array}{l}\text { Part III Assistance and resources developed for the use of instructional technology for } \\
\text { members to engage in educational practice }\end{array}$} \\
\hline $\begin{array}{l}\text { - Support Communal } \\
\text { Memory } \\
\text { - Assist Others } \\
\text { - Develop Repertoire, } \\
\text { Styles, Discourses }\end{array}$ & $\begin{array}{l}\text { Theme 1. Colleagues assist each other within the College of Education } \\
\text { Theme 2. Instructional technology used in courses } \\
\text { Theme 3. Development of teacher education program database }\end{array}$ \\
\hline
\end{tabular}

\section{Part I: Knowledge and Skill Building, Learning Instructional Technology to}

\section{Participate in Educational Practice}

\section{Theme 1: Learn instructional technology through participation in the}

Faculty Academy. All participants communicated that they regularly attended the annual Faculty Academy which is a instructional technology professional development event for the faculty in the college of education. Participants defined this activity as a developmental process where faculty learned to work and interact with their colleagues 
using technology for communication and course development purposes. The Faculty Academy began in the year 2000 and some participants noted that they had not been involved with integrating instructional technology prior to attending that first Academy. Participants stated that they would take what they learned about instructional technology from the Faculty Academy and would apply it to their courses. Participants were pleased with this opportunity and believed it was important to continue to learn how to enhance their courses with the use of instructional technology. The participants of this study were regular attendees of the Academy in the last 8 years and mention that the technology that they learned also was useful for their own writing and research activities.

Theme 2: Evolving methods of practice using instructional technology. When participants spoke of their use of instructional technology, they frequently mentioned their history and evolution of practice. The development of the participants' instructional choices are unique, but they all communicate a history and progression of practice. Nathan's instructional ideal was to assign readings for his students to complete before attending class. He would like to conduct an assessment quiz before he began class to see how prepared his students were and if they actually did their assigned reading. This was conducted with paper and pencil in which he had to calculate the results before beginning his lecture. Nathan finds that he is quite pleased with a course textbook he has adopted which has its own website that conducts online quizzes of each chapter. He can obtain the results of the students' quizzes immediately. The technology that he adopted was consistent and efficient with his vision of an ideal instructional practice. For Richard, fifteen years ago, it was necessary for him to adopt a web based course management system in order to reach teachers all over the state. At that time, he adopted 
TopClass, and then went on to use WebCT, Vista, and he now uses eCampus. Richard has also developed his own course initially with FrontPage, nine years ago, and then transferred his content using Dreamweaver. He still uses and regularly updates this course each year. Ruth and Wanda, it was twenty years ago that they both taught courses through satellite TV at the university to off campus cohorts around the state. Each has adopted eCampus for their courses and uses Wimba Live Classroom to teach to their students. They feel that the synchronous technology allows them to be better connected to their students. Prior to the Faculty Academy, Charles use of instructional technology consisted of an overhead projector, handouts, and film. To date he has developed his own course website with FrontPage and then with Dreamweaver. He also uses eCampus for the functionality it provides such as the discussion board, email, and chat rooms. He has created PowerPoint presentations, PDF documents in which he uploads to his eCampus course website. Each year, Tanya had to print out packets that her students were to pick up at the school bookstore. During her participation in the Faculty Academy, she learned to create her own course website in FrontPage. Tanya then saved the documents from the packet in Adobe Acrobat and then hyperlinked them to her website. Her students can now can access these important papers at anytime. As Michael is skilled in using instructional technology, he grew concerned with the opportunity students have to copy work found on the Internet. To be better prepared as a teacher, he participated in a university webinar which is an online seminar to learn about how to use TurnItIn. He feels that it is valuable for him to be aware of his students' practices as well as know a tool that can assess the legitimacy of students' written work. 


\section{Part II: Understanding of Community mission Involving Instructional Technology that Affects how Members Engage in Educational Practice}

Theme 1: Shared understanding among faculty concerning the importance to use instructional technology in their courses. Commonly communicated by participants was that they had a shared understanding in their commitment to continue to improve upon their skills and capabilities of integrating instructional technology. Participants stated that they believed their fellow colleagues were excited about the possibilities and potential instructional technology could bring to their college and to their classroom. As participants commented that they perceived instructional technology to be continually changing, they were still willing to make the effort to learn because they were invested in the process of improving upon their skills and abilities. As this was a shared understanding among faculty members, it extended to a common vision shared among the departments in the college.

\section{Theme 2: Attend to the university's charge for faculty to use instructional} technology. Participants stated that they believed there was an expectation placed on faculty from the university to utilize instructional technology in their courses, research, and service activities. They believed that this charge was recognized and understood by other faculty working in the college and that people were taking responsibility to attend to that charge. As participants stated they could see the potential that instructional technology could have as far as growing a larger student base, it was important to them that continuous professional development would be provided by the college in order to adhere to the university's charge. 


\section{Theme 3: Proceed to use instructional technology, but its use must be}

purposeful. Participants stated that it was their intention to continue to use instructional technology in their courses, but it was important that it was used purposefully to help them achieve their instructional objectives. Technology was commonly referred to by participants as a supportive set of "tools" that could assist with their instruction as a method to better convey their subject matter. Participants mentioned that they were seeking ways in which they could use the instructional technology to be more prevalent and useful in the future in order for their integration efforts to be productive. The value participants’ placed on instructional technology was geared toward the instruction of their subject matter as well as toward their students so that they could see the importance of adopting it for their own instruction.

Theme 4: Understanding the comprehensive revision of the state department of education's content standards and objectives. The next item mentioned by participants was the $21^{\text {st }}$ Century curriculum for students, which was a new initiative announced by the state superintendent regarding the comprehensive revision of the state's content standards and objectives that now included the $21^{\text {st }}$ Century content standards and objectives. The number of standards was reduced and they now aligned with the $21^{\text {st }}$ Century content and skills for the purpose of preparing students to be successful in the global economy. As this was a new initiative at the time of the interviews, participants teaching in the teacher education program expressed that it was important for their fellow faculty and their students to explore and understand this new focus. 


\section{Theme 5: State department of education's requirement of 3 credit hour}

course for teacher education programs. An initiative that participants mentioned was that the state' department of education placed a new technology requirement that would affect the students entering into the five-year teacher education program of the Fall 2008. This requirement caused teachers within the program to examine how to fit this three credit hour course that was supposed to be focused on technology integration within an already fully scheduled program. The state department required that students' transcripts show that they completed the three-credit hour technology course. Participants as they discussed this new mandate communicated that they were dismayed as they had already spent effort toward developing and using a Technology Integration Plan. This plan proposed how instructional technology would be utilized through course activities throughout the five year program. Pre-service teachers would have the opportunity to learn new technology, see how it is integrated into class activities, and see it modeled through their teaching faculty. They could take these learning experiences with them as they began their student teaching in the PDSs. Participants explained that they were disappointed with the state's requirement as the teacher education program's approach to integrate instructional technology was a more comprehensive approach than the state's three-credit hour mandate. 


\section{Part III: Resources Developed for the Use of Instructional Technology for Members to Engage in Educational Practice}

Theme 1: Colleagues assist each other within the college of education.

Participants recognized people in their own departments within the college as important resources critical to the success of integrating instructional technology. Participants acknowledged that most departments had someone to rely on for technology support for their classes as well as graduate assistants who provided additional support for when they created and taught their web based courses. Participants reported that they were able to learn from faculty with technology expertise and were influenced by their capabilities. It was recognized that these fellow faculty members were critical, as they assisted their educational community towards accomplishing the goals of teaching with instructional technology through collaboration, planning for professional development, and providing an example of teaching with instructional technology.

Theme 2: Instructional technology used in courses. The instructional technology participants commonly used in their courses involved course websites, communication technology, and presentation technology. Table 39 displays the participants use of instructional for the Fall 2008 semester. 
Table 39

Participants use of instructional technology for Fall 2008 semester

\begin{tabular}{|c|c|c|c|c|c|c|c|c|}
\hline $\begin{array}{l}\text { Web and } \\
\text { Computer-Based } \\
\text { Technology Used in Class }\end{array}$ & $\begin{array}{l}\text { Ẽ } \\
\stackrel{\Xi}{ \pm} \\
Z\end{array}$ & $\frac{\mathscr{\Xi}}{\stackrel{\Xi}{\sigma}}$ & T: & $\underset{\Xi}{\Xi}$ & 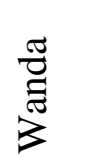 & $\frac{\mathscr{巳}}{\stackrel{\Xi}{己}}$ & 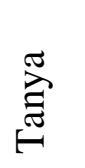 & 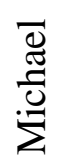 \\
\hline \multicolumn{9}{|l|}{ Course Website } \\
\hline $\begin{array}{l}\text { Web Authored Course } \\
\text { (Dreamweaver/FrontPage) }\end{array}$ & & & $\mathrm{X}$ & & & $\mathrm{X}$ & $\mathrm{X}$ & \\
\hline eCampus & $\mathrm{X}$ & $\mathrm{X}$ & $\mathrm{X}$ & $X$ & $\mathrm{X}$ & $\mathrm{X}$ & $\mathrm{X}$ & $\mathrm{X}$ \\
\hline Wimba & & & & $\mathrm{X}$ & $\mathrm{X}$ & & & \\
\hline Textbook Website & $\mathrm{X}$ & & & & & & & \\
\hline Textbook CD & & $\mathrm{X}$ & & & & & & \\
\hline Subject-related web resource & & & $\mathrm{X}$ & & & & & \\
\hline \multicolumn{9}{|l|}{ Communication } \\
\hline Email & $\mathrm{X}$ & $\mathrm{X}$ & $\mathrm{X}$ & $\mathrm{X}$ & $\mathrm{X}$ & $\mathrm{X}$ & $\mathrm{X}$ & $\mathrm{X}$ \\
\hline Discussion Boards & $\mathrm{X}$ & $\mathrm{X}$ & $\mathrm{X}$ & $\mathrm{X}$ & $\mathrm{X}$ & $\mathrm{X}$ & $\mathrm{X}$ & $\mathrm{X}$ \\
\hline Listserv & $\mathrm{X}$ & $\mathrm{X}$ & & & & & $\mathrm{X}$ & \\
\hline Chat & & & & $\mathrm{X}$ & & $\mathrm{X}$ & & \\
\hline Instant Messaging & $\mathrm{X}$ & $\mathrm{X}$ & & & & & & \\
\hline \multicolumn{9}{|l|}{ Technology Used in Course } \\
\hline PowerPoint & & $\mathrm{X}$ & & $\mathrm{X}$ & $\mathrm{X}$ & $\mathrm{X}$ & $\mathrm{X}$ & $\mathrm{X}$ \\
\hline Video & & $\mathrm{X}$ & & & $\mathrm{X}$ & $\mathrm{X}$ & & $\mathrm{X}$ \\
\hline Simulations & & & & & $\mathrm{X}$ & & & \\
\hline Wiki & & & & & & & $\mathrm{X}$ & \\
\hline PDF Documents & & & & & & $\mathrm{X}$ & $\mathrm{X}$ & \\
\hline Inspiration & & & $\mathrm{X}$ & & & & & \\
\hline Microsoft Word for presentation & $\mathrm{X}$ & $\mathrm{X}$ & & & & & & \\
\hline Microsoft Excel & & & $\mathrm{X}$ & & & & & \\
\hline Online Libraries/Journals & & & $\mathrm{X}$ & & & & $\mathrm{X}$ & $\mathrm{X}$ \\
\hline Online Journals & & & & & & & & $\mathrm{X}$ \\
\hline
\end{tabular}

Theme 3: Development of teacher education program database. Participants

were interested in working with technology beyond what could be used in their courses.

They wanted to use technology in ways that could inform them to make program

decisions. The teacher education program had begun a process of transferring documents

required from pre-service teachers into e-forms which would then be uploaded into a

database. The ability for faculty to upload and access these documents from an organized 
structure in a database could help them have better tracking of their student teachers which could then help inform the teacher education program make informed decisions. 
Research Question 3: How do university teachers interpret and understand their experience of integrating instructional technology?

\begin{tabular}{|l|l|}
\hline Meaning \\
\hline Meaning Subcomponents & Themes \\
\hline $\begin{array}{l}\text { Part I Interpretation and understanding of community participation integrating } \\
\text { instructional technology }\end{array}$ \\
\hline - Negotiation of Meaning & $\begin{array}{l}\text { Theme 1. Change and evolution with instructional practice } \\
\text { Theme 2. Benefits of technology use in education } \\
\text { Theme 3. Mixed feelings about the benefits of technology use } \\
\text { Theme 4. Perceptions of online communication technologies }\end{array}$ \\
\hline $\begin{array}{l}\text { • Participation } \\
\text { • Duality of Meaning }\end{array}$ & $\begin{array}{l}\text { Theme 1. Preferences of technology use } \\
\text { Theme 2. Increase in work responsibilities due to technology } \\
\text { Theme 3. Technology and multitasking behavior } \\
\text { Theme 4. Lack of community opportunities to dialogue about } \\
\text { technology }\end{array}$ \\
\hline $\begin{array}{l}\text { Part III Creation of guidelines and tools that guide educational practice regarding } \\
\text { instructional technology }\end{array}$ & $\begin{array}{l}\text { Theme 1. Evolution of Policies } \\
\text { Theme 2. University Policies } \\
\text { Theme 3. College Policies } \\
\text { Reification }\end{array}$ \\
\hline
\end{tabular}

\section{Part I: Interpretation and Understanding of Community's Participation Integrating}

\section{Instructional Technology}

Theme 1: Change and evolution with instructional practice. Participants

initially spoke of how quickly the computer and the Internet became an important part of the educational process in the last decade where it previously had been progressing along steadily for years. As the participants described themselves as "late adopters, early adopters, and second adopters,” there was a consensus among all participants that computers and technology had changed their traditional educational practice. All participants stated that technology now plays a major role in their work and they use it on a daily basis. As these participants have been involved in professional development 
efforts since the year 2000, each has used instructional technology in their courses to a varying degree.

Participants felt that they must evolve their instructional practices in order to meet students' current needs and become more comfortable with an evolving practice. One participant explained that this evolution forced a "reaction" from education faculty, but it felt that it invigorated teaching practices. For the participants that teach in the teacher education program, they believed it is their responsibility to model appropriate technology use for their students and provide instructional examples using technology that these students could use in the public school. This motivated participants examine new education possibilities for their students.

Along with the evolution of practice, some participants were sensitive to the needs of their learners who do not learn as well through an online medium and felt conflicted that students were not provided with options to choose what instructional platform they preferred. Other participants cautioned that as technology can provide a different educational experience, they must not make assumptions that students can perform as well as they would in a traditional setting.

Theme 2: Benefits of technology use in education. Participants viewed the instructional possibilities technology could offer positively for the educational resources that it could offer to their courses, the opportunities for instructional improvement, the ability to solve problems, the opportunity to reach learners on different levels, and the ability for university and public teachers to collaborate on the same level. Participants most commonly spoke of the abundance of educational resources and information available through the Internet that would otherwise not be accessible in traditional 
practice. It was thought by participants that this was one of the biggest advantages to educators as they could expand the boundaries of the classroom and share more content to their students. Another positive aspect participants felt about the use of instructional technology was the possibility to enhance the learning skills of their students by providing them with various methods of instruction. Technology enabled them to improve the delivery of their instruction and show more of their instructional content, which would convey the subject matter better to their students. It was noted that the use of instructional technology could provide for a deeper level of reflection as it could include the visual and auditory aspects of the learner.

On a different level, one participant felt that the professional development efforts shared by both university faculty and public school teachers to learn to integrate instructional technology, provided them with a shared experience in which everyone started at the same level. The participant stated that this experience allowed them to share in common experiences in which all teachers were equal, united in their commitment to learn about instructional technology.

Theme 3: Mixed feelings about the benefits of technology use. Participants' perceptions about the use of technology included the combination of enthusiasm and caution. As they were eager to explore the instructional possibilities technology could provide for their courses, they remained cautious about increasing their workload, using technology in uniformed ways, and feeling left with questions of how to integrate technology meaningfully. Their caution reflected a need to make informed decisions about using technology as their experience would be different from their traditional teaching practices. Caution with integrating instructional technology mostly came from 
previous experiences where participants became overwhelmed due to a new methods of instructional practice, an increase in workload, or both. Participants felt that it was easy to become seduced with the instructional opportunities technology could offer and they had to make informed choices as the experience did not just affect them, but their students as well. In order not to be seduced by the technology, participants each repeatedly clarified that technology was regarded as a "tool” that should be used purposefully for the best pedagogical practice and that technology itself should not be the main focus.

Theme 4: Perceptions of online communication technologies. The use of online communication technologies among participants was popular as they commonly used email, discussion boards, and chat rooms for their courses. Participants saw great benefit with the immediacy of contact and the transfer of information web-based communication technologies offered to the students in their courses as well as their colleagues. They were also wary of the expectation that they must immediately respond to emails they received. Another concern expressed by participants was the possibility for online communication sent through emails, discussion boards and chat rooms to be misinterpreted and that they must be careful how they communicate.

Participants remarked that the use of discussion boards and chat room technologies were especially beneficial during the Spring semester when winter weather is a concern for students and faculty. As participants felt it was convenient to be able to teach from their own home or office environment at times, they also questioned how technology affected the interaction and social involvement of their students. The participants who taught through Wimba felt that the communication with students 
through synchronous audio communication was surprisingly similar to their traditional teaching practices.

\section{Part II: Interpretation and Understanding of Faculty’s Own Participation Integrating Instructional Technology}

Theme 1: Preferences of technology use. As participants discussed their preferences for using instructional technology in their courses, most preferred to be with their students in the classroom. As participants believed in the value of instructional technology, their bias was still for traditional face-to-face instruction with their students. They favored the live interaction and connectedness they felt with their students and explained that they wanted to go through the learning process with them rather than behind a computer. Participants stated that this was especially true with the teacher education students and they questioned the appropriateness of an online degree in teaching.

Participants felt that their preference to use technology in their courses depended upon its successful use and if it added quality to their instruction. If they felt that it got in the way of their teaching, resulted in a loss of class time, or it became overly burdensome, they would chose not to continue to use it. The unfamiliarity and experience of teaching with a particular technology caused the participants to reevaluate their instructional strategies. It was important for the participants to embrace technology for learning and the improved quality of instruction.

Theme 2: Increase in work responsibilities due to technology. As participants thought about their experiences using technology in their courses, they communicated that they were aware of an increase in their workload and struggled to better manage their 
time. They noticed that teaching with technology was more time demanding in comparison with traditional teaching practices. For some participants, time management was essential, as technology received the most attention and took up most of their time at work. Some of the new time demands created by technology that participants communicated involved combining learning and applying instructional technology practices as well as seeking out support personnel to assist them in learning the new technology. As participants felt they spent time learning and working with new instructional technology, they reported that their time that was usually devoted to reading professional journals, research, grant activities and writing was taken away.

This increased workload left participants feeling overwhelmed, and a few participants stated that if the workload continued to increase, they would seek new employment. Participants commented that they observed a lot of their colleagues' high level of stress, handing more work than they believed they should. What caused concern in participants was that they did not see a resolution in sight to alleviate this situation.

Participants felt that there was an unspoken pressure to integrate technology and there was a greater demand for faculty to place their classes online to reach students beyond campus boundaries. One participant felt that this pressure could be viewed as “the tail wagging the dog," as technology was being integrated for the sake of integrating it rather than using it meaningfully for instructional purposes.

Another concern participants commented on was the blending of one’s work life into one's personal life. As participants liked the flexible aspects of technology that provided them with more freedom from on campus responsibilities, the downfall that they noticed, as one participant expressed, that they were on an "electronic leash as 
educators" and needed to set guidelines for expectations concerning their availability out of the classroom and on weekends. Participants felt that they were witnessing the blurring of the work-life boundaries more than ever before.

Theme 3: Technology and multitasking behavior. Participants identified multitasking, the multitasking learner, and the multitasking generation as a behavioral characteristic associated with their students and their use of technology. This was perceived by participants as a problematic behavior and they questioned "if the push of technology really was leading the digital learner in the right direction.” This characteristic was also seen as troublesome when participants taught in a computer lab setting with Internet access and students chose to look at their email, Facebook, and MySpace rather than listen to the lecture. Participants were concerned with the accolades given to multitasking behavior facilitated by technology as they believed that it lessened the quality of each activity.

This multitasking behavior was not only noted with the college of education students, but also among colleagues of the participants' professional community. One participant made a keen observation during a state department of education meeting that discussed important matters that would affect higher education faculty and public school teachers concerning the content standards and objectives. What was noticed by one of the participants was that attendants were multitasking and working on their laptops and cell phones rather than listening to the presentation. The participant found this to be a “major contradiction" and noted that as technology was one of the main focal points of the meeting, it was also being used for "off-task behavior." 


\section{Theme 4: Lack of community opportunities to dialogue about technology.}

As the participants' college of education is going through the experience of changing its instructional practices, they felt that it was important that they have regular opportunities to engage with their colleagues about their experiences integrating technology. Participants expressed that they would like opportunities to talk about instructional technology other than the Faculty Academy. They noted that as they are learning through the Faculty Academy, they would like additional occasions to collectively discuss and share their successes and difficulties integrating technology, talk about logistical and ethical dilemmas, and observe colleagues' various choices for pedagogical practice that includes technology. Participants regularly expressed during the interviews that they do not have the opportunity to fully articulate their experiences or discuss their concerns about the pedagogical implications of instructional technology collectively with their colleagues. Even though, participants recognize that there is a mission to increasingly use technology in their courses, they felt that they did not have a community in which they could talk about it.

\section{Part III: The Creation of Policies and Tools that Guide Community of Practice}

Theme 1: Evolution of policies. Participants remarked that the field of education is never static and policies and plans to guide new methods of practice are regularly updated. They stated that it was challenging to set priorities on what the most critical issues are around the appropriate use of instructional technologies as this is always changing. Participants said that they are always trying to adjust their efforts to change. 
Theme 2: University policies. Participants explained that ten years ago, a university policy was created that provided direction for technology integration and this policy was put into the annual review of faculty’s work. This policy communicated that there was the expectation that faculty would get credit for showing how they integrated technology into their teaching and participants felt that this influenced faculty. Beyond the university policy, participants feel pressure that "people” want faculty to use technology for learning, but some participants expressed that they can’t always see adopting it in place of their current instructional practices.

Theme 3: College policies. Regarding their own college, participants acknowledged an "urging” under the new administration in their educational community for faculty to place their courses online as there is a push to broaden the university's reach to access students. The Faculty Academy has been explained as a professional development opportunity to help teachers gain the necessary skills to accomplish that goal. Those who participated received a stipend for their time spent and participants felt that these incentives were necessary as they displayed their efforts to develop innovative instructional design practices using instructional technology so that their higher education institution could stay competitive. Participants explained that for those who participate and work on their courses in the Faculty Academy were then required to teach those courses with $50 \%$ to $75 \%$ online for the next school year.

Theme 4: Safety policies. An issue that participants felt was important were policies regarding the privacy and safety of children who appear on images and videos that are posted on the Internet in students' electronic portfolios. Participants communicated that the issue of how to protect and maintain the security for children was 
discussed numerous times at departmental meetings. It is required that students must obtain a note of permission from parents to let them be aware as well as allow students to post photos and video of their children on the Internet for their portfolios.

Also communicated by participants was that the same procedures and policies that were to be followed in the traditional teaching format regarding matters of social justice and social discrimination were included in their online courses. Participants continued to place this in their syllabus as it was posted to their eCampus courses.

Theme 5: Adopted tools. The adopted technology tools that participants most commonly used were course management tools, communication tools, and presentation tools. The technology that participants used to place their courses online included the university’s eCampus course management system as well as their own created online courses with Dreamweaver and FrontPage software. Three participants used websites that were created from the textbook that they used in their courses as an additional resource. Two participants used Wimba Live Classroom as well to teach their courses. Wikis were also created used by the educational community. The communication technology that participants used included email, discussion boards, chat rooms, listservs, and instant messaging tools. The presentation technology that participants used included PowerPoint, Professional Document Format (PDF), and video clips. 
Research Question 4: What is the university teachers' process of belonging to an educational community now responsible to integrate instructional technology into their educational practice?

\begin{tabular}{|c|c|}
\hline \multicolumn{2}{|l|}{ Community } \\
\hline $\begin{array}{l}\text { Community } \\
\text { Subcomponents }\end{array}$ & Themes \\
\hline \multicolumn{2}{|c|}{$\begin{array}{l}\text { Part I Contribute and participate in community activities that involve instructional } \\
\text { technology }\end{array}$} \\
\hline $\begin{array}{l}\text { - Community } \\
\text { - Membership } \\
\text { - Mutual Engagement }\end{array}$ & $\begin{array}{l}\text { Similarities } \\
\text { Theme 1. Engage with educational community during professional } \\
\text { development activities } \\
\text { Theme 2. Collaboration efforts facilitated by technology } \\
\text { Theme 3. Course related communities and team teaching } \\
\text { Theme 4. Acknowledgement of technologically skilled community members } \\
\text { Theme 5. Creation and participation in online communities } \\
\text { Differences } \\
\text { Theme 6. Change in faculty accessibility due to increased technology use } \\
\text { Theme 7. Lack of community felt by teaching faculty }\end{array}$ \\
\hline \multicolumn{2}{|c|}{$\begin{array}{l}\text { Part II Adhere to community missions and objectives regarding instructional technology } \\
\text { use }\end{array}$} \\
\hline - Joint Enterprise & $\begin{array}{l}\text { Theme } 1 \text {. Adhere to national and state organizational missions } \\
\text { Theme 2. Adhere to university missions } \\
\text { Theme 3. Adhere to college of education missions } \\
\text { Theme } 4 \text {. Adhere to teacher education program mission }\end{array}$ \\
\hline \multicolumn{2}{|c|}{ Part III Shared resources and tools to assist teaching with instructional technology } \\
\hline - Shared Resources & $\begin{array}{l}\text { Theme } 1 \text {. The technology support center and staff } \\
\text { Theme 2. Colleagues within the college of education } \\
\text { Theme 3. Digital resources }\end{array}$ \\
\hline
\end{tabular}

\section{Part I: The Process of Belonging to an Educational Community of Practice Similarities}

Theme 1: Engage with educational community during professional

development activities. An event that has a significant and positive impact expressed by all participants was the annual professional development activity, the Faculty Academy, in which the college faculty have the opportunity to come together and work toward the common goal of learning to integrating instructional technology. Bringing the faculty together that teach in different educational programs within the college, participants 
collectively found that this opportunity allowed them to engage and interact with fellow faculty in a new light because the focus was on the use of instructional technology rather than content. It was found that this was a new way for faculty to relate to one another as their courses are different, they could see the various ways in which computer and web based technology influenced other faculty's instructional decisions that they would otherwise not be aware of. Collectively learning and building their levels of competence integrating instructional technology, participants found that having the chance to see what other people were doing in their courses as well as witnessing their level of skill and knowledge using instructional technology was a great benefit. Without the Faculty Academy, participants felt that the college faculty would not have the opportunity to talk or share their experiences with one another in which instructional technology is the focus. Participants found that they were pleased with the knowledge and experiences of learning from colleagues about their choices of using instructional technology and giving them the encouragement to try these new teaching methods for themselves. Participants explained that learning during the Faculty Academy was a "cyclical experience.” As the faculty observe, learn, and share their experiences, other faculty are then influenced to experiment with these instructional practices for themselves in which they can inform their colleagues of their experiences during the next year’s Faculty Academy. Participants acknowledged the consistency in participation by stating that the people who participated in the year 2000 Faculty Academy are still participating eight years later.

Theme 2: Collaboration efforts facilitated by technology. Collaborative efforts communicated by participants involved engagement facilitated by technology in educational communities both inside and outside the university. Participants revealed 
other opportunities that they could collaborate with their colleagues that involved the use of web based technology was during their collective efforts toward research projects, grant writing and the development of conference presentation materials. Having the ability to work as a group in separate locations but still be able to collectively and simultaneously contribute their iterations and efforts toward the same document was seen as significant benefit to the participants. This collaborative activity was also conducted with content-related educational communities that resided outside the college enabling participants to stay current and connected with other professionals in their subject area. This was also recognized by participants as a mechanism for them to see what other people were doing in their field in regard to teaching and research in which they believed helped them stay more current than they otherwise would be.

Collaboration in grant writing activities with other colleges in the university was found by participants to be a wonderful experience that enabled interactions among educational programs which provided a greater degree of contribution to larger educational university community. Participants found that these collaborative methods using email, Google Docs, and Adobe Acrobat also informed them of ways that they could communicate and provide feedback to their students.

Other structured interactions participants mentioned included events organized by the state department of education that involved the collaboration from other higher education institutions and public school teachers in the state focusing on teacher education programs. These efforts focused on people trying to work and meet needs of $21^{\text {st }}$ Century Learning Framework that was a work in progress at that time. These events 
provided opportunities for each community to be aware of the efforts of other educational communities toward the use of instructional technology.

Theme 3: Course related communities and team teaching. Identified by participants were course and subject-related communities in which people from the same educational department collaborate and share in team teaching activities. This was mentioned as an activity that participants engage in or an activity that they wish they could participate. It was mentioned that faculty who share the same subject area and background have the opportunity to contribute to each others course work. Courses that have multiple sections in which faculty, who are members of the same educational department, work collaboratively and contribute toward the instruction and delivery of a multiple-sectioned course. The successful and not so successful experiences of using instructional technology during the team taught course were then discussed by the individual team members and instructional decisions were shared and made collectively. For those participants who do not have the opportunity to team teach with other faculty in their department, they felt "envious" of the collaborative activity and wished they had subject related colleagues in which they could also share in team teaching activities.

Theme 4: Acknowledgement of highly skilled community members. Important to the participants as a significant factor for the community's success of integrating instructional technology were the contributions made by the educational community’s members who had a high level of competency and knowledge using instructional technology. Identified were a few faculty within the college of education who were leading the charge of integrating technology and were perceived as enthusiastic to support and participate in efforts to help other education faculty learn and acquire 
skills. Participants felt it was to their benefit to be invited to learn from these colleagues and were pleased to be a part of their learning process. These acknowledged skilled community members contributed to their educational community by leading and teaching in the Faculty Academy, helping and engaging in dialogue with faculty about their courses using instructional technology, and co-teaching in a class to support a participant using Wimba. Participants expressed that these efforts helped improve their competency levels using instructional technology as well as their level of comfort knowing that they

Theme 5: Creation and participation in digital communities. For the college, the creation of web-based communities and communication technologies such as Wikis and listservs provide the community with mechanisms to share their experiences and facilitate the joining together of faculty.

A departmental Wiki was developed for faculty to be able to communicate their experiences and discuss departmental goals and agendas. The Wiki assisted faculty It was with discussing issues at faculty meetings, sharing what they were doing with colleagues and a place for posting meeting agendas for their colleagues to see. This Wiki was designed to help faculty to not become isolated due to an increased use of technology. Participants expressed that as they were aware of the Wiki and there was a lack of participation because most felt they had currently met their technology threshold working on their courses and had not yet engaged in using it. A Wiki was also developed for the teacher education program as the director of the program was looking for innovative methods to promote interaction and collaboration among teachers. Another communication technology mentioned was the use of a Microsoft product called 
SharePoint which is similar to a listserv and acts as a collaborative workspace where faculty can share and manipulate information.

\section{Differences}

\section{Theme 6: Change in faculty availability due to increased technology use.}

Administration participants who are in leadership roles, cite the importance to have open channels of communication with their educational community and not see people isolated due to the use of technology. They talked about a noticeable change among the members of their educational community formally built on more traditional teaching practices. They believed there was a transition in the physical accessibility of faculty in the college building. One administrative participant believed that a change was occurring in the workplace and the classroom. It was stated that the faculty who teach most web based courses are now seen the least. This left the administrative participants questioning what it meant to be in higher education as students become more comfortable taking classes online.

Theme 7: A Lack of community felt by teaching faculty. The teacher participants in this study questioned the meaning of "educational community" as it was asked of them during the interviews and expressed that they felt a "lack of community" within their own college. The reasoning behind this feeling for one participant was due partly to his subject matter of expertise in which he was the only one that taught his particular courses. The reasoning behind the feeling for the other participant was that it was her responsibility to teach all of her courses off-campus separating her from the conversations and daily interactions of her department community teaching on-campus. Both teachers are full professors who have taught at the college for 20-30 years. Both 
participants communicated that they have chosen to identify with a educational communities elsewhere. For the teacher participant with the subject matter expertise, he associates with community members that are related to his discipline outside of the university in which engages in developing professional organizations, scheduling online meetings and web based interactions, voting online for issues, posting to an online newspaper as well as writing in blogs. For the teacher participant who teaches off campus, she sees her off-campus students as her community in which she structures interactions beyond the online classroom for advising and students' research purposes through email, discussion boards, Wimba, and chat rooms.

Although both participate regularly in the Faculty Academy, they both felt that was the only opportunity in which they were a part of the educational community which came together to work collectively toward the goal of integrating instructional technology.

\section{Part II: Adhere to Community's Mission of Integrating Instructional Technology}

\section{Established by Larger Institutions}

Theme 1: Adhere to national and state organizational missions. Participants expressed that the accountability and accreditation in teacher education programs changed because of technology. The participants of the study explained that the teacher education program taught within the college is guided by the National Council for Accreditation of Teacher Education (NCATE) unit standards and conceptual framework. NCATE is defined as the teaching profession's organization to help establish high quality teacher, specialist, and administrator preparation. Institutions must pass the NCATE accreditation process in order to receive the recognition that their teacher education 
program has met the national professional standards for the preparation of teachers and other educators. The U. S. Department of Education and the Council for Higher Education Accreditation acknowledges NCATE as the accrediting body for schools, colleges, and departments of education

(Retrieved Jan 10, 2010 http://www.ncate.org/documents/NCATEMission.pdf).

Regarding the use of instructional technology, NCATE worked with the International Society for Technology in Education (ISTE) which is the professional education organization responsible for recommending guidelines for accreditation to NCATE for programs in educational computing and technology in teacher education programs. (Retrieved January 10, 2010 http://www.iste.org/Content/NavigationMenu/NETS/ForTechnologyFacilitatorsandLeade rs/NCATE_Standards.htm).

The college faculty who teach the students that graduate from the teacher education program to become teachers are to include the NCATE standards with every unit that they teach. A participant explained that "every teaching unit for NCATE has to have what they call conceptual framework unit standards and that these unit standards now have the use of instructional technology imbedded in them.” Teachers then have to teach from those standards and children are then tested on those standards during state tests.

For the college of education, the NCATE accreditation report visit is in the Spring of 2011, in which an institution report and exhibits are now required to be submitted electronically. Participants explain that the exhibits to be included in the report must now be submitted electronically. All hard copy items must now be digitized which requires 
members of the educational community to make electronic copies of all materials, documents, meeting minutes, graphics, syllabi and more.

The participants of the study stated that they were aware of other educational initiatives and changes occurring in the state regarding instructional technology. Because instructional technology use in the schools is an area that participants stated as constantly growing, the teacher education program stays in contact and with a state department of education liaison.

Theme 2: Adhere to university missions. Participants remarked that as they were a part of a land-grant university community who's mission was to serve and provide educational programs to the public, instructional technology was a mechanism to reach students beyond the university boundaries. This mission was recognized by participants and they commented on their charge to broaden its scope of audiences and provide access and instructional services to a larger audience through online instruction and through web based communication. One of the benefits felt by participants concerning this mission was the opportunity to reach and enroll highly qualified applicants into their educational programs.

Theme 3: Adhere to college of education mission. One participant stated that the educational college must complete a report on the number of programs and classes that are technology-based, which is defined as courses that are $50 \%$ or more online. Most participants observed that they were unaware of any explicitly written policy or official declaration requiring them and other faculty to integrate instructional technology. They did believe that an unspoken enacted policy was implied and did exist as they felt technology was valued in the college. Most participants believed that the unspoken 
charge to teach with instructional technology was more of a preoccupation with making sure the college could provide service to students at a distance. Relating back to the university's land grant mission, participants communicated that the college had pushed for the use of technology and development of online classes so that people could access them where they lived due to the geographic and accessibility barriers found in the state. Participants remarked that this unspoken charge was not related to any instructional considerations regarding faculty as learners trying to use technology for their instructional purposes or the creation of constructivist learning environments. It was noted by participants that they felt it was up to their own individual discretion how to best teach their classes. As most participants were aware of the expectation to integrate, they also they believed that it could provide meaningful learning experiences for students.

In relation to new generation of faculty coming into the college, participants felt that there is an expectation that they will be skilled at working with technology and that this will be discussed during the selection process of new hires. For those that are hired, plans made to support their efforts toward using technology involve new faculty orientation sessions that encourage them to learn about eCampus and the technology resources and support available in the college and university.

Theme 4: Adhere to teacher education program mission. The following describes the instructional technology initiatives that participants mentioned who teach for the teacher education program. The participants that teach for the five year teacher education program identified the Technology Strand as it relating to their efforts to promote students integrating technology into their coursework in the classroom. To clarify, the teacher education program has three strands that are incorporated throughout 
the curriculum of the program and one of these strands is identified as the "Technology Strand.” The objective of this strand is to provide teacher education students with experiences learning and using instructional technology in their college courses as well as in the professional development schools to better prepare them to "fully integrate technology into their teaching.” Participants made note of their responsibility to use instructional technology in their courses as it related to this strand.

An initiative most commonly mentioned among teacher education participants was the Five Year Strategic Plan for the teacher education program, which was explained as “the college of education's indigenous course of action that was in-line with the university's mission, to use instructional technology in practice to offer advantages to their students.” Sections within the Strategic Plan refer to specific goals for the teacher education program and technology is identified to assist in the achievement of these goals. The goals that refer to the use of technology include developing of strategies for professional development activities, increasing student enrollment, collaborating with teacher education agencies and institutions in the state, marketing the program and promoting the research and disseminating activities from the college and public school faculty that relate to collaborative efforts, and archiving program documents and reports. The use of online and computer based technologies are mentioned throughout the discussion of these initiatives as mechanisms to achieve these goals.

\section{Part III: Shared Tools and Resources Used by the Community}

Theme 1: The technology support center and staff. Mentioned by all participants was the technology support center as one of the main technology support resources available in the college of education. Participants mentioned that the 
technology support center is a setting that is available within the college that provides computers, technology hardware, and software resources as well as knowledgeable people to serve as technical assistance for faculty and students. What was convenient for the participants was the ability to go directly from their office to the technology support center without having to travel outside of the college building to obtain support. The support center personnel could also come up to their location to provide the help they needed. It was also noted from a few participants that the technology support center was view as a "model of practice" from other colleges within the university as they came to learn about it to be able to create a similar resource for their own setting. What was equally important to the participants was the personnel and technical expertise available to faculty that worked in the technology support center. Participants found that even though they had the technology resources, the support and assistance of the support center staff was a valuable resource to the educational community as faculty could receive assistance for both the technology and instructional options.

Theme 2: Colleagues within the college of education. Similar to the importance found with the technical expertise and support with the technology support center staff, participants recognized people in their own departments and within the college as important resources critical to the success of integrating instructional technology. Participants saw people within their departments as resources within their community to rely on for instructional technology support. Colleagues and graduate assistants with technology expertise was viewed as a resources in which participants could go to if they needed help with their web based courses. 
Theme 3: Digital resources. Participants stated that they have come to rely upon the computer based and web based resources to support their efforts of integrating instructional technology. A resource that participants mentioned that helped them learn new software were the up to date online tutorials available for faculty on the technology support center website. These tutorials were created by the support center staff and the college of education faculty can access them as they are learning new software. Another resource mentioned and used by all participants was the university's eCampus course management system available for all registered courses. Participants felt that the already created online course with its abundance of functionality including email, discussion board, and chat room options provided them with the ability to communicate with the students in their courses without having to create or add these functionalities on their own. Participants mentioned departmental Wikis and listservs as other digital resources that the college used and was helpful to their educational practice. 


\section{Discussion of Theory and Findings \\ Informative Nature of Wenger's Social Theory of Learning}

In order to deeply understand the complexities of teachers’ experience integrating instructional technology in a university setting, it was important to use a framework that provided multiple levels of inquiry. Multiple levels provided the opportunity to capture a holistic perspective of this evolving occurrence and a structure to examine the relationships among the college of education community, teachers' individual practices, and professional development projects. Lave (1996) states that being human is a relational matter, generated in social living and in social formations whose participants engage with each other as a condition and precondition for their existence. The components of the theory provided a richer explanation to examine how social connections and influences contributed to the individual instructional practices of teachers.

\section{Revealed Social Theory of Learning Model for College of Education Community}

The following displays the revealed subcomponents found from the research for a university college of education community identified as a learning organization stemming from the subcomponents of the Social Theory of Learning. Figure 2 displays a Social Theory of Learning Model relevant to a college of education community. 
Figure 2. Social Theory of Learning model applied to college of education community.

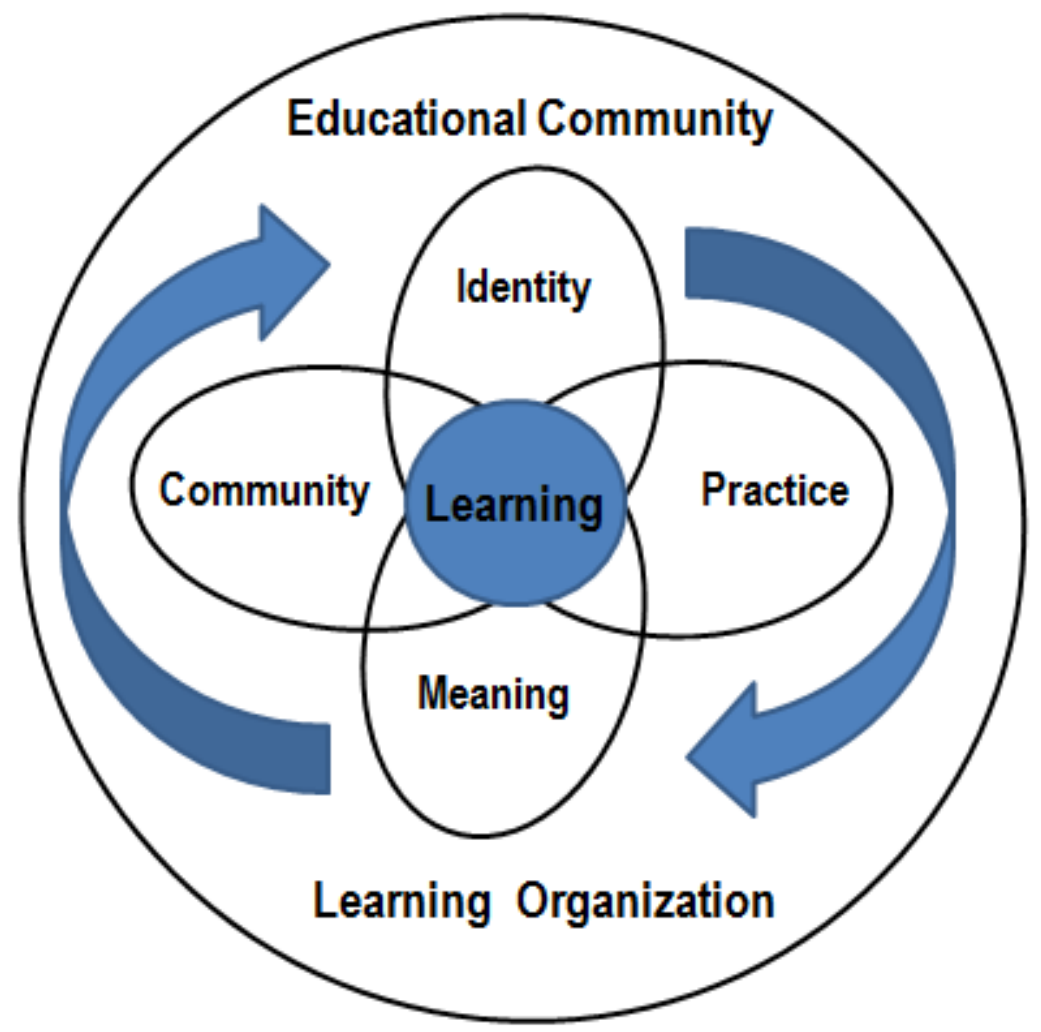

The above model reveals an evolving structure of an educational community of practice with learning at the center of the four main Social Theory of Learning components of identity, practice, meaning, and community. Learning drives the evolution of an educational community as it's practice is recognized as a learning organization. Below in Table 40 are 12 subcomponents that were revealed from the research that relate to the university college of education's community of practice. 
Table 40

Subcomponents relevant for college of education community

\begin{tabular}{|l|l|}
\hline \multicolumn{3}{|l|}{12 Subcomponents Revealed for a University College of Education Community } \\
\hline $\begin{array}{l}\text { Identity } \\
\text { (becoming) }\end{array}$ & $\begin{array}{l}\text { 1. History and path into educational community } \\
\text { 2. Identities influenced through competency building activities } \\
\text { 3. Vision for the future of educational community }\end{array}$ \\
\hline $\begin{array}{l}\text { Practice } \\
\text { (doing) }\end{array}$ & $\begin{array}{l}\text { 1. Building competencies through learning activities } \\
\text { 2. Developing evolving educational community missions } \\
\text { 3. Developing and creating of educational community resources }\end{array}$ \\
\hline $\begin{array}{l}\text { Meaning } \\
\text { (interpreting) }\end{array}$ & $\begin{array}{l}\text { 1. Interpretation of educational community evolution and development } \\
\text { 2. Interpretation of community members' participation in practice } \\
\text { 3. Creation of guidelines and tools that guide educational practice }\end{array}$ \\
\hline $\begin{array}{l}\text { Community } \\
\text { (belonging) }\end{array}$ & $\begin{array}{l}\text { 1. Contribute and participate in educational community activities } \\
\text { 2. Adhere to educational community missions and objectives } \\
\text { 3. Shared resources to assist educational community of practice }\end{array}$ \\
\hline
\end{tabular}

\section{Understanding Teachers’ Belonging to the University Culture}

University teachers are inducted over a long time into the higher education social processes, first through their own academic experiences as successful students and then as teaching staff and researchers (Cooper, 2004). Participants of this study were faculty who teach in a college of education and who have been a part of the same educational community in a learning and working capacity for an extended period of time, ranging from 15 to 34 years.

Participants mentioned their involvement and responsibilities to a multiple number of educational communities that were both inside and outside the university setting. Wenger (1998) acknowledges that professionals working in a community of practice develop, manage, and participate in multiple overlapping social networks within and across a community of practice boundary. The focus and intention of participants' membership to educational communities varied as participants defined the intentions of these communities to be content-focused, research focused, or process focused. Schlager 
and Fusco (2004) note that educational communities of practice differ from other groupings in the heterogeneity and diversity as their community memberships span a continuum of types of expertise and levels of competency not necessarily being defined by domain or rank. As the participants were identified in their role as teachers, the title was shared with the roles they have in other educational communities. The transition between roles is not scripted, designed or assigned as in formal training or organizational hierarchies (Schlager \& Fusco, 2004). Further research into the understanding of the participants' various roles within and outside of the university setting could provide a deeper understanding about the functions of the participants in the educational community.

Participants also carried leadership roles, which were identified through their unique participation and involvement in educational community activities. Leadership was acknowledged through their initiatives to share their expertise with their colleagues through training activities, collaborate with other colleges within the university that resulted in brining grant projects and funding into the college of education, direct and coordinate educational programs and professional development activities. Additional activities included researching, presenting, and heading national educational organizations, as well as receiving teaching awards from the college. This provided a sample of the activities, but does not include all that were mentioned by participants. Schlager and Fusco (2004) note that leadership is a central aspect of membership identity that promotes social networking and community reproduction by actions of reinforcing community rules and norms of practice as well as encouraging and supporting growth of others toward leadership. Also mentioned by Schlager and Fusco (2004) is that 
community leaders can be difficulty to spot because a formal recognized title or position acknowledges their contributions which may affect only a certain group in the community. Participant leadership was also recognized through their continual participation in professional development activities to improve their skill of teaching with instructional technology. Participants saw an urgency and need to attend to this responsibility in order to 1) stay current with the university’s practices, 2) seek opportunities to actively participate and model instructional strategies that incorporate instructional technology, and 3) be role models for future teachers. The awareness of participants' leadership qualities and memberships to multiple educational groups may not have become apparent without the framework provided by Wenger's theory. It is important to acknowledge the memberships and leadership qualities of these participants to gain a better perspective of the dimensions of the college of education and demonstrate how deeply-rooted the participants are into the fabric of the ever evolving university culture.

\section{As the University Identity Evolves, Teachers’ Identity Evolves}

The university culture, in which teachers are an integral part, is an organization that is concerned with the prospect of transforming and renewing itself through learning (Carroll, 2004). Through their extended participation, teachers find that as the university transforms and renews itself, they too are then continually constructing their identities as teachers in a sense of continual 'becoming' through their experiences of learning and working through the university community. The university is the central location in which faculty experience changes in their teaching practices because learning is situated within the daily practice of its community (Knight \& Trowler, 2001). An example of 
renewal can be seen with the advent of instructional technology which caused a shift in the pedagogical practices of the university culture. University institutions now require an increased accountability from its teachers to develop their courses online for the purposes of enhancing the quality of instruction and also to remain competitive among other universities by directing their efforts to recruit and retain students. Teachers are left with the responsibility to develop their skills and abilities to incorporate instructional technology into their courses. As the identity of the university has evolved and changed, so must the teachers' identity who work within that institution. Zukas and Malcom (2002) note that the construction of teachers' identities in higher education is a process of participation rather than acquisition. Teacher identity focuses on 'potentiality' and the continual enactment of performativity (Hull, 2002). As teachers negotiate and continue to construct their identities, they contribute to the evolution and changes within the higher education community in which they practice. Coldron and Smith (1999) note that tensions may arise as teachers may be more attached to the practices of their discipline over attending to the imposing policies and directives from their employing university.

\section{Teachers’ Pedagogical Identity Takes Precedence over Content-Expert Identity}

All participants, albeit some earlier and more willing than others, attended to the university's initiative to adopt computer and web-based technologies to use for the teaching of their courses and for the use of their own professional practice. A teacher's priority though may be focused on increasing their knowledge and expertise in their subject area over improving their pedagogical knowledge to teach that subject area. As mentioned in Chapter Two, Robson (2006) explains that unlike other professions, a teacher is likely to regard himself as an expert in a particular area and then later obtain a 
teaching position because of the knowledge and expertise that has already been acquired in an area of discipline as a result of significant study and expertise. Teaching then is perceived as an additional requirement that is separate from their from the knowledge of their discipline (Robson, 2006). Teachers may feel tension between their need to continue their development as a content expert and their need to further their skills as teachers in their subject areas.

Malcolm and Zukas (2000) argue that a critical approach to teaching and learning is necessary as the content that is taught counts as educational knowledge therefore the pedagogical identities and content-expert identities must co-exist within the field of education. One of the participants of this study acknowledged this specific detail by stating, “We're in the field of education! If we can’t do it, who can?!” Even though the participants had pedagogical expertise as well as content expertise in the field of education, teaching with instructional technology added another dimension that was different and unfamiliar from their traditional teaching practices. Over a decade later, participants expressed during their interviews that they continue to have difficulty teaching with instructional technology and that their level of confidence teaching with instructional technology is lower than it was previously teaching with traditional methods. The confidence that participants once felt with their content expertise and teaching in a traditional format has been changed due to a greater pressure from the university and college of education to teach with technology and to put their classes online. The time spent toward learning, integrating and reworking their courses has taken away time previously devoted toward staying current with their subject area. Participants communicated that the attention toward instructional methods had taken precedence over 
the attention toward their content area as they sacrificed time that was previously devoted toward their content area through reading professional journals, researching, and writing. This was a significant concern expressed by most participants. The change in instructional practice to incorporate instructional technology is another dimension of teachers’ ongoing process of continually constructing their identities as teachers in a sense of continual 'becoming' and that pedagogical identity is active and dynamic (Zukas and Malcom, 2002).

\section{Maintain Authentic Connections through Instructional Experiences with Students}

Participants expressed a preference to be with the students in the classroom using instructional technology together and favored live interaction with students. Participants of this study wanted to have teaching experiences in which they could maintain an authentic connection and an instructional experience with their students. Commonly mentioned was the word “connected” in reference to participants apprehension toward the change in their teaching practices from traditional methods to an online format. Participants acknowledged that they believed there were benefits to teaching their classes online, and that they did not want to "lose the connection" with their students through the instructional process. Participants were interested in using instructional technology that provided seamless real time two-way audio and video communication with their students for their courses and also specifically for students’ student teaching experiences.

Participants said that this seamless connection could provide them with the capability to give immediate feedback to their students who were at a distance. Participants were aware of current technology applications available to them in the college of education already, such as Wimba Live Classroom. They said that this application was still "too 
clunky" and "buggy" to use and wanted to wait a while longer to see if there would be improvements made before attempting to use it again. Participants stated during the interviews that elements that they enjoyed being a teacher was the connections that they felt with their students and being with them along their educational journey. Their visions for instructional technology use in the future were to maintain this authentic connection.

\section{Change Influencing Teachers’ Instructional Practices}

Policies and Mandates. Participants stated that the field of education is never static and the policies to guide new methods of practice are regularly updated. A community of practice, Scribner, Cockrell, Cockrell and Valentine (1999) describes, is subject to influence from formal policies and hierarchies that can subordinate and disrupted a community through acts of reorganization, changes in leadership, or the additions of policies. Participants stated that they believed there was a collective understanding among their colleagues in the college of education to adhere to the university's charge for faculty to develop technology integrated online courses. Participants stated that they felt pressure from the university as it is a land-grant institution with its mission to serve and provide education programs to the public. This mission can be served by broadening the scope of audiences by providing access and instructional services through online instruction and web-based communication. It was interesting that most participants noted that they were unaware of any official or specific declaration requiring faculty to integrate instructional technology. They mention though that they feel pressure through an "unspoken policy" as technology is valued in the college to create their courses using instructional technology even if it didn't represent 
the best pedagogical practice. Participants commonly stated that their use of technology needed to be purposeful in their instruction and that they would not use technology for technology’s sake. Participants would exclaim "Technology is a tool!”

Participants teaching in the teacher education program also acknowledged that they must adhere to the nation's and state’s departments of education requirements regarding the use of instructional technology. These participants felt the affects of the changes issued by state department of education regarding the revised standards as well as the requirement for teacher education programs to include one three credit hour course focused on the use of instructional technology in K-12 education. One participant who taught for the teacher education program, stated that she spoke with one of the state department of education liaisons and was made aware that there would be a pause in the changes made in the state's content standards and objectives to allow everyone to become more familiar and understand the changes.

Instructional technology. Participants stated that the computer and the Internet quickly became a part of the educational process in the last ten years and instructional technology now plays a major role in their work and teaching practices on a daily basis. Participants had to evolve their teaching practices by examining new instructional possibilities for their courses and reevaluate what learning processes were the most appropriate for their students which may not include instructional technology and online classes. It was important for teachers to be able to use instructional technology successfully in the classroom and not have it "get in the way of their teaching." Participants wanted to feel comfortable and have a sense of familiarity when using the 
instructional technology that enhances student learning and improves the quality of their instruction.

Course management systems. During the Faculty Academy, participants talked about their frustration with the change in the university's course management systems. In the last decade, participants have had to develop and redevelop their courses each year with iterations of WebCT, Vista and currently eCampus. Continual changes in course management systems forced faculty to repeatedly start from the beginning to learn a new system or adjust and retool their classes due to updates in the application which brought them back to an original place of unfamiliarity with the tool. Rather than experiencing progress in their course development, the change in course management systems cause teachers to remain on a horizontal rather than vertical trajectory of advancement that leaves them coming back to the same place which is again learning and developing their courses on a new course management system. As there may be an increase in value with each new course management system in comparison to the previous model, the value of the teachers instruction using the system may not increase as they are brought back to "square one” with learning the new iteration of each product.

Another important point that was discussed among participants both during the interviews and in the Faculty Academy that is the unfortunate design of most course management systems that do not support the social structures that promote community of learning processes. Schlager and Fusco (2004) concur by stating that most course management technologies such as WebCT are designed to support highly structured, university style learning situations that may not be the most appropriate for informal sharing and learning in an educational community of practice. Only people who are 
officially a part of the course are part of the "community” and when the course concludes at the end of the semester, so does the "community.” Schlager and Fusco (2004) further specify that as teachers need a structure for highly structured e-learning environments, teachers also need to have a set of online learning and collaboration capabilities. The design of these types of course management systems are not created for the intention for people outside the registered class to enter. For this fact, several of the college of education teachers have chosen to develop their courses using FrontPage and Dreamweaver so that people outside of their students can see and enter their courses. Also, the use of HTML editors prevent teachers from having to redevelop their courses with a new course management system.

\section{Variation of Instructional Technology Use Based on Faculty's Professional Position}

It was noted through the identification and charting of the participants' use of instructional technology that instructional technology selections differed among participant groups. The variation in technology use could be relative to their positions and roles within the educational community. In relation to the course websites and teaching of the course, all three administrative teachers chose to use textbook websites or a textbook CD as additional resources in their courses where the teaching faculty and program support teachers did not. Another difference found was that the two out of the three teaching faculty chose to use Wimba technology to teach their courses where the administrative teachers and the program support teachers did not.

In relation to communication technology, administrative teachers used commonly used listservs and instant messaging applications where as the teaching faculty did not and only one out of the two program support teachers used listservs. The teaching faculty 
used chat rooms in their courses, where administrative teachers and program support teachers did not mention the use of chat rooms in their courses.

In relation to presentation technology applications, the teaching faculty commonly used PowerPoint and digital video in their courses more than both the administrative teachers and the program support teachers. Two out of the three administrative teachers used Microsoft Word documents as an overhead to guide the students through the class agenda as well as refer to upcoming assignments.

In relation to research applications, online journals were commonly used with the program support teachers and the administrative teachers. Although the teaching faculty could have used or directed students to online journals, it wasn't captured during this study. Commonly used technology applications among all participants included the university's eCampus course management system, email, discussion boards, PowerPoint, and digital video.

\section{Value of Professional Development Opportunities}

The Faculty Academy is an example of an exemplar of embedded professional development involving instructional technology in the higher education community. Participants of this study placed significant value in the opportunity to learn and improve their skills with instructional technology through their participation each year in the Faculty Academy. Participants stated that this activity provided them with a way to relate to one another regarding the instruction of their courses that they would otherwise not be aware of. Yearly participation in the Faculty Academy established a cyclical pattern of participation described as the following: 
1. Faculty observe how their peers used a specific instructional technology application or strategy in their courses during the sharing sessions in the Faculty Academy.

2. The observation of other faculty's experiences using instructional technology would influence and encourage faculty to learn how use and integrate that instructional technology application or strategy for their courses.

3. The next academic year, these faculty would then teach with the new instructional methods using instructional technology in their courses in which they would gain learning experiences different from their previous instructional practice.

4. During then next Faculty Academy, they would then return and share their experiences which would then influence other faculty to learn and try the new instructional methods for themselves.

This cyclical pattern of observing, learning, practicing, and sharing was a common occurrence during the Faculty Academy. Participants expressed that it was important to learn and hear about other faculty’s experiences with changed pedagogical practices using instructional technology. Schlager and Fusco (2004) confirm that when professional development is embedded in a strong community of practice that focuses on instructional improvement, the community owns a stake in the outcome and success of activity which is learned as they teach in the classroom. The community benefits from the infusion and spread of knowledge gained by teachers, who then help other teachers a source of new community members with new skills, which enables the community of practice to grow, spread innovation and reproduce itself (Barab \& Duffy, 2000). 
As participants placed value in this professional development experience, they stated that they would like more opportunities to come together to work and talk about their efforts integrating instructional technology throughout the year to support their efforts in sustaining practice. Little (2001) suggests that resources for the improvement of teaching are created through interactions among teachers through more traditional communities as opposed to those that are organized specifically around a particular intervention as they work with teaching and learning artifacts in the context of their daily practice.

\section{Accessible Technology Support Within the College of Education}

Participants expressed that they were fortunate to have the support networks available to assist in their efforts and minimize their intimidation through their experiences integrating instructional technology. Participants mentioned that support was available through technology expertise from their peers and support personnel, the technology support center located within the college, and the digital resources available to assist faculty in their efforts working with technology.

Regarding the technology expertise, participants mentioned specific colleagues that worked in their academic department as well as technical support personnel who work in the technology support center as people they could learn from and rely on when they needed help integrating instructional technology. Participants felt that the technology expertise from faculty and personnel within the college assisted their educational community toward accomplishing the goal of teaching with instructional technology. 
The technology support center was one of the main resources available within the college of education. The center provides technology hardware and software as well as knowledgeable people to assist the college of education faculty and students. Faculty have the convenience of being able to go directly from their office to the center without having to travel outside the college building to obtain support.

Lastly, participants commented on the digital resources available to faculty both within the college and the university to help in their efforts to integrate instructional technology. Within the college, the technology resource center continually develops tutorials for new software applications for faculty to access on the center’s website. These tutorial resources area available for faculty to help guide them through learning new software in an efficient manner. University-wide resources available for faculty to use included the eCampus course management system created for each registered course as well as an email system available to all faculty and staff.

\section{Challenges with New Instructional Practice}

As the participants reflected upon their experiences integrating and teaching with technology they communicated that they had experienced a significant increase in their workload. Participants stated that they try to develop strategies to better manage their time, but the increase in their workload continued to leave them feeling overwhelmed. Participants stated that they did not believe their circumstances would change as there was an unspoken expectation for faculty to place their courses online. This expectation was a source of frustration with faculty as it did not translate to an improvement in instructional practice, but rather it was using technology for technology’s sake. In reference to this expectation, one participants felt that the "tail was wagging the dog." 
Another participant felt that faculty were "on an electronic leash" in reference to the increased responsibilities that relate to technology. As participants discussed the increase in their workload, they also commented that the boundaries between their work life and their home life were becoming more blurred. Participants also mentioned that they have "met their own threshold" as it related to their capacity to attend to their responsibilities using instructional technology and did not see possible solutions to alleviate the situation.

Administration participants noted that faculty were not as available within the college of education building as before due to the increased use of instructional technology to teach classes. Participants stated that those who teach the most web-based courses were seen the least. Little (2001) suggests that it is the ordinary, mundane exchanges among teachers that a professional community is forged and opportunities to learn are created and foreclosed. The absence of teaching faculty within the college of education setting reduces the opportunities for peer conversations and interactions.

\section{Need for Professional Development Activities that Focus on Pedagogical Practice}

Participants stated that as the computer and the Internet quickly became a part of the educational process, they had to evolve their teaching practices and examine new instructional possibilities. The task was two-fold as they had to learn how to use the new technology applications as well as learn how to redesign their instruction using the new technology for the purposes of enhancing the students' learning process. As participants were pleased with the opportunity to participate in the Faculty Academy, they were seeking further professional development activities in which they could work and learn from others about best teaching practices that incorporated instructional technology. 
These professional development sessions would acknowledge the use of technology, but efforts would be focused on pedagogical practice where they felt the greatest challenge.

\section{Lack of Community to Share and Talk about Pedagogical Experiences}

Participants stated that it was important to have regular opportunities to talk with colleagues about their experiences integrating instructional technology. Currently, participants said that they did not have enough of these types of structured opportunities. Schlager and Fusco (2004) comment that much of what the teacher needs to know and know how to do is learned in the context of practice. Participants stated that as they recognize the university's mission and the state's standards for teacher education programs, it is important that they have opportunities in which they can share and learn from each other through scheduled meetings. What interested participants was the faceto-face dialogue, the showcasing of courses, and the discussion of teaching experiences that existed in pockets of the Faculty Academy. Participants would like more opportunities to engage with their colleagues from all academic departments within the college of education to create a community learners focused on pedagogical practice.

\section{Implications}

The implications resulting from the research findings for faculty who develop and teach courses with instructional technology in a college of education are described below.

1. Provide increased opportunities for teaching faculty to collectively discuss their experiences integrating instructional technology in order to learn and provide support for each other across academic disciplines in the college of education.

2. Provide professional development opportunities for teachers that focuses specifically on pedagogical practices using instructional technology. These 
learning opportunities would be separate from training opportunities to learn the technology applications.

3. Provide increased number of professional development opportunities throughout the year that allows teachers to work without interruption on the development of their courses similar to the Faculty Academy for the purposes of sustaining their practice of integrating instructional technology.

4. Create an online repository for faculty to upload their courses so that other teachers can access and view them to encourage dialogue and provide peer critiques.

5. Maintain the same course management system in the university to allow teaching faculty to experience growth in the development in their online courses. As updates are common in technology applications, staying with the same system could prove to be beneficial for faculty.

6. Provide opportunities for teachers to become trained and more familiar with synchronous audio-video communication technology to allow for authentic teaching and communication experiences with their students.

\section{Limitations}

The following describes the limitations experienced during the research study. Complexity of the Theory. Wenger's Social Theory of Learning is a complex theory with four overlapping and interrelating components which led to difficulties coding the data obtained from the participant interview questions. Although the interview questions were designed to inform specific subcomponents of the four components of the theory, participant answers were found to be also relevant to other 
subcomponents of the four components of the theory. The theory is designed to show the relationships and connections among the theories four main components. As capturing these connections is the benefit of the theory, it is difficult to code the data correctly as it may relate to more than one subcomponent or component of the theory. It is possible that another perspective could have coded the data differently informing the research questions with another point of view.

Data Analysis Process. This research study collected a significant amount of data from the professional development activity and data to inform the participant case studies in which important information could have been looked over and not recognized as significant during the data reduction coding process. Additional reviews of the data and another perspective other than the researcher's could prove to be informative to the study. The use of qualitative data analysis software could have been used to clarify and reveal more information about the research study.

Document Analysis of Faculty Academy. Limitations were found with the document analysis of the binders and agendas from previous Faculty Academies starting with the year 2000. Not all years were recovered and years 2001 and 2005 were not available for review which didn't allow for the researcher to observe all of the changes in the professional development practice. These binders and agendas only provided a superficial perspective of what was scheduled to occur for each year and could not inform the research of the rich detail of the experienced activities.

Participant Responses to the Interview Questions. Participant responses to the interview questions had a tendency to inform other research questions which was again representative of the overlapping nature of the theory's four components. As participants 
would read down the list of questions, they would believe that they had already answered a question when in fact the question was relevant to a different component. A redesign of the interview questions or the study of individual components could possibly reduce this confusion.

Document Analysis of Participant Course Materials. There was a variety of the course documents that were available from the participants' course websites which did not provide for a consistent assessment across all participants. Because the study only captured coursework for one academic semester, the process of participants developing their courses could not be fully captured. The changes and alterations in their online courses could also not be fully realized due to the change in course management systems within the university.

Faculty Academy Observation. The observation of the week long college of education annual professional development activity attempted to capture members collectively participating in a professional development activity. The data captured was mainly limited to the researchers' perspective and could not capture all of the occurrences throughout the week. Potential important data could have been lost due to the lack of being able to observe each session as multiple sessions occurred simultaneously throughout the week. Presentation activities were conducted in two rooms at a time and participants at times worked individually with support personnel in the technology support center area. Participants also worked within their individual offices which removed them from the observation area. Data from the observation was also not able to capture the individual participants’ process of developing and constructing their courses throughout the week. 


\section{Recommendations for Further Research}

The following information describes possible suggestions for future research studies and strategies relative to the research findings found within this study. As previously mentioned above, the use of qualitative data analysis software could prove beneficial. Computer software packages such as Atlas.ti and Nudist provide the researcher with a more complex way of looking at the relationships in the data; provide a formal structure for writing and storing memos to develop the analysis; and, aid more conceptual and theoretical thinking about the data (Barry, 1998).

The study of individual components or the combination and relations from two components from the Social Theory of Learning (identity, practice, meaning, and community) could provide a richer perspective than the study of all four components collectively.

A similar type of study comparing participants teaching from different academic departments or disciplines within the college of education. Data results could then be examined to compare the similarities and differences from one academic department to another academic department.

A study similar in nature to the research design of this study over a longer period of time with a collective group of researchers each individually assigned to one of the four components of the theory. The opportunity to capture the development, iterations, and teachers' experiences teaching an online course over several semesters could provide an informative perspective in an academic field experiencing continuous change in technology applications and pedagogical practice. 


\section{References}

Araya, A. (1997). Experiencing the world through interactive learning environments. Society for Philosophy and Technology, 3 (2), 5-19.

Araya, A. (2001). Changing encounters with things and ontological transformations: The case of ubiquitous computing. Research in Philosophy and Technology: Metaphysics, Epistemology, and Technology, 4 (19), 3-31.

Barab, S. \& Duffy, T. (2000). From practice fields to communities of practice. In D.H. Jonassen and S.M. Land (Eds.) Theoretical Foundations of Learning Environments. Mahwah, NJ: Lawrence Erlbaum Associates.

Barrett, W. (1978). The illusion of technique. New York, NY: Doubleday.

Bathmaker, A., Avis, J. and Parsons, J. (2000). Becoming a lecturer in further education: Trainee lecturers' experience of FE. Paper presented at Research for the New Learning and Skills Sector Conference, $4^{\text {th }}$ Annual Conference of the FE Research Network, Warwick, 11-13 December.

Brew, A. (2003). Teaching and research: New relationships and their implications for inquiry based teaching and learning in higher education, Higher Education Research and Development, 23 (1), 3-18.

Brookfield, S. (1995). Becoming a critically reflective teacher. San Francisco: CA, Jossey-Bass.

Brown, J., A. Collins, and P. Duguid. (1989). Situated Cognition and the Culture of Learning. Educational Researcher, 18 (1), 32-42.

Berg, B. (2001). Qualitative research methods for the social sciences. (4 ${ }^{\text {th }}$ ed.) Boston, MA: Allyn and Bacon. 
Bleakly, A. (2002). Teaching as hospitality: The gendered gift and teaching style. In Howie, G. and Tauchert A. (Eds.) Teaching and Research in Higher Education, Challenges for the $21^{\text {st }}$ Century. Aldershot: Ashgate Publishing.

Bogdan, R. \& Bilken, S. (1998). Qualitative research for education: An introduction to theory and methods. ( $3^{\text {rd }}$ ed.) Boston: Allyn and Bacon.

Carroll, D. (2003). We can't do that, can we? Challenging best practice. Post-16 Educator. 2 (18), 19-21.

Coldron, J. \& Smith, R. (1999). Active location in teachers’ constructions of their professional identities. Journal for Curriculum Studies, 31 (3), 711-726.

Cooper, A. (2004). From tension fields to productive environments - critical reflections of programs in learning and teaching in higher education. In Baume, D. and Kahn, P. (Eds.) Enhancing Staff and Educational Development. London: Routledge.

Coyne, R. (1995). Designing information technology in the postmodern age. Cambridge, MA: MIT Press.

Creswell, J. (1994). Research design: Qualitative and quantitative approaches. Thousand Oaks, CA: Sage.

Creswell, J. (1998). Qualitative inquiry and research design: Choosing among five traditions. Thousand Oaks, CA: Sage.

Creswell, J. (2003). Research design: Qualitative, quantitative, and mixed methods approaches. (2nd ed.) Thousand Oaks, CA: Sage.

Dearlove, J. (1997). The Academic labour process: From collegiality and professionalism to managerialism and proletarianization. Higher Education Review, 30 (2), 56-75. 
Denzin, N. \& Lincoln, Y. (1998). Collecting and interpreting qualitative materials. London, UK: Sage Publications.

Doll, W. (1993). A post-modern perspective on curriculum. New York, NY: Teachers College Press.

Driscoll, M. (2005). Psychology of learning for instruction. Boston, MA: Pearson Education, Inc.

Eisner, E. (1991). The enlightened eye: Qualitative inquiry and the enhancement of educational practice. New York, NY: Macmillan Publishing Company.

Eisner, E. \& Peshkin, A. (1990). Qualitative inquiry in education. New York, NY: Teachers College Press.

Ellul, J. (1964). The technological society. New York: NY: Random House.

Freeman, D. (1995). Asking good questions: Perspectives from qualitative research on practice, knowledge, and understanding in teacher education. TESOL Quarterly, 29 (3), 581-585.

Harkin, J., Clow, R. and Hillier, Y. (2003). Recollected in tranquility? FE teachers' perceptions of their initial training. London, UK: Learning and Skills Development Agency.

Heidegger, M. (1977). The question concerning technology and other essays. New York, NY: Harper \& Row.

Heim, M. (1994). Electronic language: A philosophical study of word processing. New Haven, CT: Yale University Press.

Henkel, M. (2000). Academic identities and policy change in higher education. London, UK: Jessica Kingsley Press. 
Hoepfl, M.C. (1997). Choosing qualitative research: A primer for technology education researchers. Journal of Technology Education. 9 (1), 12-39.

Hull, G. (2002). Enacting a self. In Searle, J. and Roebuck, D. (Eds.) Envisioning Practice-Implementing Change. Brisbane, Australia: Australian Academic Press.

Hyland, T. \& Merrill, B. (2003). The changing face of further education. London, UK: Routledge-Falmer.

lhde, D. (1979). Technics and praxis. Boston, MA: Reidel Publishing Company.

Knight, P. \& Trowler, P. (2001). Departmental leadership in higher education: New directions for communities of practice. Buckingham, UK: Open University Press.

Laurel, B. (1990). The art of human-computer interface design. Reading, MA: Addison Wesley.

Lave, J. \& Wenger, E. (1991). Situated learning: Legitimate peripheral participation. New York, NY: Cambridge University Press.

Lave, J. (1996). Teaching, as learning, in practice. Mind, Culture and Activity, 3 (3) 149-164.

LeCompte, M. \& Schensul, J. (1999). Analyzing and interpreting ethnographic data. Walnut Creek, CA: Altamira Press.

Lewins, A. Taylor, C. \& Gibbs, T. (2005). What is qualitative data analysis (QDA)? Retrieved January 13, 2008, from http://onlineqda.hud.ac.uk/Intro_QDA/what_is_qda.php 
Little, J. (2001). Inside teacher community: Representations of classroom practice. Paper presented at the conference of International Study Association on Teachers and Teaching, Fargo, Portugal.

Malcolm, J. \& Zukas, M. (2000). Becoming an educator: Communities of practice in HE. In McNay, I. Higher education and its communities. Buckingham, UK: Open University Press.

Mayes, T. (2002). The Technology of Learning in a Social World. In R. Harrison, F. Reeve, A. and J. Clark Supporting lifelong learning: Perspectives on Learning. London, UK: Routledge-Falmer.

Marsick, V. (1997). Current thinking on the learning organization. Paper presented at $5^{\text {th }}$ International Conference on Post-Compulsory Education and Training, Queensland, Australia, 26-28 November.

McCarthy, J. \& Wright, P. (2004). Technology as experience. Cambridge, MA: MIT Press.

Molony, B. (2001). Technology \& identity: Is rapidly accelerating technology eroding our sense of who we are? Retrieved March 31, 2007, from http://www.scu.edu/sts/nexus/summer2001/MolonyArticle.cfm

McLuhan, M. (1999). Understanding media: The extension of man. Cambridge, MA: MIT Press.

Mertens, D. (2005). Research methods in education and psychology: Integrating diversity with quantitative and qualitative approaches. $\left(2^{\text {nd }}\right.$ ed.) Thousand Oaks, CA: Sage. Miles, M. \& Huberman, A. (1994). Qualitative data analysis. Newbury Park, CA: Sage. 
Mitcham, C. (n.d.). European school of faculty quote. Retrieved March 16, 2007, from http://www.egs.edu/faculty/mitcham-resources.html

Nardi, B. \& O’Day, V. (1999). Information ecologies: Using technology with heart. Cambridge, MA: MIT Press.

Parsons, K. (1997). The male experience of care-giving for a family member with Alzheimer’s disease. Qualitative Health Research, 7 (3), 391-407.

Patton, M. (2002). Qualitative research \& evaluation methods. Thousand Oaks, CA: Sage Publications.

Robson, J. (2006). Teacher professionalism in further and higher education: Challenges to culture and practice. New York, NY: Routledge.

Robson, J. (2002). The voices of vocational teachers in the UK: Their perceptions of the nature and status of the further education teacher's professional knowledge. Australian and New Zealand Journal of Vocational Education Research, 10 (2), 95-113.

Rowland, S. (2001). Surface learning about teaching in higher education: The need for more critical conversations. The International Journal for Academic Development, 6 (3), 162-7.

Schensul, S., L.;Schensul, J., and LeCompte, M. (1999). Essential ethnographic methods: Observations, interviews, and questionnaires. Walnut Creek, CA: Altamira Press. 
Schlager, M. \& Fusco, J. (2004). Teacher professional development, technology, and communities of practice: Are we putting the cart before the horse? In Barab, S., Kling, R. and Gray, J. (Eds.) Designing for virtual communities in the service of learning. Cambridge, UK: Cambridge University Press.

Scribner, J., Cockrell, K., Cockrell, D. and Valentine, J. (1999). Creating professional communities in schools through organizational learning. Educational Administration Quarterly, 35 (1), 130-161.

Shulman, L. (1986). Those who understand knowledge: Knowledge growth in teaching. In L. Shulman, (Ed.) The wisdom of practice: Essays on teaching, learning, and learning to teach. San Francisco, CA: Jossey-Bass.

Turkle, S. (2005). The second self: Computers and the human spirit. New York, NY: Simon and Schuster.

Van Manen, M. (1990). Researching lived experience: Human science for an action sensitive pedagogy. Albany, NY: SUNY Press.

Watkins, K. \& Marsick, V. (1993). Sculpting the learning organization: Lessons in the art and science of systematic change. San Francisco, CA: Jossey-Bass.

Wenger, E. (1998). Communities of practice: Learning, meaning and identity. Cambridge, UK: Cambridge University Press.

Winner, L. (1985). Autonomous technology: Technics out of control as a theme in political thought. Cambridge, MA: MIT Press. 
Zukas, M. \& Malcolm, J. (2002). Playing the game: Regulatory, scrutiny and pedagogic identities in post compulsory education. In Searle, J. and Roebuck, D. (Eds.) Envisioning Practice-Implementing Change. Brisbane, Austria: Australian Academic Press. 
Using Wenger's STL 432

\section{Appendices}




\title{
Appendix A: IRB Permission Letter to Observe Faculty Academy
}

\author{
West VirginiaUniversity. \\ Office of Research Compliance \\ Expedited - IRB Protocol - Exemption
}

\author{
To: $\quad$ Shambaugh, Neal \\ From: $\quad$ WVU Office of Research Compliance \\ Date: $\quad$ Wednesday, May 14, 2008 \\ Subject: No action required \\ Tracking \#: $\mathrm{H}-20935$ \\ Title: $\quad$ Using Wenger's Social Theory of Learning to Examine University \\ Teachers' Understanding of How Technology Affects Their \\ Experience in Practice
}

The above-referenced study was reviewed by the Institutional Review Board and was granted exemption on 5/14/2008 in accordance with 45 CFR 46.101(1-2).

While no action is required on your part, the IRB made the following findings:

This research study was granted an exemption in accordance with Research on normal educational practices [45 CFR 46.101(1)], Educational tests, survey procedures, interview procedures, or observation of public behavior [45 CFR 46.101(2)]. If you have questions please refer to the IRB website.

The following documents have been approved and validated for use in this study and are available in the BRAAN system:

Thank you.

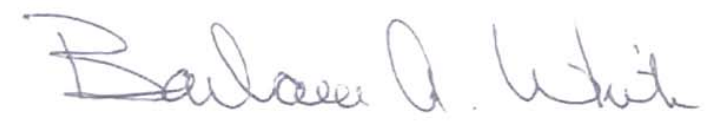

Board Designee: White, Barbara

Letter Sent By: White, Barbara, 5/14/2008 2:23 PM

Once you begin your human subject research the following regulations apply: 1. Unanticipated or serious adverse events/side effects encountered in this research study must be reported to the IRB within five (5) days. 


\title{
Appendix B: IRB Letter to Interview and Observe Teachers
}

\author{
WestVirginiaUniversity. \\ Office of Research Compliance
}

\section{Expedited - Amendment - Exemption}

\author{
To: $\quad$ Shambaugh, Neal \\ From: $\quad$ WVU Office of Research Compliance \\ Date: $\quad$ Thursday, June 26, 2008 \\ Subject: $\quad$ No action required \\ Tracking \#: AMEND-1101 (H-20935) \\ Title: $\quad$ Using Wenger's Social Theory of Learning to Examine University \\ Teachers' Understanding of How Technology Affects Their \\ Experience in Practice
}

On 6/25/2008 the following changes to the study were reviewed and approved:

This amendment to this study "Using Wenger's Social Theory of Learning to Examine University Teachers' Understanding of How Technology Affects Their Experience in Practice" seeks to employ additional research methods to explore this topic.

The currently approved IRB Exempt Protocol sought to conduct unobtrusive observations to gather information of the normal educational research practices of university teachers learning and working together during an annual faculty academy concerning the integration of instructional technology in their educational setting

This amendment includes the following additional research methods to explore this research topic further:

- Interviews - HR\&E university faculty

- Classroom Observations - HR\&E university faculty who are interviewed A cover letter has been acknowledged for use with this study.

The above-referenced study was granted exemption in accordance with 45 CFR 46.101 (2).

Thank you.

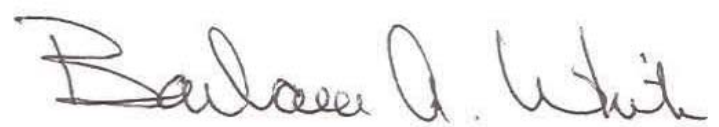

Board Designee: White, Barbara

Letter Sent By: White, Barbara, 6/26/2008 10:15 AM 


\title{
Appendix C: Permission Letter to Observe Faculty Academy
}

\author{
WestVirginiaUniversity \\ Colleg of Human Resources and Education
}

May 8, 2008

Dear Dr. Rye,

My name is Laura Adams and I am currently a doctoral candidate in Technology Education at West Virginia University. I am conducting my research for my dissertation that will explore how the integration of instructional technology over the past ten years has reshaped the traditional contexts and professional practice of teaching and informing learners. It is important to continue to capture how instructional technology has changed the teachers instructional practice as well as the educational communities in which they participate.

I am requesting your permission to conduct observations of WVU faculty during the 6 day oncampus Faculty Academy on May 12, 2008 to May 20, 2008 during its series of workshops and information sessions on the use and integration of instructional technology for their coursework.

Purpose of this Study: The purpose of this study is to explore how university teachers come to understand their experience in educational practice and their role as teachers integrating technology into their instruction using the framework provided by Wenger's social theory of learning. The framework of the social theory of learning views learning accomplished through the engagement and participation in communities in which we practice.

Description of Procedures: I am asking your permission to conduct observations for the Faculty Academy in an unobtrusive manner as the faculty engage and participate during the academy's sessions. My presence in the location will be silent and minimal and I am only requesting that I may take field notes during the observations.

Risks and Discomforts: There are no known risks or discomforts from participating in these observations. If my presence of observations becomes uncomfortable or presents a problem for faculty, I will remove myself from the location immediately.

Benefits: It is my hope that this research that the social theory of learning can inform university faculty about the strengths of engaging and participating collectively in educational communities. Social participation can strengthen the relationships and collective work of the educational community and help sustain future efforts toward their continued collaboration.

Confidentiality: Confidentiality will be maintained with respect to field notes taken during and after the observations that will be coded to maintain anonymity and kept under lock and key. Voluntary Participation: Participation is entirely voluntary in this process. Again if my
presence of observations becomes uncomfortable or presents a problem for fachlty, will femeve myself from the location immediately.

Sincerely,

Laura Adams
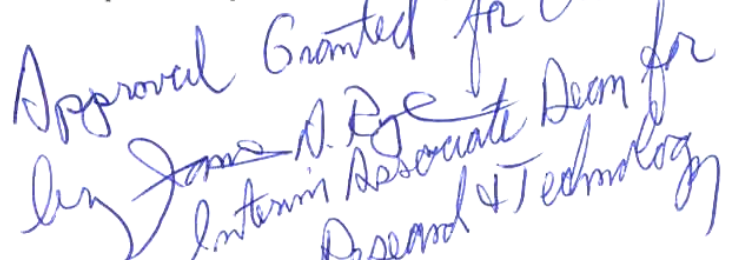


\section{Appendix D: Interview Protocol for First Interview}

\section{First Interview Protocol}

\section{Using the Social Theory of Learning as a lens to examine how faculty understand their experience using instructional technology in their teaching and practice.}

Social theory of Learning places a strong connection between knowledge and activity (learning in practice) - Social engagement and participation in the world shapes:

- Who we are

- What we do

- What it means to us

- Communities we participate in

Out of the 4 components identity, practice, meaning and community, today we will discuss the first two components: Identity and Practice

Identity questions will reflect:

- Your own history and background

- Influence of technology and role in your educational experience

- Activities and programs, projects/roles and responsibilities you have

- How you would like to imagine education using instructional technology

- How you would like to envision your own future path - how technology plays a role

Practice questions will reflect:

- Affect that technology has had in your practice

- Working with others/ influence and contributions technology has had on your educational community

- How technology contributes to your own work and process of learning

- How technology contributes to the evolution of your educational community

- Educational community's current goals

- How you've navigated your way through change

- How information and knowledge is shared using technology 


\section{Appendix E: Interview Protocol for Second Interview}

\section{Second Interview Protocol}

\section{Using the social theory of learning as a lens to examine how faculty understand their experience using instructional technology in their teaching and practice.}

Social theory of Learning places a strong connection between knowledge and activity (learning in practice) - Social engagement and participation in the world shapes:

- Who we are

- What we do

- What it means to us

- Communities we participate in

Out of the 4 components identity, practice, meaning and community, today we will discuss the last two components: Meaning and Community

Meaning questions will reflect:

- Perspectives about teaching and education today using instructional technology

- Your understanding of your experience of the evolution and change in education

- How your involvement \& participation in education shaped your experience as a teacher - how \& if technology has changed that experience

- Any guidelines, procedures, policies created for your educational community

Community questions will reflect:

- How you would define your educational community with the use of instructional technology

- How instructional technology has affected the way people of your community interact

- How does technology contribute or influence the opportunities you have to work with other educational faculty or staff

- How has educational community defined its mission and overall goal concerning the use of instructional technology

- Tools, methods, concepts that help your educational community in practice resources/assistance 


\title{
Appendix F: Interview Questions for First Interview
}

\author{
Education Faculty Initial Interview Questions
}

Identity - How do you see yourself?

1. Talk to me about your experience and career in education. (history \& background, roles \& responsibilities, subject areas of interest)

2. What influence has technology had on your role in education? (responsibilities, interactions, future plans, connections)

3. What are some of the activities you are involved in that use instructional technology? (programs or projects, roles \& responsibilities)

4. How would you like to imagine your educational community including instructional technology?

5. How do you envision your future path in education and how would instructional technology play a role?

Practice - What do you do?

1. How does instructional technology affect the way you engage in your educational practice?

2. What is it like working with other members of your educational community with the use of instructional technology? (influences, contributions)

3. How has instructional technology contributed to your work in education and your own process of learning?

4. How do you see instructional technology contributing to the evolution of your educational community?

5. What are some your educational community's current goals in relation to instructional technology?

6. How have you and your fellow colleagues navigated your way through change with the integration of instructional technology?

7. With the use of technology, how is knowledge and information shared among your fellow colleagues? 


\title{
Appendix G: Interview Questions for Second Interview
}

\author{
Education Faculty Second Interview Questions
}

Meaning - What do you understand from your experiences?

1. What is your perspective about teaching and education today with the integration of instructional technology?

2. How do you come to understand the experience of evolution and change in education due to the integration of instructional technology?

3. What does your experience in education mean to you now with the use of instructional technology?

4. How has your participation in education shaped your experience as a teacher? Has technology changed your experience?

5. Are there any recent guidelines, procedures, protocol, or policies that have been created for your educational community concerning the use of instructional technology?

Community - How do you belong in your group?

1. How would you define your educational community now with the use and integration of instructional technology?

2. How has technology affected the way members of your community interact and communicate?

3. How does technology contribute or influence the opportunities you have to work with other education faculty and staff?

4. How has your educational community defined its mission and overall goal concerning the use of instructional technology?

5. Describe some of the tools, methods, or concepts that help your educational community in practice. (resources or assistance for example) 